\title{
A.B. OCTPOYX
}
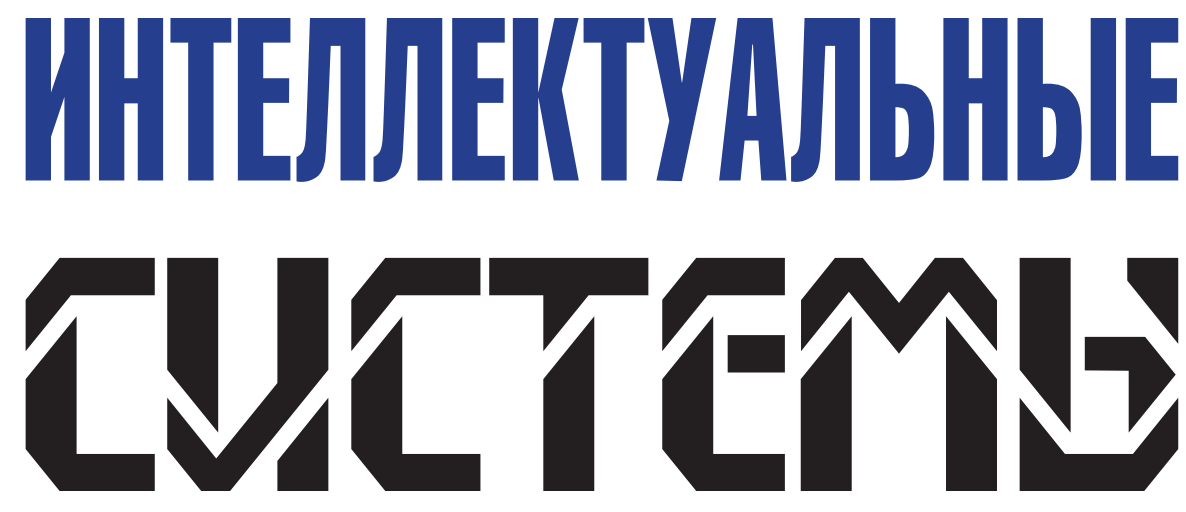


\section{А.В. Остроух \\ ИНТЕЛЛЕКТУАЛЬНЫЕ СИСТЕМЫ}

Монографрия

Красноярск, 2020 
УДК 004.382.7:681.3

ББК 32.973.26:32.844

079

Рецензенты:

Попов Д.И., д.Т.н., профессор кафедры «Информационных технологий», "Сочинский государственный университет" (СГУ);

Варламов О.О., д.Т.н., директор НИИ «МИВАР», профессор кафредры «Системы обработки информации и управления» МГТУ им Н. Э. Баумана

\section{Остроух, A.B.}

О79 Интеллектуальные системы: монография / А.В. Остроух. Красноярск: Научно-инновационный центр, 2020. - 316 с.

\section{ISBN 978-5-907208-27-8}

DOI: $10.12731 / 978-5-907208-27-8$

В монографии изложены концептуальные основы и методы представления знаний в интеллектуальных системах. Рассмотрены различные подходы, применяемые при проектировании и разработке интеллектуальных систем и технологий в транспортном комплексе, а также рассмотрены тенденции развития интеллектуальных систем.

Монография может быть использована для формирования профессиональной компетентности студентов высших учебных заведений, аспирантов и научных сотрудников обучающихся и ведущих научные исследования в области разработки и практического применения интеллектуальных систем по укрупнённой группе направлений подготовки 09.00 .00 - «Информатика и вычислительная техника».

УДК 004.382.7:681.3

ББК 32.973.26:32.844

ISBN 978-5-907208-27-8 C A.B. Остроух, 2020

(С) МАДИ, 2020

(C) Научно-инновационный центр, 2020 


\section{ОГЛАВЛЕНИЕ}

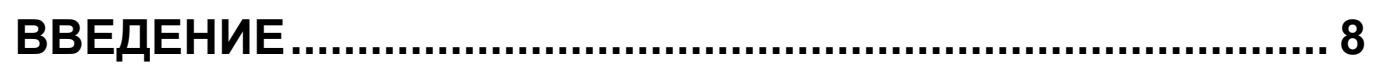

1. СОСТАВ И СТРУКТУРА ИНТЕЛЛЕКТУАЛЬНЫХ CИCTEM

1.1. Роль интеллектуальных систем В процессе решения трудноформализуемых задач .............................. 13

1.2. Задачи предметной области и методы их решения

1.3. Основные принципы организации

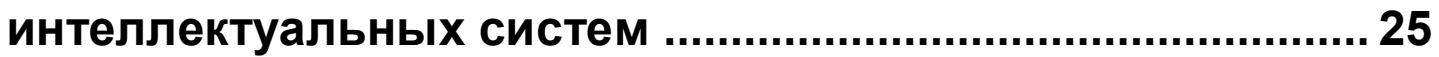

1.4. Модели представления знаний ............................ 30

1.4.1. Неформальные (семантические) модели ......... 31

1.4.2. Формальные модели представления знаний ... 36

1.5. Архитектура интеллектуальных систем .............. 38 1.6. Перспективы интеллектуализации

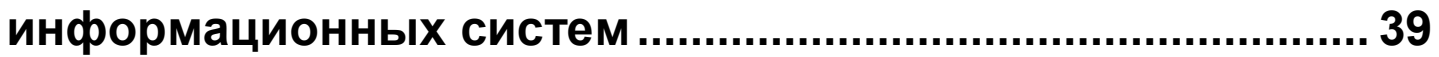

Контрольные вопросы ................................................ 58

2. ИНТЕЛЛЕКТУАЛЬНЫЕ ИНФОРМАЦИОННЫЕ

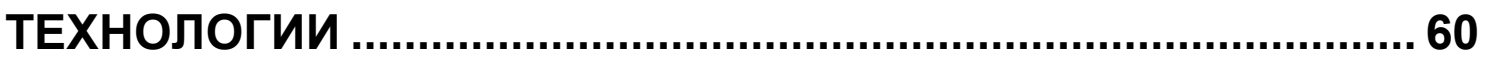

2.1. Понятие интеллектуальной информационной технологии .................................................................................60 60

2.2. Классификация интеллектуальных

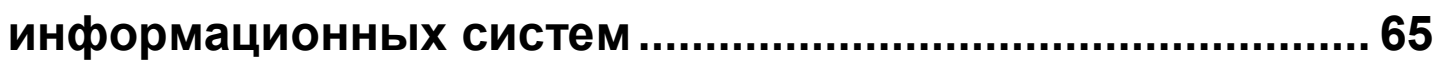

2.3. Перспективные информационные технологии проектирования, создания, анализа и сопровождения интеллектуальных систем 67

2.3.1. Системы с интеллектуальным интерфейсом ... 67

2.3.2 Экспертные системы .......................................... 69 
2.3.3 Самообучающиеся системы.....

2.3.4. Адаптивные информационные системы ..... 81

Контрольные вопросы 82

3. ИНФОРМАЦИОННЫЕ ПРОЦЕССЫ В ОБЛАСТИ ПРИМЕНЕНИЯ И УПРАВЛЕНИЯ ИНТЕЛЛЕКТУАЛЬНЫМИ

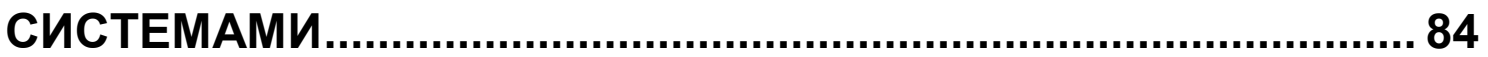

3.1. Процессы по развитию функциональных возможностей интеллектуальных систем на всех стадиях их жизненного цикла............................................................... 84

3.1.1. Инструментальные средства разработки MAC 85

3.1.2. AgSDK: среда разработки и реализации MAC . 89 3.2. Основные тенденции развития интеллектуальных систем, связанных с изменениями условий в области применения .......................................... 97

3.3. Обеспечение информационной безопасности в интеллектуальных системах 109

3.3.1. Цели обеспечения информационной безопасности 109

3.3.2. Задачи системы информационной безопасности 110

3.3.3. Принципы обеспечения информационной безопасности 112

3.4. Управляемость интеллектуальных систем...... 114 3.5. Задачи управления интеллектуальными системами 118

3.5.1. Управление информационными ресурсами ... 119

3.5.2. Управление решателями задач 132

3.5.3. Управление пользовательским интерфейсом 138 
3.6. Методы научных исследований по теории, технологии разработки

и эксплуатации

интеллектуальных систем 142

Контрольные вопросы 145

4. ПРИМЕНЕНИЕ ИНТЕЛЛЕКТУАЛЬНЫХ СИСТЕМ В ПРОФЕССИОНАЛЬНОЙ ДЕЯТЕЛЬНОСТИ 147

4.1. Организация диалога между человеком и интеллектуальной системой 147

4.1.1. Диалоговые системы, основанные на распознавании рукописного текста 147

4.1.2. Диалоговые системы, основанные на распознавании речи 153

4.1.4. Системы с биологической обратной связью... 158

4.1.4. Системы с семантическим резонансом. Компьютерные Ч-технологии и интеллектуальный подсознательный интерфейс 163

4.1.5. Системы виртуальной реальности. Эфрректы присутствия, деперсонализации и модификация сознания пользователя. 166

4.1.6. Системы с дистанционным телекинетическим интерфейсом .
4.2.
Построение
сложных
предметноориентированных интеллектуальных систем на основе естественно-языкового интерфейса 179

4.2.1. Сравнительный анализ ЕЯ-интерфейсов и традиционных интерфейсов к структурированным источникам данных. 180

4.2.2. Критерии качества ЕЯ-интерфейсов 187 
4.2.3. Критерии стоимости построения и сопровождения ЕЯ-интерфейса...................................... 188

4.2.4. Вопросы портируемости ................................ 190

4.2.5. Основные составные части ЕЯ-интерфейсов 192

4.4. Создание и внедрение технических и экономических проектов при помощи современных интеллектуальных систем ................................................... 193

4.4.1. Принципы и методы создания интеллектуальных инфрормационных систем ............................................... 193

4.4.2. Этапы создания информационных систем ..... 204

4.4.3. Реинжиниринг бизнес-процессов с помощью

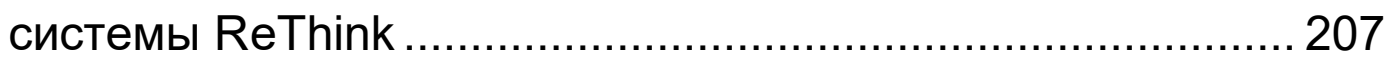

4.4.4. Интеллектуальный анализ данных ................. 214

4.4. Работы с основными объектами, процессами и явлениями, связанными с интеллектуальными системами и использование методов их научного исследования ..................................................................... 217

4.4.1. Структура систем интеллектуального управления 218

4.4.2. Модели принятия решения в условиях конфрликта 222

4.4.4. Определение оптимальной интеллектуальной системы принятия решения и управления в условиях

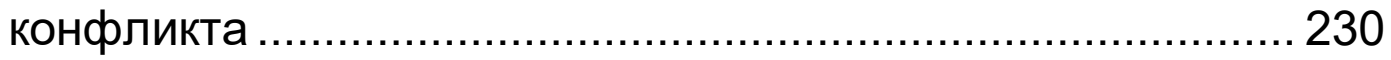

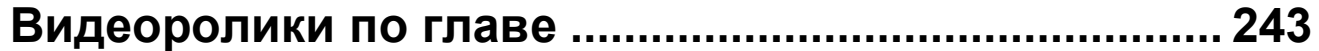

КОНТРОЛЬНЫЕ ВОПРОСЫ.......................................... 244

5. ИНТЕЛЛЕКТУАЛЬНЫЕ СИСТЕМЫ ТЕХНОЛОГИИ В ОТРАСЛЯХ ТРАНСПОРТНО-ДОРОЖНОГО КОМПЛЕКСА .... 245 


\section{1. Интеллектуальные системы АКТИВНОЙ}

ПОМОЩИ ВОДИТЕЛЮ

5.1.1. Адаптивное управление головным светом ..... 246

5.1.2. Система ночного видения. 248

5.1.3. Система мониторинга положения автомобиля 249

5.1.4. Система распознавания дорожных знаков ..... 250

5.1.5. Система контроля степени усталости водителя 252

5.1.6. Система натяжения ремней безопасности перед неизбежным столкновением . 253

5.1.7. Система радарных датчиков среднего и дальнего радиуса действия для предотвращения столкновений 255

5.2. Интеллектуальная система управления наземным городским пассажирским транспортом 257

5.2.1. Общие сведения об интеллектуальной транспортной системе. 257

5.2.2. Концепция интеллектуальной транспортной системы 259

5.2.3. Интеллектуальная система мониторинга уличнодорожной сети 263

5.2.4. Интеллектуальные системы повышения качества обслуживания пассажиров наземного городского пассажирского транспорта ................................................ 269

Видеоролики по главе .............................................. 290 СПИСОК ИСПОЛЬЗОВАННЫХ ИСТОЧНИКОВ ............. 292 


\section{ВВЕДЕНИЕ}

Искусственный интеллект (ИИ) - раздел информатики, изучающий принципы действия интеллектуальных машин.

Начало исследований в области ИИ (конец 50-х годов) связывают с работами Ньюэлла, Саймона и Шоу, исследовавших процессы решения различных задач. Результатами их работ явились такие программы как "ЛОГИКТЕОРЕТИК", предназначенная для доказательства теорем в исчислении высказываний, и "ОБЩИЙ РЕШАТЕЛЬ ЗАДАЧ". ЭТи работы положили начало первому этапу исследований в области ИИ, связанному с разработкой программ, решающих задачи на основе применения разнообразных эвристических методов.

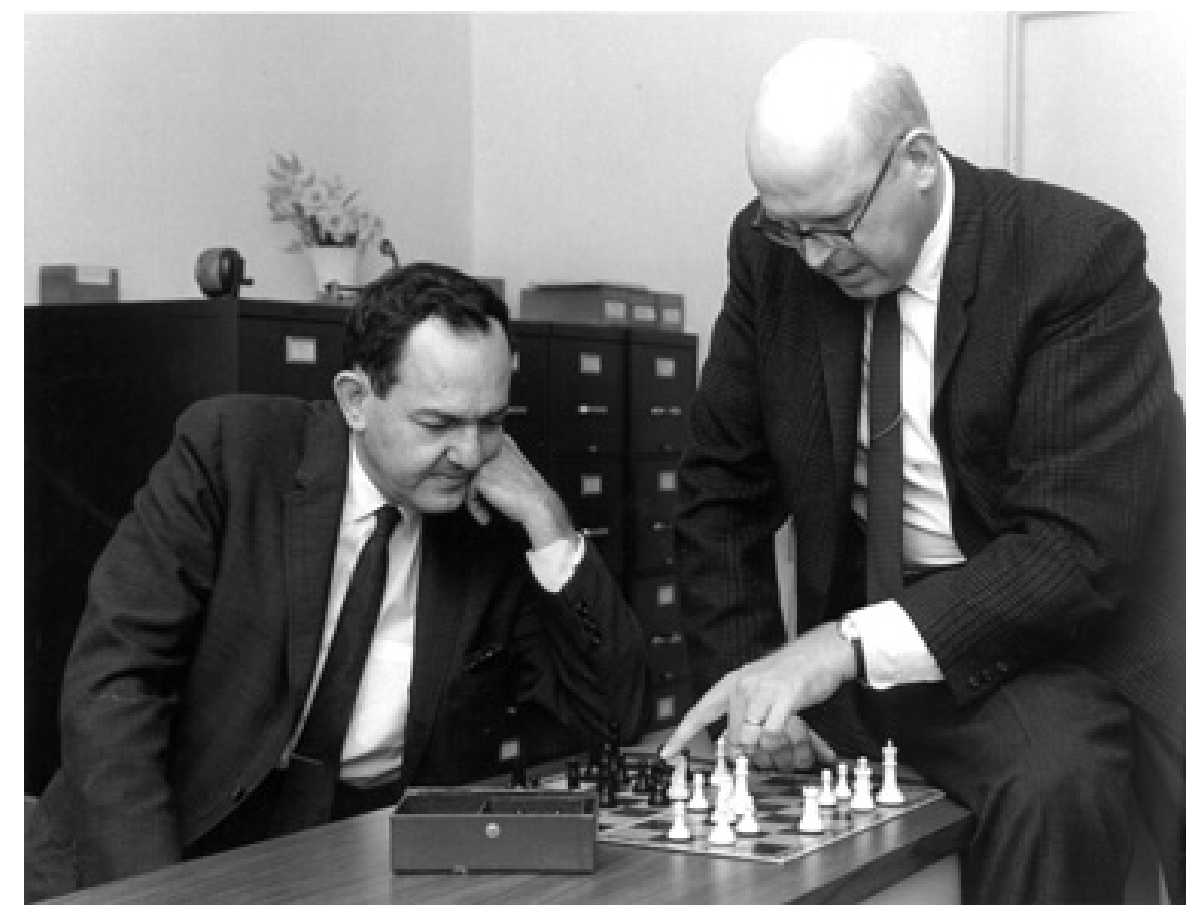

Герберт Саймон (слева) и Аллен Ньюэлл (справа)

Эвристический метод решения задачи при этом рассматривался как свойственный человеческому мышлению 
"вообще", для которого характерно возникновение догадок о пути решения задачи с последующей проверкой их. Ему противопоставлялся используемый в ЭВМ алгоритмический метод, который интерпретировался как механическое осуществление заданной последовательности шагов, детерминировано приводящей к правильному ответу. Трактовка эвристических методов решения задач как сугубо человеческой деятельности и обусловила появление и дальнейшее распространение термина ИИ. Так, при описании своих программ Ньюэлл и Саймон приводили в качестве доводов, подтверждающих, что их программы моделируют человеческое мышление, результаты сравнения записей доказательств теорем в виде программ с записями рассуждения <думающего вслух> человека. В начале 70-х годов они опубликовали много данных подобного рода и предложили общую методику составления программ, моделирующих мышление. Примерно в то время, когда работы Ньюэлла и Саймона стали привлекать к себе внимание, в Массачусетском технологическом институте, Стэндфордском университете и Стэндфордском исследовательском институте также сформировались исследовательские группы в области ИИ. В противоположность ранним работам Ньюэлла и Саймона эти исследования больше относились к формальным математическим представлениям. Способы решения задач в этих исследованиях развивались на основе расширения математической и символической логики. Моделированию же человеческого мышления придавалось второстепенное значение.

На дальнейшие исследования в области ИИ большое влияние оказало появление метода резолюций Робинсона, 
основанного на доказательстве теорем в логике предикатов и являющегося исчерпывающим методом доказательства. При этом определение термина ИИ претерпело существенное изменение. Целью исследований, проводимых в направлении ИИ, стала разработка программ, способных решать "человеческие задачи". Так, один из видных исследователей ИИ того времени Р. Бенерджи в 1969 году писал: "Область исследований, обычно называемую ИИ, вероятно, можно представить как совокупность методов и средств анализа и конструирования машин, способных выполнять задания, с которыми до недавнего времени мог справиться только человек. При этом по скорости и эффрективности машины должны быть сравнимы с человеком." Функциональный подход к направленности исследований по ИИ сохранился в основном до настоящего времени, хотя еще и сейчас ряд ученых, особенно психологов, пытаются оценивать результаты работ по ИИ с позиций их соответствия человеческому мышлению.

Исследовательским полигоном для развития методов ИИ на первом этапе явились всевозможные игры, головоломки, математические задачи. Некоторые из этих задач стали классическими в литературе по ИИ (задачи об обезьяне и бананах, миссионерах и людоедах, Ханойской башне игра в 15 и другие). Выбор таких задач обуславливался простотой и ясностью проблемной среды (среды, В которой разворачивается решение задачи), ее относительно малой громоздкостью, возможностью достаточно легкого подбора и даже искусственного конструирования "под метод". Основной расцвет такого рода исследований приходится на конец 60-х годов, после чего стали делаться первые попытки применения 
разработанных методов для задач, решаемых не в искусственных, а в реальных проблемных средах. Необходимость исследования систем ИИ при их функционировании в реальном мире привело к постановке задачи создания интегральных роботов. Проведение таких работ можно считать вторым этапом исследований по ИИ. В Стэндфордском университете, Стэндфордском исследовательском институте и некоторых других местах были разработаны экспериментальные роботы, функционирующие в лабораторных условиях. Проведение этих экспериментов показало необходимость решения кардинальных вопросов, связанных с проблемой представления знаний о среде функционирования, и одновременно недостаточную исследованность таких проблем, как зрительное восприятие, построение сложных планов поведения в динамических средах, общение с роботами на естественном языке. Эти проблемы были более ясно сформулированы и поставлены перед исследователями в середине 70-х гг., связанных с началом третьего этапа исследований систем ИИ. Его характерной чертой явилось смещение центра внимания исследователей с создания автономно функционирующих систем, самостоятельно решающих в реальной среде поставленные перед ними задачи, к созданию человеко-машинных систем, интегрирующих в единое целое интеллект человека и способности ВМ для достижения общей цели - решение задачи, поставленной перед интегральной человеко-машинной решающей системой. Такое смещение обуславливалось двумя причинами:

К этому времени выяснилось, что даже простые на первый взгляд задачи, возникающие перед интегральным роботом при 
его фрункционирование в реальном времени, не могут быть решены методами, разработанными для экспериментальных задач специально сформированных проблемных средах;

Стало ясно, что сочетание дополняющих друг друга возможностей человека и компьютера позволяет обойти острые углы путем перекладывания на человека тех фрункций, которые пока еще не доступны для компьютера. На первый план выдвигалась не разработка отдельных методов машинного решения задач, а разработка методов средств, обеспечивающих тесное взаимодействие человека и вычислительной системы в течение всего процесса решения задачи с возможностью оперативного внесения человеком изменений в ходе этого процесса.

Развитие исследований по ИИ в данном направлении обусловливалось также резким ростом производства средств вычислительной техники и также резким их удешевлением, делающим их потенциально доступными для более широких кругов пользователей. 


\section{1. СОСТАВ И СТРУКТУРА ИНТЕЛЛЕКТУАЛЬНЫХ СИСТЕМ}

\section{1. РОЛЬ ИНТЕЛЛЕКТУАЛЬНЫХ СИСТЕМ В ПРОЦЕССЕ РЕШЕНИЯ ТРУДНОФОРМАЛИЗУЕМЫХ ЗАДАЧ}

Интеллектуальная информационная система (ИИС) автоматизированная информационная система, основанная на знаниях, или комплекс программных, лингвистических и логикоматематических средств для реализации основной задачи осуществления поддержки деятельности человека и поиска информации в режиме продвинутого диалога на естественном языке.

Кроме того, информационно-вычислительными системами с интеллектуальной поддержкой для решения сложных задач называют те системы, в которых логическая обработка информации превалирует над вычислительной.

Таким образом, любая информационная система, решающая интеллектуальную задачу или использующая методы искусственного интеллекта, относится к интеллектуальным.

Исследователи, работающие в этом направлении, надеются достичь такого понимания механизмов интеллекта, при котором можно будет составлять компьютерные программы с человеческим или более высоким уровнем интеллекта. Общий подход состоит в разработке методов решения задач, для которых отсутствуют формальные алгоритмы: понимание естественного языка, обучение, доказательство теорем, распознавание сложных образов и т.д. Теоретические исследования направлены на изучение интеллектуальных процессов и создание соответствующих математических 
моделей. Экспериментальные работы ведутся путем составления компьютерных программ и создания машин, решающих частные интеллектуальные задачи или разумно ведущих себя в заданной ситуации. Систематические исследования в области искусственного интеллекта начались лишь с появлением цифрового компьютера. Первая научная статья по искусственному интеллекту была опубликована в 1950 А. Тьюрингом. Развитие интеллектуальных систем на современном этапе идет в соответствии с тремя направлениями исследований

Первое направление объектом исследований рассматривает структуру и механизмы работы мозга человека, а конечной целью - раскрытие тайн мышления. Необходимыми этапами исследований В этом направлении являются построение моделей интеллектуальной деятельности на основе психофизиологических данных.

Второе направление в качестве объекта исследования рассматривает искусственную интеллектуальную систему. Здесь речь идет о моделировании интеллектуальной деятельности с помощью вычислительных машин. Целью работ В этом направлении является создание программного обеспечения, позволяющего решать некоторые виды интеллектуальных задач так же, как их решил бы человек.

Третье направление ориентировано на создание человеко-машинных, или, как еще говорят - интерактивных, интеллектуальных систем. Важнейшими проблемами в этих исследованиях является организация семантически безупречного диалога между человеком и такой системой. 
Типологию ИС на современном этапе их развития представляется двумя крупными категориями.

К первой категории относятся ИС, получившие название экспертных систем (ЭС). Основными компонентами ЭС являются база знаний и логическая машина (универсальный решатель), которая интерпретирует содержащиеся в базе знания. Главной особенностью этой категории ИС является то, что они основаны на применении к содержащимся в базе знаниям определенных наборов правил (содержащихся в решателе) и на соблюдении определенных последовательностей применения этих правил.

Ко второй категории относятся ИС, получившие название искусственных нейронных сетей. Искусственная нейронная сеть (ИНС) представляет собой структуру, состоящую из нескольких слоев электронных моделей нервных клеток человеческого мозга - нейронов: одного входного слоя, нескольких внутренних (скрытых) слоев и одного выходного слоя. Поток подлежащей обработке (распознанию) информации поступает на входной слой, проходит через внутренние слои и результаты обработки информации выдаются через выходной слой искусственных нейронов. Во внутренних слоях устанавливаются связи между входным и выходным сигналами нейронной сети. Изменчивость связей между входом и выходом такой сети обеспечивается за счет различия порогов чувствительности входного и выходного слоев, которые устанавливаются и корректируются в процессе обучения сети. Наиболее популярен метод, основанный на корректировке ее структуры с учетом результатов пробных решений. Суть его в том, что предварительно готовится достаточно 
представительная обучающая выборка - множество пар входных и выходных сигналов. Затем входные данные обучающей выборки последовательно вводятся в сеть для получения выходных данных сети, которые потом сравниваются с выходными данными обучающей выборки. Если они совпадают, то сеть считается обученной и никакой корректировки связей внутри сети не производится. В противном случае эти связи корректируются, и процесс обучения повторяется до тех пор, пока не будет достигнута необходимая точность совпадения выходных данных сети с выходными данными обучающей выборки. Главной особенностью этих ИС является то, что они ориентированы на использование примеров (прецедентов) или образцов приемлемого исполнения целевой функции. При проектировании ИНС нет необходимости формализовать процесс решения задачи. Необходимо лишь подготовить достаточно представительную выборку обучающих примеров и провести на ее основе обучение системы.

Качество ИС определяется следующими аспектами:

- коммуникативность, трактуемая как многообразие доступных всем категориям пользователей способов общения с системой;

- универсальность по отношению к множеству задач, в пределах которого должна функционировать система;

- умение обучаться на основе приобретаемого опыта и знаний, приспосабливаясь к изменению условий решения проблемы; 
- умение перестроиться при изменении принципиальных положений (концепций) предметной и проблемной области.

Интеллектуальные информационные технологии (ИИТ) (англ. Intellectual information technology, IIT) - это информационные технологии, помогающие человеку ускорить анализ политической, экономической, социальной и технической ситуации, а также - синтез управленческих решений. При этом используемые методы не обязательно должны быть логически непротиворечивы или копировать процессы человеческого мышления.

Использование ИИТ на практике подразумевает учет специфики проблемной области, которая может характеризоваться следующим набором признаков:

- качество и оперативность принятия решений;

- нечеткость целей и институциональных границ;

- множественность субъектов, участвующих в решении проблемы;

- хаотичность, фрлюктуируемость и квантованность поведения среды;

- множественность взаимовлияющих друг на друга фракторов;

- слабая формализуемость, уникальность, нестереотипность ситуаций;

- латентность, скрытость, неявность информации;

- девиантность реализации планов, значимость малых действий;

- парадоксальность логики решений и др. 
ИИТ фоормируются при создании информационных систем и информационных технологий для повышения эффективности принятия решений в условиях, связанных с возникновением проблемных ситуаций. В этом случае любая жизненная или деловая ситуация - от выбора партнера по жизни до социального конфликта - описывается в виде некоторой познавательной модели (когнитивной схемы, архетипа, фрейма и пр.), которая впоследствии используется в качестве основания для построения и проведения моделирования, в том числе - компьютерного.

Гносеологический фундамент ИИТ наиболее явно видится в работах Канта, Гегеля, Гуссерля. Собственно явную историю ИИТ удобно начать с середины XX века, когда появился термин «Искусственный интеллект». История ИИТ начинается с середины 1970-х годов и связывается с совместным практическим применением интеллектуальных инфрормационных систем, систем искусственного интеллекта, систем поддержки решений и информационных систем. Эта история связана также с развитием трех научных направлений: компьютерной фрилософии, компьютерной психологии и продвинутой компьютерной науки (англ. Advanced computer science). C организационно-технологической стороны ИИТ дополняются прогрессом в создании: ситуационных центров, инфрормационно-аналитических систем. Программноматематическое обеспечение составляют эволюционные вычисления и генетические алгоритмы, системы поддержки общения человека с компьютером на естественном языке, когнитивное моделирование, системы автоматического тематического рубрицирования документов, системы 
стратегического планирования, инструментарий технического и фундаментального анализа фринансовых рынков, системы менеджмента качества, системы управления интеллектуальной собственностью и др.

С середины 1940-х вплоть до ранних 1970-х гг. создание ИИТ рассматривалось преимущественно в рамках логического решения задач. Этот период развития ИИТ характеризуется сравнительно большой определенностью и низкой динамичностью объекта управления. Вместе с тем уже в 1943 году появились «продукции Поста» и методы решения некорректных (обратных) задач на метризуемых пространствах, а в 1947 году для моделирования сложных экономических ситуаций активно начали использоваться методы причинного нелогического вывода, которые позже легли в основу методов системной динамики, немонотонных вычислений, когнитивного моделирования.

Создание центров управления полетами, организация штабных работ с применением средств визуализации и автоматизации, зарубежные публикации на тему создания специальных ситуационных центров вдохновили в 1970-е годы инженеров на создание ситуационных комнат для совершенствования управления крупными социальными и институциональными системами. В создании таких комнат и интеллектуальных технологий больше внимания стало придаваться средствам визуализации, диалоговым системам, помогающим использовать базы знаний и модели для решения плохо структурированных проблем.

В середине 1970-х годов на основе ИИТ в корпоративном мире начинают развиваться системы поддержки решений для 
эфффективного управления ресурсами, осуществления контроллинга. Ряд замечательных практических идей и результатов, например, связанных с теорией нейронных сетей, многоагентных и активных систем, оптических и голографических процессоров, появилось именно в это время. Тот период можно отметить успехами в создании всеобъемлющих моделей ситуационного управления регионами в периоды кризисов. Его характеризует вера в практически неограниченные возможности искусственного интеллекта.

В середине 1980-х годов был отмечен крах иллюзий относительно неограниченных возможностей успешной формализации процессов мышления с помощью систем логической обработки естественного языка. Вместе с тем появились интеллектуальные технологии для ограниченной поддержки исследовательской и профессиональной деятельности лиц, принимающих решения. Практическое применение получили подходы, основанные на использовании достоверного и правдоподобного вывода, немонотонных логик и нечетких систем, лингвистических процессоров. Тогда же появилась явная потребность в оптических и квантовых вычислениях - для решения многомерных и слабо распараллеливающихся задач. Видимые успехи появились в сорере обработки текстов естественного языка, высококачественного поиска документов, слежения за динамичными объектами управления, решения задач распознавания образов, имитационного моделирования, статистической обработки данных, решения транспортных задач, построения нечетких контроллеров. 
В конце 1980-х внимание разработчиков ИИТ все больше акцентируется на исследовании адаптивных свойств информационных систем, учитывающих умственную активность человека при осуществлении речевых актов, дискурса и принятии решений.

С начала 1990-х ИИТ все активней используются в стратегическом менеджменте, управлении ресурсами, реинжиниринге, создании ситуационных центров. Все более заметно внедряются интеллектуальные информационные технологии аналитической обработки больших массивов информации, технологии поддержки решений. В 1990-х годах в совокупности и взаимосвязи развиваются: экспертные системы реального времени, интеллектуальные агенты, активные системы, достоверный и правдоподобный вывод, эволюционные и квантовые вычисления, когнитивные модели, ситуационные центры и пр. Эксклюзивное место в развитии ИИТ с середины 1990-х заняла разработка необходимых условий конвергентности (сходимости) процессов управления, поиска информации и синтеза управленческих решений, направленных на обеспечение необходимых условий устойчивой сходимости этих процессов к намечаемым целям.

С 2000 года начал приобретать новое звучание процесс электронизации деятельности органов власти, бизнеса и населения. Концепция электронной демократии, предполагающая: осуществление гражданского контроля, проведение выборов и референдумов, поддержку процессов самоорганизации населения, обеспечение возможности участия населения в принятии государственных решений, расширение технологической возможности обмена мнениями - также 
предусматривает расширение возможностей интеллектуальных информационных технологий. Концепции электронной коммерции, включающие: маркетинг, управление корпоративными ресурсами, повышение качества продукции и услуг, расширение доступа к капиталу, электронные торги, развитие инноваций, поддержку процессов самоорганизации бизнеса - не могла не активизировать работы по дальнейшему развитию систем поддержки решений с помощью ИИТ.

\section{2. ЗАДАЧИ ПРЕДМЕТНОЙ ОБЛАСТИ И МЕТОДЫ ИХ РЕШЕНИЯ}

Обобщенный перечень классов задач разработки ИС для практического применения выглядит следующим образом:

- разработка средств, обеспечивающих эффрективное общение человека с машиной (автоматом) на естественном языке;

- автоматический перевод текстовой информации с естественного языка на внутримашинный и обратно;

- автоматический концептуальный анализ, поиск и интерпретация данных и знаний;

- разработка алгоритмов и методов поддержки принятия решений по целесообразному управлению различными системами, объектами и процессами в экономике, фринансах, производстве, науке, образовании, медицине, экологии, природопользовании, вооружении и других отраслях хозяйства с учетом неопределенности в реализации фракторов внешней среды и связанных с этим рисков; 
- разработка алгоритмов и методов мониторинга и диагностики состояния систем, объектов и процессов;

- автоматическое проектирование систем и устройств с оптимальными свойствами;

- разработка алгоритмов логических выводов и доказательства теорем;

- разработка поведенческих алгоритмов в условиях неопределенности и риска;

- автоматическое распознавание образов различной природы;

создание автоматически обучающихся систем.

В рамках каждого из трех направлений развития ИС существуют различные подходы к построению ИС.

Логический подход. Основой для данного подхода является применение различных правил логического вывода, изложенных с помощью аппарата математической логики (булевой алгебры и исчисления предикатов). ИС, основанная на логическом подходе, представляет собой машину для решения задач логических выводов и доказательства теорем. При этом исходные данные хранятся в базе знаний в виде аксиом и правил построения логического вывода путём задания отношений между этими данными. К сожалению, выразительность математической логики недостаточна для реализации полных возможностей логического мышления человека, но зато неоспоримо, что все, что можно реализовать на ЭВМ, принципиально реализуемо С помощью логики предикатов, и, наоборот. Для логических методов характерна большая трудоемкость, поскольку поиск доказательства может потребовать полного перебора всех 
возможных вариантов решений. Поэтому данный подход требует эффективной реализации вычислительного процесса и хорошо «работает» при сравнительно небольшом объеме базы знаний.

Физический подход объединяет методы моделирования интеллектуальных возможностей человека с помощью компьютера и различных фризических устройств. Одной из первых таких попыток был перцептрон Фрэнка Розенблатта. Структурной единицей перцептрона (как и большинства других вариантов такого моделирования) является компьютерная модель нейрона - нервной клетки. Из них строятся "искусственные нейронные сети" (ИНС). Нейронные сети в настоящее время есть коммерческие аппаратно - программные продукты, представляющие собой законченные ИС, применяемые в различных областях деятельности. Их действие основано на перестройке параметров нейронной сети под воздействием предъявляемых примеров правильного решения задачи.

Широкое распространение получило эволюционное моделирование. Этот процесс начинается с создания начального варианта модели ИС для решения конкретной интеллектуальной задачи и набора правил, по которым эта модель может изменяться. Затем формулируется критерий правильного (или приемлемого) решения этой задачи. Начальный вариант модели ИС обычно не отвечает установленному критерию качества решения задачи. С этого момента начинается пошаговое улучшение начального варианта модели ИС. Оно заключается в следующем. Описание начальной модели, правила вычисления критерия оценки её 
качества и правила (стратегии) её изменения вводятся в компьютер, который «проигрывает» работу начальной модели по каждой из возможных стратегий её развития и отбирает наилучший по установленному критерию результат эволюции в качестве новой начальной модели, которая вновь опробуется на допустимых правилами стратегиях работы. Такие циклы эволюции продолжаются, пока модель не придёт к требуемому уровню качества работы.

Имитационное моделирование. Оно связано с классическим для кибернетики базовым понятием - "черным ящиком" (ЧЯ). Так называют устройство, информация о внутренней структуре и содержании которого отсутствуют полностью, но известна матрица обязательного соответствия сигналов на входе в него и сигналов на его выходе. Задача состоит в подборе правил соответствия сигналов на входе и выходе.

\section{3. ОСНОВНЫЕ ПРИНЦИПЫ ОРГАНИЗАЦИИ ИНТЕЛЛЕКТУАЛЬНЫХ СИСТЕМ}

Информация, с которой имеют дело ЭВМ, разделяется на процедурную и декларативную. Процедурная информация овеществлена в программах, которые выполняются в процессе решения задач, декларативная информация - в данных, с которыми эти программы работают.

По мере развития исследований в области ИС возникла концепция знаний, которые объединили в себе многие черты процедурной и декларативной информации.

В ЭВМ знания так же, как и данные, отображаются в знаковой форме - в виде фрормул, текста, фрайлов, 
информационных массивов и т.п. Поэтому можно сказать, что знания - это особым образом организованные данные. Но это было бы слишком узкое понимание. А между тем, в системах ИИ знания являются основным объектом формирования, обработки и исследования.

База знаний (Б3; англ. knowledge base, KB) в информатике и исследованиях искусственного интеллекта - это особого рода база данных, разработанная для оперирования знаниями (метаданными). База знаний содержит структурированную информацию, покрывающую некоторую область знаний, для использования кибернетическим устройством (или человеком) с конкретной целью. Современные базы знаний работают совместно с системами поиска информации, имеют классификационную структуру и формат представления знаний.

Полноценные базы знаний содержат в себе не только фактическую информацию, но и правила вывода, допускающие автоматические умозаключения о вновь вводимых фрактах и, как следствие, осмысленную обработку информации. Область наук об искусственном интеллекте, изучающая базы знаний и методы работы со знаниями, называется инженерией знаний.

Перечисленные ниже пять особенностей информационных единиц определяют ту грань, за которой данные превращаются в знания, а базы данных перерастают в базы знаний (БЗ).

Внутренняя интерпретируемость. Каждая информационная единица должна иметь уникальное имя, по которому ИС находит еe, а также отвечает на запросы, в которых это имя упомянуто. Когда данные, хранящиеся в памяти, были лишены имен, то отсутствовала возможность их 
идентификации системой. Данные могла идентифицировать лишь программа, извлекающая их из памяти по указанию программиста, написавшего программу. Что скрывается за тем или иным двоичным кодом машинного слова, системе было неизвестно.

Таблица 1.1 - Сведения о сотрудниках учреждения

\begin{tabular}{|l|c|l|c|}
\hline Фамилия & $\begin{array}{l}\text { Год } \\
\text { рождения }\end{array}$ & Специальность & $\begin{array}{l}\text { Стаж, число } \\
\text { лет }\end{array}$ \\
\hline Попов & 1965 & Слесарь & 5 \\
\hline Сидоров & 1946 & Токарь & 20 \\
\hline Иванов & 1925 & Токарь & 30 \\
\hline Петров & 1937 & Сантехник & 25 \\
\hline
\end{tabular}

Если, например, в память ЭВМ нужно было записать сведения о сотрудниках учреждения, представленные в таблице 1.1, то без внутренней интерпретации в память ЭВМ была бы занесена совокупность из четырех машинных слов, соответствующих строкам этой таблицы. При этом информация о том, какими группами двоичных разрядов в этих машинных словах закодированы сведения о специалистах, у системы отсутствуют.

Они известны лишь программисту, который использует данные таблице 1.1 для решения возникающих у него задач. Система не в состоянии ответить на вопросы типа "Что тебе известно о Петрове?" или "Есть ли среди специалистов сантехник?".

При переходе к знаниям в память ЭВМ вводится информация о некоторой протоструктуре информационных единиц. В рассматриваемом примере она представляет собой 
специальное машинное слово, в котором указано, в каких разрядах хранятся сведения о фамилиях, годах рождения, специальностях и стажах. При этом должны быть заданы специальные словари, в которых перечислены имеющиеся в памяти системы фамилии, года рождения, специальности и продолжительности стажа. Все эти атрибуты могут играть роль имен для тех машинных слов, которые соответствуют строкам таблицы. По ним можно осуществлять поиск нужной информации. Каждая строка таблицы будет экземпляром протоструктуры. В настоящее время СУБД обеспечивают реализацию внутренней интерпретируемости всех информационных единиц, хранящихся в базе данных.

Структурированность. Информационные единицы должны обладать гибкой структурой. Для них должен выполняться "принцип матрешки", т.е. рекурсивная вложенность одних информационных единиц в другие. Каждая информационная единица может быть включена в состав любой другой, и из каждой информационной единицы можно выделить некоторые составляющие ее информационные единицы. Другими словами, должна существовать возможность произвольного установления между отдельными информационными единицами отношений типа "часть - целое", "род - вид" или "элемент - класс".

Связность. В информационной базе между информационными единицами должна быть предусмотрена возможность установления связей различного типа. Прежде всего, эти связи могут характеризовать отношения между информационными единицами. Семантика отношений может носить декларативный или процедурный характер. Например, 
две или более информационные единицы могут быть связаны отношением "одновременно", две информационные единицы отношением "причина - следствие" или отношением "быть рядом". Приведенные отношения характеризуют декларативные знания. Если между двумя информационными единицами установлено отношение "аргумент - фрункция", то оно характеризует процедурное знание, связанное с вычислением определенных функций. Далее будем различать отношения структуризации, функциональные отношения, каузальные отношения и семантические отношения. С помощью первых задаются иерархии информационных единиц, вторые несут процедурную информацию, позволяющую находить (вычислять) одни информационные единицы через другие, третьи задают причинно - следственные связи, четвертые соответствуют всем остальным отношениям.

Между информационными единицами могут устанавливаться и иные связи, например, определяющие порядок выбора информационных единиц из памяти или указывающие на то, что две инфрормационные единицы несовместимы друг с другом в одном описании.

Перечисленные три особенности знаний позволяют ввести общую модель представления знаний, которую можно назвать семантической сетью, представляющей собой иерархическую сеть, в вершинах которой находятся информационные единицы. Эти единицы снабжены индивидуальными именами. Дуги семантической сети соответствуют различным связям между инфрормационными единицами.

Семантическая

информационных единиц метрика.

В некоторых
$\mathrm{Ha}$

множестве 
задавать отношение, характеризующее ситуационную близость информационных единиц, т.е. силу ассоциативной связи между информационными единицами. Его можно было бы назвать отношением релевантности для информационных единиц. Такое отношение дает возможность выделять в информационной базе некоторые типовые ситуации. Отношение релевантности при работе с информационными единицами позволяет находить знания, близкие к уже найденным.

Активность. Все процессы, протекающие в ЭВМ, инициируются командами, а данные используются этими командами лишь в случае необходимости. Для ИС эта ситуация не приемлема. Как и у человека, в ИС актуализации тех или иных действий способствуют знания, имеющиеся в системе. Таким образом, выполнение программ в ИС должно инициироваться текущим состоянием информационной базы. Появление в базе фактов или описаний событий, установление связей может стать источником активности системы.

Совокупность средств, обеспечивающих работу со знаниями, образует систему управления базой знаний (СУБЗ). В настоящее время не существует баз знаний, в которых в полной мере были бы реализованы внутренняя интерпретируемость, структуризация, связность, введена семантическая мера и обеспечена активность знаний.

\section{4. МОДЕЛИ ПРЕДСТАВЛЕНИЯ ЗНАНИЙ}

Существуют два типа методов представления знаний (ПЗ):

- формальные модели П3; 
- неформальные (семантические, реляционные) модели ПЗ.

Очевидно, все методы представления знаний, которые рассмотрены выше, включая продукции (это система правил, на которых основана продукционная модель представления знаний), относятся к неформальным моделям. В отличие от формальных моделей, в основе которых лежит строгая математическая теория, неформальные модели такой теории не придерживаются. Каждая неформальная модель годится только для конкретной предметной области и поэтому не обладает универсальностью, которая присуща моделям формальным. Логический вывод - основная операция в ИС - в формальных системах строг и корректен, поскольку подчинен жестким аксиоматическим правилам. Вывод в неформальных системах во многом определяется самим исследователем, который и отвечает за его корректность.

\subsection{1. Неформальные (семантические) модели}

Каждому из методов ПЗ соответствует свой способ описания знаний.

Логические модели. В основе моделей такого типа лежит формальная система, задаваемая четверкой вида: $M=<T, P$, $A, B>$. Множество $T$ есть множество базовых элементов различной природы, например слов из некоторого ограниченного словаря, деталей детского конструктора, входящих в состав некоторого набора и т.п. Важно, что для множества $T$ существует некоторый способ определения принадлежности или непринадлежности произвольного элемента к этому множеству. Процедура такой проверки может 
быть любой, но за конечное число шагов она должна давать положительный или отрицательный ответ на вопрос, является ли х элементом множества $T$. Обозначим эту процедуру П $(T)$.

Множество $P$ есть множество синтаксических правил. С их помощью из элементов $T$ образуют синтаксически правильные совокупности. Например, из слов ограниченного словаря строятся синтаксически правильные фразы, из деталей детского конструктора с помощью гаек и болтов собираются новые конструкции. Декларируется существование процедуры $\Pi(P)$, с помощью которой за конечное число шагов можно получить ответ на вопрос, является ли совокупность $X$ синтаксически правильной.

В множестве синтаксически правильных совокупностей выделяется некоторое подмножество $A$. Элементы $A$ называются аксиомами. Как и для других составляющих формальной системы, должна существовать процедура П $(A)$, с помощью которой для любой синтаксически правильной совокупности можно получить ответ на вопрос о принадлежности ее к множеству $A$.

Множество $B$ есть множество правил вывода. Применяя их к элементам $A$, можно получать новые синтаксически правильные совокупности, к которым снова можно применять правила из $B$. Так формируется множество выводимых в данной формальной системе совокупностей. Если имеется процедура $П(B)$, с помощью которой можно определить для любой синтаксически правильной совокупности, является ли она выводимой, то соответствующая формальная система называется разрешимой. Это показывает, что именно правило 
вывода является наиболее сложной составляющей формальной системы.

Для знаний, входящих в базу знаний, можно считать, что множество $A$ образуют все информационные единицы, которые введены в базу знаний извне, а с помощью правил вывода из них выводятся новые производные знания. Другими словами формальная система представляет собой генератор порождения новых знаний, образующих множество выводимых в данной системе знаний. Это свойство логических моделей делает их притягательными для использования в базах знаний. Оно позволяет хранить в базе лишь те знания, которые образуют множество $A$, а все остальные знания получать из них по правилам вывода.

2. Сетевые модели. В основе моделей этого типа лежит конструкция, названная ранее семантической сетью. Сетевые модели формально можно задать в виде $H=<1, C_{1}, C_{2}, \ldots, C_{n}$, Г>. Здесь / есть множество информационных единиц; $C_{1}, C_{2}, \ldots$, $C_{n}$ - множество типов связей между информационными единицами. Отображение Г задает между информационными единицами, входящими в I, связи из заданного набора типов связей.

В зависимости от типов связей, используемых в модели, различают классифицирующие сети, функциональные сети и сценарии. В классифицирующих сетях используются отношения структуризации. Такие сети позволяют в базах знаний вводить разные иерархические отношения между информационными единицами. Функциональные сети характеризуются наличием функциональных отношений. Их часто называют вычислительными моделями, т.к. они позволяют описывать 
процедуры "вычислений" одних информационных единиц через другие. В сценариях используются каузальные отношения, а также отношения типов "средство - результат", "орудие действие" и т.п. Если в сетевой модели допускаются связи различного типа, то ее обычно называют семантической сетью.

3. Продукционные модели. В моделях этого типа используются некоторые элементы логических и сетевых моделей. Из логических моделей заимствована идея правил вывода, которые здесь называются продукциями, а из сетевых моделей - описание знаний в виде семантической сети. В результате применения правил вывода к фррагментам сетевого описания происходит трансформация семантической сети за счет смены ее фррагментов, наращивания сети и исключения из нее ненужных фрагментов. Таким образом, в продукционных моделях процедурная информация явно выделена и описывается иными средствами, чем декларативная информация. Вместо логического вывода, характерного для логических моделей, в продукционных моделях появляется вывод на знаниях.

4. Фреймовые модели. В отличие от моделей других типов во фреймовых моделях фриксируется жесткая структура информационных единиц, которая называется протофрреймом. В общем виде она выглядит следующим образом:

(Имя фррейма:

Имя слота 1(значение слота 1)

Имя слота 2(значение слота 2)

Имя слота К (значение слота К)). 
Значением слота может быть практически что угодно (числа или математические соотношения, тексты на естественном языке или программы, правила вывода или ссылки на другие слоты данного фррейма или других фреймов). В качестве значения слота может выступать набор слотов более низкого уровня, что позволяет во фреймовых представлениях реализовать "принцип матрешки".

При конкретизации фрейма ему и слотам присваиваются конкретные имена, и происходит заполнение слотов. Таким образом, из протофреймов получаются фрреймы - экземпляры. Переход от исходного протофррейма к фррейму - экземпляру может быть многошаговым, за счет постепенного уточнения значений слотов.

Например, структура таблицы 1.1, записанная в виде протофрема, имеет вид

(Список работников:

Фамилия (значение слота 1);

Год рождения (значение слота 2);

Специальность (значение слота 3);

Стаж (значение слота 4)).

Если в качестве значений слотов использовать данные табл. 1.1, то получится фррейм - экземпляр

(Список работников:

Фамилия (Попов - Сидоров - Иванов - Петров);

Год рождения (1965 - 1946 - 1925 - 1937);

Специальность (слесарь - токарь - токарь - сантехник);

Стаж (5 - 20 - 30 - 25)).

Связи между фреймами задаются значениями специального слота с именем "Связь". Часть специалистов по 
ИС считает, что нет необходимости специально выделять фрреймовые модели в представлении знаний, т.к. В них объединены все основные особенности моделей остальных типов.

\subsection{2. Формальные модели представления знаний}

ИС в определенном смысле моделирует интеллектуальную деятельность человека и, в частности, логику его рассуждений. В грубо упрощенной форме наши логические построения при этом сводятся к следующей схеме: из одной или нескольких посылок (которые считаются истинными) следует сделать "логически верное" заключение (вывод, следствие). Очевидно, для этого необходимо, чтобы и посылки, и заключение были представлены на понятном языке, адекватно отражающем предметную область, В которой проводится вывод. В обычной жизни это наш естественный язык общения, в математике, например, это язык определенных формул и т.п. Наличие же языка предполагает, во - первых, наличие алфравита (словаря), отображающего в символьной форме весь набор базовых понятий (элементов), с которыми придется иметь дело и, во - вторых, набор синтаксических правил, на основе которых, пользуясь алфавитом, можно построить определенные выражения.

Логические выражения, построенные в данном языке, могут быть истинными или ложными. Некоторые из этих выражений, являющиеся всегда истинными. Объявляются аксиомами (или постулатами). Они составляют ту базовую систему посылок, исходя из которой и пользуясь определенными правилами вывода, можно получить 
заключения в виде новых выражений, также являющихся истинными.

Если перечисленные условия выполняются, то говорят, что система удовлетворяет требованиям формальной теории. Ее так и называют формальной системой (ФС). Система, построенная на основе формальной теории, называется также аксиоматической системой.

Формальная теория должна, таким образом, удовлетворять следующему определению:

всякая формальная теория $F=(A, V, W, R)$, определяющая некоторую аксиоматическую систему, характеризуется:

- наличием алфравита (словаря), $A$;

- множеством синтаксических правил, V;

- множеством аксиом, лежащих в основе теории, W;

- множеством правил вывода, $R$.

Исчисление высказываний (ИВ) и исчисление предикатов (ИП) являются классическими примерами аксиоматических систем. Эти ФС хорошо исследованы и имеют прекрасно разработанные модели логического вывода - главной метапроцедуры в интеллектуальных системах. Поэтому все, что может и гарантирует каждая из этих систем, гарантируется и для прикладных ФС как моделей конкретных предметных областей. В частности, это гарантии непротиворечивости вывода, алгоритмической разрешимости (для исчисления высказываний) и полуразрешимости (для исчислений предикатов первого порядка).

ФС имеют и недостатки, которые заставляют искать иные формы представления. Главный недостаток - это "закрытость" 
ФС, их негибкость. Модификация и расширение здесь всегда связаны с перестройкой всей ФС, что для практических систем сложно и трудоемко. В них очень сложно учитывать происходящие изменения. Поэтому ФС как модели представления знаний используются в тех предметных областях, которые хорошо локализуются и мало зависят от внешних факторов.

\section{5. АРХИТЕКТУРА ИНТЕЛЛЕКТУАЛЬНЫХ СИСТЕМ}

Архитектура интеллектуальных систем включает три комплекса вычислительных средств (рисунок 1.1).

Первый комплекс представляет собой совокупность средств, выполняющих программы (исполнительную систему), спроектированных с позиций эфффективного решения задач, имеет в ряде случаев проблемную ориентацию.

$$
\text { Второй комплекс - совокупность средств }
$$
интеллектуального интерфейса, имеющих гибкую структуру, которая обеспечивает возможность адаптации в широком спектре интересов конечных пользователей.

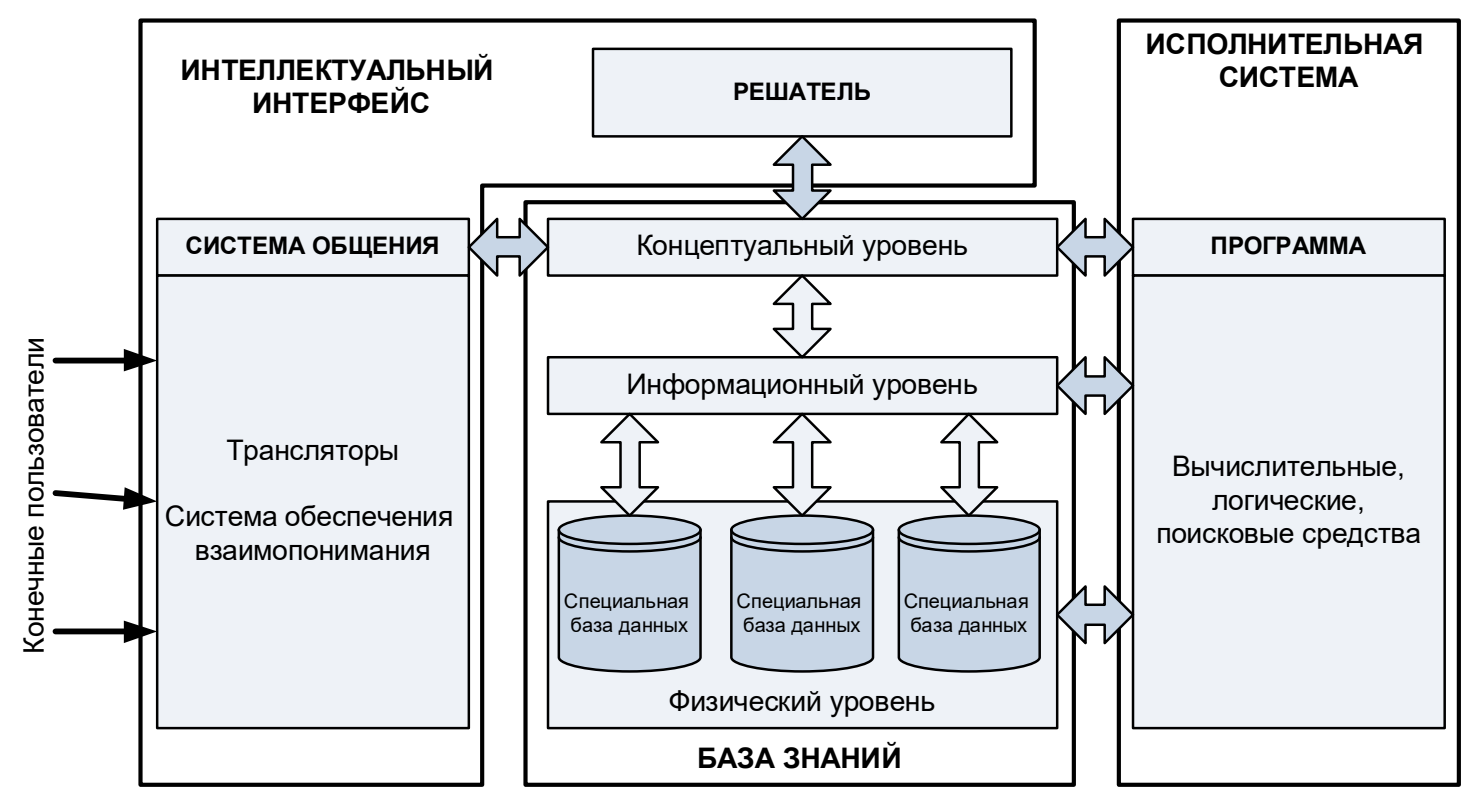




\section{Рисунок 1.1 - Архитектура интеллектуальных систем}

Третьим комплексом средств, с помощью которых организуется взаимодействие первых двух, является база знаний, обеспечивающая использование вычислительными средствами первых двух комплексов целостной и независимой от обрабатывающих программ системы знаний о проблемной среде. Исполнительная система объединяет всю совокупность средств, обеспечивающих выполнение сформированной программы. Интеллектуальный интерфейс - система программных и аппаратных средств, обеспечивающих для конечного пользователя использование компьютера для решения задач, которые возникают в среде его профессиональной деятельности либо без посредников, либо с незначительной их помощью. База знаний (БЗ - занимает центральное положение по отношению к остальным компонентам вычислительной системы в целом, через БЗ осуществляется интеграция средств ВC, участвующих в решении задач.

\section{6. ПЕРСПЕКТИВЫ ИНТЕЛЛЕКТУАЛИЗАЦИИ СИСТЕМ}

\subsection{1. Развитие экспертных систем}

Программные средства, базирующиеся на технологии и методах искусственного интеллекта, получили значительное распространение в мире. Их важность, и, в первую очередь, экспертных систем и нейронных сетей, состоит в том, что данные технологии существенно расширяют круг практически значимых задач, которые можно решать на компьютерах, и их решение приносит значительный экономический эффект. В то 
же время, технология экспертных систем является важнейшим средством в решении глобальных проблем традиционного программирования: длительность и, следовательно, высокая стоимость разработки приложений; высокая стоимость сопровождения сложных систем; повторная используемость программ и т.п. Кроме того, объединение технологий экспертных систем и нейронных сетей с технологией традиционного программирования добавляет новые качества к коммерческим продуктам. Это становится возможным за счет обеспечения динамической модификации приложений пользователем, а не программистом, большей "прозрачности" приложения (например, знания хранятся на ограниченном естественном языке, что не требует комментариев к ним, упрощает обучение и сопровождение), лучших графических средств, пользовательского интерфейса и взаимодействия.

По мнению специалистов, в недалекой перспективе экспертные системы будут играть ведущую роль во всех фразах проектирования, разработки, производства, распределения, продажи, поддержки и оказания услуг. Их технология, получив коммерческое распространение, обеспечит революционный прорыв в интеграции приложений из готовых интеллектуальновзаимодействующих модулей.

Использование экспертных систем и нейронных сетей приносит значительный экономический эфффект. Так, например:

- American Express сократила свои потери на 27 млн. долларов в год благодаря экспертной системе, определяющей целесообразность выдачи или отказа в кредите той или иной фрирме; 
- DEC ежегодно экономит 70 млн. долларов в год благодаря системе XCON/XSEL, которая по заказу покупателя составляет конфигурацию вычислительной системы VAX. Ее использование сократило число ошибок от $30 \%$ до $1 \%$;

- Sira сократила затраты на строительство трубопровода в Австралии на 40 млн. долларов за счет управляющей трубопроводом экспертной системы, реализованной на базе системы G2.

Коммерческие успехи к экспертным системам и нейронным сетям пришли не сразу. На протяжении ряда лет (с 1960-х годов) успехи касались в основном исследовательских разработок, демонстрировавших пригодность систем искусственного интеллекта для практического использования. Начиная примерно с 1985, в первую очередь, экспертные системы, а в последние годы и нейронные сети стали активно использоваться в реальных приложениях.

\subsection{2. Автономные агенты}

Одно из наиболее популярных направлений последних лет связано с понятием автономных агентов. Их нельзя рассматривать как "подпрограммы", - это скорее прислуга, даже компаньон, поскольку одной из важнейших их отличительных черт является автономность, независимость от пользователя. Идея агентов опирается на понятие делегирования своих функций. Другими словами, пользователь должен довериться агенту в выполнении определенной задачи или класса задач. Всегда существует риск, что агент может что-то перепутать, сделать что-то не так. Следовательно, доверие и риск должны 
быть сбалансированными. Автономные агенты позволяют существенно повысить производительность работы при решении тех задач, в которых на человека возлагается основная нагрузка по координации различных действий.

В том, что касается автономных (интеллектуальных) агентов, хотелось бы отметить один весьма прагматичный проект, который сейчас ведется под руководством профессора Генри Либермана в Media-лаборатории MIT (MIT Media Lab). Речь идет об агентах, отвечающих за автоматическое генерирование технической документации. Для решения этой задачи немало сделал в свое время академик Андрей Петрович Ершов, сформулировавший понятие деловой прозы как четко определенного подмножества естественного языка, которое может быть использовано, в частности, для синтеза технической документации (это одно из самых узких мест в любом производстве). Группа под руководством профрессора Либермана исследует возможности нового подхода к решению этой проблемы, теперь уже на основе автономных агентов.

\subsection{3. Генетическое программирование}

Следующее направление в области искусственной жизни генетическое программирование (genetic programming является попыткой использовать метафору генной инженерии для описания различных алгоритмов.

Генети́ческий алгори́тм (англ. genetic algorithm - это эвристический алгоритм поиска, используемый для решения задач оптимизации и моделирования путём случайного подбора, комбинирования и вариации искомых параметров с использованием механизмов, напоминающих биологическую 
эволюцию. Является разновидностью эволюционных вычислений, с помощью которых решаются оптимизационные задачи с использованием методов естественной эволюции, таких как наследование, мутации, отбор и кроссинговер. Отличительной особенностью генетического алгоритма является акцент на использование оператора «скрещивания», который производит операцию рекомбинации решенийкандидатов, роль которой аналогична роли скрещивания в живой природе.

Строки (string) искусственной "генетической" системы аналогичны хромосомам в биологических системах. Законченный набор строк называется структурой (structure). Структуры декодируются в набор параметров, альтернативы решений или точку в пространстве решений. Строки состоят из характеристик, или детекторов, которые могут принимать различные значения. Детекторы могут размещаться на разных позициях в строке. Все это сделано по аналогии с реальным миром. В природных системах полный генетический пакет называется генотипом. Организм, который образуется при взаимодействии генотипа с окружающей средой, носит название фенотипа. Хромосомы состоят из генов, которые могут принимать разные значения. (Например, ген цвета для глаза животного может иметь значение "зеленый" и позицию 10).

В генетических алгоритмах роль основных строительных блоков играют строки фриксированной длины, тогда как в генетическом программировании эти строки разворачиваются в деревья, столь знакомые специалистам в области трансляции. 
Ныне одним из лидеров в области генетического программирования является группа исследователей из Стэндфордского университета (Stanford University), работающая под руководством профессора Джона Коза. Генетическое программирование вдохнуло новую жизнь в хорошенько уже подзабытый язык LISP (List Processing), который создавался группой Джона Маккарти (того самого, кто в 60-е годы ввел в наш обиход термин "искусственный интеллект") как раз для обработки списков и функционального программирования. Кстати, именно этот язык в США был и остается одним из наиболее распространенных языков программирования для задач искусственного интеллекта.

\subsection{4. Нейронные сети глубокого обучения}

Глубокое обучение (глубинное обучение; англ. Deep learning) - совокупность методов машинного обучения (с учителем, с частичным привлечением учителя, без учителя, с подкреплением), основанных на обучении представлениям (англ. feature/representation learning), а не специализированным алгоритмам под конкретные задачи. Многие методы глубокого обучения были известны ещё в 1980-е (и даже ранее[1]), но результаты были невпечатляющими[2], пока продвижения в теории искусственных нейронных сетей (предобучение нейросетей с помощью специального случая ненаправленной графической модели, так называемой ограниченной машины Больцмана) и вычислительные мощности середины 2000-х (прежде всего, графических процессоров Nvidia, а в настоящее время и тензорных процессоров Google) не позволили создавать сложные технологические архитектуры нейронных 
сетей, обладающие достаточной производительностью и позволяющие решать широкий спектр задач, не поддававшихся эфффективному решению ранее, например, в компьютерном зрении, машинном переводе, распознавании речи, причём качество решения во многих случаях теперь сопоставимо, а в некоторых случаях превосходит эффрективность «белковых» экспертов.

Глубинная нейронная сеть (ГНС, англ. DNN - Deep neural network) - это искусственная нейронная сеть (ИНС) с несколькими слоями между входным и выходным слоями [35, 36]. ГНС находит корректный метод математических преобразований, чтобы превратить исходящие данные в выходящие, независимо от линейной или нелинейной корреляции. Сеть продвигается по слоям, рассчитывая вероятность каждого выхода. Например, ГНС, которая обучена распознавать породы собак, пройдет по заданному изображению и вычислит вероятность того, что собака на изображении относится к определенной породе. Пользователь может просмотреть результаты и выбрать вероятности, которые должна отображать сеть (выше определенного порога, например), и вернуть в сеть предложенную метку. Каждое математическое преобразование считается слоем, а сложные ГНС имеют много слоев, отсюда и название «глубинные» или «глубокие» сети.

ГНС могут моделировать сложные нелинейные отношения. Архитектуры ГНС генерируют композиционные модели, в которых объект выражается в виде многоуровневой композиции примитивов [37]. Дополнительные уровни позволяют составлять элементы из более низких уровней, 
потенциально моделируя сложные данные с меньшим количеством единиц, чем мелкая сеть с аналогичными показателями [35].

Глубокая архитектура включает в себя множество вариантов нескольких основных подходов. Каждая архитектура нашла успех в определенных областях. Не всегда возможно сравнить производительность нескольких архитектур, если они не были оценены на одних и тех же наборах данных.

ГНС, как правило, представляют собой сети с прямой связью, в которых данные передаются от входного уровня к выходному уровню без обратной связи. Сначала ГНС создает карту виртуальных нейронов и назначает случайные числовые значения или «веса» соединениям между ними. Веса и входные данные умножаются и возвращают выходной сигнал от 0 до 1. Если сеть не точно распознала конкретный шаблон, алгоритм будет корректировать весовые коэффрициенты [38]. Таким образом, алгоритм может сделать определенные параметры более значимыми, пока он не определит правильные математические манипуляции для полной обработки данных.

Глубокое обучение характеризуется как класс алгоритмов машинного обучения, который [39]:

- использует многослойную систему нелинейных фильтров для извлечения признаков с преобразованиями. Каждый последующий слой получает на входе выходные данные предыдущего слоя. Система глубокого обучения может сочетать алгоритмы обучения с учителем и без учителя, при этом анализ образца представляет собой обучение без учителя, а классификация - обучение с учителем. 
- обладает несколькими слоями выявления признаков или параметров представления данных (обучение без учителя). При этом признаки организованы иерархически, признаки более высокого уровня являются производными от признаков более низкого уровня.

- является частью более широкой области машинного обучения изучения представлений данных.

- формирует в процессе обучения слои на нескольких уровнях представлений, которые соответствуют различным уровням абстракции; слои образуют иерархию понятий.

Все определения констатируют

1. наличие нескольких слоев нелинейной обработки

2. обучение с учителем или без учителя признаков каждого слоя, фрормируя иерархию от низкого до высокого уровня [39].

Состав конкретных нелинейных слоёв зависит от решаемой проблемы. Используются как скрытые слои нейронной сети, так и слои сложных логических преобразований [40]. Система может включать скрытые переменные, организованные послойно в глубоких генеративных моделях, таких как узлы в глубокой сети доверия и глубокой ограниченной машине Больцмана.

Алгоритмы глубокого обучения противопоставлены алгоритмам неглубокого обучения по количеству параметризованных преобразований, с которыми сталкивается сигнал, распространяющийся от входного слоя к выходному слою, где параметризованным преобразованием считается 
такой блок обработки данных, у которого есть обучаемые параметры, такие как веса или пороги [41]. Цепочка преобразований от входа к выходу называется САР - путём передачи ответственности (англ. credit assignment path, CAP). САР описывают потенциальные причинные связи вдоль сети от входа к выходу, при этом путь в разных ветвях может иметь разную длину. Для нейронной сети прямого распространения (feedforward) глубина CAP не отличается от глубины сети и равна количеству скрытых слоев плюс один (выходной слой также параметризован). Для рекуррентных нейронных сетей, в которых сигнал может перескакивать через слои минуя промежуточные, САР из-за обратной связи потенциально неограничен в длине. Не существует универсально согласованного порога глубины деления неглубокого обучения от глубокого обучения, но обычно считается, что глубокое обучение характеризуется несколькими нелинейными слоями (САР > 2). Йорген Шмидхубер выделяет также «очень глубокое обучение», когда САР > 10 [41].

Глубокое обучение - это алгоритмы машинного обучения для моделирования высокоуровневых абстракций с применением многочисленных нелинейных преобразований [39 ... 43].

В первую очередь к глубинному обучению относятся следующие методы и их вариации:

- определённые системы обучения без учителя, такие как ограниченная машина Больцмана для предварительного обучения, автокодировщик, глубокая сеть доверия, генеративно-состязательная сеть; 
- определённые системы обучения с учителем, такие как свёрточная нейронная сеть, которая вывела на новый уровень технологии распознавания образов;

- рекуррентные нейронные сети, позволяющие обучаться на процессах во времени;

- рекурсивные нейронные сети, позволяющие включать обратную связь между элементами схемы и цепочками.

Комбинируя эти методы, создаются сложные системы, соответствующие различным задачам искусственного интеллекта.

Глубокое обучение является апробированной выборкой из широкого семейства методов машинного обучения для представлений данных, наиболее соответствующих характеру задачи. Изображение, например, может быть представлено многими способами, такими как вектор интенсивности значений на пиксель, или (в более абстрактной фрорме) как множество примитивов, областей определённой фооры, и т. д. Удачные представления данных облегчают решение конкретных задач например, распознавания лиц и выражений лица [44]). В системах глубокого обучения автоматизирует сам процесс выбора и настройки признаков, проводя обучение признаков без учителя или с частичным привлечением учителя, используя для этого эфрфективные алгоритмы и иерархическое извлечение признаков [45].

Исследования в этой области позволили усовершенствовать модели работы с большими объёмами немаркированных данных. Некоторые подходы возникли в результате достижений в области нейронаук, успехов интерпретации обработки информации, построения 
коммуникационных моделей в нервной системе, таких как нейронное кодирование, связанное с определением отношения между стимулом и нейронными реакциями и взаимосвязи электрической активности между нейронами в головном мозге [46].

Системы глубокого обучения нашли применение в таких областях, как компьютерное зрение, распознавание речи, обработка естественного языка, аудиораспознавание, биоинформатика, где для ряда задач были продемонстрированы существенно лучшие результаты, чем ранеe.

Несмотря на успехи использования глубинного обучения, у него всё же есть фундаментальное ограничение: модели глубинного обучения ограничены в том, что они могут представлять, и большинство программ нельзя выразить в виде непрерывного геометрического морфинга многообразия данных [47].

Осталось, однако, и скептическое представление, что глубокое обучение - не что иное, как модное слово или ребрендинг для нейронных сетей [48, 49].

\subsection{5. Интеллектуальные роботы}

Еще одно перспективное направление развития интеллектуальных систем - разработка интеллектуальных роботов (ИР, рисунок 1.2).

Общепринято мнение, что интеллектуальный робот обладает т.н. моделью внешнего мира или внутренней средой, что позволяет роботу действовать в условиях неопределенности информации. В том случае, если эта модель 
реализована в виде базы знаний, то целесообразно, чтобы эта база знаний была динамической. При этом коррекция правил вывода в условиях меняющейся внешней среды естественным образом реализует механизмы самообучения и адаптации.

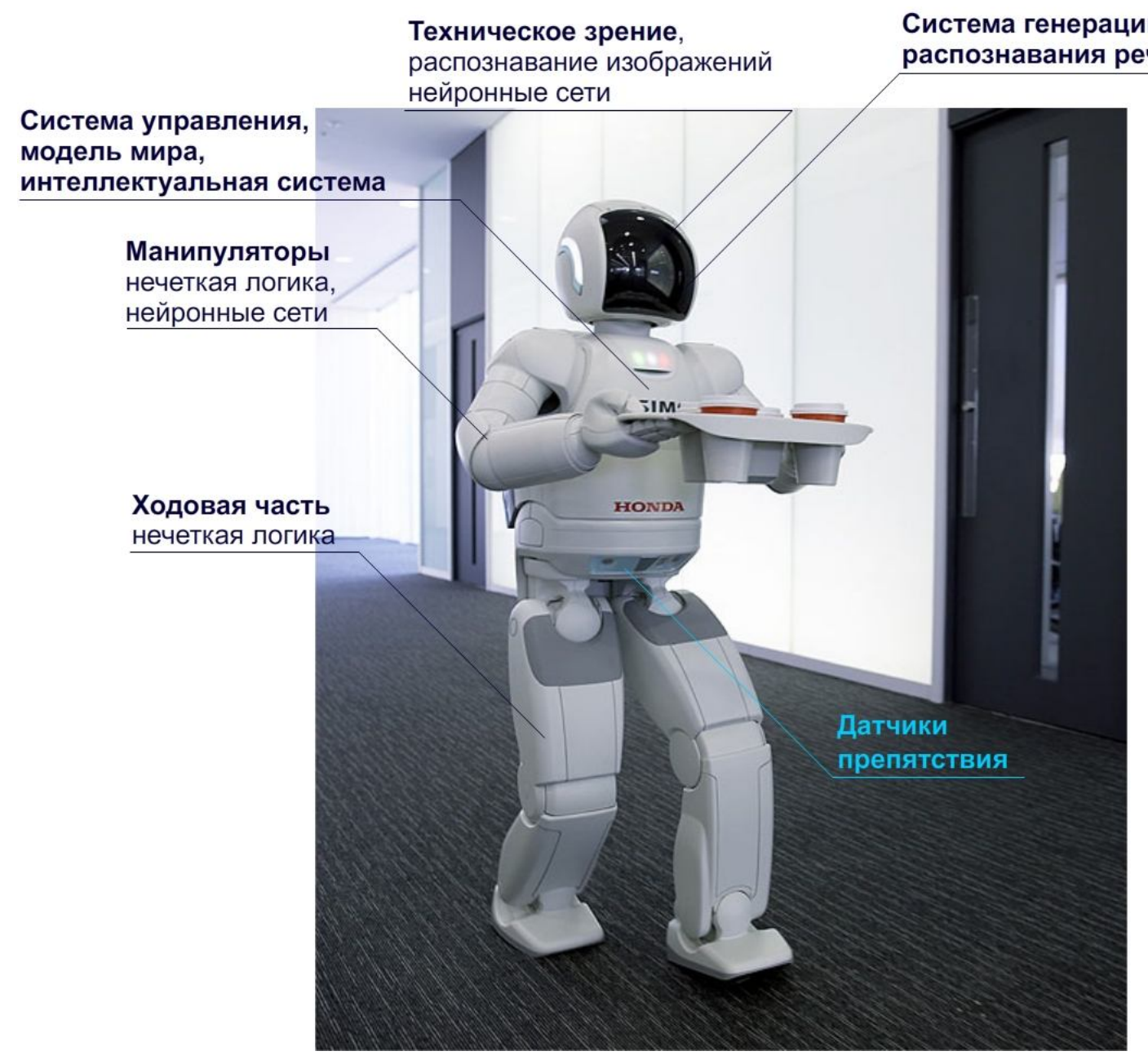

\section{Рисунок 1.2 - Компоненты интеллектуального робота ASIMO, разработанного компанией HONDA}

На сегодняшний день считается, что в состав интеллектуального робота должны входить:

Исполнительные органы - это манипуляторы, ходовая часть и др. устройства, с помощью которых робот может воздействовать на окружающие его предметы. Причем по своей структуре это сложные технические устройства, имеющие в 
своем составе сервоприводы, мехатронные части, датчики, системы управления. По аналогии с живыми организмами это руки и ноги робота.

Датчики - это системы технического зрения, слуха, осязания, датчики расстояний, локаторы и др. устройства, которые позволяют получить информацию из окружающего мира.

Система управления - это мозг робота, который должен принимать информацию от датчиков и управлять исполнительными органами. Эта часть робота обычно реализуется программными средствами. В состав системы управления интеллектуального робота должны входить следующие компоненты:

Модель мира - отражает состояние окружающего робот мира в терминах, удобных для хранения и обработки. Модель мира выполняет функцию запоминания состояния объектов в мире и их свойств.

Система распознавания - сюда входят системы распознавания изображений, распознавания речи и т.п. Задачей системы распознавания является идентификация, т.е. «узнавание» окружающих робот предметов, их положения в пространстве. В результате работы компонентов системы распознавания строится модель мира.

Система планирования действий - осуществляет «виртуальное» преобразование модели мира с целью получения какого-нибудь действия. При этом обычно проверяется достижимость поставленной цели. Результатом работы планирования действий является построение планов, т.е. последовательностей элементарных действий. 
Система выполнения действий - пытается выполнить запланированные действия, подавая команды на исполнительные устройства и контролируя при этом процесс выполнения. Если выполнение элементарного действия оказывается невозможным, то весь процесс прерывается и должно быть выполнено новое (или частично новое) планирование.

Система управления целями - определяет иерархию, т.е. значимость и порядок достижения поставленных целей.

Важными свойствами системы управления является способность к обучению и адаптации, т.е. способность генерировать последовательности действий для поставленной цели, а также подстраивать свое поведение под изменяющиеся условия окружающей среды для достижения поставленных целей.

Причины, приведшие системы искусственного интеллекта к коммерческому успеху, следующие:

1. Специализация. Переход от разработки инструментальных средств общего назначения к проблемно/предметно специализированным средствам, что обеспечивает сокращение сроков разработки приложений, увеличивает эффрективность использования инструментария, упрощает и ускоряет работу эксперта, позволяет повторно использовать информационное и программное обеспечение (объекты, классы, правила, процедуры).

2. Использование языков традиционного программирования и рабочих станций. Переход от систем, основанных на языках искусственного интеллекта (Lisp, Prolog и т.п.), к языкам традиционного программирования (C, C++ и т.п.) 
упростил "интегрированность" и снизил требования приложений к быстродействию и емкости памяти. Использование рабочих станций вместо ПК резко увеличило круг возможных приложений методов искусственного интеллекта.

3. Интегрированность. Разработаны инструментальные средства искусственного интеллекта, легко интегрируемые с другими информационными технологиями и средствами (с CASE, СУБД, контроллерами, концентраторами данных и т.п.).

4. Открытость и переносимость. Разработки ведутся с соблюдением стандартов, обеспечивающих данные характеристики.

5. Архитектура клиент/сервер. Разработка распределенной информационной системы в данной архитектуре позволяет снизить стоимость оборудования, используемого в приложении, децентрализовать приложения, повысить надежность и общую производительность, поскольку сокращается объем информации, пересылаемой между ЭВМ, и каждый модуль приложения выполняется на адекватном оборудовании.

Перечисленные причины могут рассматриваться как общие требования к инструментальным средствам создания систем искусственного интеллекта.

\subsection{6. Цифровое производство}

Цифровое производство - это целая система, основанная на интегрированных компьютерных технологиях. Благодаря подобному инновационному подходу каждое промышленное предприятие способно выйти на высокий уровень конкурентоспособности и эффрективности. Система цифрового 
производства относится к «Индустрии 4.0» и четвертой промышленной революции.
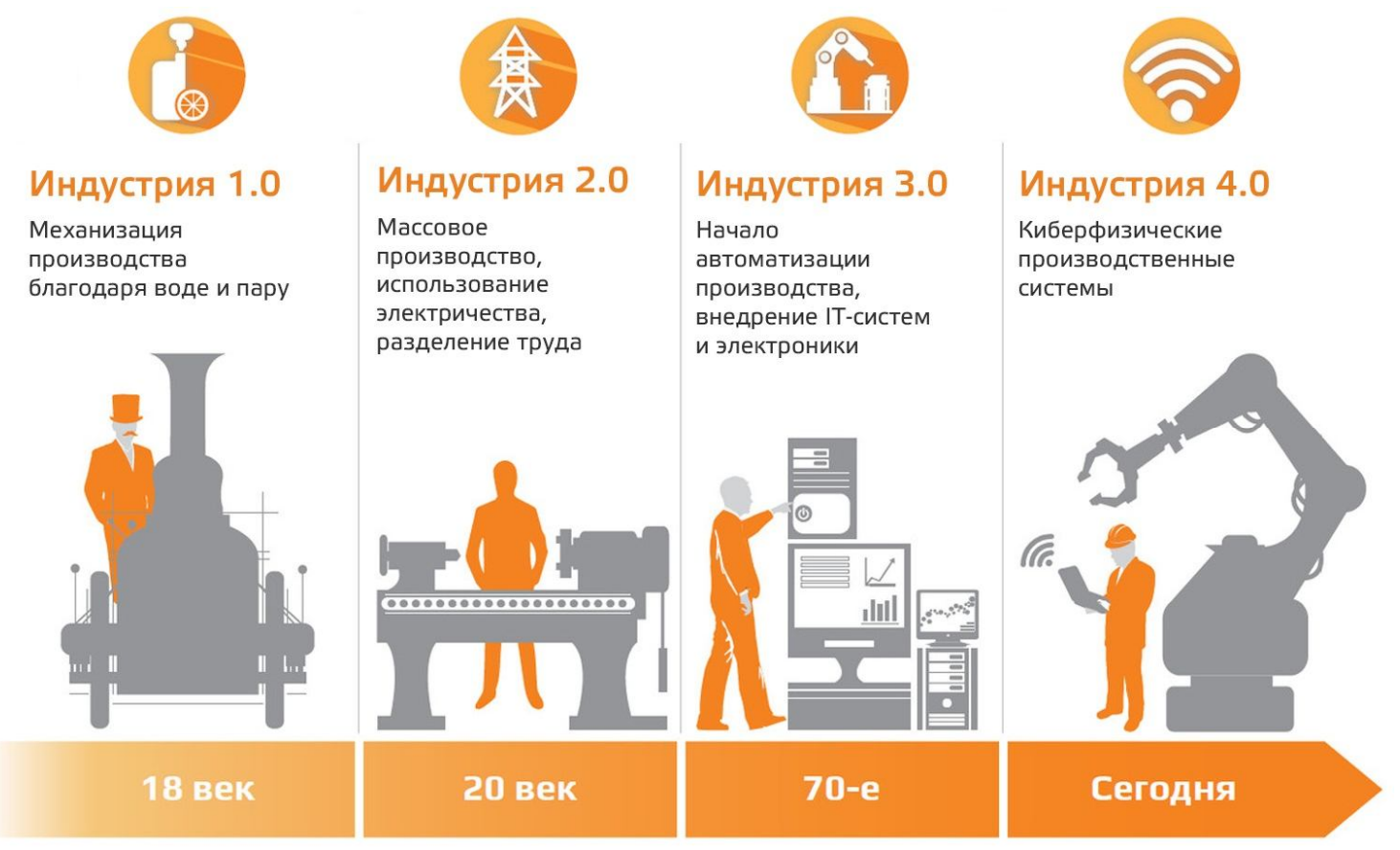

Рисунок 1.3 - Промышленные революции

Цисровое производство, по данным актуальных исследований, включает следующие инновационные основы, разработанные за последние 20-25 лет.

Средства численного моделирования. Своевременное создание математических моделей различных производственных процессов позволяет сократить промышленные расходы и уменьшить издержки.

Трехмерная

(компьютерная визуализация.

облегчило
3D-моделирование графика)

$$
\text { облегинло }
$$

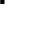

предварительного согласования объектов и снизило затраты на реальные макеты. В виртуальной среде можно создавать полноценные описания технологического процесса, включая планировку цехов, сборочные линии и все ресурсы предприятия. Фактически речь идет о формировании целого 
цифрового двойника той или иной детали или конечного продукта. В дальнейшем на базе данной технологии была разработана 3D-печать - метод создания различных деталей и материалов.

Обобщенная информационная модель. СІМ-модель обеспечивает оперативный и бесперебойный обмен информацией между различными приложениями и устройствами, разработанными разными компаниями. СІМ основа интегрированных промышленных процессов в XXI веке.

Проектирование для производства. Концепция DFM обеспечивает конструирование объектов на базе технологичности с предварительным расчетом точной стоимости процессов.

Управление жизненным циклом изделия (PLM). Прикладное программное обеспечение должно эффрективно работать уже на стадии разработки макета продукции. После производственных процедур управление сохраняется над эксплуатацией и утилизацией объектов. Главная цель сократить издержки на последующую доработку товаров на каком-либо этапе. 


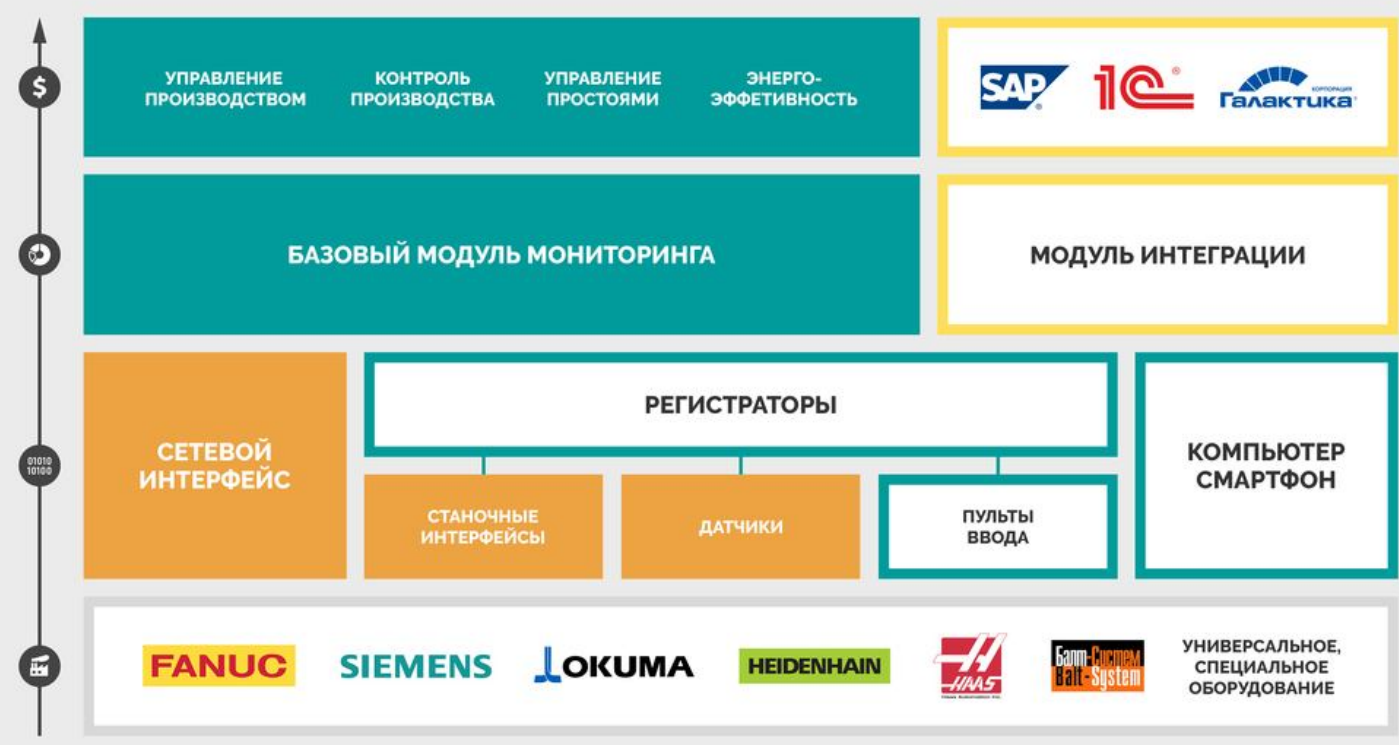

\section{Рисунок 1.4 - Компоненты цифрового производства}

Кроме указанных технологий, развитие предприятия осуществляется за счет разных средств совместной работы и инженерного анализа, которые облегчают создание конструкционных элементов и другие технологические процессы.

Благодаря таким разработкам легко организовать современное промышленное предприятие, которые будет соответствовать всем стандартам безопасности, рациональности и экологичности.

Инновационные технологии поддерживают экономику любой компании, поскольку снижают ее траты на лишнее оборудование и человеческие ресурсы.

Цифровые разработки помогают в организации гибкого производства: при необходимости предприятие может переориентироваться на выпуск другой продукции или изменить объемы и сроки производства для поддержания конкурентоспособности и выхода на международный рынок. 
Технологические системы и современное оборудование обеспечивают своевременный обмен данными между технологами и конструкторами, что ускоряет достижение производственных целей и часто снижает себестоимость продукции.

Главная миссия цифровой комплексной системы создание оптимальных условий для массового производства товаров по индивидуальным заказам потребителей. В этих целях на каждом предприятии нужно заниматься автоматизацией таких процессов, как конструкторская разработка, непосредственно создание товара, сбыт. В то же самое время требуется фрормирование единого информационного поля, где и осуществляется в реальном режиме управление и контроль над сообщающимися системами предприятия.

\section{КОНТРОЛЬНЫЕ ВОПРОСЫ}

1. Охарактеризуйте основные направления исследований, проводимых в области искусственного интеллекта.

2. Приведите известные вам примеры интеллектуальных систем.

3. Назовите основные функции, присущие ИС. На чем основана их реализация?

4. Сфрормулируйте основные отличия систем искусственного интеллекта от обычных программных средств.

5. Чем отличаются знания от данных? Приведите определение знаний. 
6. Дайте характеристику основных признаков, по которым классифицируются знания (природа знаний, способ приобретения знаний, тип представления знаний).

7. Расскажите о логических способах представления знаний. Укажите преимущественную область применения логической модели. 


\section{2. ИНТЕЛЛЕКТУАЛЬНЫЕ ИНФОРМАЦИОННЫЕ ТЕХНОЛОГИИ}

\section{1. ПОНЯТИЕ ИНТЕЛЛЕКТУАЛЬНОЙ ИНФОРМАЦИОННОЙ ТЕХНОЛОГИИ}

\section{Интеллектуальные информационные технологии}

(ИИТ) (англ. Intellectual information technology, IIT - это информационные технологии, помогающие человеку ускорить анализ политической, экономической, социальной и технической ситуации, а также - синтез управленческих решений. При этом используемые методы не обязательно должны быть логически непротиворечивы или копировать процессы человеческого мышления.

Использование ИИТ на практике подразумевает учет специфики проблемной области, которая может характеризоваться следующим набором признаков:

- качество и оперативность принятия решений;

- нечеткость целей и институциональных границ;

- множественность субъектов, участвующих в решении проблемы;

- хаотичность, фрлюктуируемость и квантованность поведения среды;

- множественность взаимовлияющих друг на друга фракторов;

- слабая фрормализуемость, уникальность, нестереотипность ситуаций;

- латентность, скрытость, неявность информации;

- девиантность реализации планов, значимость малых действий; 
- парадоксальность логики решений и др.

ИИТ формируются при создании информационных систем и информационных технологий для повышения эффрективности принятия решений в условиях, связанных с возникновением проблемных ситуаций. В этом случае любая жизненная или деловая ситуация - от выбора партнера по жизни до социального конфликта - описывается в виде некоторой познавательной модели (когнитивной схемы, архетипа, фрейма и пр.), которая впоследствии используется в качестве основания для построения и проведения моделирования, в том числе - компьютерного.

Гносеологический фундамент ИИТ наиболее явно видится в работах Канта, Гегеля, Гуссерля. Собственно же явную историю ИИТ удобно начать с середины XX века, когда появился термин «Искусственный интеллект» (Artificial Intelligence). История ИИТ начинается с середины 1970-х годов и связывается с совместным практическим применением интеллектуальных информационных систем, систем искусственного интеллекта, систем поддержки решений и информационных систем. Эта история связана также с развитием трех научных направлений: компьютерной философии, компьютерной психологии и продвинутой компьютерной науки (англ. Advanced computer science). C организационно-технологической стороны ИИТ дополняются прогрессом в создании: ситуационных центров, информационно-аналитических систем. Программноматематическое обеспечение составляют эволюционные вычисления и генетические алгоритмы, системы поддержки общения человека с компьютером на естественном языке, 
когнитивное моделирование, системы автоматического тематического рубрицирования документов, системы стратегического планирования, инструментарий технического и фундаментального анализа финансовых рынков, системы менеджмента качества, системы управления интеллектуальной собственностью и др.

С середины 1940-х вплоть до ранних 1970-х гг. создание ИИТ рассматривалось преимущественно в рамках логического решения задач. Этот период развития ИИТ характеризуется сравнительно большой определенностью и низкой динамичностью объекта управления. Вместе с тем уже в 1943 году появились «продукции Поста» и методы решения некорректных (обратных) задач на метризуемых пространствах, а в 1947 году для моделирования сложных экономических ситуаций активно начали использоваться методы причинного нелогического вывода, которые позже легли в основу методов системной динамики, немонотонных вычислений, когнитивного моделирования. Создание центров управления полетами, организация штабных работ с применением средств визуализации и автоматизации, зарубежные публикации на тему создания специальных ситуационных центров вдохновили в 1970-е годы инженеров на создание ситуационных комнат для совершенствования управления крупными социальными и институциональными системами. В создании таких комнат и интеллектуальных технологий больше внимания стало придаваться средствам визуализации, диалоговым системам, помогающим использовать базы знаний и модели для решения плохо структурированных проблем. В середине 1970-х годов на основе ИИТ в корпоративном мире начинают развиваться 
системы поддержки решений для эффрективного управления ресурсами, осуществления контроллинга. Ряд замечательных практических идей и результатов, например, связанных с теорией нейронных сетей, многоагентных и активных систем, оптических и голографических процессоров, появилось именно в это время. Тот период можно отметить успехами в создании всеобъемлющих моделей ситуационного управления регионами в периоды кризисов. Его характеризует вера в практически неограниченные возможности искусственного интеллекта. В середине 1980-х годов был отмечен крах иллюзий относительно неограниченных возможностей успешной формализации процессов мышления с помощью систем логической обработки естественного языка. Вместе с тем появились интеллектуальные технологии для ограниченной поддержки исследовательской и профессиональной деятельности лиц, принимающих решения. Практическое применение получили подходы, основанные на использовании достоверного и правдоподобного вывода, немонотонных логик и нечетких систем, лингвистических процессоров. Тогда же появилась явная потребность в оптических и квантовых вычислениях - для решения многомерных и слабо распараллеливающихся задач. Видимые успехи появились в сорере обработки текстов естественного языка, высококачественного поиска документов, слежения за динамичными объектами управления, решения задач распознавания образов, имитационного моделирования, статистической обработки данных, решения транспортных задач, построения нечетких контроллеров. В конце 1980-х внимание разработчиков ИИТ все больше акцентируется на исследовании адаптивных свойств информационных систем, 
учитывающих умственную активность человека при осуществлении речевых актов, дискурса и принятии решений. С начала 1990 годов ИИТ все активней используются в стратегическом менеджменте, управлении ресурсами, реинжиниринге, создании ситуационных центров. Все более заметно внедряются интеллектуальные информационные технологии аналитической обработки больших массивов информации, технологии поддержки решений. В 1990-х годах в совокупности и взаимосвязи развиваются: экспертные системы реального времени, интеллектуальные агенты, активные системы, достоверный и правдоподобный вывод, эволюционные и квантовые вычисления, когнитивные модели, ситуационные центры и пр. Эксклюзивное место в развитии ИИТ с середины 1990-х заняла разработка необходимых условий конвергентности (сходимости) процессов управления, поиска информации и синтеза управленческих решений, направленных на обеспечение необходимых условий устойчивой сходимости этих процессов к намечаемым целям. С 2000 года начал приобретать новое звучание процесс электронизации деятельности органов власти, бизнеса и населения. Концепция электронной демократии, предполагающая: осуществление гражданского контроля, проведение выборов и референдумов, поддержку процессов самоорганизации населения, обеспечение возможности участия населения в принятии государственных решений, расширение технологической возможности обмена мнениями - также предусматривает расширение возможностей интеллектуальных информационных технологий. Концепции электронной коммерции, включающие: маркетинг, управление 
корпоративными ресурсами, повышение качества продукции и услуг, расширение доступа к капиталу, электронные торги, развитие инноваций, поддержку процессов самоорганизации бизнеса - не могла не активизировать работы по дальнейшему развитию систем поддержки решений с помощью ИИТ.

\section{2. КЛАССИФИКАЦИЯ ИНТЕЛЛЕКТУАЛЬНЫХ ИНФОРМАЦИОННЫХ СИСТЕМ}

Интеллектуальная информационная система (ИИС) основана на концепции использования базы знаний для генерации алгоритмов решения прикладных задач различных классов в зависимости от конкретных инфрормационных потребностей пользователей.

Для ИИС характерны следующие признаки [5]:

- развитые коммуникативные способности;

- умение решать сложные плохо фрормализуемые задачи;

- способность к самообучению;

- адаптивность.

Каждому из перечисленных признаков условно соответствует свой класс ИИС. Различные системы могут обладать одним или несколькими признаками интеллектуальности с различной степенью проявления.

Средства ИИ могут использоваться для реализации различных функций, выполняемых ИИС. 


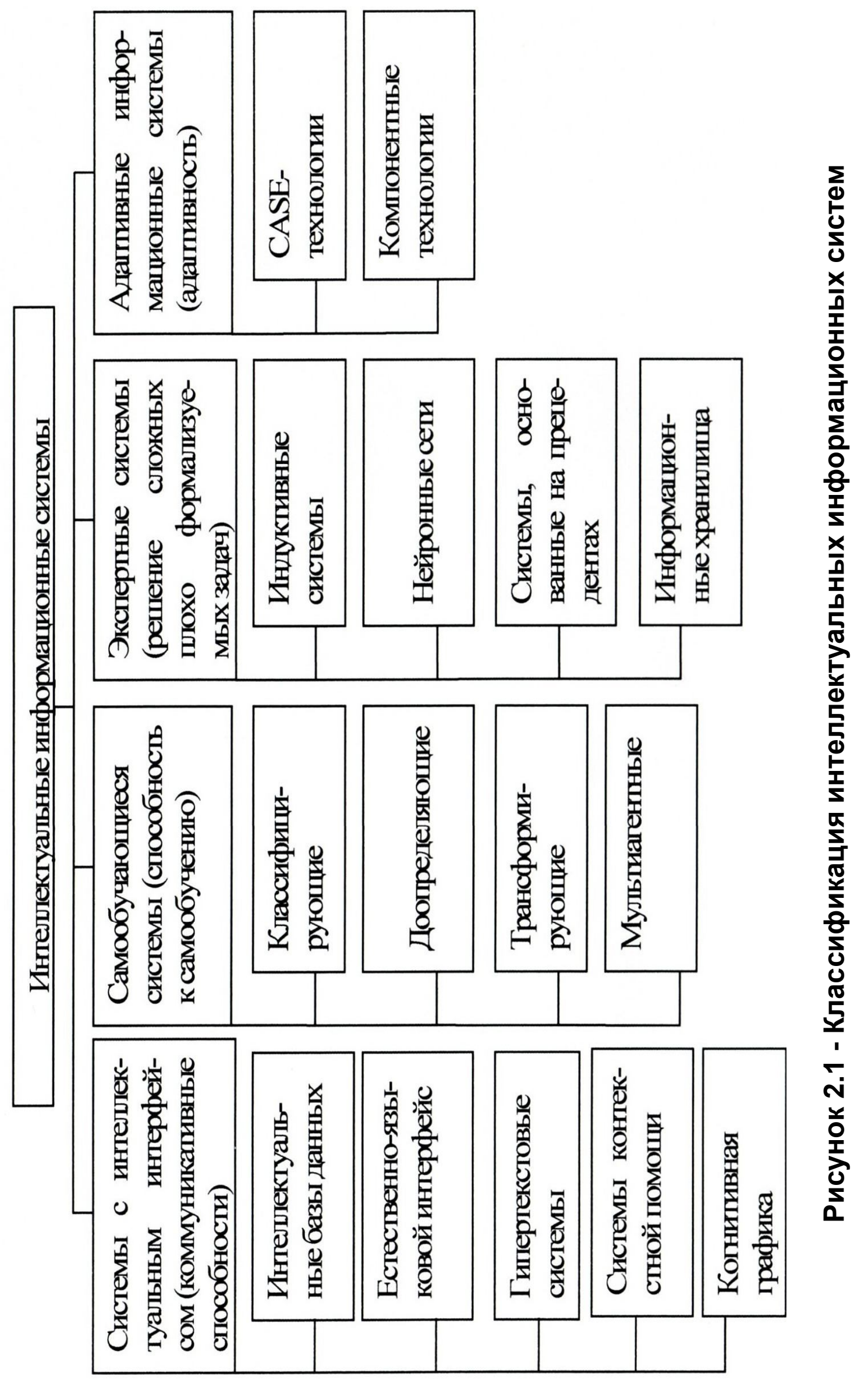


На рисунке 2.1 приведена классификация ИИС, признаками которой являются следующие интеллектуальные функции:

- коммуникативные способности - способ взаимодействия конечного пользователя с системой;

- решение сложных плохо фрормализуемых задач, которые требуют построения оригинального алгоритма решения в зависимости от конкретной ситуации, характеризующейся неопределенностью и динамичностью исходных данных и знаний;

- способность к самообучению - умение системы автоматически извлекать знания из накопленного опыта и применять их для решения задач;

адаптивность - способность системы к развитию в соответствии с объективными изменениями области знаний.

\section{3. ПЕРСПЕКТИВНЫЕ ИНФОРМАЦИОННЫЕ ТЕХНОЛОГИИ ПРОЕКТИРОВАНИЯ, СОЗДАНИЯ, АНАЛИЗА И СОПРОВОЖДЕНИЯ ИНТЕЛЛЕКТУАЛЬНЫХ СИСТЕМ}

\subsection{1. Системы с интеллектуальным интерфейсом}

Применение ИИ для усиления коммуникативных способностей информационных систем привело к появлению систем с интеллектуальным интерфейсом, среди которых можно выделить следующие типы.

1. Интеллектуальные базы данных. Позволяют в отличие от традиционных БД обеспечивать выборку необходимой информации, не присутствующей в явном виде, а выводимой из совокупности хранимых данных.

2. Естественно-языковой интерфейс. Применяется для доступа к интеллектуальным базам данных, контекстного поиска 
документальной текстовой информации, голосового ввода команд в системах управления, машинного перевода с иностранных языков. Для реализации естественно-языкового интерфейса (ЕЯ-интерфейса) необходимо решить проблемы морфологического, синтаксического и семантического анализа, а также задачу синтеза высказываний на естественном языке. При морфологическом анализе осуществляются распознавание и проверка правильности написания слов в словаре. Синтаксический контроль предполагает разложение входных сообщений на отдельные компоненты, проверку соответствия грамматическим правилам внутреннего представления знаний и выявление недостающих частей. Семантический анализ обеспечивает установление смысловой правильности синтаксических конструкций. В отличие от анализа синтез высказываний заключается В преобразовании цифрового представления информации в представление на естественном языке.

3. Гипертекстовые системы. Используются для реализации поиска по ключевым словам в базах данных с текстовой информацией. Для более полного отражения различных смысловых отношений терминов требуется сложная семантическая организация ключевых слов. Решение этих задач осуществляется с помощью интеллектуальных гипертекстовых систем, в которых механизм поиска сначала работает с базой знаний ключевых слов, а затем - с самим текстом. Аналогичным образом проводится поиск мультимедийной информации, включающей кроме текста графическую информацию, аудио- и видеообразы. 
4. Системы контекстной помощи. Относятся к классу систем распространения знаний. Такие системы являются, как правило, приложениями к документации. Системы контекстной помощи - частный случай гипертекстовых и ЕЯ-систем. В них пользователь описывает проблему, а система на основе дополнительного диалога конкретизирует ее и выполняет поиск относящихся к ситуации рекомендаций. В обычных гипертекстовых системах, наоборот, компьютерные приложения навязывают пользователю схему поиска требуемой информации.

5. Системы когнитивной графики. Ориентированы на общение с пользователем ИИС посредством графических образов, которые генерируются в соответствии с изменениями параметров моделируемых или наблюдаемых процессов. Когнитивная графика позволяет в наглядном и выразительном виде представить множество параметров, характеризующих изучаемое явление, освобождает пользователя от анализа тривиальных ситуаций, способствует быстрому освоению программных средств и повышению конкурентоспособности разрабатываемых ИИС. Применение когнитивной графрики особенно актуально в системах мониторинга и оперативного управления, в обучающих и тренажерных системах, в оперативных системах принятия решений, работающих в режиме реального времени.

\subsection{2 Экспертные системы}

Экспертные системы как самостоятельное направление в искусственном интеллекте сформировалось в конце 1970-х гг. История ЭС началась с сообщения японского комитета по 
разработке ЭВМ пятого поколения, в котором основное внимание уделялось развитию «интеллектуальных способностей» компьютеров. С тем, чтобы они могли оперировать не только данными, но и знаниями, как это делают специалисты (эксперты) при выработке умозаключений. Группа по экспертным системам при Комитете British Computer Society определила ЭС как «воплощение в ЭВМ компоненты опыта эксперта, основанной на знаниях, в такой форме, что машина может дать интеллектуальный совет или принять решение относительно обрабатываемой функции». Одним из важных свойств ЭС является способность объяснить ход своих рассуждений понятным для пользователя образом [5].

Область исследования ЭС называют «инженерией знаний». Этот термин был введен Е. Фейгенбаумом и в его трактовке означает «привнесение принципов и инструментария из области искусственного интеллекта в решение трудных прикладных проблем, требующих знаний экспертов». Другими словами, ЭС применяются для решения неформализованных проблем, к которым относят задачи, обладающие одной (или несколькими) из следующих характеристик:

- задачи не могут быть представлены в числовой форме;

- исходные данные и знания о предметной области обладают неоднозначностью, неточностью, противоречивостью;

- цели нельзя выразить с помощью четко определенной целевой функции;

- не существует однозначного алгоритма решения задачи; 
- алгоритмическое решение существует, но его нельзя использовать по причине большой размерности пространства решений и ограничений на ресурсы (времени, памяти).

Обычно к ЭС относят системы, основанные на знании, т. е. системы, вычислительная возможность которых является в первую очередь следствием их наращиваемой базы знаний (БЗ) и только во вторую очередь определяется используемыми методами. Методы инженерии знаний (методы ЭС) в значительной степени инвариантны тому, в каких областях они могут применяться. Области применения ЭС весьма разнообразны: военные приложения, медицина, электроника, вычислительная техника, геология, математика, космос, сельское хозяйство, управление, финансы, юриспруденция и т. д. Среди этих областей лидируют бизнес, производство, медицина, проектирование и системы управления. Более критичны методы инженерии знаний к типу решаемых задач. В настоящее время ЭС используются при решении задач следующих типов: принятие решений в условиях неопределенности (неполноты), интерпретация символов и сигналов, предсказание, диагностика, конструирование, планирование, управление, контроль и др.

Назначение и особенности ЭС. Знания, которыми обладает специалист в какой-либо области (дисциплине), можно разделить на формализованные (точные) и неформализованные (неточные). Формализованные знания формулируются в книгах и руководствах в виде общих и строгих суждений (законов формул, моделей, алгоритмов и т. п.), отражающих универсальные знания. Неформализованные 
знания, как правило, не попадают в книги и руководства в связи с их конкретностью, субъективностью и приблизительностью. Знания этого рода являются результатом обобщения многолетнего опыта работы и интуиции специалистов. Они обычно представляют собой многообразие эмпирических (эвристических) приемов и правил.

В зависимости от того, какие знания преобладают в той или иной области (дисциплине), ее относят к формализованным (если преобладают точные знания) или к неформализованным (если преобладают неточные знания) описательным областям. Задачи, решаемые на основе точных знаний, называют формализованными, а задачи, решаемые с помощью неточных знаний, - неформализованными. Речь идет не о неформализуемых, а о неформализованных задачах, т. е. о задачах, которые, возможно, и формализуемы, но эта формализация пока неизвестна.

Как правило, неформализованные задачи обладают неполнотой, ошибочностью, неоднозначностью и (или) противоречивостью знаний (как данных, так и используемых правил преобразования).

Экспертные системы не отвергают и не заменяют традиционного подхода к программированию, они отличаются от традиционных программ тем, что ориентированы на решение нефрормализованных задач и обладают следующими особенностями:

- алгоритм решений не известен заранее, а строится самой ЭС с помощью символических рассуждений, базирующихся на эвристических приемах; 
- ясность полученных решений, т. е. система «осознает» в терминах пользователя, как она получила решение;

- способность анализа и объяснения своих действий и знаний;

- способность приобретения новых знаний от пользователя-эксперта, не знающего программирования, и изменения в соответствии с ними своего поведения;

- обеспечение «дружественного», как правило, естественно-языкового (ЕЯ) интерфейса с пользователем.

Главное отличие ЭС и систем искусственного интеллекта от систем обработки данных состоит в том, что в них используется символьный, а не числовой способ представления данных, а в качестве методов обработки информации применяются процедуры логического вывода и эвристического поиска решений.

Во многих случаях ЭС являются инструментом, усиливающим интеллектуальные способности эксперта. Кроме того, ЭС может выступать в роли:

- консультанта для неопытных или непрофессиональных пользователей;

- ассистента эксперта-человека в процессах анализа вариантов решений;

- партнера эксперта в процессе решения задач, требующих привлечения знаний из разных предметных областей.

Для классификации ЭС используются следующие признаки: 
- способ фрормирования решения;

- способ учета временного признака;

- вид используемых данных и знаний;

- число используемых источников знаний.

По способу формирования решения ЭС можно разделить на анализирующие и синтезирующие. В системах первого типа осуществляется выбор решения из множества известных решений на основе анализа знаний, в системах второго типа решение синтезируется из отдельных фррагментов знаний.

В зависимости от способа учета временного признака ЭС делят на статические и динамические. Статические ЭС предназначены для решения задач с неизменяемыми в процессе решения данными и знаниями, а динамические ЭС допускают такие изменения.

По видам используемых данных и знаний различают ЭС с детерминированными и неопределенными знаниями. Под неопределенностью знаний и данных понимаются их неполнота, ненадежность, нечеткость.

ЭС могут создаваться с использованием одного или нескольких источников знаний.

В соответствии с перечисленными признаками можно выделить четыре основных класса ЭС (рисунок 2.2): классифицирующие, доопределяющие, трансформирующие и мультиагентные. 


\begin{tabular}{|c|c|c|c|}
\hline & Анализ & Синтез & \\
\hline $\begin{array}{c}\text { Детерминиро- } \\
\text { ванность } \\
\text { знаний }\end{array}$ & $\begin{array}{c}\text { Классифици } \\
\text { рующие }\end{array}$ & $\begin{array}{c}\text { Трансформи } \\
\text { рующие }\end{array}$ & $\begin{array}{c}\text { Один источник } \\
\text { знаний }\end{array}$ \\
\hline \multirow[t]{2}{*}{$\begin{array}{l}\text { Неопределенность } \\
\text { знаний }\end{array}$} & $\begin{array}{c}\text { Доопределя } \\
\text { ющие }\end{array}$ & $\begin{array}{c}\text { Мультиаген } \\
\text { тные }\end{array}$ & $\begin{array}{c}\text { Несколько } \\
\text { источников } \\
\text { Знаний }\end{array}$ \\
\hline & Статика & Динамика & \\
\hline
\end{tabular}

\section{Рисунок 2.2 - Основные классы ЭС}

Классифицирующие ЭС решают задачи распознавания ситуаций. Основным методом формирования решений в таких системах является дедуктивный логический вывод.

Доопределяющие ЭС используются для решения задач с не полностью определенными данными и знаниями. В таких ЭС возникают задачи интерпретации нечетких знаний и выбора альтернативных направлений поиска в пространстве возможных решений. В качестве методов обработки неопределенных знаний могут использоваться байесовский вероятностный подход, коэфффициенты уверенности, нечеткая логика.

Трансформирующие ЭС относятся к синтезирующим динамическим экспертным системам, в которых предполагается повторяющееся преобразование знаний в процессе решения задач. В ЭС данного класса используются различные способы обработки знаний:

- генерация и проверка гипотез; 
- логика предположений и умолчаний (когда по неполным данным формируются представления об объектах определенного класса, которые впоследствии адаптируются к конкретным условиям изменяющихся ситуаций);

- использование метазнаний (более общих закономерностей) для устранения неопределенностей в ситуациях.

Мультиагентные системы - это динамические ЭС, основанные на интеграции нескольких разнородных источников знаний. Эти источники обмениваются между собой получаемыми результатами в ходе решения задач. Системы данного класса имеют следующие возможности:

- реализация альтернативных рассуждений на основе использования различных источников знаний и механизма устранения противоречий;

- распределенное решение проблем, декомпозируемых на параллельно решаемые подзадачи с самостоятельными источниками знаний;

- применение различных стратегий вывода заключений в зависимости от типа решаемой проблемы;

- обработка больших массивов информации из баз данных;

- использование математических моделей и внешних процедур для имитации развития ситуаций. 


\subsection{3 Самообучающиеся системы}

Самообучающиеся интеллектуальные системы основаны на методах автоматической классификации ситуаций из реальной практики, или на методах обучения на примерах. Примеры реальных ситуаций составляют так называемую обучающую выборку, которая фрормируется в течение определенного исторического периода. Элементы обучающей выборки описываются множеством классификационных признаков.

Стратегия «обучения с учителем» предполагает задание специалистом для каждого примера значений признаков, показывающих его принадлежность к определенному классу ситуаций. При обучении «без учителя» система должна самостоятельно выделять классы ситуаций по степени близости значений классификационных признаков.

В процессе обучения проводится автоматическое построение обобщающих правил или функций, описывающих принадлежность ситуаций к классам, которыми система впоследствии будет пользоваться при интерпретации незнакомых ситуаций. Из обобщающих правил, в свою очередь, автоматически фрормируется база знаний, которая периодически корректируется по мере накопления информации об анализируемых ситуациях.

Построенные в соответствии с этими принципами самообучающиеся системы имеют следующие недостатки:

- относительно низкую адекватность баз знаний возникающим реальным проблемам из-за неполноты и/или зашумленности обучающей выборки; 
- низкую степень объяснимости полученных результатов;

- поверхностное описание проблемной области и узкую направленность применения из-за ограничений в размерности признакового пространства.

Индуктивные системы позволяют обобщать примеры на основе принципа индукции «от частного к общему». Процедура обобщения сводится к классификации примеров по значимым признакам. Алгоритм классификации примеров включает следующие основные шаги.

1. Выбор классификационного признака из множества заданных.

2. Разбиение множества примеров на подмножества по значению выбранного признака.

3. Проверка принадлежности каждого подмножества примеров одному из классов.

4. Проверка окончания процесса классификации. Если какое-то подмножество примеров принадлежит одному подклассу, т.е. у всех примеров этого подмножества совпадает значение классификационного признака, то процесс классификации заканчивается.

5. Для подмножеств примеров с несовпадающими значениями классификационных признаков процесс распознавания продолжается, начиная с первого шага. При этом каждое подмножество примеров становится классифицируемым множеством.

Нейронные сети представляют собой классический пример технологии, основанной на примерах. Нейронные сети обобщенное название группы математических алгоритмов, 
обладающих способностью обучаться на примерах, «узнавая» впоследствии черты встреченных образцов и ситуаций. Благодаря этой способности нейронные сети используются при решении задач обработки сигналов и изображений, распознавания образов, а также для прогнозирования.

Нейронная сеть - это кибернетическая модель нервной системы, которая представляет собой совокупность большого числа сравнительно простых элементов - нейронов, топология соединения которых зависит от типа сети. Чтобы создать нейронную сеть для решения какой-либо конкретной задачи, следует выбрать способ соединения нейронов друг с другом и подобрать значения параметров межнейронных соединений.

В системах, основанных на прецедентах, Б3 содержит описания конкретных ситуаций (прецеденты). Поиск решения осуществляется на основе аналогий и включает следующие этапы: получение информации о текущей проблеме;

- сопоставление полученной инфрормации со значениями признаков прецедентов из базы знаний;

- выбор прецедента из базы знаний, наиболее близкого к рассматриваемой проблеме;

- адаптация выбранного прецедента к текущей проблеме;

- проверка корректности каждого полученного решения;

- занесение детальной информации о полученном решении в БЗ.

Прецеденты описываются множеством признаков, по которым строятся индексы быстрого поиска. Однако в системах, основанных на прецедентах, в отличие от индуктивных систем 
допускается нечеткий поиск с получением множества допустимых альтернатив, каждая из которых оценивается некоторым коэффициентом уверенности. Наиболее эфффективные решения адаптируются к реальным ситуациям с помощью специальных алгоритмов.

Системы, основанные на прецедентах, применяются для распространения знаний и в системах контекстной помощи.

Информационные хранилища отличаются от интеллектуальных баз данных, тем, что представляют собой хранилища значимой информации, регулярно извлекаемой из оперативных баз данных. Хранилище данных - это предметноориентированное, интегрированное, привязанное ко времени, неизменяемое собрание данных, применяемых для поддержки процессов принятия управленческих решений. Предметная ориентация означает, что данные объединены в категории и хранятся в соответствии с теми областями, которые они описывают, а не с приложениями, которые их используют. Привязанность данных ко времени выражает их «историчность», т.е. атрибут времени всегда явно присутствует в структурах хранилища данных. Неизменяемость означает, что, попав однажды в хранилище, данные уже не изменяются в отличие от оперативных систем, где данные присутствуют только в последней версии, поэтому постоянно меняются. Технологии извлечения знаний из хранилищ данных основаны на методах статистического анализа и моделирования, ориентированных на поиск моделей и отношений, скрытых в совокупности данных.

Для извлечения значимой информации из хранилищ данных имеются специальные методы (OLAP-анализа, Data 
Mining или Knowledge Discovery), основанные на применении методов математической статистики, нейронных сетей, индуктивных методов построения деревьев решений и др. [5].

\section{Технология OLAP (On-Line Analytical Processing -} оперативный анализ данных) предоставляет пользователю средства для фрормирования и проверки гипотез о свойствах данных или отношениях между ними, на основе разнообразных запросов к базе данных. Они применяются на ранних стадиях процесса извлечения знаний, помогая аналитику сфокусировать внимание на важных переменных. Средства Data Mining отличаются от OLAP тем, что кроме проверки предполагаемых зависимостей они способны самостоятельно (без участия пользователя) генерировать гипотезы о закономерностях, существующих в данных, и строить модели, позволяющие количественно оценить степень взаимного влияния исследуемых фракторов на основе имеющейся информации.

\subsection{4. Адаптивные информационные системы}

Потребность в адаптивных информационных системах возникает в тех случаях, когда поддерживаемые ими проблемные области постоянно развиваются. В связи с этим адаптивные системы должны удовлетворять ряду специфических требований, а именно:

- адекватно отражать знания проблемной области в каждый момент времени;

- быть пригодными для легкой и быстрой реконструкции при изменении проблемной среды.

Адаптивные свойства информационных систем обеспечиваются за счет интеллектуализации их архитектуры. 
Ядром таких систем является постоянно развиваемая модель проблемной области, поддерживаемая в специальной базе знаний - репозитории. Ядро системы управляет процессами генерации или переконфригурирования программного обеспечения.

В процессе разработки адаптивных информационных систем применяется оригинальное или типовое проектирование. Оригинальное проектирование предполагает разработку информационной системы с «чистого листа» на основе сформулированных требований. Реализация этого подхода основана на использовании систем автоматизированного проектирования, или CASE-технологий.

При типовом проектировании осуществляется адаптация типовых разработок к особенностям проблемной области. Для реализации этого подхода применяются инструментальные средства компонентного (сборочного) проектирования инфрормационных систем (R/3, BAAN IV, Prodis и др.).

Главное отличие подходов состоит в том, что при использовании CASE-технологии на основе репозитория при изменении проблемной области каждый раз выполняется генерация программного обеспечения, а при использовании сборочной технологии - конфигурирование программ и только в редких случаях - их переработка.

\section{КОНТРОЛЬНЫЕ ВОПРОСЫ}

1. Дайте краткую характеристику систем с интеллектуальным интерфейсом, экспертных систем, самообучающихся систем и адаптивных информационных систем. 
2. Каким требованиям должны удовлетворять адаптивные системы?

3. Перечислите сфреры применения экспертных систем.

4. Назовите основные классы экспертных систем.

5. Какие этапы составляют поиск решения на основе аналогий в системах, основанных на прецедентах? 


\section{3. ИНФОРМАЦИОННЫЕ ПРОЦЕССЫ В ОБЛАСТИ ПРИМЕНЕНИЯ И УПРАВЛЕНИЯ ИНТЕЛЛЕКТУАЛЬНЫМИ СИСТЕМАМИ}

\section{1. ПРОЦЕССЫ ПО РАЗВИТИЮ ФУНКЦИОНАЛЬНЫХ ВОЗМОЖНОСТЕЙ ИНТЕЛЛЕКТУАЛЬНЫХ СИСТЕМ НА ВСЕХ СТАДИЯХ ИХ ЖИЗНЕННОГО ЦИКЛА}

В настоящее время в технологиях разработки сложных
систем наблюдается сдвиг от изолированных инструментов
(даже адекватных и мощных) к интегрированным и сбалансированным инструментальным комплексам поддержки всего жизненного цикла разработки. При этом современные тенденции в данной области связываются с интеллектуализацией инструментов на основе использования методов и средств представления и обработки знаний, а также интеграцией таких интеллектуальных инструментов в общие технологические среды, использующие классические подходы, разработанные и апробированные в технологии программирования.

Дальнейшим развитием функциональных возможностей интеллектуальных систем является применение парадигмы мультиагентных систем (MAC), которая имеет уже более чем десяти летнюю историю активных исследований и разработок. Но одной из самых "горячих" точек этой бурно развивающейся области в настоящее время является инструментарий для создания MAC. Так как проектирование и реализация таких систем задача сложная, трудоемкая и предполагающая наличие у разработчиков значительного объема знаний и опыта в тематически разных плоскостях - от представления и обработки 
знаний до проектирования распределенных приложений и агентно-ориентированного программирования.

\subsection{1. Инструментальные средства разработки МАС}

В целом процесс создания МАС хорошо вписывается в рамки современных технологий разработки и реализации сложных программных систем. Ведь и здесь необходимы такие традиционные этапы, как анализ, проектирование и реализация, отладка и тестирование, интеграция и сопровождение. При этом агентно-ориентированное проектирование и программирование во многом схожи с объектно-ориентированным подходом к созданию сложных программных комплексов. Однако в данной области создатели МАC работают со значительно более сложными сущностями (агентами) и на более высоком уровне абстракции, чем это обычно делается в рамках объектноориентированной парадигмы. Поэтому инструментальные средства поддержки разработки МАС должны быть более "сообразительными" и обеспечивать разные активности в рамках интегрированного окружения.

\section{Состояние исследований}

Существует много публикаций и Интернет-ресурсов, связанных с обсуждением средств проектирования и реализации агентов и мультиагентных систем. Впечатляющая коллекция ссылок на соответствующие проекты представлена на сайте Intelligent Information Integration [13, 2000]. Не имея места для сколько-нибудь подробного обсуждения таких проектов и инструментария, в них разрабатываемого, в данной работе мы остановимся на двух мощных инструментариях - 
AgentBuilder и ZEUS [AgentBuilder, 1999; Collis et al., 1999] и их кратком сравнении.

Философия инструментария AgentBuilder адресована разработчикам программного обеспечения, которым нужны мощные средства поддержки разработки агентноориентированных приложений. Цель проекта ZEUS обеспечение быстрого прототипирования новых приложений за счет "внедрения" В инструментарий общих принципов проектирования агентных систем и компонент, лежащих в основе уже существующих МАС. Анализ архитектуры и функциональных возможностей этих инструментальных систем показывает, что AgentBuilder ближе к использованию методов и средств инженерии знаний, разработанных в рамках ИИ, а ZEUS - к подходу, связанному с повторным использованием и реинженерингом компонент, характерному для современной технологии программирования.

AgentBuilder состоит из 2-х основных компонент - Toolkit и Run-Time System. Первая включает средства для управления процессом разработки, анализа предметной области, в которой должны функционировать агенты, проектирования среды коммуникации агентов, спецификации поведения отдельных агентов, а также отладки и тестирования созданного программного обеспечения. Вторая компонента инструментария AgentBuilder обеспечивает окружение периода исполнения. Реализован инструментарий на языке Java.

Инструментарий ZEUS состоит из множества компонент (также реализованных на языке Java), которые можно разбить на три функциональные группы (библиотеки): Agent Component Library, Agent Building Tool и Suite of Utility Agents. Детальный 
анализ состава библиотек ZEUS показывает, что здесь имеется более широкий набор полезных процедур (utility tools), чем в AgentBuilder. Различаются эти инструментальные системы и тем, что AgentBuilder ориентирован на интерпретацию спецификаций агентов, а ZEUS манифестирует использование режима компиляции.

AgentBuilder поддерживает расширение ментальной модели Шохама [Shoham, 1993], позволяющее описывать поведение агентов на основе специальных правил. Поведение агентов в ZEUS специфицируется на основе модели вложенных графов (nested graphs model). Оба инструментария используют KQML в качестве базиса коммуникации агентов. Язык представления знаний системы AgentBuilder - RADL (Reticular's Agent Definition Language). Это LISP-подобный по фоорме и продукционно-фреймовый по сути язык представления знаний (ЯПЗ). Представление знаний в системе Zeus кажется более простым и ограниченным. По существу, оно базируется на использовании композиций базовых действий (generic actions) и настройке их на конкретное приложение за счет параметров.

Анализ рассмотренных выше инструментальных средств построения МАС, а также сравнение многих других средств этого класса показывает, что в настоящее время нет одной системы, которая бы "покрывала" даже основные потребности разработчиков МАС и делала бы это на основе действительно интеллектуальных инструментов. Результаты сравнения инструментария AgentBuilder и ZEUS сведены в таблице 3.1 (дополнительная колонка таблицы фриксирует свойства инструментария AgSDK проекта AgentFlight). 
Таблица 3.1 - Основные требования к МАС-инструментарию

\begin{tabular}{|l|l|l|l|}
\hline & AgentBuilder & ZEUS & AgentFlight \\
\hline Управление проектом & +++ & +++ & +++ \\
\hline $\begin{array}{l}\text { Инновации в разработке } \\
\text { агентов }\end{array}$ & +++ & ++ & ++ \\
\hline $\begin{array}{l}\text { Инновации в разработке } \\
\text { МАС }\end{array}$ & ++ & +++ & ++++ \\
\hline $\begin{array}{l}\text { Уровень использования } \\
\text { знаний }\end{array}$ & +++ & + & +++++ \\
\hline $\begin{array}{l}\text { Набор вспомогательных } \\
\text { процедур }\end{array}$ & +++ & +++ & ++ \\
\hline Средства отладки & +++ & ++++ & ++ \\
\hline Технология реализации & +++ & +++ & ++++ \\
\hline
\end{tabular}

Анализ состояния работ и тенденций в области инструментальной поддержки разработки мультиагентных систем позволяет выдвинуть следующие основные требования к МАС-инструментарию:

- эксплицитная поддержка методологии и технологии разработки и реализации МАC;

- ориентация на жизненный цикл MAC;

- поддержка пользователей разного уровня компетентности;

- ориентация на современные парадигмы визуального проектирования и программирования;

- разработка самого инструментария как системы, основанной на знаниях.

Перечисленные выше требования и положены в основу проектных решений при создании инструментария AgSDK, обсуждаемого в оставшейся части настоящей работы. 


\subsubsection{AgSDK: среда разработки и реализации MAC}

Интеллектуальная среда разработки мультиагентных систем AgSDK ориентирована на поддержку эксплицитного представления методологии и технологии создания таких систем, должна быть функционально замкнутой и платформенно независимой. Реализация программного обеспечения AgSDK осуществляется по контракту с компанией VERIDAN ERIM International Inc. Разработка инструментария осуществляется в среде JDK 1.2 и Swing 1.2, что позволяет использовать AgSDK на всех вычислительных платформах со стандартным окружением Sun Java, версия 1.2 и выше.

Семантически данная программная платформа делится на две основные части: средства визуального проектирования MAC (AgSDK) и объектную библиотеку AgentLib, которая обсуждается в отдельной статье [Матюшкин и др., 2000].

\section{Методология и управление}

В соответствии с общей концепцией инструментарий AgSDK архитектурно представлен интегрированным набором управляющих компонент, специализированных редакторов и специальных процедур, обеспечивающих разработчикам MAC интеллектуальное ассистирование в процессе спецификации мультиагентной среды в целом, поведения отдельных агентов, фрункционирующих в этой среде, а также генерацию собственно мультиагентных приложений. Технологическая схема проектирования и реализации MAC в среде AgSDK может быть описана потоковой диаграммой, представленной на рисунке 3.1. 
Анализ \& Спецификация

предметной области

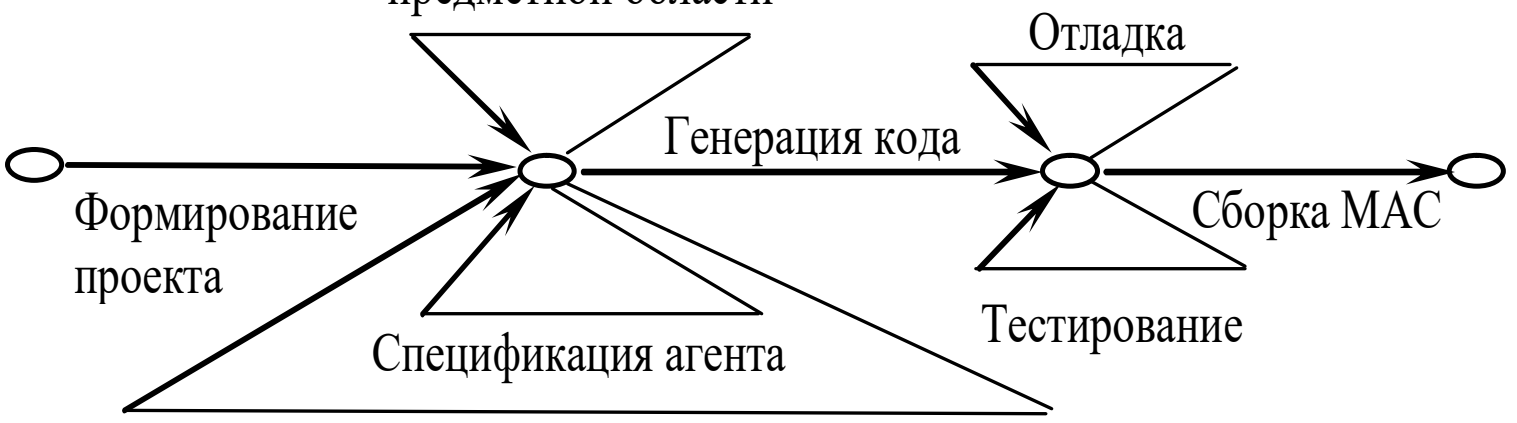

Спецификация агенства

\section{Рисунок 3.1 - Технологическая схема проектирования и реализации MAC на базе AgSDK}

Начинается разработка со стадии формирования проекта, которая поддерживается компонентами Project Management Tools, включающих два основных инструмента: Project Manager и Repository Manager. Первый обеспечивает идентификацию проекта, управление его выполнением и реинжениринг уже использованных проектных решений, а второй - контроль доступа ко всей информации по проекту.

\section{Онтологический инструментарий AgSDK}

Обмен сообщениями между агентами MAC в рассматриваемом подходе, как и в большинстве современных разработок, осуществляется на основе KQML-протокола [Finin et al., 1997]. Но взаимодействие это существенно более сложный процесс, предполагающий понимание смысла передаваемых сообщений и, как следствие, наличие общих и разделяемых знаний. На современном этапе такие знания, как правило, представляются в виде онтологий [Guarino, 1996]. Детальное обсуждение онтологического инструментария AgSDK 
- тема отдельной работы. Поэтому здесь мы лишь зафиксируем принципы, положенные в основу его проектирования и реализации.

Дуга «анализ \& спецификация предметной области» технологической схемы разработки МАC инкапсулирует жизненный цикл создания онтологий (рисунок 3.2), который в рамках инструментария AgSDK базируется на интеграции модели METHONTOLOGY [Fernandez, et al., 1997] и спиральной модели Боэма [Boehm, 1986].

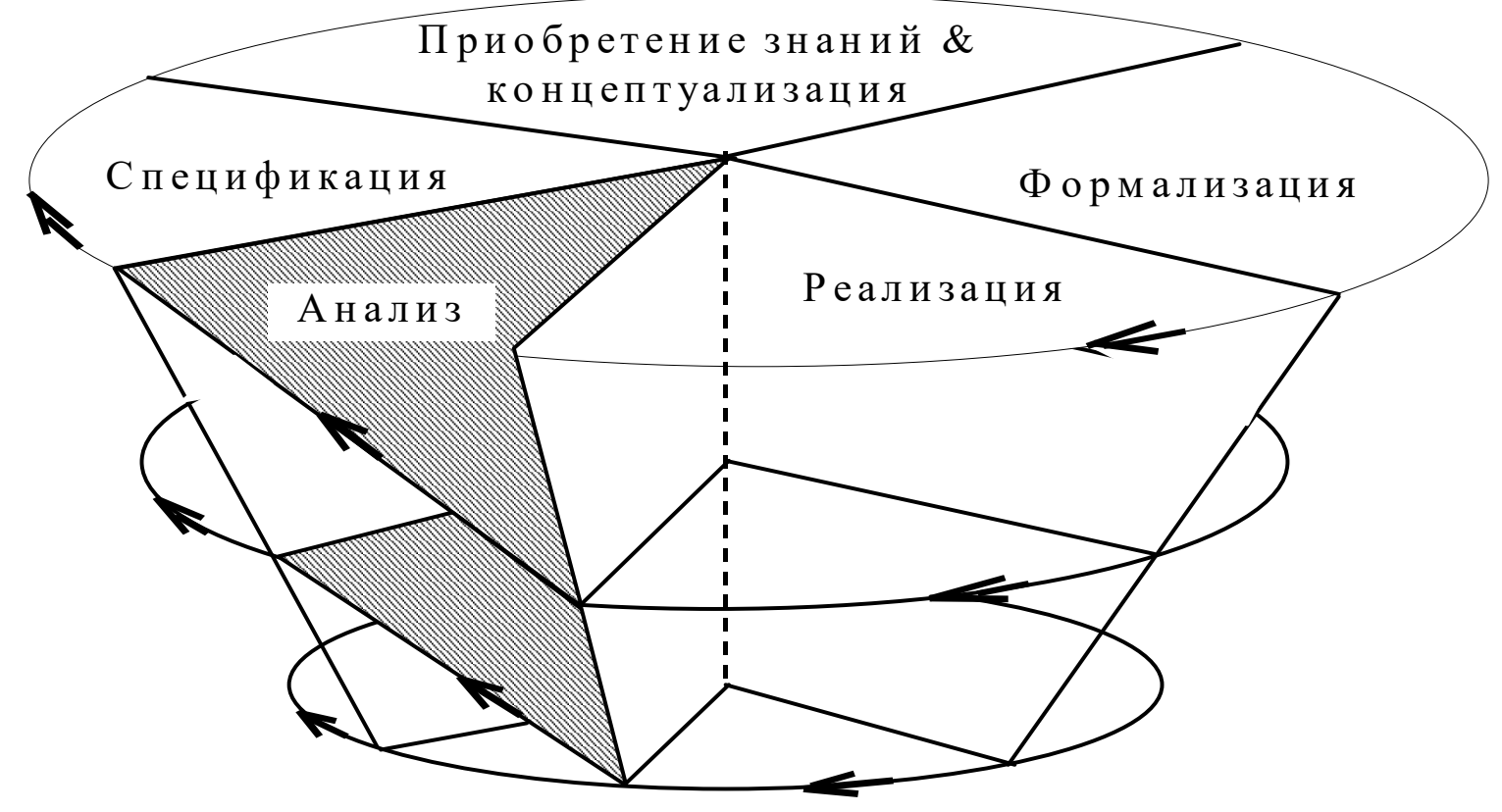

\section{Рисунок 3.2 - Жизненный цикл разработки онтологий в инструментарии AgSDK}

Специфика нашего подхода в том, что здесь каждый виток спирали представляет технологическую карту активностей (спецификация, концептуализация, фрормализация и реализация) и связей между ними, а переход с уровня на уровень - анализ полученных результатов. Таким образом 
процесс разработки онтологии трансформирует «начальный продукт» (потребность в создании определенной онтологии) в «конечный продукт» (документированную и закодированную в фрормальном языке онтологию).

Соответствующие активности поддерживаются на уровне AgSDK компонентой Domain Specification, которая представлена тремя инструментами: Ontology Manager, Ontology Editor и Ontology Specification Converter.

Ontology Manager обеспечивает разработчика средствами идентификации создаваемой онтологии и управления всем процессом. В качестве основных характеристик идентификации используется набор, аналогичный разработанному в рамках проекта (ONTO) ${ }^{2}$ [Vega et al., 1999].

Ontology Editor поддерживает следующие две стадии процесса разработки онтологии. При этом стадия приобретения знаний и концептуализации дает структурированное спецификацию всех концептов онтологии и их атрибутов, описание значимых отношений между концептами, а также требуемых аксиом и правил вывода, связанных с концептами и отношениями. Стадия фрормализации базируется на использовании специального языка представления знаний OntoPilot, который является развитием языка представления знаний (ЯПЗ) Pilot/2 [Khoroshevsky, 1994] с учетом результатов, полученных в проектах Ontobroker и SHOE [Benjamins et al., 1998; Heflin, et al., 1998]. Ontology Editor представляет собой интеллектуальный графический редактор, обеспечивающий разработчика средствами визуального проектирования онтологий. 
Ontology Specification Converter реализует последнюю стадию создания онтологии - трансформацию OntoPilotспецификации в соответствующие классы библиотеки AgLib и/или в XML-представление онтологии, интегрированные с машиной вывода OntoPilot.

Стадия анализа «замыкает» виток в спирали жизненного цикла онтологии и обеспечивает, при необходимости, переход к следующему витку этой спирали. А собственно спецификация MAC осуществляется компонентами Agency $и$ Agent, обсуждаемыми ниже.

Для определенности дальнейшего изложения рассмотрим модельную задачу проектирования МАC.

\section{Модельный пример}

Пусть проектируется мультиагентная система, в архитектуре которой представлены несколько групп агентов, каждой из которых "руководит" свой менеджер. Предположим также, что в каждую группу могут входить агенты разных типов. Задача менеджеров групп состоит во взаимодействии с другими менеджерами с целью накопления информации о составе агентных групп и типах агентов в них представленных для того, чтобы в дальнейшем сфрормировать межгрупповые коллективы, куда бы входили лишь агенты одного и того же типа. После формирования таких коллективов взаимодействие между их членами должно осуществляться без вмешательства менеджеров групп.

Для определенности предположим, что в разрабатываемой МАС представлены две группы (группа-А и группа-В), "руководимые" менеджерами ManagerA и ManagerB соответственно. Пусть также типы агентов, функционирующих в 
каждой группе, ограничены следующими: "Танцоры" (Dancers), "Певцы" (Singers) и "Маляры" (Painters). Тогда результатом работы МАС должно стать образование трех коллективов "любителей танца", "любителей пения" и "клуба маляров", где общение заключается в реализации определенной схемы диалога [Хорошевский, 1999]. В общем случае такая схема включает приветствие, собственно взаимодействие и прощание. Предположим, что в ответ на предложение по установлению контакта каждый агент сфрормированного коллектива может реагировать случайным образом - либо принять предложение, либо отказаться от взаимодействия. В последнем случае агент-инициатор общения "засыпает" на определенное время, после чего повторяет попытку установления контакта.

\section{Проектирование агентной среды}

Как отмечалось выше, одной из основных задач, возникающих перед разработчиками MAC, является проектирование мультиагентной среды, где должны функционировать агенты. B AgSDK решение этой задачи возлагается на интеллектуальную компоненту Agency Suite, обеспечивающую создание, редактирование и визуализацию объектов агенства и допустимых взаимодействий между ними на основе знаний об архитектуре создаваемой МАС. Экранная форма с результатами проектирования агентства для обсуждаемого ниже примера представлена на рисунке 3.3.

Для модельной задачи, рассмотренной выше, процесс проектирования агентства заключается в спецификации его состава (в нашем случае это менеджер MasterAgentA и агенты 
его группы DancerA, PainterA и SingerA, а также менеджер MasterAgentB и агенты его группы DancerB, PainterB и SingerB.

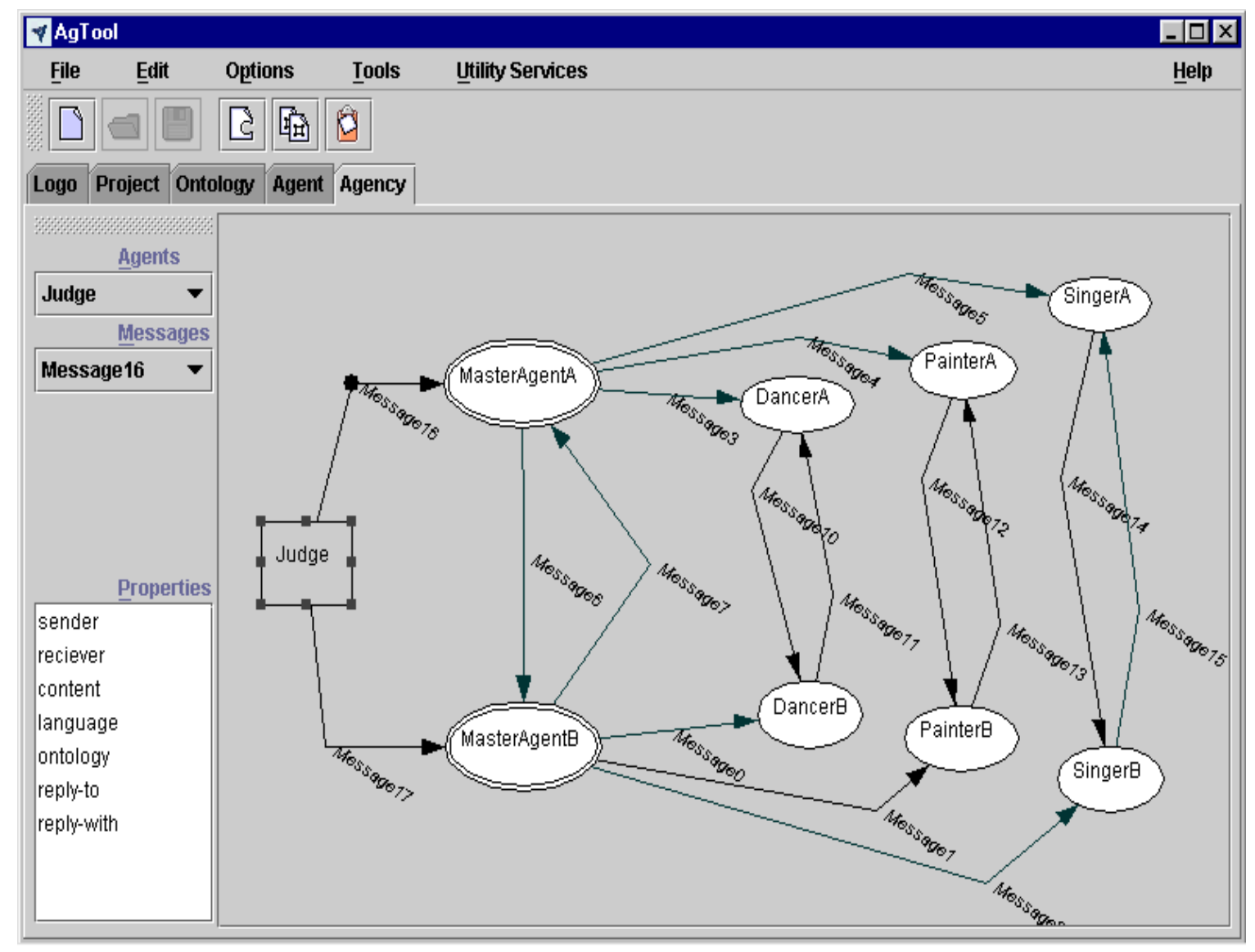

Рисунок 3.3 - Панель спецификации агентства инструментария AgSDK

Для взаимодействия со средой в агентство включен и специальный объект Judge, основной задачей которого является инсталляция менеджеров групп. Кроме спецификации всех объектов агентства в компоненте Agency Suite определяются и потоки сообщений, которыми данные объекты обмениваются между собой и со средой.

Для ассистирования в процессе спецификации компонента Agency Suite использует специальную фреймовую БЗ, основными прототипами в которой являются фрреймы GenericMaster, GenericAgent и Environment. Результат 
проектирования погружается в базу текущего проекта и используется в дальнейшем на этапе генерации исполнительного кода.

\section{Спецификация агентов}

Второй инструментальной составляющей проектирования MAC является Agent Suite. Основная ее задача - спецификация поведения агентов и среды. Заметим, что у каждого из агентов может быть несколько "линий поведения", которые могут существовать одновременно и быть независимыми иІили связанными с друг другом. Так, например, для нашего модельного примера целесообразно считать, что генетическое поведение менеджеров содержит две линии - активную (DonorMasterBehaviour) и пассивную (RecipientMasterBehaviour). Первая из них предполагает, что агент, ее реализующий, является инициатором общения, а вторая - что он лишь отвечает на активность других агентов. При этом обе линии поведения агента могут активироваться лишь в случае согласия от партнера по взаимодействию. В работе [Хорошевский, 1999] рассмотрена система потоковых диаграмм, реализующих специфицированное выше поведение. На рисунке 3.4 показана панель Agent Suite инструментария AgSDK, в рамках которой происходит спецификация поведения агентов.

Диаграмма Inv, представленная на рисунке 3.4 , описывает компоненту "установление-контакта". Перформативы, использованные в этой диаграмме неоднородны по своему уровню и сложности. Так, например, Request, Thanks, Sorry имеют непосредственное отражение на соответствующие перформативы KQML, a waitForReply, ProcReply и некоторые 
другие представляются последовательностью действий, среди которых, в частности, присутствуют и перформативы KQML.

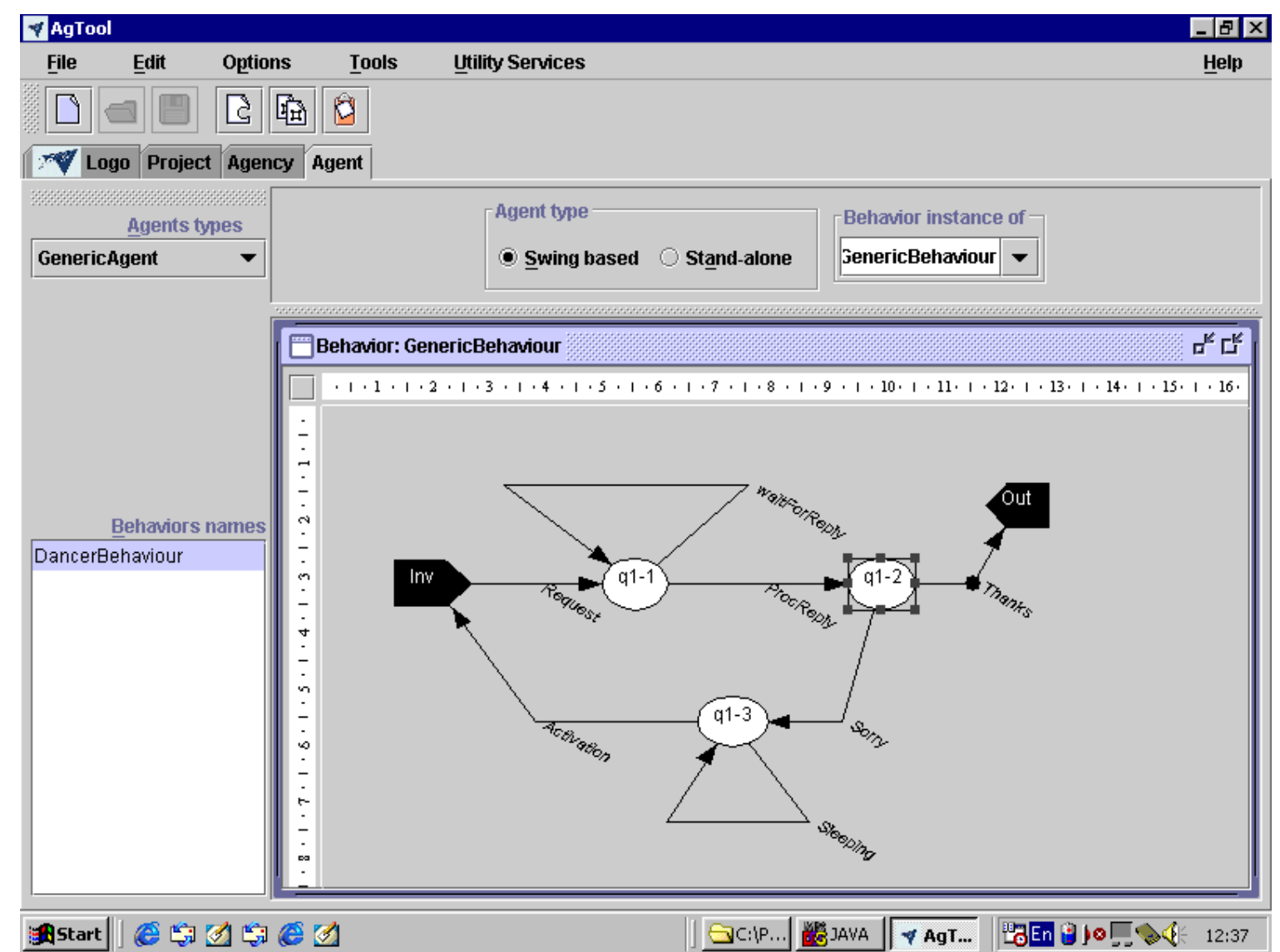

\section{Рисунок 3.4 - Панель спецификации поведения агентов}

Описанный выше инструментарий расширяется за счет компоненты создания онтологий и более мощного генератора исполнительных программ.

\section{2. ОСНОВНЫЕ ТЕНДЕНЦИИ РАЗВИТИЯ ИНТЕЛЛЕКТУАЛЬНЫХ СИСТЕМ, СВЯЗАННЫХ С ИЗМЕНЕНИЯМИ УСЛОВИЙ В ОБЛАСТИ ПРИМЕНЕНИЯ}

Современный уровень развития информационных технологий позволяет сегодня воплощать на практике фундаментальные решения в области искусственного интеллекта (ИИ), разработанные в последние десятилетия прошлого века, создавая не просто корпоративные 
информационные системы, но интеллектуальные системы управления предприятием. В то же время повышение уровня «интеллектуальности» корпоративных информационных систем отвечает потребностям бизнеса - руководителю нужны интеллектуальные системы, позволяющие перенести отработанные многолетней практикой управленческие решения в область компьютерных технологий, высвободив интеллектуальный потенциал для стратегического мышления, определения направлений развития предприятия и решения нестандартных задач, требующих не искусственного, но естественного интеллекта.

Эволюция корпоративных информационных систем определяется также такими факторами изменения производственно-экономической системы, как интеграцией видов бизнеса и развития бизнеса e-business on demand (бизнес по требованию, бизнес по запросу), необходимостью адекватно реагировать на все изменения внешней среды, динамично перераспределяя ресурсы предприятия.

Корпоративную информационную систему (КИС) можно отнести к классу интеллектуальных, если она использует методы искусственного интеллекта при решении задач, возникающих в процессе управления. В частности, интеллектуальная система управления предприятием должна обеспечивать ситуационную поддержку принятия решений, автоматизировать процесс поиска управляющих решений на основе накопленных знаний о предметной области, обеспечивать принятие решений в условиях неопределенности.

Корпоративная интеллектуальная система управления (КИСУ) представляет собой новый уровень развития КИС, когда 
система автоматически определяет место возникновения несоответствия (противоречия) или отклонения, распознает ситуацию, сложившуюся на объекте и в среде управления, определяет множество возможных решений, а в определенных ситуациях реализует управляющее воздействие и автоматически осуществляет контроль его исполнения. Системы поддержки принятия решений, экспертные системы, информационно-аналитические системы, системы прогнозирования и моделирования должны быть интегрированы в Корпоративную инфрормационную систему управления предприятием.

Требования к корпоративной интеллектуальной

\section{системе управления}

1. КИСУ должна поддерживать все задачи, возникающие в процессе управления: планирование - учет- контроль - анализ приятие решений, используя методы ИИ на каждом шаге цикла управления.

2. Архитектура системы помимо реляционной базы данных должна включать базу знаний, содержащую интенсиональную составляющую описания предметной области (ПО), а также средства автоматизации пополнения базы знаний: извлечение закономерностей из множества фрактов на основе методов индуктивного вывода, выявления неявных причинноследственных связей, расширение описания ПО методом дедуктивного вывода, классификации понятий предметной области.

3. Система должна поддерживать интеллектуальные технологии, решающие задачи: 
- прогнозирования развития ситуации и изменения состояний внутренней и внешней среды,

- моделирования описания предметной области и последствий принятия управляющих решений,

- распознавания объектов, их состояний и ситуаций, сложившихся на объекте и в среде управления.

4. Применение интеллектуальных технологий должны охватывать все:

- контуры управления (оперативный и регулярный менеджмент, стратегическое и ситуационное управление),

- сореры управления (управление фринансовыми, трудовыми, производственными и материальнотехническими ресурсами, управление клиентами и поставщиками и т.д.),

- бизнес-процессы предприятия (основные, обеспечивающие, управленческие, инвестиционные),

- функциональные подсистемы корпоративной системы менеджмента (система электронного документооборота, CRM, SRM, сбыт, материальнотехническое обеспечение и т.д.),

- уровни управления - корпорация, дочернее предприятие, структурное подразделение,

- цели управления - снижение производственных, финансовых, экологических и т.д. рисков, повышение надежности и эффрективности работы производственной системы, совершенствование системы менеджмента качества и т.д., 
- роли и рабочие места (рабочее место руководителя, аналитика, администратора, владельца бизнеспроцесса и т.д.)

\section{Интеграция информационных и технологических}

\section{систем}

Повышение интеллектуального уровня Корпоративных инфрормационных систем обеспечивает также развитие геоинформационных (ГЕО) технологий, аэрокосмических и телекоммуникационных технологий и их интеграция с информационными технологиями. Сегодня стало возможным применять интеллектуальные технологии в рамках интегрированной системы менеджмента, управляющей в рамках единого инфокоммуникационного пространства как производственными и техническими объектами, так и социально-экономической системой. 21 век действительно время реализации фантазий специалистов в области ИИ 20ого века. В качестве примера можно привести КИСУ, интегрированную с системой управления Интеллектуальным домом, когда все параметры здания обрабатываются информационной системой в общей системе показателей.

Ярким примером интеграции информационных и технологических систем является интеллектуальный аэропорт, где интегрируются достижения ГЕО, телекоммуникационных, информационных технологий и методов ИИ. В едином инженерно- телекоммуникационном и информационном пространстве автоматизированы процессы от видеонаблюдения и управления экологической безопасностью до управления клиентами. Комплексное управление работой 
аэропорта включает интеграцию и синхронизацию работы таких процессов, как:

- управление воздушным движением (взлет/посадка),

- управление наземными службами,

- формирование пассажиропотоков (бронирование и продажа билетов),

- формирование грузопотоков,

- обслуживание самолетного парка,

- управление расписанием,

- управление материально-техническими и трудовыми ресурсами,

- управление финансовыми ресурсами и т.д.,

- управление инфраструктурой (расчет арендных платежей, планирование схем автостоянок),

- управление процессом реконструкции (моделирование расположения объектов),

- визуализация объектов и процессов управления и Т.д.

Интеграция ERP-систем и автоматизированных систем управления технологическими объектами позволяют использовать методы ИИ для мониторинга и интегрированного управления всеми видами ресурсов предприятия, включая производственные, материально-технические и финансовые ресурсы.

Оркестр играет без дирижера: размышления об эволюции некоторых технических систем и управлении ими - так называлась книга выдающихся российских ученых В. И 
Варшавского и Д. А.Поспелова, идеи которых по-прежнему актуальны и активно используются.

Аккумулирование в хранилищах данных инсоормации, отражающей жизненные циклы производственных, технологических, фринансово-хозяйственных и социальноэкономических процессов предприятия, позволяет сегодня использовать методы ИИ для поиска корреляций, тенденций, взаимосвязей и закономерностей между данными, расширить область использования систем поддержки принятия решений, и переместить их за пределы сфреры оперативного управления в область поддержки принятия стратегических решений.

Методы ИИ позволяют строить замкнутые контуры управления, поддерживать принятие решений в условиях неопределенности, распознавать ситуации, сложившиеся на объекте и в среде управления, поддерживать информационную целостность и безопасность баз данных и баз знаний, метазнаний, извлекать, обобщать и приобретать знания.

В таблице 3.2 показано место интеллектуальных технологий в системе управления предприятием.

\section{Интеллектуальный документооборот}

Рассмотрим применение интеллектуальных технологий на примере создания важной интеграционной компоненты Корпоративной информационной системы управления системы Электронного документооборота.

Интеллектуальный документооборот является саморазвивающейся, самообучающейся и саморегулирующий системой. 
Таблица 3.2 - Место интеллектуальных технологий в системе управления предприятием

\begin{tabular}{|c|c|}
\hline $\begin{array}{l}\text { Интеллектуальные } \\
\text { технологии }\end{array}$ & Место в системе управления \\
\hline $\begin{array}{lr}\text { Представление } & \text { знаний: } \\
\text { фреймовые модели, } & \text { логико- } \\
\text { лингвистические } & \text { модели, } \\
\text { семантические } & \text { сети, } \\
\text { семиотические } & \text { системы, } \\
\text { продукционные модели }\end{array}$ & $\begin{array}{l}\text { Нормативно-справочная } \\
\text { информация, база знаний, } \\
\text { метазнания, хранилище } \\
\text { данных, основные данные } \\
\text { корпоративной } \\
\text { информационной системы } \\
\end{array}$ \\
\hline $\begin{array}{l}\text { Вывод на сетях, фрормальные } \\
\text { системы }\end{array}$ & $\begin{array}{l}\text { Целостность баз знаний, баз } \\
\text { данных }\end{array}$ \\
\hline $\begin{array}{l}\text { Классификация, } \\
\text { кластеризация } \\
\text { предметной области }\end{array}$ & $\begin{array}{l}\text { Система электронного } \\
\text { документооборота, нормативно- } \\
\text { справочная инфрормация }\end{array}$ \\
\hline $\begin{array}{l}\text { Накопление знаний, обучение, } \\
\text { самоорганизация }\end{array}$ & Функциональные подсистемы \\
\hline 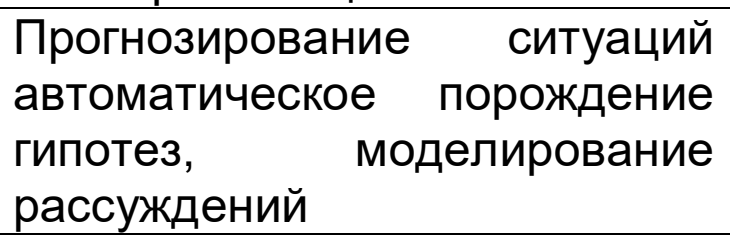 & $\begin{array}{l}\text { Системы поддержки принятия } \\
\text { решений, рабочее } \\
\text { руководителя }\end{array}$ \\
\hline $\begin{array}{lr}\text { Интеллектуальный } & \text { анализ } \\
\text { данных и обработка образной } \\
\text { информации, обнаружение } \\
\text { закономерностей } \\
\text { извлечение знаний }\end{array}$ & $\begin{array}{l}\text { Работа с хранилищем данных } \\
\text { (средства DATA MINING) }\end{array}$ \\
\hline $\begin{array}{l}\text { Распознавание с ситуаций, } \\
\text { объектов и их состояний на } \\
\text { основе нейронных сетей }\end{array}$ & $\begin{array}{l}\text { ЭЦП, функциональные блоки, В } \\
\begin{array}{l}\text { частности } \text { ФБ } \\
\text { финансами }\end{array} \\
\end{array}$ \\
\hline Нечеткие логики & $\begin{array}{l}\text { Поддержка Принятие решений } \\
\text { в условиях неопределенности }\end{array}$ \\
\hline $\begin{array}{l}\text { Ситуационное, динамическое } \\
\text { планирование }\end{array}$ & $\begin{array}{l}\text { Системы бюджетирования и } \\
\text { бизнес-планирования, } \\
\text { управление инвестициями, } \\
\text { стратегическое планирование }\end{array}$ \\
\hline Моделирование & $\begin{array}{l}\text { Обследование } \\
\text { концептуальное } \\
\text { проектирование }\end{array}$ \\
\hline $\begin{array}{l}\text { Саморегуляция, } \\
\text { самообучение, самонастройка }\end{array}$ & $\begin{array}{l}\text { Интеллектуальные бизнес- } \\
\text { процессы, интеллектуальный } \\
\text { документооборот, адаптивная } \\
\text { стратегия }\end{array}$ \\
\hline
\end{tabular}


Для реализации подобных свойств система электронного документооборота должна включать механизмы генетического наследования и классификации, инструменты извлечения знаний из неструктурированной информации, механизмы накопления и обработки статистической информации, в частности информации, возникающей в процессе согласования документов или движения служебных записок.

Интегрированная модель представления знаний, положенная в основу систему интеллектуального документооборота помимо знаний о фрормировании структуры и шаблонов документов, а также знания о формировании маршрутных схем движения документов должна содержать лингвистические знания и знания о предметной области, включая знания об объекте, субъекте, задачах и процессах управления.

Потребность в модели предметной области порождает тот факт, что система интеллектуального документооборота наиболее эффрективно работает, когда она полностью интегрирована с информационной системой управления.

При построении системы интеллектуального документооборота используются следующие интеллектуальные технологии:

- систематизация потоков документов - механизм кластеризации и классификации,

- оценка полноты, целостности и непротиворечивости множества документов - аппарат формальной логики,

- «умное» движение документов - продукционные правила, 
- генерация событий и новых документов - процедуры в структуре документов, инициируемые ситуациями,

- автоматизированный поиск ответов на запросы генерация ответов за счет семантического анализа текста запроса,

- накопление знаний для поддержки принятия оптимальных решений - создание баз знаний.

Интеграция моделей представления знаний в системе интеллектуального документооборота включает:

- логические модели - аксиоматика ПО-оценки целостности, полноты и непротиворечивости,

- продукционные модели - правила изменения предметной области - автоматизация формирования маршрутных схем,

- семантические сети - семантические структуры для выявления угроз, прогнозирование событий и формирования ответов на запросы при работе с документами,

- нейронные сети - задачи распознавания и классификации документов.

Инструментальные средства поддержки интеллектуальных технологий

В таблице 3.3 приведены примеры инструментальных средств поддержки интеллектуальных технологий, представляющих собой интегрированный комплекс совместимых продуктов. 
Таблица 3.3 - Инструментальные средства поддержки интеллектуальных технологий

\begin{tabular}{|c|c|}
\hline Инструментальная среда & Назначение \\
\hline $\begin{array}{lr}\text { Инструментальная } & \text { среда } \\
\text { ARIS (Architecture of } \\
\text { Integrated Information System) }\end{array}$ & $\begin{array}{l}\text { Развитая среда описания и } \\
\text { моделирования ПО на стадии } \\
\text { концептуального } \\
\text { проектирования КИСУ }\end{array}$ \\
\hline POWERSIM & $\begin{array}{lr}\text { Система } & \text { динамического } \\
\text { моделирования } & \text { и } \\
\text { прогнозирования } & \\
\end{array}$ \\
\hline $\begin{array}{lcc}\text { ERP } & \text { SAP } & \text { R3 } \\
\text { Resource Planning) }\end{array}$ & 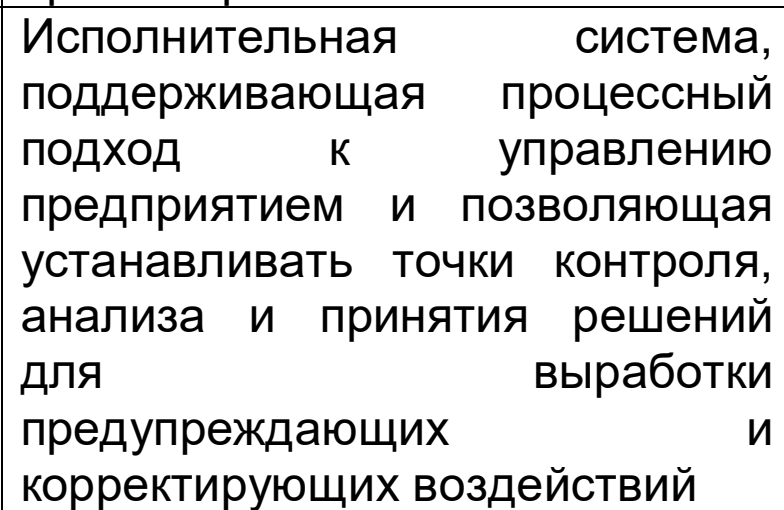 \\
\hline $\begin{array}{l}\text { Business Intelligence ( } \mathrm{BI} \text { my } \\
\text { SAP BS) }\end{array}$ & 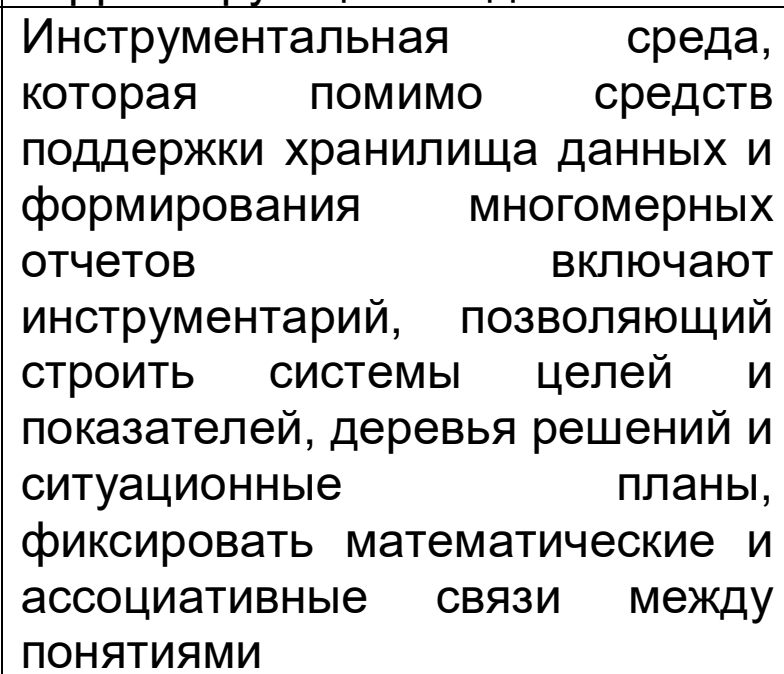 \\
\hline SAP ERP 2005 & $\begin{array}{l}\text { Инструментальная среда для } \\
\text { создания интеллектуальной } \\
\text { системы управления, } \\
\text { интегрированная } \\
\text { технологическими системами }\end{array}$ \\
\hline $\begin{array}{l}\text { Adobe LiveCycle } \\
\text { Designe }\end{array}$ & $\begin{array}{l}\text { Среда } \quad \text { разработки } \\
\text { интеллектуальных документов в } \\
\text { виде фрорм, бланков, отчетов }\end{array}$ \\
\hline
\end{tabular}




\section{Специализация в области интеллектуальных}

\section{технологий в управлении предприятием}

Таким образом, одним из направлений подготовки специалистов в области ИИ может быть специализация, нацеленная на практическое применение технологий и методов ИИ для совершенствования и развития Корпоративной информационной системы управления предприятием. С этой целью, помимо приобретения навыков и знаний в области технологий, методов и инструментальных средств ИИ, необходимо формирование целостного взгляда на предприятие, как объект управления и Корпоративную информационную систему, как инструмент управления.

Подготовка специалистов должна охватывать такие области знаний, как:

- архитектура, базовые компоненты и функциональные подсистемы КИСУ,

- уровни и этапы проектирования и создания,

- взаимодействие компонент КИСУ, организационнофрункциональное проектирование и развитие,

- технология проектирования и описания ПО - модели описания ПО (объектов, бизнес-процессов, логических, структурных и фрункциональных зависимостей),

- фрункциональный охват - знание таких функциональных подсистем, как система электронного документооборота, CRM, SRM, система материально-техническое обеспечение и т.д.,

- инструментальные средства поддержки процесса проектирования и создания КИСУ и ее подсистем, 
- стандарты, используемые B процессе проектирования и создания КИСУ и ее подсистем,

- вопросы интеграции с технологическими системами.

Специалист в области проектирования и создания КИСУ должен обладать знаниями предметной области, владеть такими понятиями как счет-фрактура, спецификации рабочего места, технологическая карта и т.д. Но главное, специалист должен понимать, в чем состоит управление предприятием, различать различные контуры управления - уровень оперативного (регулярного) менеджмента и уровень стратегического управления, задачи управления, точки контроля, анализа и принятия решений.

\section{3. ОБЕСПЕЧЕНИЕ ИНФОРМАЦИОННОЙ БЕЗОПАСНОСТИ В ИНТЕЛЛЕКТУАЛЬНЫХ СИСТЕМАХ}

\subsection{1. Цели обеспечения информационной безопасности}

Целями обеспечения информационной безопасности являются обеспечение сохранности и конфиденциальности информации, защита и гарантия доступности, достоверности и целостности информации, избежание утечки информации, минимизация ущерба от событий, несущих угрозу информационной безопасности.

Для обеспечения информационной безопасности должны быть достигнуты следующие цели:

- обеспечение конфиденциальности информации в соответствии с проведенной классификацией;

- обеспечение целостности информации на всех этапах, связанных с нею процессов (создание, обработка, 
хранение, передача и уничтожение) при предоставлении публичных услуг;

- обеспечение своевременной доступности информации при предоставлении публичных услуг;

- обеспечение наблюдаемости, направленной на фиксирование любой деятельности пользователей и процессов;

- обеспечение аутентичности и неотказуемости от транзакций и действий производимых участниками предоставления публичных услуг;

- учет всех процессов и событий, связанных с вводом, обработкой, хранением, предоставлением и уничтожением данных.

\subsection{2. Задачи системы информационной безопасности}

Для достижения целей обеспечения безопасности необходимо выполнение следующих задач:

- идентификация информационных ресурсов и систем и их классификация в зависимости от их ценности и важности в процессе предоставления публичных услуг (компоненты анализа должны включать данные, приложения, технологии, телекоммуникационные и аппаратные средства, помещения, человеческие ресурсы и т.д.);

- идентификация угроз информационной безопасности и определение возможных источников угрозы по каждому информационному ресурсу и системе;

- идентификация уязвимых мест по каждой идентифицированной угрозе; 
- оценка

рисков

по

идентифицированным

информационным ресурсам и системам;

- выбор мероприятий по управлению информационной безопасностью на основе анализа соотношения стоимости их реализации к эфффекту от снижения рисков и возможным убыткам в случае нарушения безопасности;

- разработка и внедрение механизма и мер оперативного реагирования на угрозы информационной безопасности и проявления негативных тенденций в функционировании информационных ресурсов и систем предоставления публичных услуг;

- разработка и внедрение системы контролей, позволяющих обеспечивать эфрективное функционирование механизма и мер обеспечения безопасности;

- организация процесса эффрективного пресечения посягательств на информационные ресурсы и системы;

- организация процесса обеспечения непрерывности предоставления услуг и создание условий для максимально возможного возмещения и локализации наносимого ущерба неправомерными действиями физических и юридических лиц, ослабление негативного влияния последствий нарушения информационной безопасности;

- организация процесса обеспечения безопасности при наличии поставщиков услуг, имеющих доступ к инфрормационным ресурсам или системам при предоставлении публичных услуг. 


\subsection{3. Принципы обеспечения информационной безопасности}

Система обеспечения информационной безопасности должна создаваться на следующих принципах:

- принцип равнопрочности - означает обеспечение защиты оборудования, программного обеспечения и системы управления от всех видов угроз;

- принцип непрерывности - предусматривает непрерывное обеспечение безопасности информационных ресурсов, ИС для непрерывного предоставления публичных услуг;

- принцип разумной достаточности - означает применение таких мер и средств защиты, которые являются разумными, рациональными и затраты на которые, не превышают стоимости нарушения информационной безопасности;

- принцип комплексности - для обеспечения безопасности во всем многообразии структурных элементов, угроз и каналов несанкционированного доступа должны применяться все виды и формы защиты в полном объеме. Недопустимо применять отдельные фрормы или технические средства;

- принцип комплексной проверки - заключается в проведении специальных исследований и проверок, специального инженерного анализа оборудования, верифрикационных исследований программных средств. Должен осуществляться непрерывный мониторинг аварийных сообщений и параметров ошибок, постоянно должно выполняться тестирование аппаратного и 
программного оборудования, а также контроль целостности программных средств, как при загрузке программных средств, так и в процессе функционирования;

- принцип надежности - методы, средства и фрормы защиты должны надежно перекрывать все пути проникновения и возможные каналы утечки информации, для этого допускается дублирование средств и мер безопасности;

- принцип универсальности - меры безопасности должны перекрывать пути угроз независимо от места их возможного воздействия;

- принцип плановости - планирование должно осуществляться путем разработки детальных планов действий по обеспечению информационной защищенности всех компонент системы предоставления публичных услуг;

- принцип централизованного управления - в рамках определенной структуры должна обеспечиваться организованно-фрункциональная самостоятельность процесса обеспечения безопасности при предоставлении публичных услуг;

- принцип целенаправленности - необходимо защищать то, что должно защищаться в интересах конкретной цели;

- принцип активности - защитные меры обеспечения безопасности в работе процесса предоставления услуг должны претворяться в жизнь с достаточной степенью настойчивости; 
- принцип квалисрикации обслуживающего персонала обслуживание оборудования должно осуществляться сотрудниками, подготовленными не только в вопросах эксплуатации техники, но и в технических вопросах обеспечения безопасности информации;

- принцип ответственности - ответственность за обеспечение информационной безопасности должна быть ясно установлена, передана соответствующему персоналу и утверждена всеми участниками в рамках процесса обеспечения информационной безопасности.

\section{4. УПРАВЛЯЕМОСТЬ ИНТЕЛЛЕКТУАЛЬНЫХ СИСТЕМ}

В системах, управляющих программным средством, будем выделять четыре типа подсистем - мониторинга, т.е. регулярного сбора информации, необходимой для управления; ручного (интерактивного) управления для осуществления управляющих воздействий (изменения свойств программного средства) управляющими программным средством; автоматического управления, т.е. изменения свойств программного средства без участия управляющих; автоматизированного управления, реализующего сочетание ручного и автоматического управления (в частности, ручного управления параметрами средства автоматического управления). Разработку же программного средства можно рассматривать как управление им, начиная с состояния, когда этого программного средства еще нет, но уже есть система, управляющая им, аналогично тому, как сопровождение программного средства обычно рассматривается как его продолжающаяся разработка. 
Программное средство как объект управления является многоцелевым объектом, поскольку предназначено для достижения нескольких заданных результатов функционирования (например, заданные результаты функционирования решателя задач и пользовательского интерфейса обычно слабо связаны между собой). Можно выделить как минимум три вида знаний, на основе которых принимаются решения о выработке управляющих воздействий при управлении программными средствами: априорные, явно или неявно представленные знания; знания о задачах, ранее решенных программным средством (о входном потоке данных, обработанных программным средством, и о том результате, который должен получиться после обработки); знания об особенностях пользователей этого программного средства. Поскольку эти три вида знаний в значительной степени независимы друг от друга, можно считать, что управление программным средством, т.е. выработка управляющих воздействий, осуществляется в «трехмерном» пространстве, «координатами» которого являются априорные знания, знания о входном потоке и о пользователях программного средства.

Большинство программных средств обладает тем свойством, что время их жизни разбивается на совокупность периодов, в одни из которых они не функционируют, но могут сопровождаться (будем называть их периодами сопровождения), а в другие они фрункционируют, но не сопровождаются (будем называть их периодами функционирования). Для такого программного средства можно говорить либо об управлении им в периоды сопровождения, когда управляющие воздействия вырабатываются и 
осуществляются в те периоды времени, когда программное средство не функционирует, либо об управлении им в периоды функционирования, когда выработка и осуществление управляющих воздействий происходит в периоды функционирования программного средства.

Для того чтобы программное средство было управляемым, необходимо, чтобы оно удовлетворяло определенным требованиям, предъявляемым управляющим объектом. Таким образом, средства управления и управляемое ими программное средство должны быть взаимно согласованы - управляющие воздействия, формируемые средствами управления, должны иметь фрорму, непосредственно воспринимаемую объектом управления.

Архитектуру интеллектуальных систем, как класса программных средств, содержащих базу знаний, в первом приближении можно представлять себе как взаимосвязанную тройку, состоящую из базы знаний (и других инфрормационных ресурсов - баз данных, онтологий, метаонтологий и т.п.), решателя задач и пользовательского интерфейса. Частные цели управления этими тремя компонентами интеллектуальной системы в общем случае различны и в значительной степени независимы. В соответствии с этим в архитектуре системы, управляющей интеллектуальной системой, будем выделять подсистемы, управляющие информационными ресурсами, решателем задач и пользовательским интерфейсом (рисунок 3.5). 


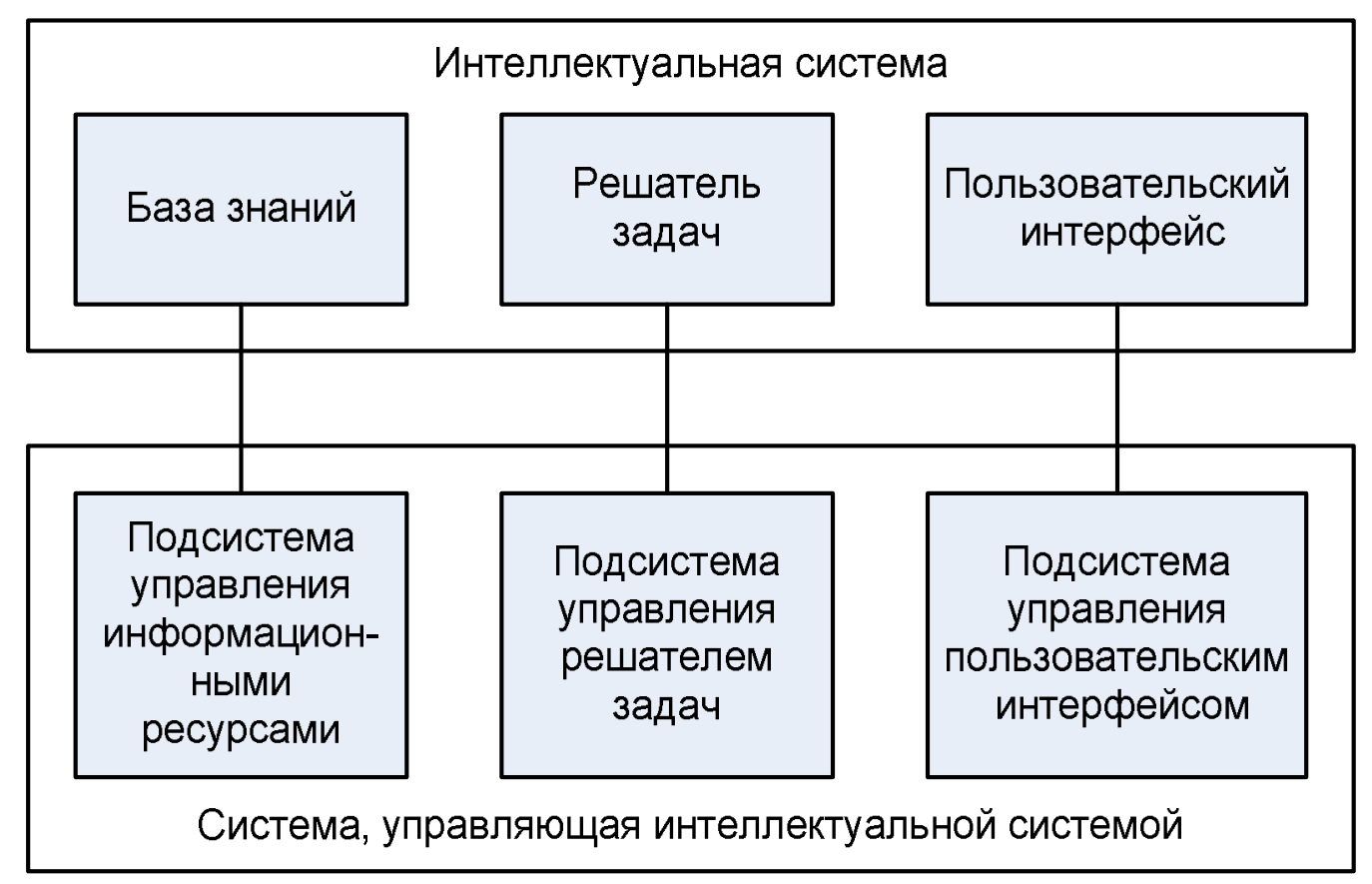

\section{Рисунок 3.5 - Структура системы управления интеллектуальной системой}

Исходя из того, что в архитектуре интеллектуальной системы, как объекта управления, можно выделить три самостоятельных компоненты (инфрормационные ресурсы, в том числе базу знаний, решатель задач и пользовательский интерфейс), а в системе, управляющей программным средством, - четыре типа подсистем (мониторинга, ручного управления, автоматического управления и автоматизированного управления), задачи управления интеллектуальными системами можно разделить на двенадцать классов (рисунок 3.6). 


\begin{tabular}{|c|c|c|}
\hline $\begin{array}{c}\text { Информационные } \\
\text { ресурсы }\end{array}$ & Решатель задач & $\begin{array}{c}\text { Пользовательский } \\
\text { интерфейс }\end{array}$ \\
\hline M & $\begin{array}{llllllll}\circ & \mathrm{H} & и & \mathrm{~T} & \mathrm{o} & \mathrm{p} & \text { и } & \mathrm{H}\end{array}$ & \ulcorner \\
\hline$P$ y 4 & y $п р$ a $\mathrm{B}$ s & e $\mathrm{H}$ и $\mathrm{e}$ \\
\hline A в $\mathrm{T} \circ \mathrm{M}$ a & ॥ и еско е у п р & авлени е \\
\hline А в & и $\mathrm{p} \circ \mathrm{B} \mathrm{a} \mathrm{H}$ HO & правлени е \\
\hline
\end{tabular}

\section{Рисунок 3.6 - Классификация задач управления интеллектуальными системами}

\section{5. ЗАДАЧИ УПРАВЛЕНИЯ ИНТЕЛЛЕКТУАЛЬНЫМИ СИСТЕМАМИ}

В настоящем параграфе будут рассмотрены некоторые общие и частные задачи управления информационными ресурсами, решателями задач и интерфейсами интеллектуальных систем.

При рассмотрении задач управления интеллектуальными системами будут приведены примеры подсистем управления двух основных типов: проблемно-зависимых и проблемнонезависимых. Примеры проблемно-зависимых подсистем управления будут продемонстрированы для Интеллектуальной системы интерактивного доказательства теорем и Экспертной системы медицинской диагностики с функцией диагностического тренажера. Приводимые в примерах подсистемы управления либо разрабатываются в настоящее 
время в коллективе, либо планируются к разработке, за исключением случаев, где сказано о существовании прототипа.

\subsection{1. Управление информационными ресурсами}

Целью управления информационными ресурсами является перманентное приведение их содержания в соответствие с постоянно меняющимися априорными знаниями управляющих и входным потоком данных интеллектуальной системы. В информационном ресурсе важно содержание информации, и ее удобное представление для управляющих, а не способ ее компьютерного представления. Исходя из этого, выдвигаются следующие принципы управления информационными ресурсами. Информационные ресурсы должны:

- допускать создание и ручное управление носителями информации без посредников;

- управляться независимо от конкретных интеллектуальных систем;

- быть доступными для обработки решателями различных интеллектуальных систем.

Далее будут рассматриваться только задачи управления концептуальными информационными ресурсами, которые могут обрабатываться интеллектуальными системами, представлены в терминах некоторой онтологии, а структура и содержание которых понятны управляющим ими. Из вышесказанного следует, что концептуальные информационные ресурсы, в том числе и базы знаний, имеют чисто декларативное и структурное представление (такой инфрормационный ресурс можно представлять себе в виде семантической сети, структура 
которой определяется некоторой онтологией, а каждый термин, вводимый в этой сети, относится к некоторому классу, определяемому этой онтологией). Примерами информационных ресурсов, не являющихся концептуальными, могут служить базы правил и системы фреймов. В них объединены два типа информации - о знаниях предметной области и о способе решения задачи. Если количество правил (фреймов) в такой базе велико, то ручное управление ей оказывается практически нереальным. Поскольку носителем знаний предметной области является эксперт, а носителем знаний о способе решения задачи - инженер знаний, то чтобы обеспечить правильное функционирование интеллектуальной системы, инженер знаний должен взять на себя функции управления такой базой знаний, но при этом эксперт может потерять контроль над ее содержанием.

Поскольку концептуальный информационный ресурс представляется в терминах соответствующей онтологии, он является неразрывной парой, состоящей из этой онтологии и собственно содержания (контента) этого ресурса, которые находятся между собой в определенном соответствии. Онтология информационного ресурса формируется инженером знаний, а его содержание - носителем соответствующей информации. Таким образом, к концептуальной базе знаний должны иметь доступ и инженер знаний (к онтологии), и эксперт (к знаниям), причем для ручного управления этим ресурсом им нужен разный интерфейс.

Теперь перейдем к обсуждению некоторых задач, возникающих при управлении информационными ресурсами. 
Мониторинг информационных ресурсов направлен на получение неявной информации, содержащейся В них. В случае, когда мониторинг осуществляется в соответствии с априорными знаниями управляющих, этими знаниями могут быть, например, явные определения структурных моделей этих ресурсов, их структурных свойств в терминах этих моделей, десектов, недостатков, неудобств и особенностей этих ресурсов в терминах этих свойств (рисунок 3.6$)[9,18]$.

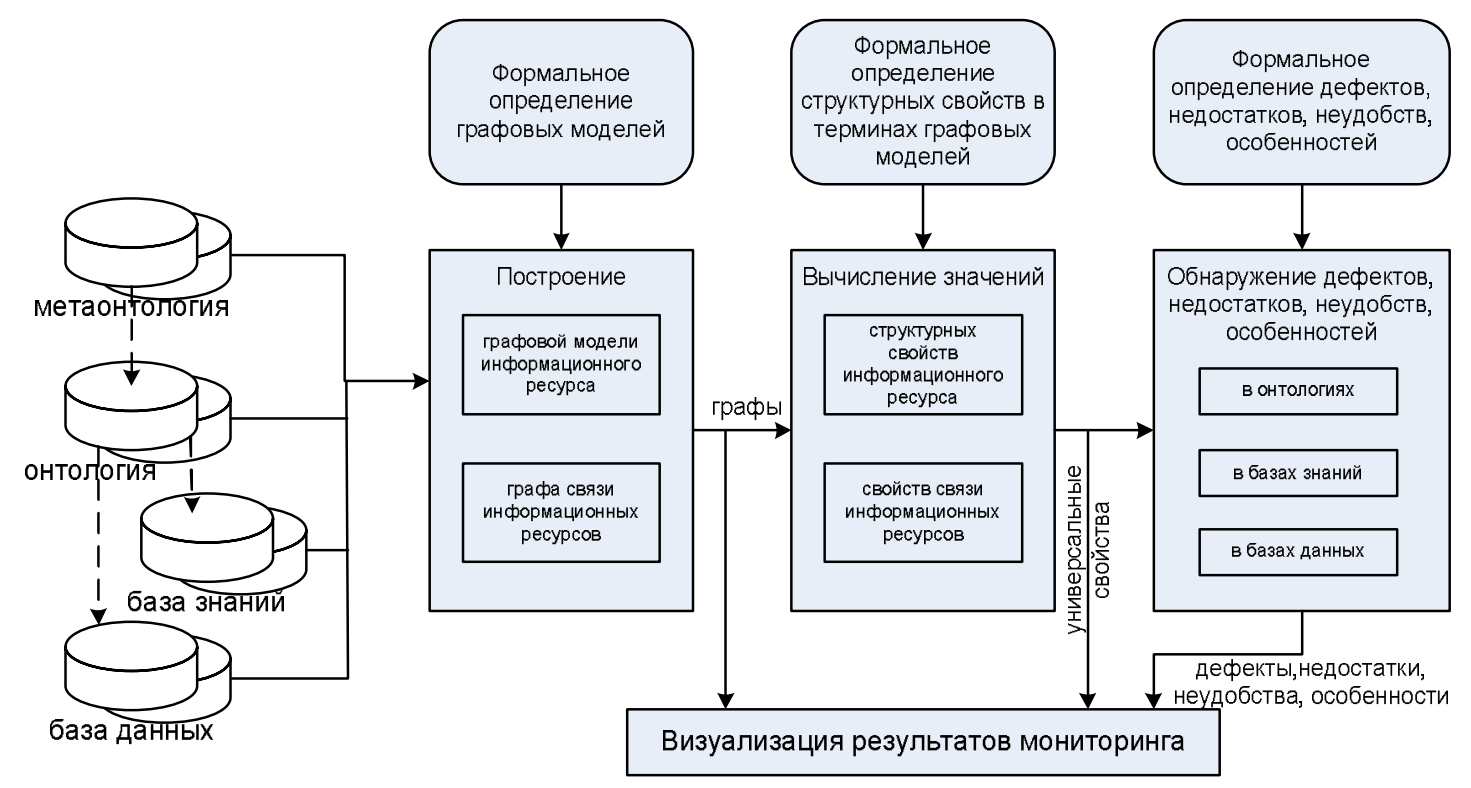

\section{Рисунок 3.7 - Общая схема подсистемы мониторинга информационных ресурсов}

Задачами мониторинга информационных ресурсов в этом случае являются построение на основе этих знаний структурных моделей этих ресурсов, определение значений их структурных свойств, выявление дефектов, недостатков, неудобств и особенностей в них (рисунок 3.7).

Онтология концептуального информационного ресурса также является априорными знаниями, которые ограничивают управление этим информационным ресурсом - управление им 
не может нарушать ограничений целостности этого инфрормационного ресурса, явно представленных в его онтологии. Однако информационный ресурс может быть формально неполон относительно своей онтологии - некоторые его элементы, наличие которых предписывается онтологией, на стадии формирования информационного ресурса или его изменения могут отсутствовать. Поэтому задачей мониторинга инфрормационного ресурса в этом случае является получение информации об его формальной полноте относительно его онтологии.

Ручное управление информационными ресурсами может осуществляться на основе результатов их мониторинга. В этом случае задачей ручного управления информационными ресурсами является устранение выявленных в них дефектов, недостатков и неудобств с помощью интерактивных средств управления. Кроме того, ручное управление информационными ресурсами может быть направлено на приведение их содержания в соответствие с представлениями об этом содержании у лиц, управляющих этими информационными ресурсами, в частности, с учетом выявленных особенностей. Типичными задачами этого класса являются ручное управление с помощью интерактивных средств управления: базой знаний, осуществляемое экспертом предметной области; базой данных, осуществляемое специалистами предметной области; онтологией (предметной области, базы знаний или базы данных), осуществляемое инженером знаний. На рисунке 3.8 приведена схема работы интерактивного средства ручного управления информационными ресурсами, которое по описанию языка представления онтологий, представленному на 
этом же языке, в режиме инженера знаний позволяет интерактивно формировать онтологию информационного ресурса на том же языке, а в режиме эксперта - управлять самим этим информационным ресурсом.

Автоматическое управление информационными ресурсами, как и ручное, также может осуществляться на основе результатов их мониторинга. В этом случае задачами автоматического управления информационными ресурсами являются автоматическое устранение выявленных в них дефектов, недостатков, неудобств и особенностей.

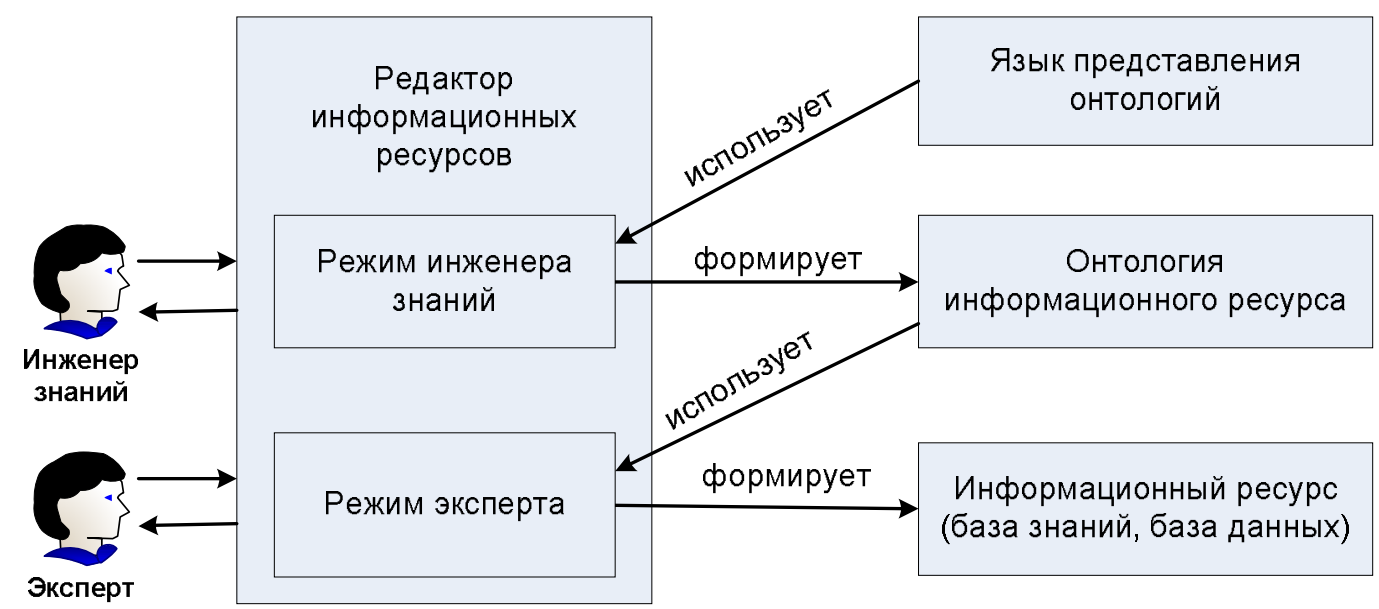

\section{Рисунок 3.8 - Схема интерактивного средства ручного управления информационными ресурсами}

Если же в качестве априорных знаний рассматривается онтология информационного ресурса, то одной из задач автоматического управления становится контроль соответствия между информационным ресурсом и его онтологией. Еще одним классом являются задачи управления взаимосвязанными информационными ресурсами.

Примером может служить управление базой знаний (например, базой заболеваний) и базой данных (например, 
архивом историй болезни), часть информации в которых представлена в терминах одной и той же онтологии (например, базы наблюдений) (рисунок 3.9). Для автоматического контроля целостности взаимосвязей этих трех концептуальных инфрормационных ресурсов (при их автономном ручном управлении) онтология каждого из них должна содержать еще и описание этих связей. Онтология связи базы заболеваний с базой наблюдений позволяет формировать базу заболеваний в терминах базы наблюдений и приводить базу заболеваний в соответствие с базой наблюдений при изменении последней; аналогичную роль играет и онтология связи архива историй болезни с базой наблюдений.

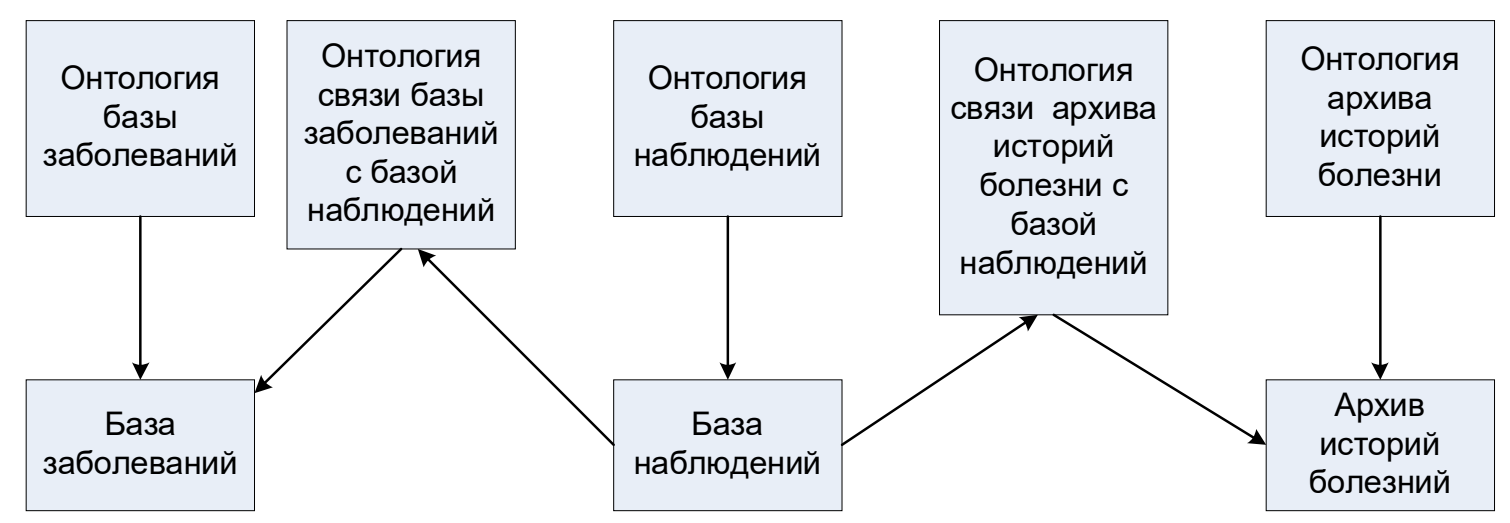

Рисунок 3.9 - Пример взаимосвязанных информационных ресурсов - базы заболеваний, базы наблюдений и архива историй болезни

Если некоторая подсистема управления информационными ресурсами является интеллектуальной системой, т.е. системой, основанной на знаниях, то управление ее базой знаний может рассматриваться как частный случай автоматизированного управления информационными ресурсами - ручного управления параметрами этой подсистемы 
управления информационными ресурсами. Примером может служить задача ручного управления мониторингом информационных ресурсов, в которой инженеры знаний изменяют явно заданные описания структурных моделей информационных ресурсов, определений их структурных свойств, дефектов, недостатков, неудобств и особенностей. Это, в свою очередь, влияет на результаты автоматического мониторинга информационных ресурсов (рисунок 3.7). Если инженеры знаний посредством ручного управления изменяют онтологию информационного ресурса, то соответствие между этим ресурсом и его онтологией нарушается. При этом одной из задач автоматизированного управления становится задача косвенного управления этим информационным ресурсом, состоящая в том, чтобы через автоматическое управление восстановить соответствие между этим ресурсом и его изменившейся онтологией, пожертвовав его полнотой. Аналогичная (но более сложная) задача косвенного управления возникает и в случае такого ручного управления одним из взаимосвязанных информационных ресурсов, при котором нарушается целостность взаимосвязей между этими ресурсами (рисунок 3.9).

Если знания экспертов не вполне отражают реальное состояние предметной области, ручное управление базой знаний, осуществляемое экспертом, может не дать требуемого эффректа. Такая ситуация имеет место, например, в медицине, где база знаний, сформированная отдельным экспертом, чаще всего имеет невысокие оценки на контрольной выборке историй болезни. В таких ответственных предметных областях, как медицина, базы знаний должны обладать свойством 
эталонности. Они должны быть понятны экспертам и другим специалистам предметной области, в том числе, удовлетворять количественным ограничениям (например, в ряде случаев известному психологическому критерию $7 \pm 2$ ). Базы знаний и онтологии, в терминах которых они представлены, не должны иметь заранее определенных внутренних дефектов; базы знаний должны иметь убедительные и понятные экспертам оценки на больших выборках примеров и контрпримеров. Эталонные базы знаний должны допускать их использование специалистами в практической деятельности непосредственно, и без интеллектуальной системы, как надежный справочник, а их оценки должны служить средством обеспечения доверия к ним. Для достижения эталонности базы знаний управление ей должно осуществляться в соответствии с входным потоком данных.

В этом случае мониторинг должен быть направлен на получение информации о соответствии базы знаний этому входному потоку. Это соответствие определяется онтологией предметной области, которая включает онтологию базы знаний, онтологию действительности (которой соответствуют данные из входного потока) и онтологические соглашения о взаимосвязи знаний и действительности (рисунок 3.10).

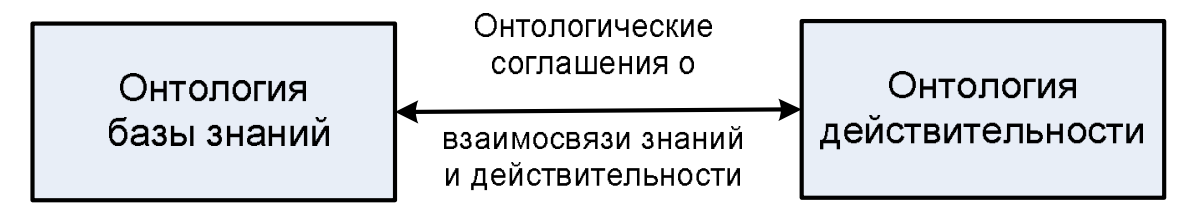

\title{
Рисунок 3.10 - Схема онтологии предметной области
}

\author{
Задачами такого мониторинга является получение \\ информации о том, какие онтологические соглашения
}


нарушены и на каких элементах базы знаний и входного потока (рисунок. 3.11).

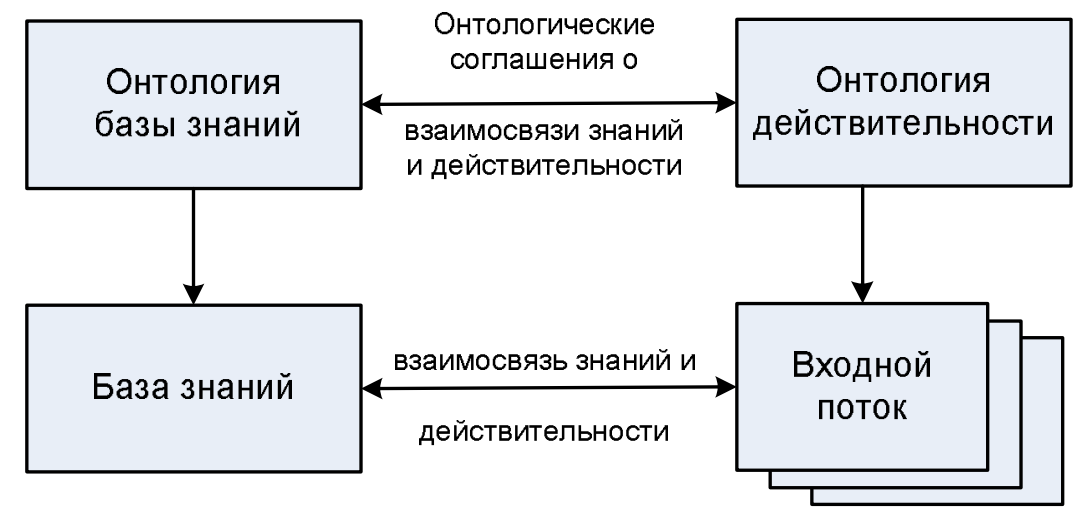

\section{Рисунок 3.11 - Мониторинг соответствия базы знаний входному потоку}

Результаты этого мониторинга могут быть использованы для устранения некоторых ошибок в данных входного потока (ручного управления им), но в ряде случаев использование этих результатов для ручного управления базой знаний может представлять чрезмерную интеллектуальную сложность (например, для экспертной системы медицинской диагностики, где входной поток состоит из большого числа историй болезни). В других случаях, когда объем базы знаний предполагается большим, а элементы базы знаний слабо связаны друг с другом, ручное управление оказывается возможным. Например, в интерактивной системе доказательства теорем, использующей технологию облачных вычислений (Cloud computing), где входной поток состоит из теорем, уже доказанных пользователями системы, интегратор общей базы знаний может включать в эту базу элементы входного потока из персональных баз знаний исследователей по своему усмотрению (рисунок 3.12). 


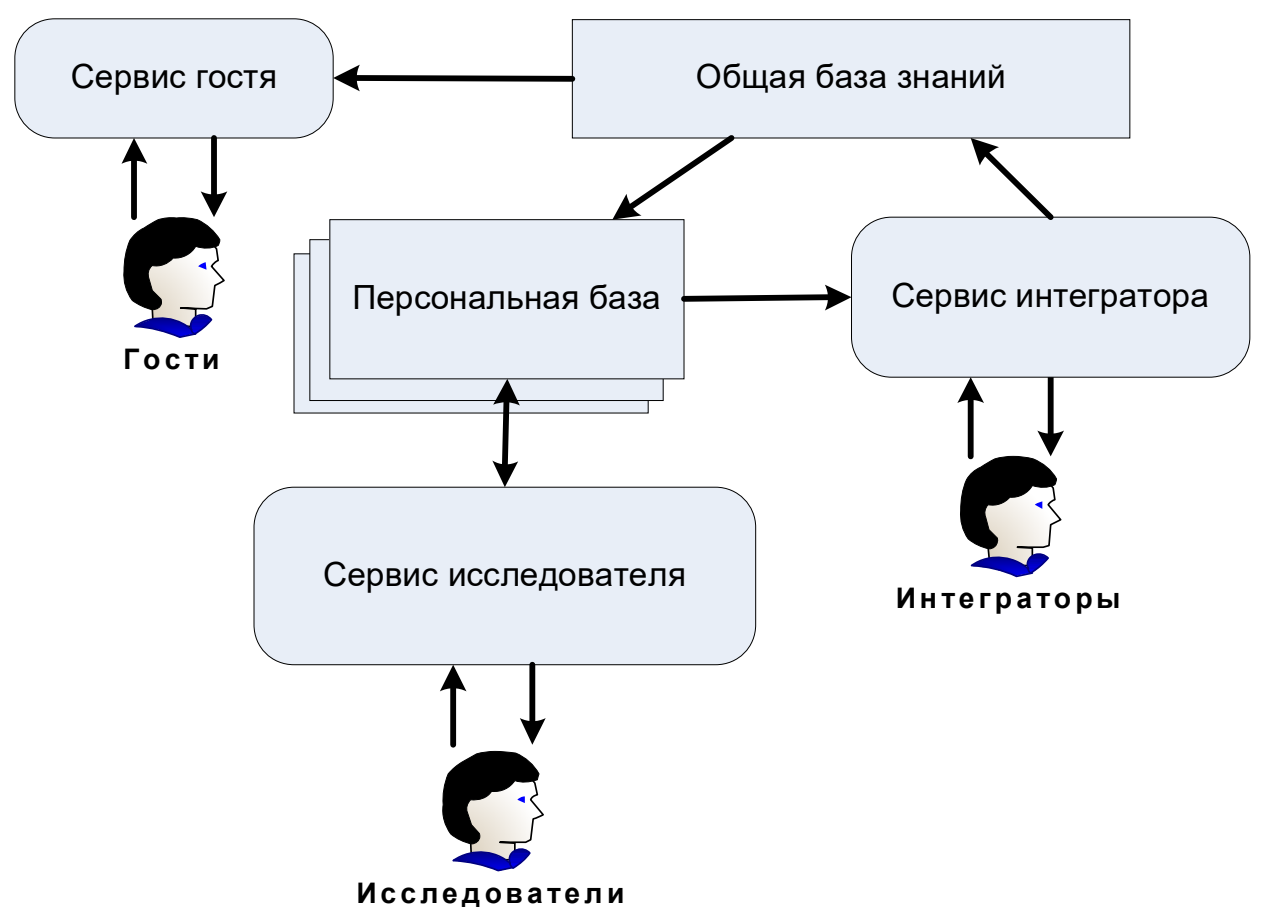

\section{Рисунок 3.12 - Ручное управление базой знаний} интерактивной системы доказательства теорем на основе результатов мониторинга ее входного потока

Если ручное управление базой знаний в соответствии с входным потоком оказывается чрезмерно сложным для управленцев, возникают задачи автоматического управления базой знаний - ее индуктивного формирования в соответствии с данными входного потока [10]. Итеративный алгоритм индуктивного формирования концептуальной базы знаний включает два асинхронных процесса - первый из них обрабатывает поступающие один за другим примеры из обучающей выборки и после обработки некоторой порции новых примеров передает результат своей работы (множество возможных баз знаний) второму процессу для обновления эталонной базы знаний (рисунок 3.13). 


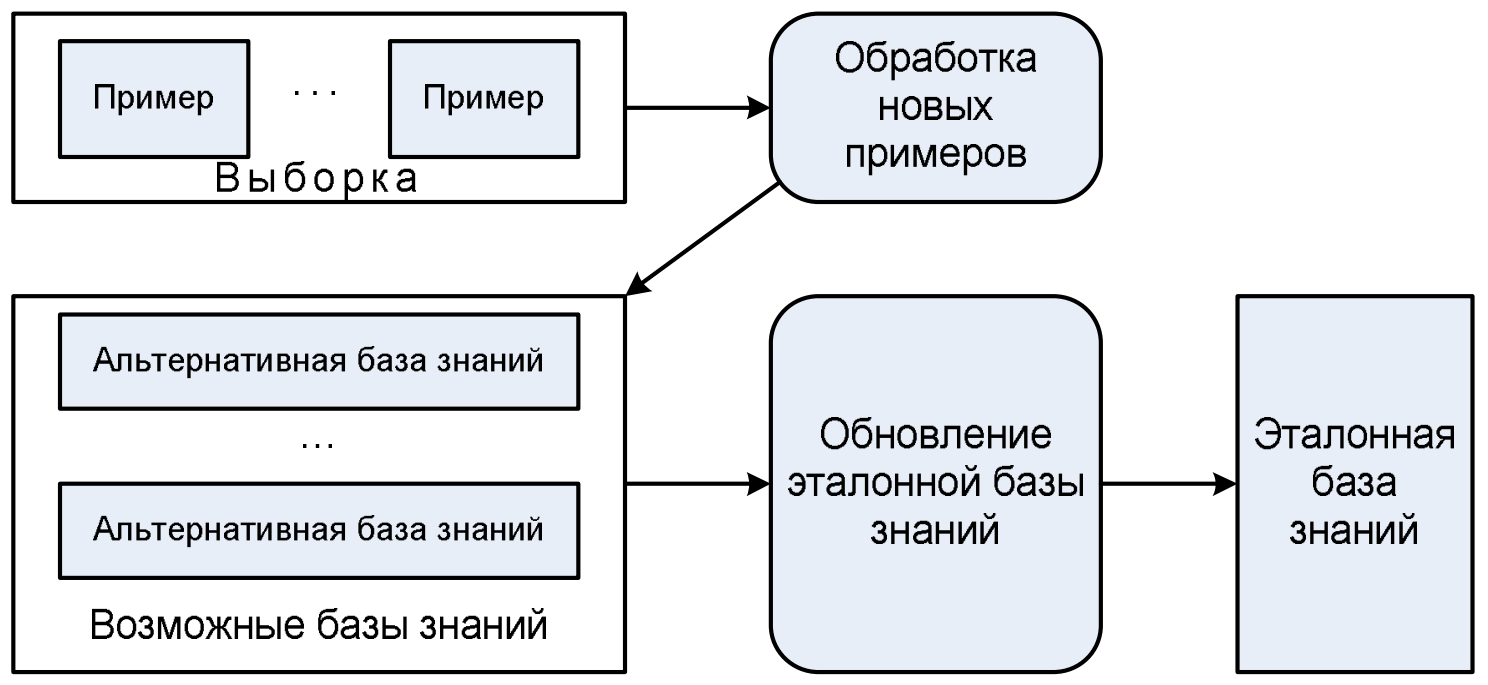

Рисунок 3.13 - Схема итеративного алгоритма индуктивного формирования концептуальной базы знаний

Процесс обработки новых примеров циклически обрабатывает один пример за другим, формируя варианты обобщения примеров (например, по времени, если предполагается, что данные зависят от времени); эти варианты обобщения используются затем для пересчета множества альтернативных баз знаний. После обработки заданного числа примеров варианты базы знаний передаются процессу обновления эталонной базы знаний (который тем самым запускается), а процесс обработки новых примеров продолжается (рисунок 3.14). Когда запускается процесс обновления эталонной базы знаний, по выборке контрпримеров вычисляются оценки альтернативных баз знаний, выбирается база знаний с наилучшей оценкой, которая и заменяет эталонную оценку, после чего процесс переходит в состояние ожидания нового множества возможных баз знаний (рисунок 3.15). 


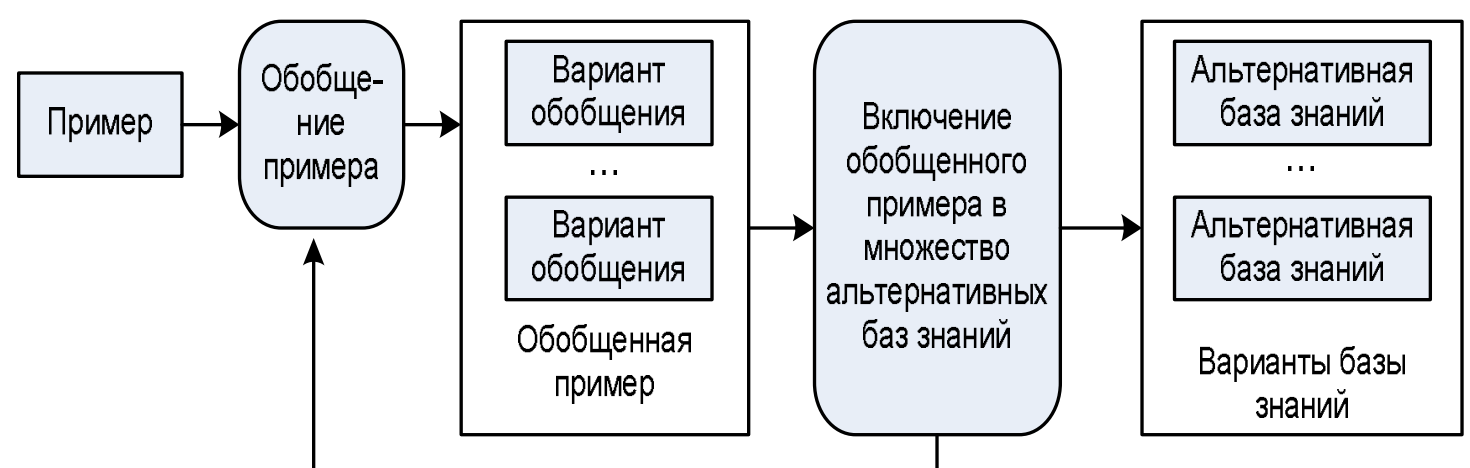

Рисунок 3.14 - Обработка новых примеров

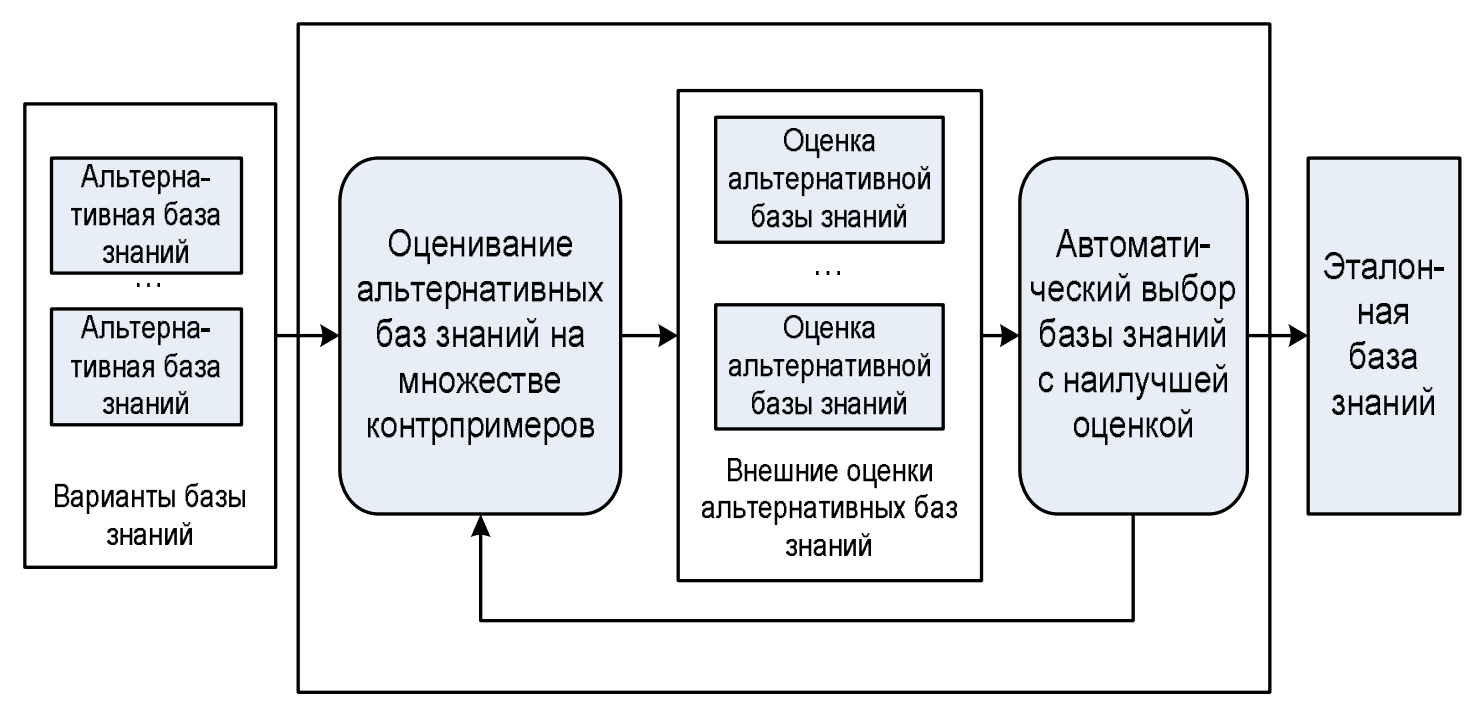

Рисунок 3.15 - Обновление эталонной базы знаний

Комбинирование возможностей мониторинга, ручного и автоматического управления базой знаний экспертной системы в соответствии с входным потоком данных приводит к задачам автоматизированного управления (человеко-машинной отладки базы знаний), в которых эксперту предоставляются результаты мониторинга базы знаний относительно входного потока. Целью управления является улучшение этих результатов, решение задач автоматического управления базой знаний на основе методов индуктивного формирования предоставляет эксперту 
возможные варианты изменения базы знаний, выбор из которых он делает по своему усмотрению (рисунок 3.16).

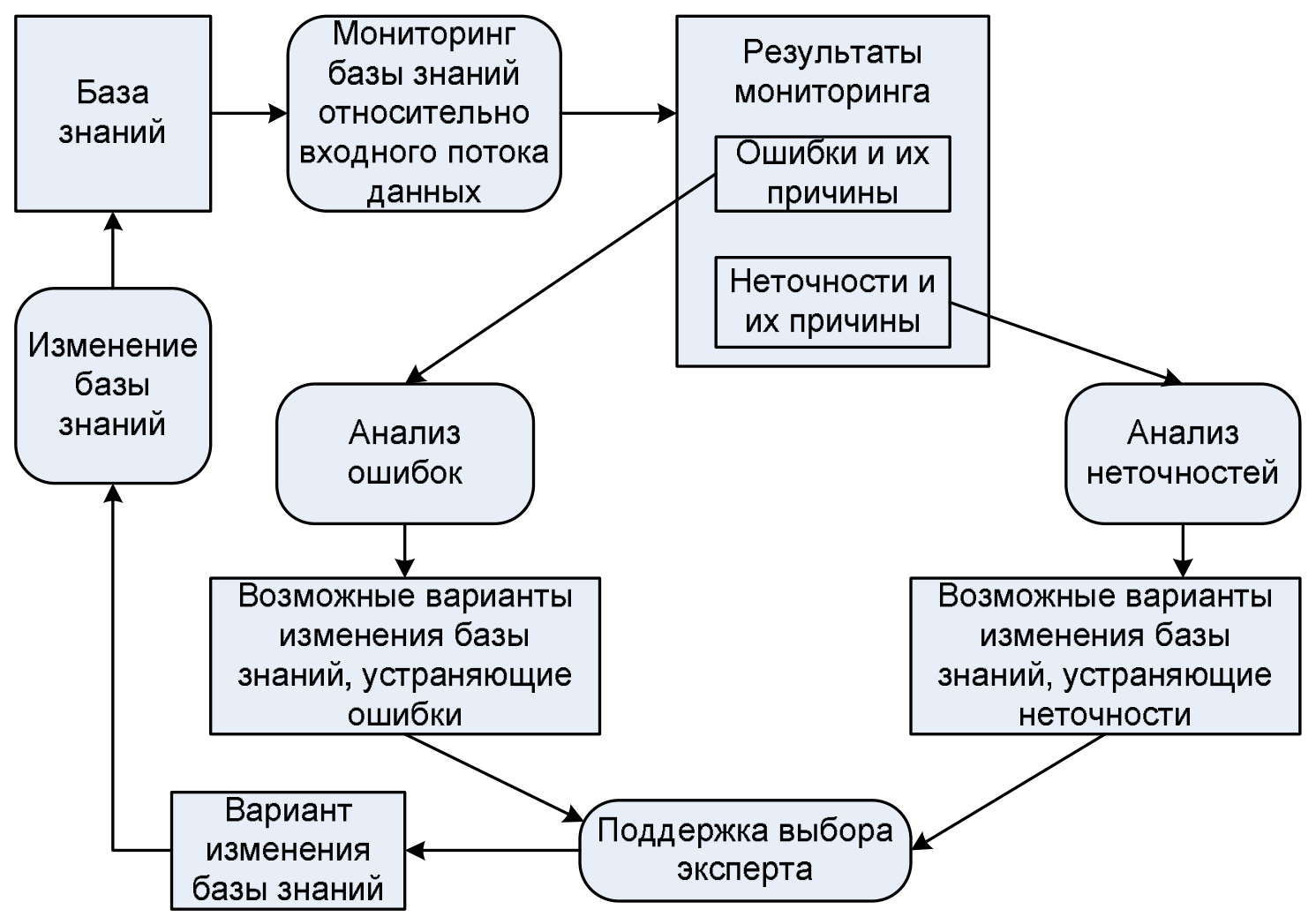

Рисунок 3.16 - Отладка базы знаний

Другим примером задачи автоматизированного управления базой знаний, где также осуществляется комбинирование возможностей мониторинга, автоматического и ручного управления в соответствии с входным потоком, является один из видов управления базой знаний интерактивной системы доказательства теорем. Задача мониторинга базы знаний состоит в обобщении каждого элемента входного потока (построенного средствами системы доказательства) до метадоказательства [12]; задача автоматического управления базой знаний состоит в построении множества теорем, аналогичных ранее доказанным, на основе этих метадоказательств и базы знаний [12]; 
интегратор общей базы знаний, решая задачу ручного управления, включает некоторые из этих теорем в базу знаний по своему усмотрению (рисунок 3.17 ).

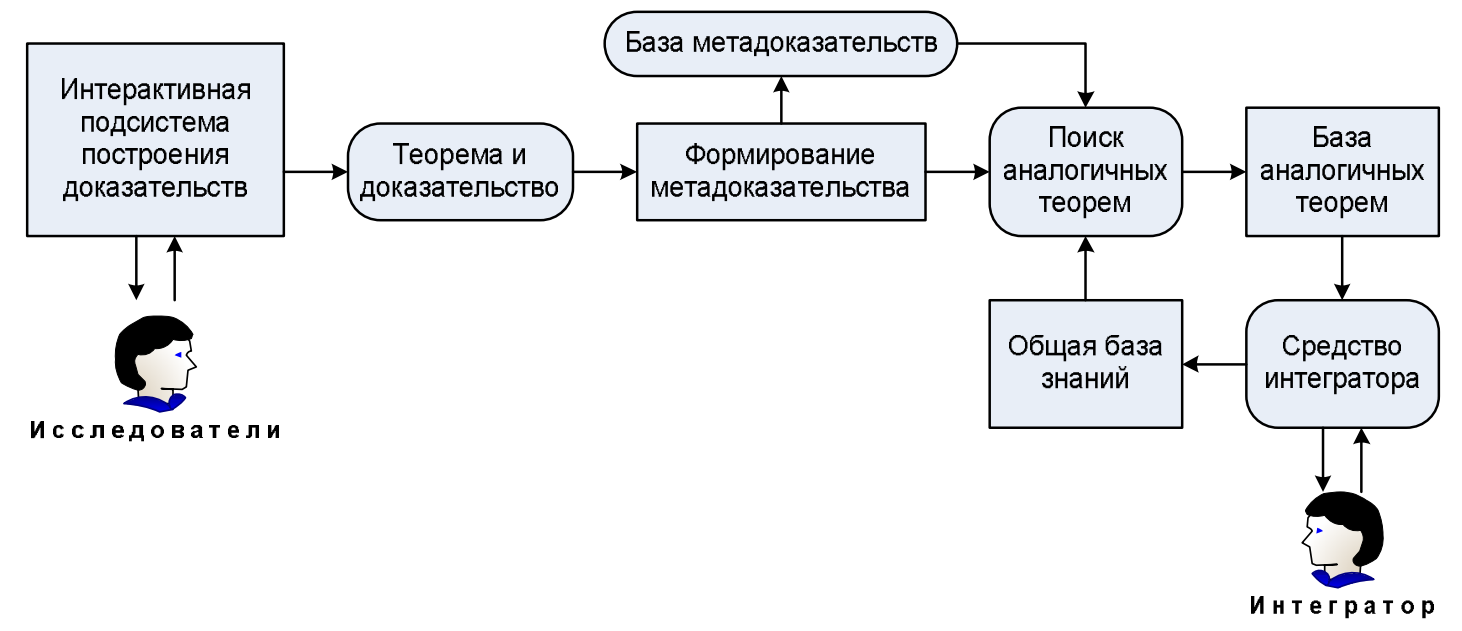

Рисунок 3.17 - Автоматизированное управление общей базой знаний интерактивной системы доказательства теорем

\subsection{2. Управление решателями задач}

Целью управления решателями задач является перманентное приведение их свойств в соответствие с постоянно изменяющимися текущими требованиями, условиями эксплуатации, знаниями предметной области, а также возможными изменениями онтологии предметной области.

Если база знаний интеллектуальной системы является концептуальной, т.е. имеет чисто декларативное представление, то использование при реализации этой интеллектуальной системы какой-либо универсальной машины вывода (оболочки) оказывается невозможным. В этом случае самостоятельным компонентом интеллектуальной системы становится решатель задач, т.е. программа, которая, используя 
базу знаний, решает задачи интеллектуальной системы. Решатель задач является специализированным интерпретатором концептуальных баз знаний, в котором зафиксированы онтология базы знаний (и других обрабатываемых им информационных ресурсов) и алгоритмы решения задач интеллектуальной системы. Для каждой новой интеллектуальной системы, для которой зафиксированы онтологии обрабатываемых информационных ресурсов и алгоритмы решения задач, решатель задач должен разрабатываться заново.

В настоящее время разработка и сопровождение программ осуществляется на основе следующей парадигмы. Программа представляется в виде текста (строки символов) на некотором процедурном языке. Синтаксический и семантический анализаторы процессора этого языка формируют на основе этого текста совокупность промежуточных декларативных структур - дерево грамматического разбора программы в абстрактном синтаксисе, ее управляющий и информационный графы и т.п. Генератор кода процессора этого языка на основе этих декларативных структур формируют объектный код программы, который и управляет процессом еe выполнения. Сопровождение программы, т.е. изменение ее свойств, требует изменения текста программы, после чего формирование нового объектного кода выполняется таким же способом по измененному тексту программы. Промежуточные декларативные структуры обычно недоступны для просмотра и, тем более, изменения. Их анализ и изменение с целью получения нового объектного кода, помимо всего прочего, затруднены тем, что они формируются 
автоматически, а их связь с текстом программы достаточно нетривиальна.

Управляемость программы в процессе ее жизненного цикла может быть повышена за счет инверсии указанной выше парадигмы, а именно, за счет представления программы в виде декларативной структуры данных (семантической сети), с терминальными вершинами которой связаны модули, содержащие программный код, т.е. за счет разделения декларативного и процедурного компонентов. В этом случае декларативный компонент программы становится объектом мониторинга и ручного управления, а процедурный - объектом сопровождения и автоматического управления. Достижение управляемости программы в процессе ее жизненного цикла состоит в сведении к некоему разумному минимуму ее процедурного компонента за счет представления как можно большей информации в ее декларативном компоненте. В последнее десятилетие близкие идеи используются в области интеграции отдельных программ в программные системы с использованием декларативного представления схемы интеграции [2, 14, 15].

Управляемость программы в процессе eе функционирования может быть повышена за счет подключения к решателю задач модулей, решающих задачи управления в процессе его функционирования. Таким способом может осуществляться мониторинг потока данных, т.е. извлечение из него неявной информации, и основанное на его результатах автоматическое управление решателем задач.

Мониторинг решателя задач, выполняемый в соответствии с априорными знаниями управленцев, направлен на получение 
неявной информации о декларативном компоненте этого решателя. Примерами таких задач мониторинга являются оценивание программ и поиск в них дефектов в соответствии с заданными метриками и определениями дефектов.

Примерами мониторинга решателя задач, выполняемого в соответствии с входным потоком данных, является получение информации о свойствах схемы его распараллеливания при работе некоторого решателя задачи на многопроцессорной вычислительной системе, а также перманентная коррекция списка уже доказанных утверждений или базы метадоказательств в процессе работы интерактивной системы доказательства теорем (рисунок 3.17) [11, 12].

Ручное управление решателем задач направлено на изменение его декларативного компонента лицами, управляющими этим решателем, с учетом результатов его мониторинга. Примерами могут служить задачи устранения с помощью интерактивных средств выявленных дефектов в декларативной компоненте решателя, задачи изменения схемы распараллеливания решателя задач с учетом информации о степени его реального параллелизма при работе на различных данных и т.п.

Автоматическое управление решателем задач направлено на автоматическое (без участия человека) изменение его свойств с учетом результатов мониторинга обрабатываемых им информационных ресурсов, либо результатов мониторинга самого решателя задач (адаптацию к результатам мониторинга). Примером адаптации решателя задач к результатам мониторинга базы знаний экспертной системы медицинской диагностики является задача сужения множества 
гипотез о диагнозе на основе совокупности наблюдаемых значений признаков пациента без детального анализа их временной структуры. При этом для каждого значения признака вычисляется множество заболеваний, при которых возможно это значение (рисунок 3.18).

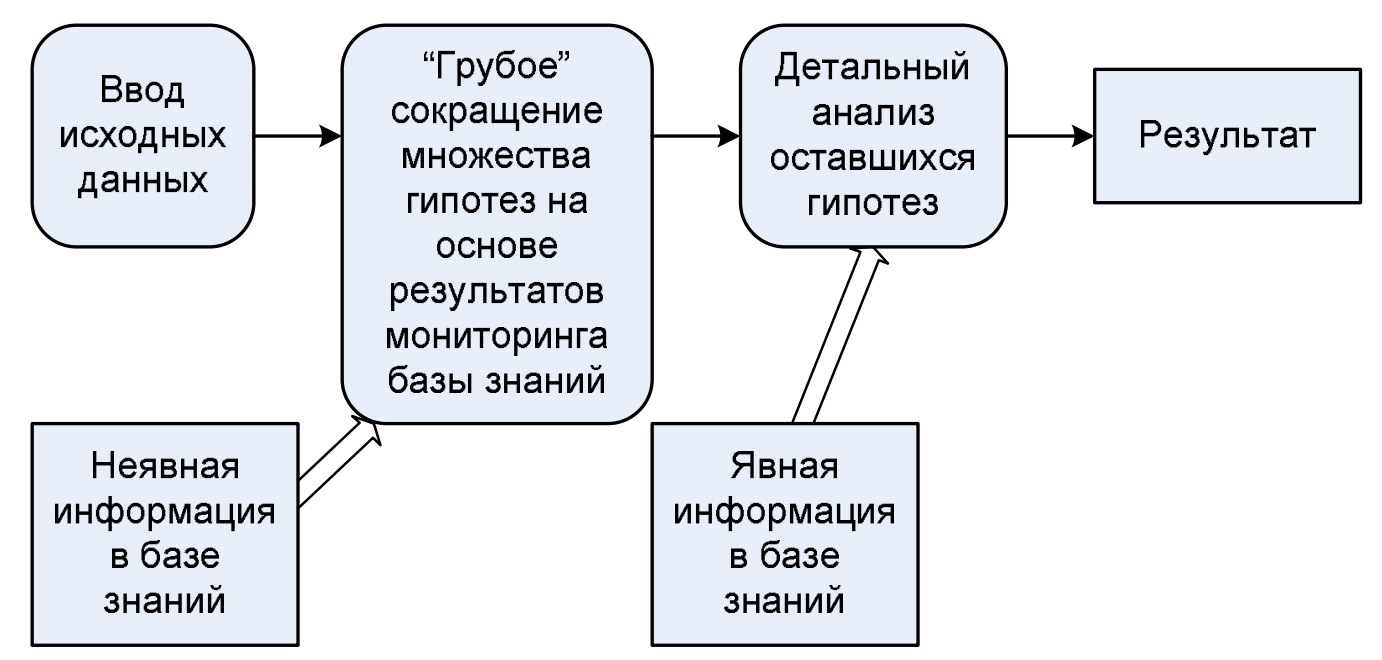

\section{Рисунок 3.18 - Адаптация решателя задач к результатам мониторинга базы знаний экспертной системы}

Примером адаптации решателя задач к результатам его потокового анализа является задача оптимизации программ. Примерами адаптации решателя задач к результатам его мониторинга, осуществляемого в соответствии с входным потоком данных, для интерактивной системы доказательства теорем являются исключение повторного доказательства одних и тех же целей на основе анализа списка уже доказанных утверждений, или исключение необходимости интерактивного построения доказательства цели в случае, если доказательство этой цели может быть получено по аналогии с использованием базы метадоказательств (рисунок 3.19). 


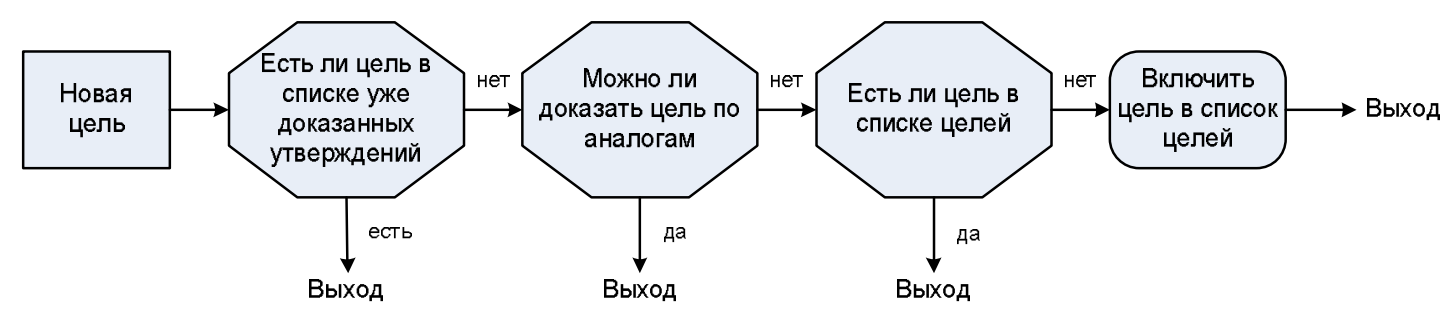

\section{Рисунок 3.19 - Включение новой цели в список целей} интерактивной системы доказательства теорем

Если некоторая подсистема управления решателем задач является интеллектуальной системой, то управление ее базой знаний может рассматриваться как задача автоматизированного управления информационными ресурсами. Примерами задач автоматизированного управления, ориентированного на априорные знания управленцев, является ручное управление базами знаний подсистем мониторинга решателя задач и оптимизации программ. Расширение функциональности решателя задач интерактивной системы доказательства теорем, на случай построения интуитивных (неполных) доказательств требует включения в решатель механизмов автоматического управления, обеспечивающих проверку правильности таких доказательств и ориентированных на входной поток данных. Однако такие механизмы обладают свойством алгоритмической полуразрешимости. Естественным выходом из этой ситуации является переход к задаче автоматизированного управления решателем задач, когда неудачи механизма автоматического управления исправляются через механизм ручного управления (рисунок 3.20). 


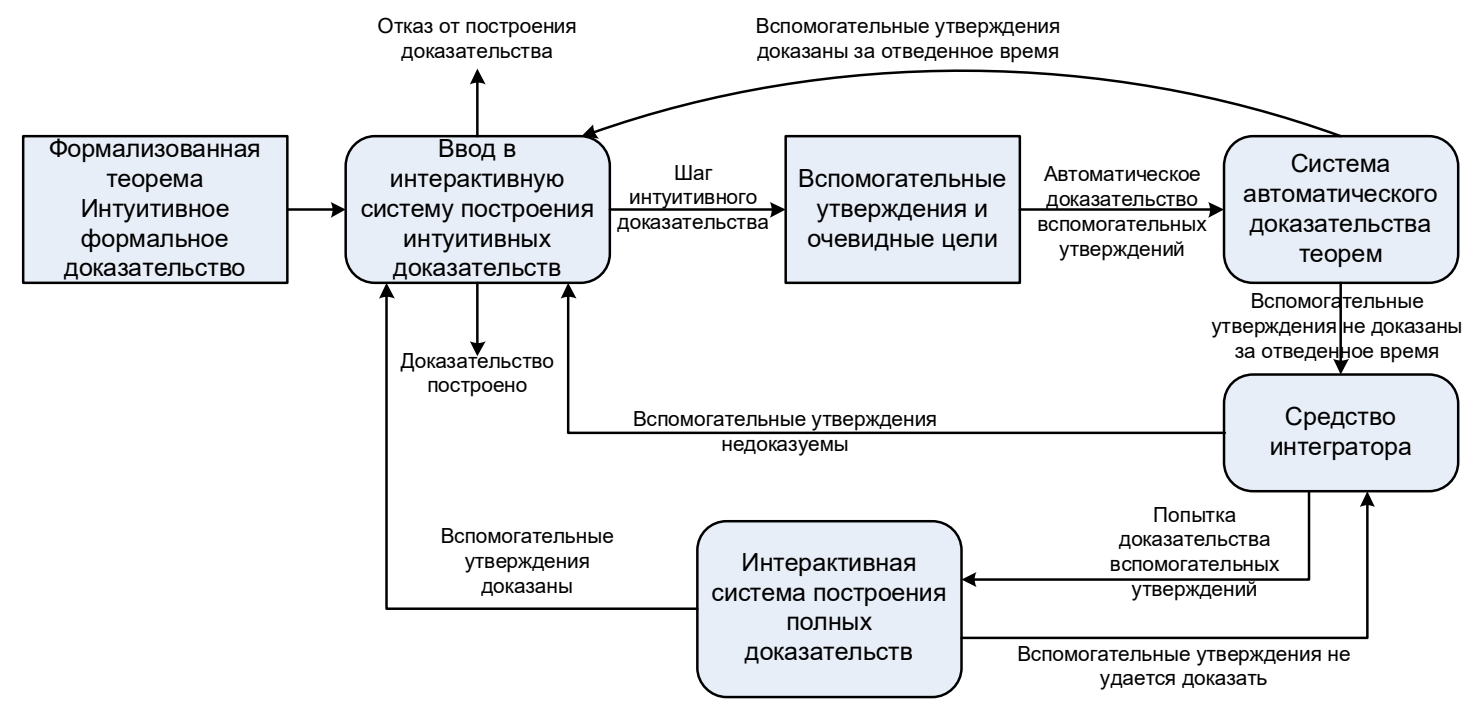

\section{Рисунок 3.20 - Автоматизированное управление}

\section{интерактивной системой построения правильных}

интуитивных доказательств

\subsection{3. Управление пользовательским интерфейсом}

Целью управления пользовательским интерфейсом является перманентное приведение его свойств в соответствие с постоянно изменяющимися онтологией предметной области, текущими требованиями и условиями эксплуатации.

Управляемость в процессе жизненного цикла пользовательского интерфейса может быть достигнута, если его проект представлять декларативно в виде концептуального информационного ресурса, а функционирующий интерфейс получать из этого представления проекта с помощью генератора кода или интерпретатора проекта $[5,6]$. В этом случае проект становится объектом управления в процессе жизненного цикла. Управляемость в процессе функционирования пользовательского интерфейса может быть достигнута, если к коду интерфейса или к интерпретатору проекта подключать модули, решающие задачи управления в 
процессе фрункционирования. Таким способом может осуществляться мониторинг действий пользователя и основанное на его результатах автоматическое управление пользовательским интерфейсом.

Мониторинг пользовательского интерфейса направлен на получение неявной инфрормации о нем (рисунок 3.21 ).

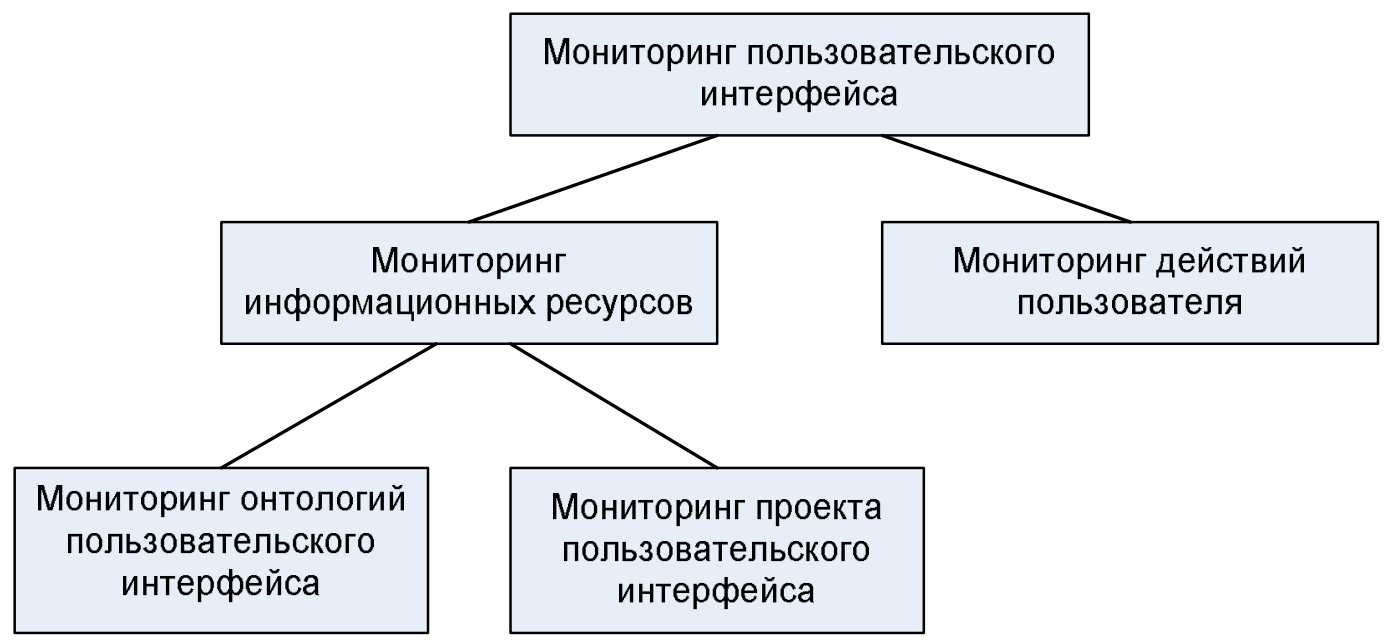

\section{Рисунок 3.21 - Мониторинг пользовательского интерфейса}

Примерами задач мониторинга, выполняемого в соответствии с априорными знаниями управленцев, являются: выявление дефектов в проекте интерфейса в соответствии с метриками юзабилити. На рисунке 3.22 представлена архитектура прототипа системы управления мониторингом проекта интерфейса, разработанной в лаборатории [3, 4]. Примерами мониторинга, выполняемого в соответствии с входным потоком данных, является мониторинг данных, поступающих от решателя задач пользовательскому интерфейсу и обратно (объем и характер данных). Примерами задач мониторинга, выполняемого в соответствии с моделью пользователя, является мониторинг действий пользователя при работе с интеллектуальной системой (время, затраченное на 
выполнение задачи, число ошибок, возвратов, обращений к справочной системе и т.п.).

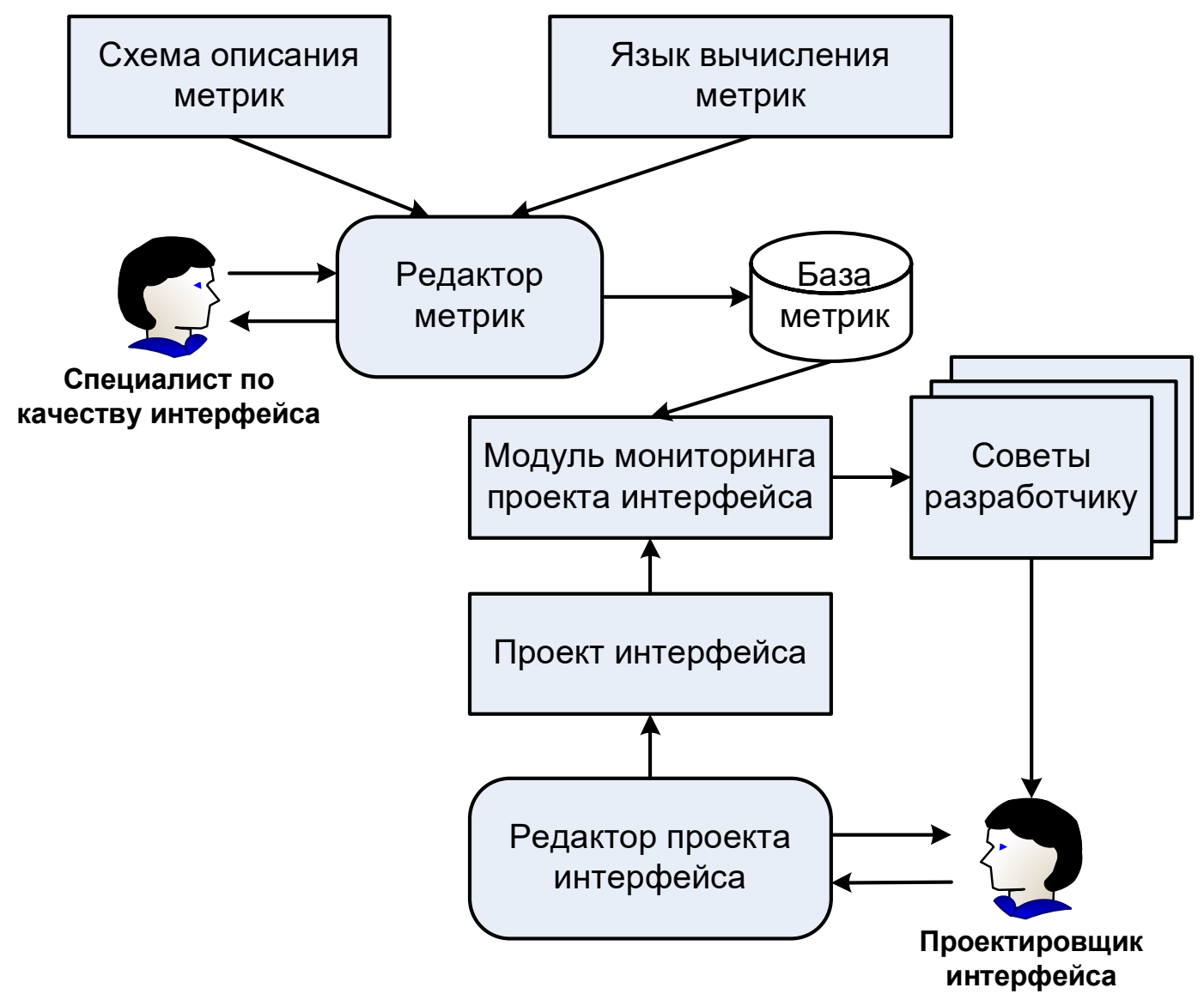

Рисунок 3.22 - Система управления мониторингом проекта интерфейса

Ручное управление пользовательским интерфейсом направлено на изменение его свойств лицами, управляющими этим интерфейсом, с учетом результатов его мониторинга (рисунок 3 23). Примерами могут служить интерактивные задачи устранения дефектов в проекте интерфейса в соответствии с метриками юзабилити или нарушений целостности проекта, изменения состава интерфейсных задач и отношений между ними, управления характеристиками пользователей, 
управления представлением информации в интерфейсе и управления системами понятий диалога.

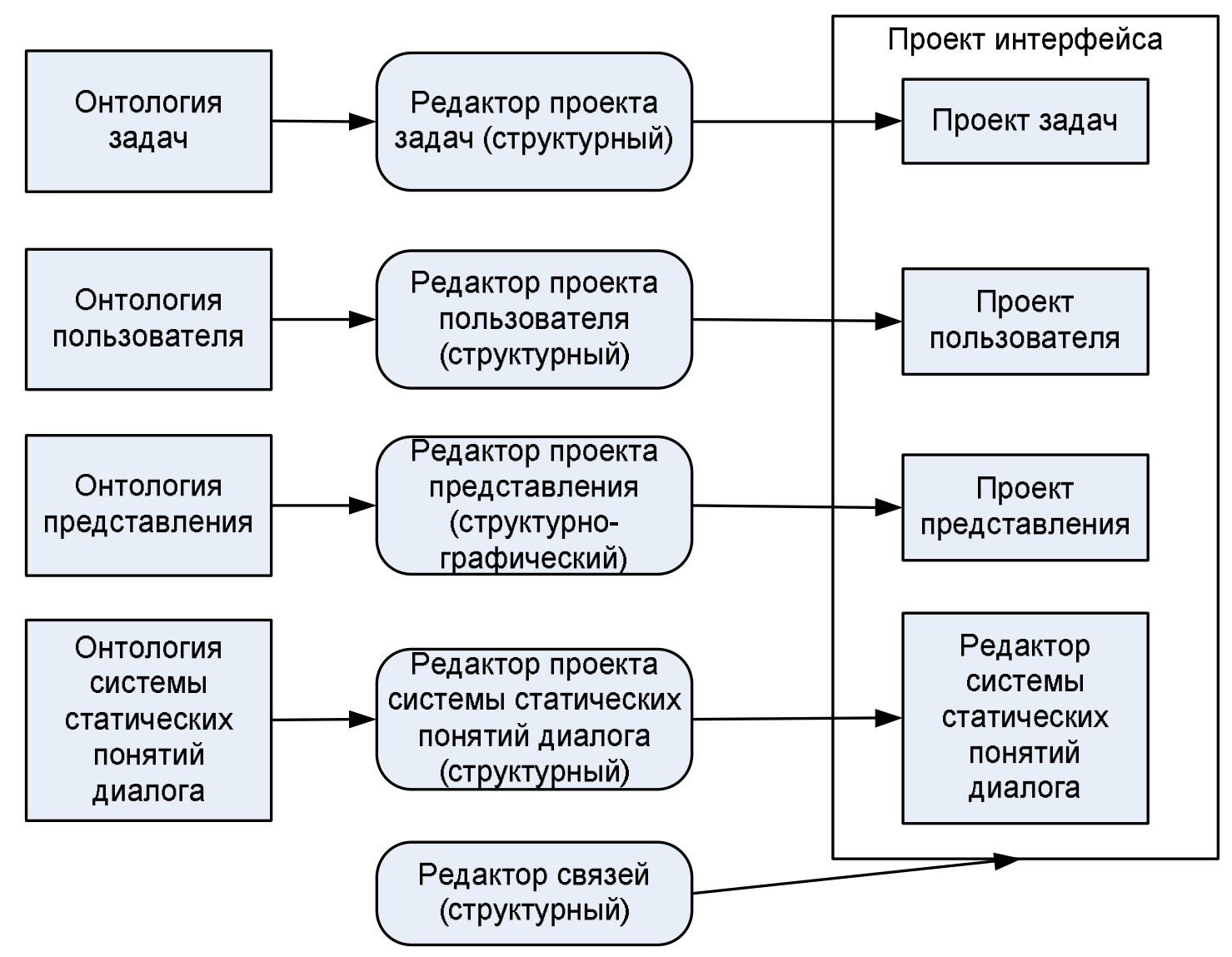

\section{Рисунок 3.23 - Система ручного управления} пользовательским интерфейсом

Задачи автоматического управления пользовательским интерфейсом состоят: в фиксированной адаптации интерфейса, когда задачи автоматического управления жестко связаны с типами пользователей; в косметической адаптации, например, опережающем вводе символов или ответов, использовании сокращений, умолчаний, многоуровневой помощи, многоязыковости и т.п.; в адаптации, основанной на модели пользователя и учитывающей его статические и динамические характеристики, такие как возраст, количество ошибок, время ответа и т.п. Кроме того, если некоторые характеристики 
пользовательского интерфейса неизвестны на этапе его проектирования, то возникают задачи автоматического управления проектом интерфейса - адаптации к объемам и структуре данных, циркулирующих между решателем задач и интерфейсом, формировании динамического сценария диалога на основе данных решателя (например, сценария запроса дополнительной информации о больном для диффреренциальной диагностики) или выбора пользователя (сценария интерактивной системы доказательства теорем).

K задачам автоматизированного управления пользовательским интерфейсом относится управление его мониторингом, которое состоит в управлении базой метрик юзабилити, модификации советов разработчику по устранению дефектов, в задании групп метрик юзабилити, по которым мониторинг должен проводиться, а также в управлении параметрами внутренних механизмов адаптации к особенностям конкретных пользователей (автозаполнение текстовых полей, двухуровневые подсказки, сокрытие элементов главного меню и другие).

\section{6. МЕТОДЫ НАУЧНЫХ ИССЛЕДОВАНИЙ ПО ТЕОРИИ, ТЕХНОЛОГИИ РАЗРАБОТКИ И ЭКСПЛУАТАЦИИ ИНТЕЛЛЕКТУАЛЬНЫХ СИСТЕМ}

Искусственный интеллект в настоящее время применяется во многих областях. В последние годы современные информационные технологии совершили резкий скачок вперед, в основном за счет повышения производительности массовых процессоров и удешевления памяти ЭВМ. Это привело к появлению приложений, в которых воплотились серьезные теоретические наработки по искусственному интеллекту. 
Основной проблемой исследовании в области искусственного интеллекта является построение машинной модели, которая бы производила сложные преобразования инфрормации, осуществляемые человеческим мозгом. Включая в частности зрительное распознавание пространственных сцен, общение на естественном языке, в том числе в форме речи, обучение на опыте, выработку новых понятий, открытие новых свойств и законов, постановку новых задач и нахождение алгоритмов их решения, разработку новых научных теорий и т. д.

Идея практического применения исследований в области искусственного интеллекта в виде экспертных систем заключается в следующем. Если пока не удается заставить машину тонко приспосабливаться к проблемной области, самой вырабатывать нужные методы поиска, находить существенно новые свойства и законы, вырабатывать новые знания, приобретать новый опыт в изучаемой ею проблемной области, то можно воспользоваться накопленным человеческим опытом, готовыми знаниями, методами, навыками решения задач в некоторой предметной области и заложить их в машину (в ее базу знаний). Тем самым будет на время снята проблема накопления машиной опыта, открытия ею новых знаний и останется проблема применения уже накопленного специалистами опыта для вывода знаний с помощью имеющихся средств.

Затем необходимо разработать программу применения этого опыта для решения тех задач, с которыми справляется специалист и при решении которых он не располагает строгими математическими алгоритмами в силу неформализованности 
соответствующих знаний, отсутствия точных математических моделей. Речь идет о том опыте, который специалист может выразить словами в терминах данной предметной области, в виде либо некоторых общих высказываний и правил, либо описания конкретных примеров, образцов решений и действий в различных конкретных ситуациях. Такие знания называются вербализуемыми. Но у человека вырабатывается и другой опыт, не описываемый терминами исследуемой предметной области. Этот опыт представляется в некоторой системе формирующихся у человека связей, образов, интуитивных предчувствий, предвидений, предпочтений, неосознаваемых реакций и т. п. Он не сформирован в четко осознаваемые человеком правила, связи, принципы, эмпирические законы.

По-видимому, описание подсознательного опыта следует проводить в другом языке - не в терминах внешнего поведения человека при обработке им информации, а в терминах нейронных структур человеческого мозга и их связей, обеспечивающих самоорганизацию и специализацию поисковых механизмов. Поэтому предметная область для экспертных систем должна быть такой, чтобы опыт, который не удается вербализовать, не играл главенствующую роль при решении задач, как, например, в задачах оценки произведений искусства, в процессах художественного творчества, дегустации и т. п.

На этапе создания экспертных систем первого поколения в них применялись наиболее проработанные фррагменты еще далеких от завершения исследований в области искусственного интеллекта. При этом из-за недостаточности научных знаний о том, как заставить машину приобретать знания и опыт, использовался накопленный человечеством научный потенциал 
и практический опыт; из-за недостаточности научных знаний о том, как передать машине ту часть человеческого опыта, которая не поддается словесным описаниям, пришлось передавать машине только опыт, поддающийся вербализации. Наконец, из вербализуемых знаний использовались в основном только так называемые поверхностные, эмпирические знания, получаемые в результате обобщения внешнего поведения исследуемых объектов, без учета их внутренней природы, внутренних законов функционирования, глубоких причинноследственных связей. Представление же глубинных знаний, а также приведение индуктивных выводов, обучение на опыте, открытие новых свойств, законов и другие сложные интеллектуальные действия включаются в разработку экспертных систем второго и последующих поколений. Тем не менее уже разработанные экспертные системы находят применение в самых разнообразных областях науки, техники, производства, культуры.

\section{КОНТРОЛЬНЫЕ ВОПРОСЫ}

1. Какие принципиальные особенности отличают новую информационную технологию от существующей?

2. На какие типы подразделяются в настоящее время системы искусственного интеллекта, функционирующие на принципах новой информационной технологии?

3. Развитие каких основных проблем предопределяет дальнейший прогресс систем искусственного интеллекта и новой информационной технологии в связи с тем, что все системы искусственного интеллекта ориентированы на знания? 
4. Какие основные пути использования психологических знаний в практике автоматизации умственного труда необходимо наметить в связи с развитием исследований и разработок систем ИИ?

5. Мультиагентные технологии. Понятие агента и его возможная реализация. 


\section{4. ПРИМЕНЕНИЕ ИНТЕЛЛЕКТУАЛЬНЫХ СИСТЕМ В ПРОФЕССИОНАЛЬНОЙ ДЕЯТЕЛЬНОСТИ}

\section{1. ОРГАНИЗАЦИЯ ДИАЛОГА МЕЖДУ ЧЕЛОВЕКОМ И ИНТЕЛЛЕКТУАЛЬНОЙ СИСТЕМОЙ}

\subsection{1. Диалоговые системы, основанные на распознавании рукописного текста}

Рукописный ввод символов (рисунок 4.1) может по праву считаться одним из самых удобных способов набора текста наравне с оперированием виртуальной клавиатурой. Голосовой набор можно применить далеко не всегда, а в случае с рукописным методом всё обстоит намного проще.

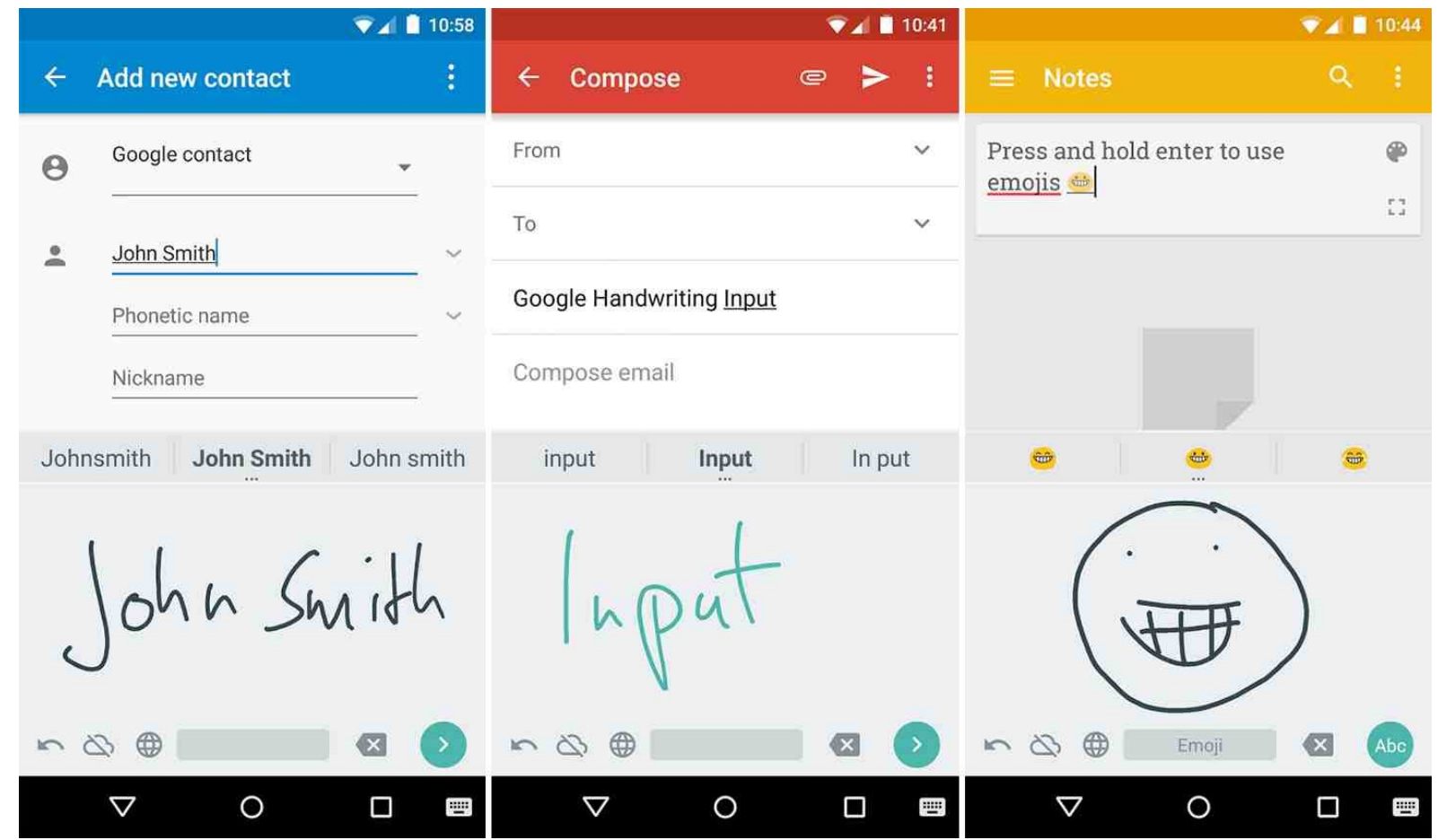

Рисунок 4.1 - Система распознавания рукописного ввода для планшетов, смартфонов и прочих мобильных устройств на платорорме Android 
Рассмотрим, в чем заключается различие между двумя формами представления одного и того же текста: рукописной и печатной. При этом могут исследоваться и сравниваться как сам процесс фрормирования текста, так и его результаты, т.е. уже сформированные тексты.

При исследовании уже ссрормированных текстов обнаруживается, что главное отличие рукописного текста от печатного состоит в значительно большей степени вариабельности начертаний одной и той же буквы разными людьми и одним и тем же человеком в различных состояниях, чем при воспроизведении тех же букв на различных пишущих машинках и принтерах.

Почерком будем называть систему индивидуальных особенностей начертания и динамики воспроизведения букв, слов и предложений вручную различными людьми или на различных устройствах печати.

В рукописной форме начертание букв является индивидуальным для каждого человека и зависит также от его состояния, хотя, конечно, в начертаниях каждой конкретной буквы всеми людьми безусловно есть и нечто общее, что и позволяет идентифицировать ее именно как данную букву при чтении.

К индивидуальным особенностям рукописного начертания букв отнесено 13 шкал с десятками градаций в каждой.

На современных компьютерах основным устройством ввода текстовой информации является клавиатура. Результат ввода текста в компьютер с точки зрения начертания букв, слов и предложений не имеет особых индивидуальных особенностей (если не считать частот использования различных шрифтов, 
кеглей, жирностей, подчеркиваний и других эффректов, изменяющих вид текста). Поэтому необходимо ввести понятие клавиатурного почерка, под которым будем понимать систему индивидуальных особенностей начертаний и динамики воспроизведения букв, слов и предложений на клавиатуре.

Таким образом, любой текст содержит не только ту информацию, для передачи которой его собственно и создавали, но и информацию о самом авторе этого текста и о технических средствах и технологии его создания.

Существует целая наука - "Психографология", которая ставит своей задачей получение максимального количества информации об авторах текстов на основе изучения индивидуальных особенностей их почерка.

В настоящее время в России действует институт графологии. На сайте этого института http://graphology.boom.ru можно познакомится с тем, что такое графология, с ее историей и задачами, которые она позволяет решать сегодня. Графологическое исследование имеет значительное преимущество перед простым тестированием или собеседованием, поскольку нет необходимости информировать человека, чей почерк подвергается изучению о производимых исследованиях.

Но текст представляет собой не просто совокупность букв, а сложную иерархическую структуру, в которой буквы образуют лишь фундамент пирамиды, а на более высоких ее уровнях находятся слова, предложения, и другие части текстов различных размеров, обладающие относительной 
целостностью и самостоятельностью (абзацы, параграфы, главы, части, книги).

Понятие почерка акцентирует внимание именно на начертании и динамике воспроизведения букв и слов. При этом в понятие почерка не входят индивидуальные особенности текстов, обнаруживаемые на более высоких уровнях иерархической организации текстов, например: частоты употребления тех или иных слов и словосочетаний, средние длины предложений и абзацев, и т.п. Но именно эти индивидуальные особенности текстов исследуются и используются при атрибуции анонимных и псевдонимных текстов (определении их вероятного авторства) и датировки.

Соответственно и текст может представлять для читателя интерес по крайней мере с трех точек зрения:

1. Как источник информации о том, о чем говорит автор, т.е. о предмете изложения.

2. Как источник информации о самом авторе.

4. Как источник информации о предмете изложения и об авторе.

В этом смысле читать А.С. Пушкина в рукописи может быть значительно интереснее, чем взяв томик с полки. Это объясняется просто: в томике есть лишь сам результаm работы поэта и выхолощена вся информация о процессе, т.е. о самом поэте, содержащаяся в почерке, способе размещения текста на листе, порядке и динамике его формирования, различных вариантах и ассоциациях, возникавших в процессе создания произведения.

Таким образом, система, оснащенная интеллектуальным интерфейсом, может вести по-разному 
в зависимости от результатов идентификации пользователя, его профессионального уровня и текущего психофизиологического состояния.

Рассмотрим подробнее некоторые вопросы идентификации пользователей по клавиатурному почерку.

Проблемы идентификации и аутентификации пользователей компьютеров являются актуальными в связи с все большим распространением компьютерных преступлений. Использование для идентификации клавиатурного почерка является одним из направлений биометрических методов идентификации личности.

Подобные системы не обеспечивают такую же точность распознавания, как системы идентификации по отпечаткам пальцев или по рисунку радужной оболочки глаз, но имеют то преимущество, что система может быть полностью скрыта от пользователя, т. е. он может даже не подозревать о наличии такой системы контроля доступа.

Аутентификация - это проверка, действительно ли пользователь является тем, за кого себя выдает. При этом пользователь должен предварительно сообщить о себе идентификационную информацию: свое имя и пароль, соответствующий названному имени.

Идентификация - это установление его личности.

И идентификация, и аутентификация являются типичными задачами распознавания образов, которое может проводиться по заранее определенной или произвольной последовательности нажатий клавиш.

При вводе информации пользователь последовательно нажимает и отпускает клавиши, соответствующие вводимому 
тексту. При этом для каждой нажимаемой клавиши можно фиксировать моменты нажатия и отпускания.

На современных компьютерах на следующую клавишу можно нажимать до отпускания предыдущих, т.е. символ помещается в буфер клавиатуры только по нажатию клавиши, тогда как аппаратные прерывания от клавиатуры возникают и при нажатии, и при отпускании клавиши.

Основной характеристикой клавиатурного почерка следует считать временные интервалы между различными моментами ввода текста:

- между нажатиями клавиш;

- между отпусканиями клавиш;

- между нажатием и отпусканием одной клавиши;

- между отпусканием предыдущей и нажатием следующей клавиши.

Кроме того, могут учитываться производные от временных интервалов вторичные показатели, например, такие как скорость и ускорение ввода.

В литературе описано четыре математических подхода к решению задачи распознавания клавиатурного почерка пользователя:

- статистический;

- вероятностно-статистический;

- на базе теории распознавания образов и нечеткой логики;

- на основе нейросетевых алгоритмов.

В настоящее время возможна разработка интеллектуальных высоконадежных интерфейсов, обеспечивающих решение этих и ряда других задач 
идентификации и прогнозирования состояния оператора $\boldsymbol{8}$ режиме реального времени непосредственно в процессе его работы с системой.

При этом система в своей работе будет гибко учитывать текущее и прогнозируемое состояние оператора, что может проявляться в адаптации как алгоритмов работы, так и вида, и содержания интерфейса.

Эти работы дополняют возможности заблаговременного отбора операторов, обладающих свойствами, необходимыми для высоко ответственных работ в экстремальных ситуациях.

\subsection{2. Диалоговые системы, основанные на распознавании речи}

Распознавание речи - прочесс преобразования речевого сигнала в цифровую информацию (напр., текстовые данные). Обратной задачей является синтез речи.

Можно выделить следующие области применения:

- голосовое управление;

- голосовой набор в различной технике (мобильники, компьютеры, и пр.);

- голосовой ввод текстовых сообщений в смартфонах и прочих мобильных компьютерах;

- голосовой поиск;

- голосовая почта.

Первое устройство для распознавания речи появилось в 1952 году, оно могло распознавать произнесённые человеком цифры. В 1964 году на ярмарке компьютерных технологий в Нью-Йорке было представлено устройство IBM Shoebox. 
Коммерческие программы по распознаванию речи появились в начале девяностых годов. Обычно их используют люди, которые из-за травмы руки не в состоянии набирать большое количество текста. Эти программы (например, Dragon NaturallySpeaking, VoiceNavigator, “Горыныч”) переводят голос пользователя в текст, таким образом, разгружая его руки. Надёжность перевода у таких программ достаточно высока, и с годами она постепенно улучшается.

Увеличение вычислительных мощностей мобильных устройств позволило для них создать программы с функцией распознавания речи и так называемых виртуальных помощников (рисунок 4.2).

Apple Siri

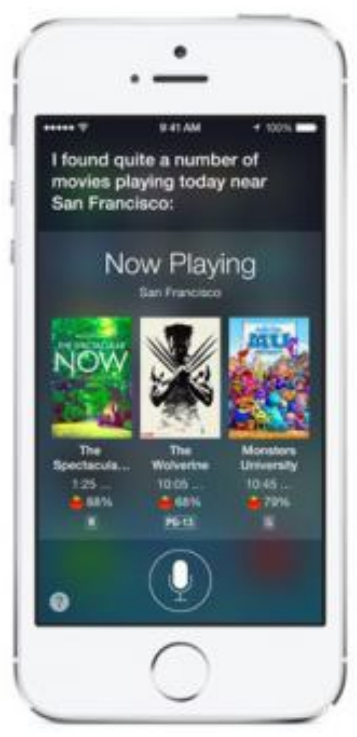

Google Now

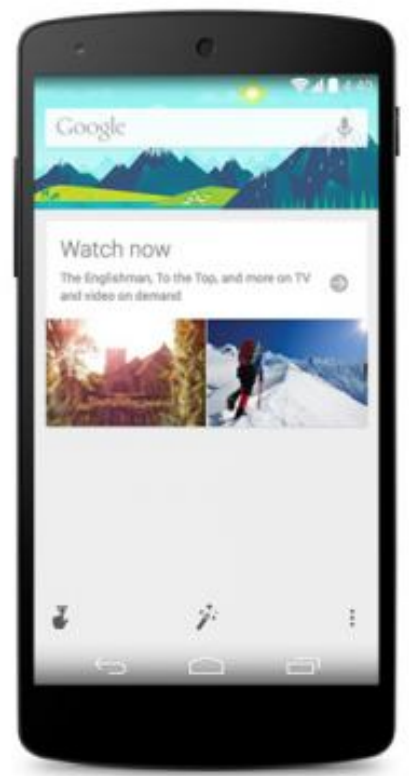

Windows Cortana

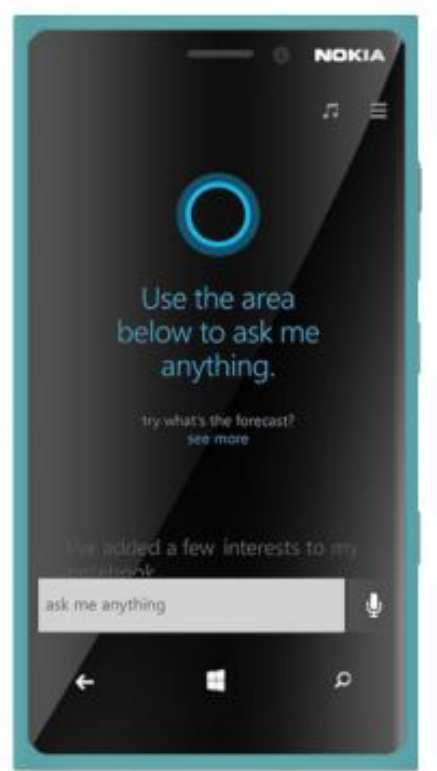

\section{Рис. 4.2. Виртуальные помощники}

Среди таких программ безусловно выделяются:

- Microsoft Cortana (Microsoft);

- Google Now (Google); 
- Siri (Apple).

Эти программы позволяет работать со многими приложениями при помощи голоса. Например, можно набрать нужный номер абонента, включить воспроизведение музыки в плеере, создать новый документ, произвести поиск нужного объекта в сети Интернет.

Siri (Apple) - 'то персональный помощник, который работает по принципу вопрос-ответ и использует обработку естественной речи. Siri задает вопросы и может быть полностью персонализирована. Есть возможность выбрать мужской или женский голос. Ориентируется в контексте вашей речи. Эволюционирует из iPhone в iPhone, становится все более интеллектуальной.

Google Now (Google) - голосовой помощник, впервые появившийся в 2012 году и получивший титул “Инновация года". Использует обработку естественного языка для ответов на вопросы, создания рекомендаций, открытия приложений, работы в сети и множества других функций. Подтягивает информацию из запросов в хроме, опираясь на режим дня, данных из календаря, местоположения, анализируя письма, персонализировать можно и вручную. Имеет интерфейс карточек. Доступен для скачивания и на iOS устройствах.

Microsoft Cortana (Microsoft) - виртуальный помощник с искусственным интеллектом. Появилась в общем доступе 14 апреля 2014 года. Cortana получила своё имя в честь персонажа серии компьютерных игр Halo, eё голос также принадлежит героине игры - виртуальную помощницу озвучила актриса Джен Тейлор. До Cortana y Windows смартфонов была Loise. Ей можно дать доступ к вашим личным 
данным, таким как электронная почта, адресная книга, история поисков в сети и т. п. - все эти данные она будет использовать для упреждения ваших нужд. Cortana заменит стандартную поисковую систему и будет вызываться нажатием кнопки «Поиск».

Интеллектуальные речевые решения, позволяющие автоматически синтезировать и распознавать человеческую речь, являются следующей ступенью развития интерактивных голосовых систем (IVR). Использование интерактивного телефонного приложения в настоящее время не веяние моды, а жизненная необходимость. Снижение нагрузки на операторов контакт-центров и секретарей, сокращение расходов на оплату труда и повышение производительности систем обслуживания вот только некоторые преимущества, доказывающие целесообразность подобных решений.

Прогресс, однако, не стоит на месте и в последнее время в телефонных интерактивных приложениях все чаще стали использоваться системы автоматического распознавания и синтеза речи. В этом случае общение с голосовым порталом становится более естественным, так как выбор в нем может быть осуществлен не только с помощью тонового набора, но и с помощью голосовых команд. При этом системы распознавания являются независимыми от дикторов, то есть распознают голос любого человека.

Следующим шагом технологий распознавания речи можно считать развитие так называемых Silent Speech Interfaces (SSI) (Интерфейсов Безмолвного Доступа). Эти системы обработки речи базируются на получении и обработке речевых сигналов на ранней стадии артикулирования. Данный этап развития 
распознавания речи вызван двумя существенными недостатками современных систем распознавания: чрезмерная чувствительность к шумам, а также необходимость четкой и ясной речи при обращении к системе распознавания. Подход, основанный на SSI, заключается в том, чтобы использовать новые сенсоры, не подверженные влиянию шумов в качестве дополнения к обработанным акустическим сигналам.

На сегодняшний день существует два типа систем распознавания речи - работающие «на клиенте» (client-based) и по принципу «клиент-сервер» (client-server). При использовании клиент-серверной технологии речевая команда вводится на устройстве пользователя и через Интернет передается на удаленный сервер, где обрабатывается и возвращается на устройство в виде команды (Google Voice, Vlingo, пр.); ввиду большого количества пользователей сервера система распознавания получает большую базу для обучения. Первый вариант работает на иных математических алгоритмах и встречается редко (Speereo Software - в этом случае команда вводится на устройстве пользователя и обрабатывается в нем же. Плюс обработки «на клиенте» в мобильности, независимости от наличия связи и работы удаленного оборудования. Так, система, работающая «на клиенте» кажется надежнее, но ограничивается, порой, мощностью устройства на стороне пользователя.

Сейчас применяется также технология SIND (без привязки к голосу конкретного человека). 


\subsection{4. Системы с биологической обратной связью}

Системами с биологической обратной связью (БОС) будем называть системы, поведение которых зависит от психофризиологического (биологического) состояния пользователя.

Это означает, что в состав систем с БОС в качестве подсистем входят информационно-измерительные системы и системы искусственного интеллекта.

Съем информации о состоянии пользователя осуществляется с помощью контактных и/или дистанционных датчиков в режиме реального времени с применением транспьютерных или обычных карт (плат) с аналого-цифровыми преобразователями (АЦП).

При этом инфрормация может сниматься по большому количеству каналов - показателей (количество которых обычно кратно степеням двойки), подавляющее большинство которых обычно являются несознаваемыми для пользователя. Это является весьма существенным обстоятельством, т.к. означает, что системы БОС позволяют вывести на уровень сознания обычно ранее не осознаваемую информацию о состоянии своего организма, т.е. расширить область осознаваемого. А это значит, что у человека появляются условия, обеспечивающие возможность сознательного управления своими состояниями, ранее не управляемыми на сознательном уровне, что является важным эволюционным достижением технократической цивилизации.

Передача информации от блока съема информации к АЦП-карте может также осуществляться либо по проводной 
связи, либо дистанционно с использованием каналов инфракрасной или радиосвязи.

Приведем три примера применения подобных систем:

1. Мониторинг состояния сотрудников на конвейере с целью обеспечения высокого качества продукции.

2. Компьютерные тренажеры, основанные на БОС, для обучения больных с фрункциональными нарушениями управлению своим состоянием.

4. Компьютерные игры с БОС.

Известно, что одной из основных причин производственного брака является ухудшение состояния сотрудников. Но сотрудники не всегда могут вовремя заметить это ухудшение, т.к. самооценка (самочувствие) обычно запаздывает по времени за моментом объективного ухудшения состояния. Поэтому является актуальным своевременное обнаружение объективного ухудшения параметров и адекватное реагирование на него.

С помощью систем БОС это достигается тем, что:

1. Каждому сотруднику одевается на руку браслет с компактным устройством диагностики ряда параметров, например, таких, как:

- частота и наполнение пульса;

- кожно-гальваническая реакция;

- температура;

- давление;

- пототделение.

2. Это же устройство и периодически передает значения данных параметров на компьютер по радиоканалу. 
4. Параметры от каждого сотрудника накапливаются в базе данных системы мониторинга на сервере, а также анализируются в режиме реального времени с учетом текущего состояния и динамики, В т.ч. вторичных (расчетных) показателей.

4. Когда параметры выходят за пределы коридора "нормы" или по их совокупности может быть поставлен диагноз, сотрудник оперативно снимается с рабочего места и заменяется другим из резерва, а затем, при наличии показаний, направляется на лечение.

Некоторыми процессами в своем организме мы не можем управлять не потому, что у нас нет рычагов управления, а лишь потому, что мы их не знаем, не имеем навыков их использования и не знаем результатов их применения. Но ключевой проблемой, без решения которой невозможно управление, является отсутствие быстрого и надежного, адекватного по содержанию канала обратной связи.

Bсе эти проблемы снимаются системами БОС (рисунок 4.3):

- на экран компьютера в наглядной и легко интерпретируемой форме в режиме реального времени выводится информация о состоянии какойлибо подсистемы организма, например, об уровне $\mathrm{pH}$ (кислотности) в желудке;

- в качестве рычагов управления пациенту предлагается применить метод визуализации тех или иных образов, которые сообщаются врачом;

- когда пациент ярко зрительно представляет заданные образы, то при этом он обнаруживает, что кривая 
кислотности на экране начинает ползти вверх или вниз в прямом соответствии с тем, что именно он себе представляет.

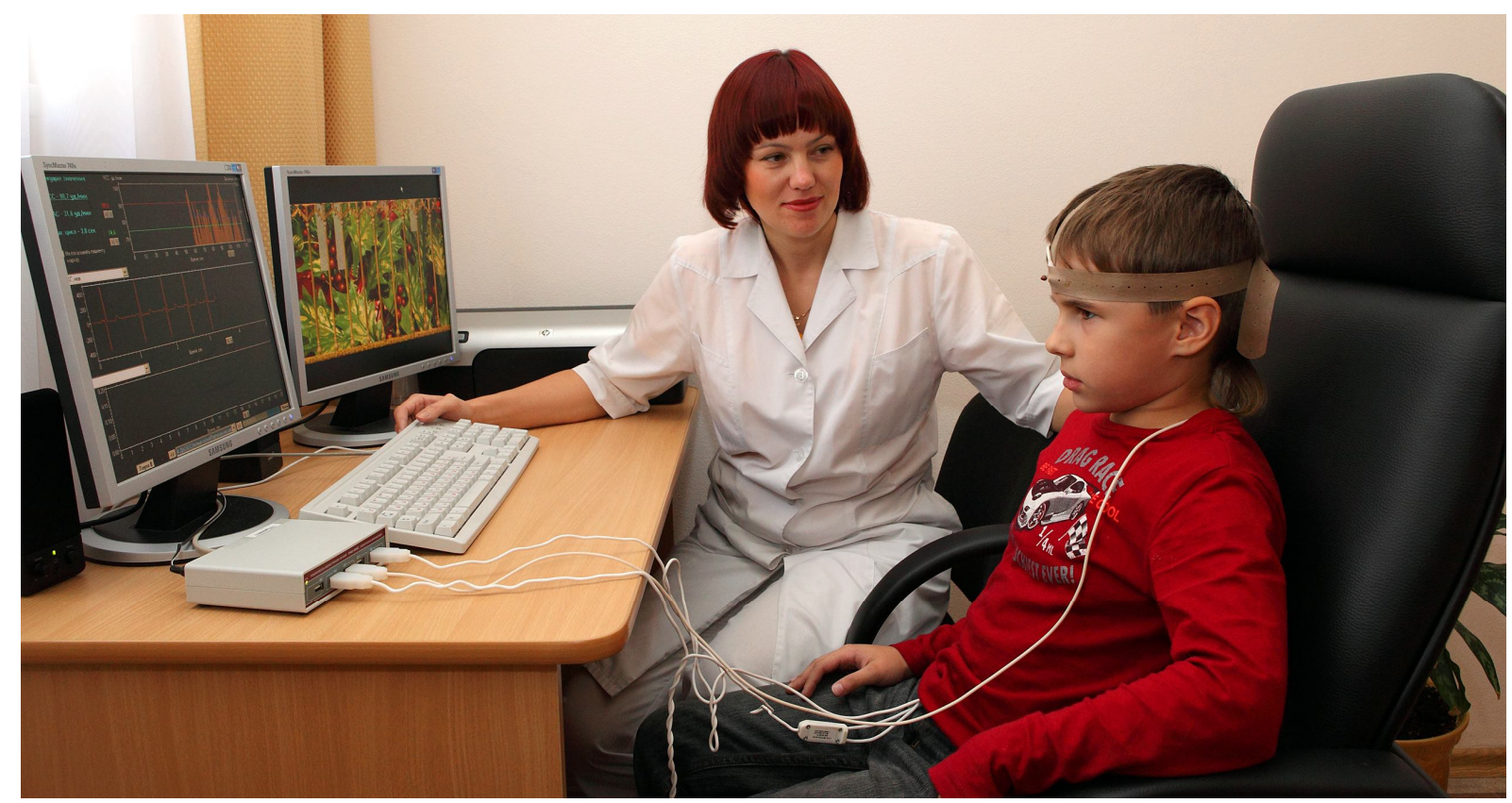

\section{Рисунок 4.3 - Система с биологической обратной связью}

Через пару недель подобных тренировок, проводимых по 15-20 минут через день пациент приобретает такой уровень навыков управления ранее не осознаваемыми процессами в своем организме, которых Хатха-йоги добиваются за многие годы упорных тренировок под руководством профессиональных опытных и ответственных наставников (Гуру). Причем скоро пациент начинает понимать, когда необходимо повысить или понизить кислотность и без компьютера с системой БОС и может делать это прямо в той обстановке, в которой возникла такая необходимость. Столь высокая эффрективность метода БОС объясняется высокой скоростью, наглядностью и адекватностью обратной связи, что является одним из 
основных фракторов, влияющих на эфффективность формирования навыков управления своим состоянием.

Имеется информация, что такими методами могут лечиться или облегчаться многие заболевания, вплоть до диабета, причем не только на стадии функциональных нарушений, но даже и при наличии органических изменений.

В последнее время появляется все больше компьютерных игр, включающих элементы БОС. При этом от психофизиологического состояния игрока может зависеть, например, и развитие сценария, и точность прицеливания при использовании оптического прицела.

В этих играх часто создаются ситуации, в которых человеку нужно быстро принимать и реализовать решения, при этом цена ошибки, а значит и психическая напряженность, и волнение игрока, постоянно увеличиваются. Этим самым создается экстремальная ситуация, напряженность которой все больше возрастает. В этих условиях лучших результатов достигает тот, у кого "крепче нервы", кто лучше может управлять собой в экстремальных ситуациях.

Поэтому игры с элементами БОС можно считать своего рода тренажерами по формированию и совершенствованию навыков адекватного поведения в экстремальных ситуациях.

Здесь необходимо отметить один очень существенный момент. В обычной реальности развитие событий зависит не непосредственно от нашего психофизиологического состояния, а лишь от того, как оно проявляется в наших действиях. В случае же виртуальной реальности развитие сценария игры может зависеть непосредственно от состояния игрока. Таким образом, в виртуальной реальности само сознательное 
(произвольное) или несознательное (непроизвольное) изменение нашего состояния по сути дела является действием. Аналогичная ситуация в обычной реальности может иметь место при высших формах сознания и проявлении сверхспособностей.

\subsection{4. Системы с семантическим резонансом.}

Компьютерные Ч-технологии и интеллектуальный подсознательный интерфейс

\section{Системами с семантическим резонансом (рисунок}

4.4) будем называть системы, поведение которых зависит om состояния сознания пользователя и его психологической реакции на смысловые стимулы.

Это означает, что в состав систем с семантическим резонансом, также как и систем с БОС, в качестве подсистем входят инфрормационно-измерительные системы и системы искусственного интеллекта, аналогично осуществляется и съём информации о состоянии пользователя.

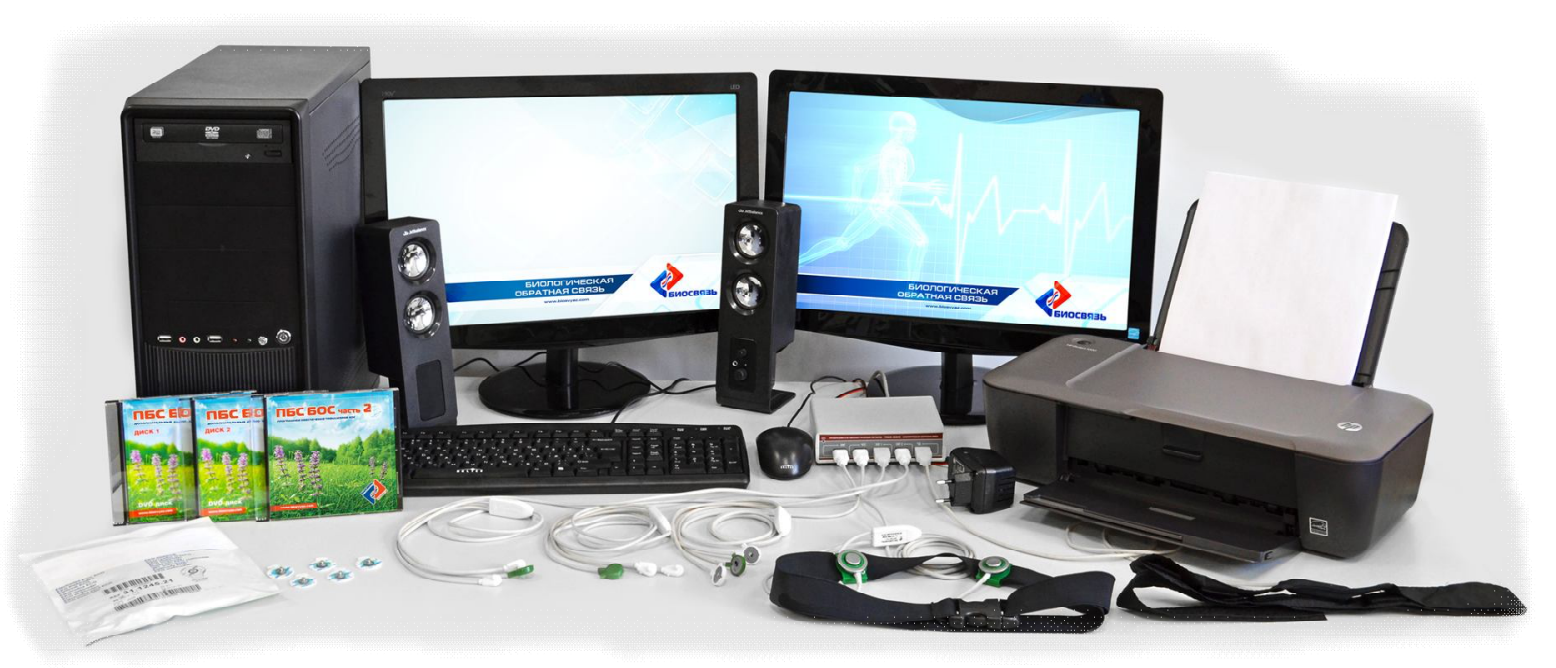

Рисунок 4.4 - Психоэмоциональный комплекс БОС 
Различие между системами с БОС и с семантическим резонансом состоит в том, что в первом случае набор снимаемых параметров и методы их математической обработки определяются необходимостью идентификации биологического состояния пользователя, тогда как во втором - его реакции на смысловые стимулы (раздражители).

В частности, имеется возможность по наличию в электроэнцефралограмме так называемых вызванных потенциалов установить реакцию человека на стимул: заинтересовался он или нет.

Здесь принципиально важно, что вызванные потенциалы после предъявления стимула по времени возникают гораздо раньше, чем его осознание.

Из этого следует ряд важных выводов:

1. Если это осознание не наступает по каким-либо причинам, то вызванные потенциалы все равно с очень высокой достоверностью позволяют прогнозировать ту реакцию, которая была бы у человека, если бы информация о стимуле проникла в его сознание (причинами, по которым зрительный образ стимула может не успеть сформироваться и проникнуть в сознание пользователя, могут быть, например, его очень сильную зашумленность, фррагментарность или слишком короткое время его предъявления).

2. Реакция на стимул на уровне вызванных потенциалов не подвергается критическому анализу и корректировке на уровне сознания, т.е. является гораздо более "искренней" и "откровенной", адекватной и достоверной, чем сознательные ответы на опросник с тем же самым стимульным 
материалом (сознательные ответы зависят от мотивации, коньюктуры и массы других обстоятельств).

4. Для получения информации о подсознательной реакции пользователя на стимульный материал он может предъявляться в значительно более высоком темпе, чем при сознательном тестировании.

4. При подсознательном тестировании пользователь может даже не знать о том, что оно проводится.

Bce это в совокупности означает, что системы с семантическим резонансом позволяют получить и вывести на уровень сознания обычно ранее не осознаваемую адекватную информацию о состоянии своего сознания, систем мотивации, целеполагания, ценностей и т.д., т.е. расширить область осознаваемого. Это позволяет создать качественно более благоприятные условия для управления состоянием сознания, чем ранее, что является важным эволюционным достижением технократической цивилизации.

Системы с семантическим резонансом могут эфффективно использоваться в ряде направлений:

- психологическое и профессиональное тестирование, подбор персонала, в т.ч. для действий в специальных условиях и в измененных формах сознания;

- модификация сознания, систем мотиваций, целеполагания, ценностей и др. (компьютерное нейролингвистическое программирование: "компьютерные НЛП-технологии");

- компьютерные игры с системами семантической обратной связи. 
4.1.5. Системы виртуальной реальности. Эффректы присутствия, деперсонализации и модификация сознания пользователя

Виртуальная реальность (ВP) - модельная трехмерная (3D) окружающая среда, создаваемая компьютерными средствами и реалистично реагирующая на взаимодействие с пользователями (рисунок 4.5).

Технической базой систем виртуальной реальности являются современные мощные персональные компьютеры и программное обеспечение высококачественной трехмерной визуализации и анимации. В качестве устройств ввода-вывода информации в системах ВР применяются виртуальные шлемы с дисплеями (HMD), в частности шлемы со стереоскопическими очками, и устройства 3D-ввода, например, мышь с пространственно управляемым курсором или "цифровые перчатки", которые обеспечивают тактильную обратную связь с пользователем. 


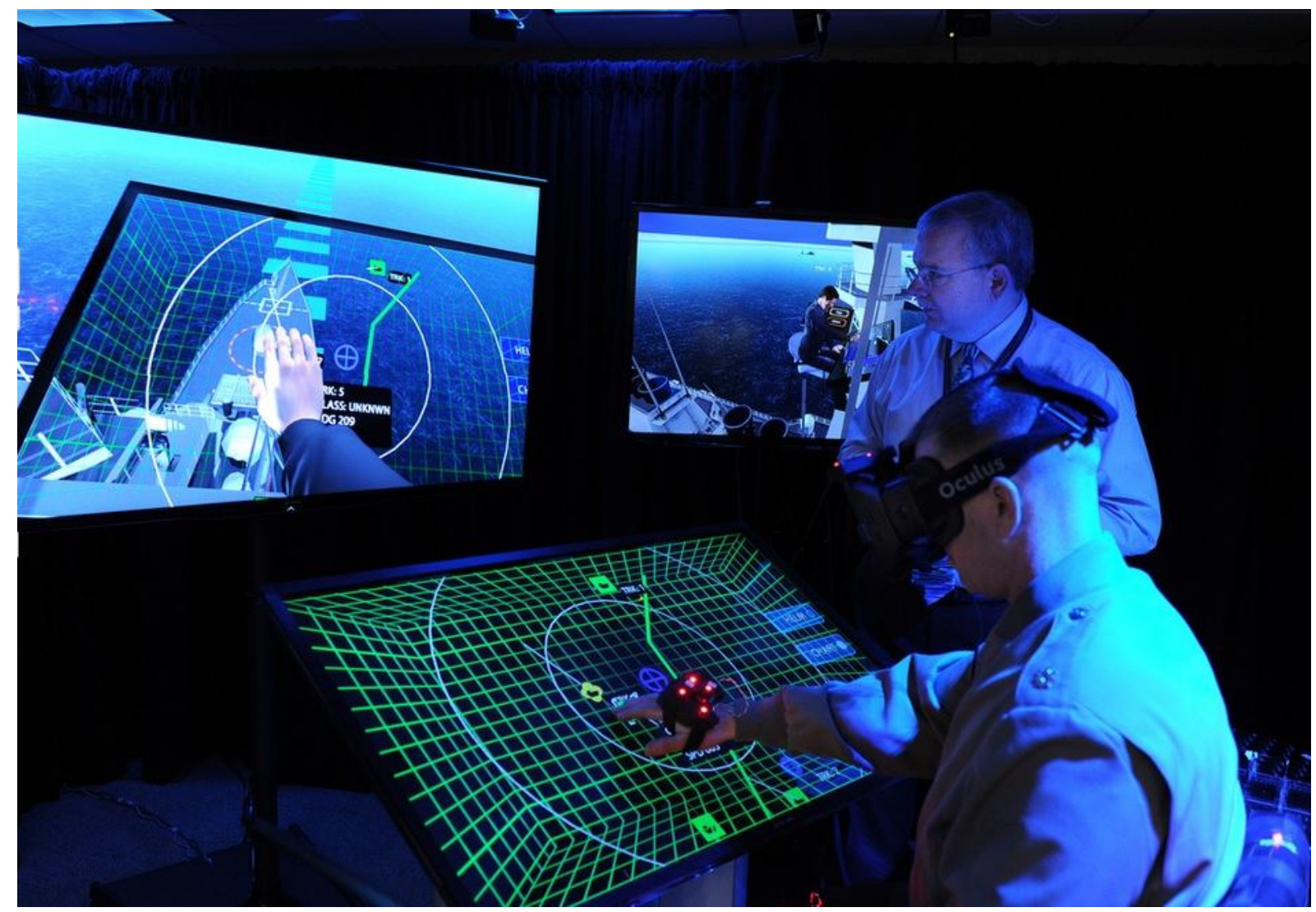

Рисунок 4.5 - Система виртуальной реальности для управления флотом

Совершенствование систем виртуальной реальности приводит ко все большей изоляции пользователя от обычной реальности, т.к. все больше каналов взаимодействия пользователя с окружающей средой замыкаются не на обычную, а на виртуальную среду - виртуальную реальность, которая, при этом, становится все более и более функционально-замкнутой и самодостаточной.

Создание систем ВР является закономерным следствием процесса совершенствования компьютерных систем отображения информации и интерфейса управления.

При обычной работе на компьютере монитор занимает не более $20 \%$ поля зрения пользователя. Системы ВР перекрывают все поле зрения. 
Обычные мониторы не являются стереоскопическими, т.е. не создают объемного изображения. Правда, в последнее время появились разработки, которые, позволяют преодолеть это ограничение (достаточно сделать поиск в yandex.ru по запросу "Стереоскопический монитор"). Системы ВР изначально были стереоскопическими.

Звуковое сопровождение, в том числе со стерео и квадрозвуком, сегодня уже стали стандартом. В системах ВР человек не слышит ничего, кроме звуков этой виртуальной реальности.

В некоторых моделях систем виртуальной реальности пользователи имеют возможность восприятия изменяющейся перспективы и видят объекты с разных точек наблюдения, как если бы они сами находились и перемещались внутри модели.

Если пользователь располагает более развитыми (погруженными) устройствами ввода, например, такими, как цифровые перчатки и виртуальные шлемы, то модель может даже надлежащим образом реагировать на такие действия пользователя, как поворот головы или движение глаз.

Необходимо отметить, что в настоящее время системы виртуальной реальности развиваются очень быстрыми темпами и явно выражена тенденция проникновения технологий виртуальной реальности в стандартные компьютерные технологии широкого применения.

Развитие этих и других подобных средств привело к появлению качественно новых эфрфектов, которые ранее не наблюдались или наблюдались в очень малой степени:

- эфрфект присутствия пользователя в виртуальной реальности; 
- эффрект деперсонализации и модификации самосознания и сознания пользователя в виртуальной реальности.

Эффрект присутствия - это создаваемая для пользователя иллюзия его присутствия в смоделированной компьютером среде, при этом создается полное впечатление "присутствия" в виртуальной среде, очень сходное с ощущением присутствия в обычном "реальном" мире.

При этом виртуальная среда начинает осознаваться как реальная, а о реальной среде пользователь на время как бы совершенно или почти полностью "забывает". При этом технические особенности интерфейса также вытесняются из сознания, т.е. мы не замечаем этот интерфейс примерно так же, как собственное физическое тело или глаза, когда смотрим на захватывающий сюжет. Таким образом, реальная среда замещается виртуальной средой.

Исследования показывают, что для возникновения и силы эффректа присутствия определяющую роль играет реалистичность движения различных объектов в виртуальной реальности, а также убедительность реагирования объектов виртуальной реальности при взаимодействии с ними виртуального тела пользователя или других виртуальных объектов. В то же время, как это ни странно, естественность вида объектов виртуальной среды играет сравнительно меньшую роль.

Системы виртуальной реальности уже в настоящее время широко применяется во многих сферах жизни.

Одними из первых технологии виртуальной реальности были применены НАСА США для тренировки пилотов 
космических челноков и военных самолетов, при отработке приемов посадки, дозаправки в воздухе и т.п.

Самолет-невидика "Стелс" вообще управляется пилотом, практически находящемся в виртуальной реальности.

Из виртуальной реальности человек управляет роботом, выполняющим опасную или тонкую работу.

Технология Motion Capture, позволяет дистанционно "снять" движения с человека и присвоить их его трехмерной модели, что широко применяется для создания компьютерных игр и анимации рисованных персонажей в фрильмах.

Особенно эффрективно применение виртуальной реальности в рекламе, особенно в Интернет-рекламе на стадии информирования и убеждения.

С использованием виртуальной реальности можно показывать различные помещения, например, совершить виртуальную экскурсию по музею, учебному заведению, дому, коттеджу или местности (прогулка по Парижу от туристической фрирмы).

Во всех этих приложениях важно, что в отличие от трехмерной графики, виртуальная реальность обеспечивает эфрфект присутствия и личного участия пользователя в наблюдаемых им событиях.

Сегодня уже для всех вполне очевидно, что виртуальная реальность может с успехом использоваться для развлечений, ведь она помогает представить себя в другой роли и в другом обличии. Однако в действительности этот эффрект связан с модификацией "Образа Я", т.е. сознания и самосознания пользователя. Это значит, что последствия этого в действительности значительно серьезнее, чем обычно 
представляют, и далеко выходит за рамки собственно развлечений.

Как показано автором в ряде работ, приведенных на сайте http://Lc.kubagro.ru, фрорма сознания и самосознания человека определяются тем, как он осознает себя и окружающее, т.е. тем:

- что он осознает, как объективное, субъективное и несуществующее;

- с чем он отождествляет себя и что осознает, как объекты окружающий среды.

Очевидно, что разработчики новейших компьютерных технологий совершенно неожиданно вторглись в абсолютно новую для себя сферу исследования измененных форм сознания, и далеко идущие системные последствия этого ими, как и вообще научным сообществом, пока еще очень мало осознаны.

Еще в 1079-1981 годах автором и Л.А. Бакурадзе были оформлены заявки на изобретение компьютерной системы, выполняющей все трудовые функции фризического тела, обеспечивающую управление с использованием дистанционного мысленного воздействия, т.е. микротелекинеза. По мнению автора телекинез представляет собой управление фризическими объектами путем воздействия на них непосредственно с высших планов без использования фризического тела, т.е. тем же способом, с помощью которого любой человек, осознает он это или нет, управляет своим физическим телом. Были предложены технические и программные решения и инженерно - психологические методики. Система предлагалась адаптивной, т.е. 
автоматически настраивающейся на индивидуальные особенности, "почерк" оператора и его состояние сознания, с плавным переключением на дистанционные каналы при повышении их надежности (которая измерялась автоматически) и могла одновременно с выполнением основной работы выступать в качестве тренажера. Человек, начиная работу с системой в обычной форме сознания с использованием традиционных каналов (интерфейса), имея мгновенную адекватную по форме и содержанию обратную связь об эфрфективности своего телекинетического воздействия, должен быстро переходить в форму сознания, оптимальную для использования телекинеза в качестве управляющего воздействия.

C учетом вышесказанного, предлагается следующее определение виртуальной реальности.

Система ВР - это система, обеспечивающая:

1. Генерацию полиперцептивной модели реальности в соответствии с математической моделью этой реальности, реализованной в программной системе.

2. Погружение пользователя в модель реальности путем подачи на все или основные его перцептивные каналы органы восприятия, программно-управляемых по величине и содержанию воздействий: зрительного, слухового, тактильного, термического, вкусового и обонятельного и других.

4. Управление системой путем использования виртуального "образа Я" пользователя и виртуальных органов управления системой (интерфейса), на которые он воздействует, представляющие собой зависящую от пользователя часть модели реальности. 
4. Реалистичную реакцию моделируемой реальности на виртуальное воздействие и управление со стороны пользователя.

5. Разрыв отождествления пользователя со своим "Образом Я" из обычной реальности (деперсонализация), и отождествление себя с "виртуальным образом Я", генерируемым системой виртуальной реальности (модификация сознания и самосознания пользователя).

6. Эффект присутствия пользователя в моделируемой реальности в своем "виртуальном образе Я", т.е. эффект личного участия пользователя в наблюдаемых виртуальных событиях.

7. Положительные результаты применения критериев реальности, т.е. фрункциональную замкнутость и самодостаточность виртуальной реальности, вследствие чего никакими действиями внутри виртуальной реальности, осуществляемыми над ее объектами, в т.ч. объектами виртуального интерфейса, с помощью своего виртуального тела, невозможно установить, "истинная" эта реальность или виртуальная.

В этой связи вспоминается ставший уже классическим первый фрильм "Матрица", в котором Морфей, обращаясь к Нео, произносит свою знаменитую фразу: "Сейчас я покажу тебе, как выглядит окончательная истинная реальность". Эта фрраза сразу вызвала у меня массу ассоциаций и вопросов, в частности:

1. А каковы критерии реальности?

2. А вдруг и эта реальность, которую Морфей назвал окончательной, истинной, в действительности является не 
более, чем симулятором следующего иерархического уровня, так сказать более фундаментальным симулятором?

Здесь возникает сложный мировоззренческий вопрос о том, возможно ли хотя бы в принципе находясь в виртуальной реальности, не выходя за ее пределы установить, что ты находишься именно в виртуальной, а не истинной реальности, или это возможно сделать только задним числом, после выхода из виртуальной реальности и перехода в истинную реальность?

\section{Итак, каковы же критерии реальности?}

По нашему мнению, прежде всего это самосогласованность реальности, т.е. получение одной и той же информации качественно различными способами и по различным каналом связи (принцип наблюдаемости):

- согласованность реальности самой с собой во времени;

- согласованность и взаимное подтверждение информации от различных органов восприятия, которые обычно реагируют на различные фрормы материи и часто являются парными (зрение, слух, обоняние) и расположенными в различных точках пространства.

Например, мы не только что-то видим, но и слышим, и осязаем, и можем попробовать его на вкус и ощутить запах и все эти восприятия ОТ РАЗЛИЧНЫХ ОРГАНОВ ЧУВСТВ соответствуют друг другу и означают, что перед нами некий определенный объект, а не галлюцинация или визуализация. Согласованная и взаимно подтверждающая информация с различных органов чувств, в соответствии с принципом 
наблюдаемости, также может рассматриваться как повышающая достоверность и адекватность восприятия.

В современных компьютерных играх мы не только видим довольно качественную визуализацию, но и соответствующее реалистичное звуковое сопровождение. $A$ в системах виртуальной реальности - визуализация стереоскопическая (то, что мы видим РАЗНЫМИ глазами как бы с разных точек в ПРОСТРАНСТВЕ, также взаимно подтверждается), а также появляется тактильный канал с обратной связью, который позволяет ощутить даже твердость, вес и температуру моделируемого в виртуальной реальности объекта. Все это вместе уже создает на столько высокую степень реалистичности, что может возникнуть эфрфект присутствия в виртуальной реальности, деперсонализация и отождествление с измененным образом Я, моделируемым в виртуальной реальности (переход в измененную форму сознания).

Представим, что эти сорормулированные критерии реальности не выполняются, т.е. нарушается ее самосогласованность. По-видимому, как своего рода "сбои" и различные "нарушения физических законов" и несогласованности в виртуальной реальности:

- "зацикливание" событий, как на заезженной пластинке, т.е. их многократное повторное осуществление без каких-либо изменений (пример: повторный проход черной кошки, с характерной остановкой и поворотом головы, в дверном проеме в "Матрице");

- прохождение сквозь стены; 
- полеты и очень длинные прыжки, а также телепортация в своем "реальном" теле;

- действия в другом темпе времени, т.е. эфффект замедления внешнего времени, соответствующий аналогичному ускорению внутреннего времени;

- действия в другом масштабе пространства, "увеличение" и "уменьшение" размеров, наблюдение мега и микроструктуры материи;

- видение сквозь стены, видение на больших расстояниях (в т.ч. с увеличением "как в телескоп"), видение прошлого и будущего;

- телекинез, пирокинез, психосинтез, левитация и т.п.;

- одновременное нахождение в нескольких местах.

Нетрудно заметить, что все эти проявления весьма напоминают так называемые "паранормальные явления", которые традиционно связывают с сверхвозможностями человека, т.е. с его возможностями при высших фрормах сознания.

Эти явления хотя и редко, но все же наблюдаются в нашем мире, что может указывать на то, что наша "истинная реальность" в определенной мере возможно является виртуальной, по крайней мере в большей степени, чем ранее предполагалось.

Вспомним известные в фризике принципы относительности Галилея и Эйнштейна:

1. Никакими экспериментами внутри замкнутой системы невозможно отличить состояние покоя от состояния равномерного и прямолинейного движения (Галилей). Следовательно, покоящаяся система отсчета физически 
эквивалентна системе отсчета, движущейся равномерно и прямолинейно под действием сил инерции.

2. Никакими экспериментами внутри ограниченной по размерам замкнутой системы невозможно установить, движется она под действием сил гравитации или по инерции (Эйнштейн). Следовательно, система отсчета, движущаяся в поле сил тяготения физически эквивалентна системе отсчета, движущейся под действием сил инерции.

Легко заметить, что фрормулировка 7-го пункта в определении системы виртуальной реальности весьма сходна с формулировками принципов относительности Галилея и Эйнштейна: никакими действиями внутри виртуальной реальности, осуществляемыми над ее объектами, в т.ч. объектами виртуального интерфейса, с помощью своего виртуального тела, невозможно установить, "истинная" эта реальность или виртуальная.

Следовательно, виртуальная система отсчета, локализованная В полнофункциональной виртуальной реальности полностью физически эквивалентна физической системе отсчета, локализованной в "истинной реальности". Учитывая эту аналогию, принцип, предложенный автором, назовем принципом относительности или принципом эквивалентности виртуальной и истинной реальности.

\subsection{6. Системы с дистанционным телекинетическим интерфейсом}

В 1981 году Л.А. Бакурадзе и Е.В. Луценко были офрормлены заявки на изобретение компьютерной системы, выполняющей все трудовые фрункции фризического тела, 
обеспечивающую управление с использованием дистанционного мысленного воздействия, т.е. микротелекинеза.

Телекинез представляет собой управление фризическими объектами путем воздействия на них непосредственно с высших планов без использования физического тела, т.е. тем же способом, с помощью которого любой человек, осознает он это или нет, управляет своим фризическим телом. К подобным системам могут быть отнесены системы с жестовым управлением (рисунок 4.6).

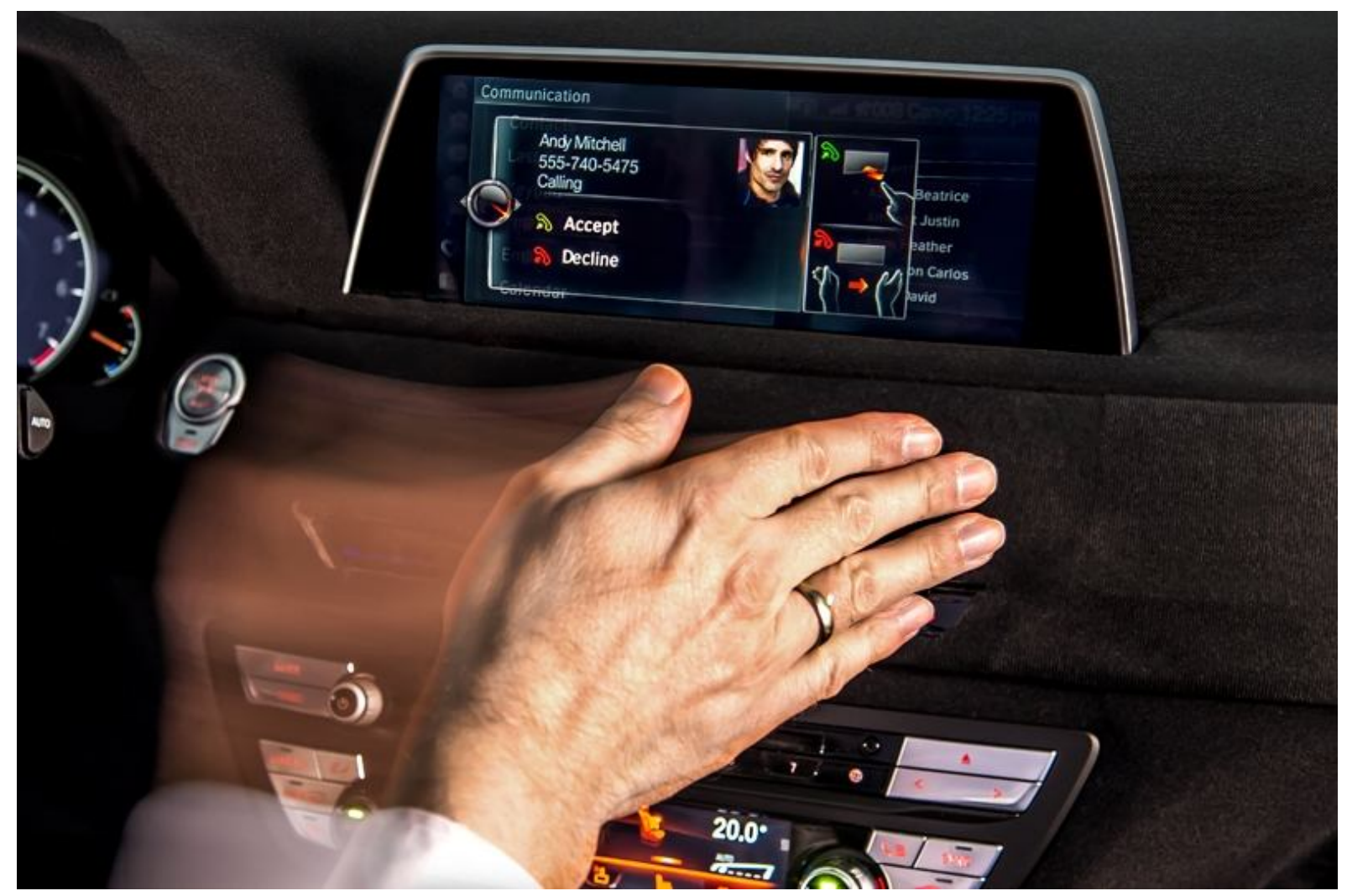

Рисунок 4.6 - Жестовое управление бортовой навигационной системой на автомобиле BMW

К настоящему времени предложены различные технические и программные решения и инженернопсихологические методики. Системы являются адаптивными, т.е. автоматически настраиваются на индивидуальные 
особенности, "почерк" оператора и его состояние сознания, c плавным переключением на дистанционные каналы при повышении их надежности (которая измерялась автоматически) и могла одновременно с выполнением основной работы выступать в качестве тренажера для овладения высшими формами сознания.

Человек, начиная работу с системой в обычной форме сознания с использованием традиционных каналов (интерфейса), имея мгновенную адекватную по форме и содержанию обратную связь об эфрфективности своего телекинетического воздействия, должен быстро переходить в одну из высших фрорм сознания, оптимальную для использования телекинеза в качестве управляющего воздействия.

\section{2. ПОСТРОЕНИЕ СЛОЖНЫХ ПРЕДМЕТНО- ОРИЕНТИРОВАННЫХ ИНТЕЛЛЕКТУАЛЬНЫХ СИСТЕМ НА ОСНОВЕ ЕСТЕСТВЕННО-ЯЗЫКОВОГО ИНТЕРФЕЙСА}

\section{Естественно-языковой интерфейс (ЕЯИ) -}

разновидность пользовательского интерфейса, который принимает запросы на естественном языке, а также, возможно, использует ЕЯ и для вывода информации (реакции системы на запрос пользователя).

На рисунке 4.7 приведены основные составляющие ЕЯинтерфейса и взаимосвязи между ними. 


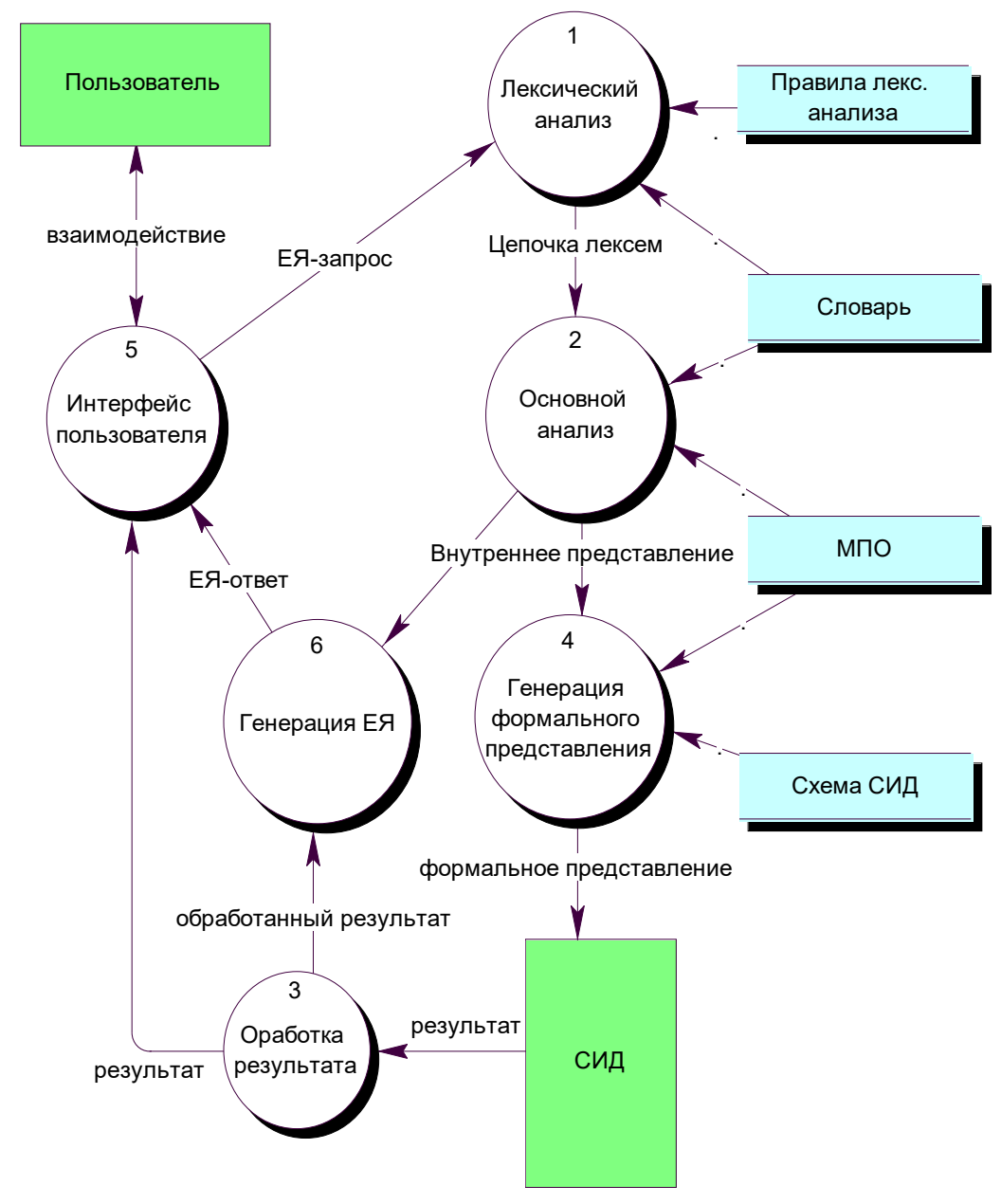

\section{Рисунок 4.7 - Основные составляющие ЕЯ-интерфейсов и} их взаимосвязи

\subsection{1. Сравнительный анализ ЕЯ-интерфейсов и традиционных интерфейсов к структурированным источникам данных \\ В противоположность ЕЯ-интерфейсам, нетрадиционным} с точки зрения распространенности, существуют другие виды пользовательских интерфейсов к структурированным источникам данных (СИД), которые можно назвать традиционными. Среди них:

- интерфейсы с формальным языком запросов

- интерфейсы с графрическим построением запросов 
- интерфейсы, основанные на заполнении форм запросов

Предполагается, что рассматриваемые здесь виды интерфейсов по своему предназначению ограничены только получением информации из базы данных, это предположение сделано в силу ограничения на ЕЯ-интерфейсы областью запросов, поскольку область занесения данных и их модификации с помощью естественно-языковых оболочек является отдельной большой темой для рассмотрения.

В интерфейсах С фрормальным языком запросов пользователь, для того, чтобы правильно задать запрос, должен, во-первых, знать синтаксис языка запросов (например, SQL), а во-вторых, представлять устройство конкретного структурированного источника данных (например, реляционную схему базы данных). При работе с этим типом интерфейсов пользователь должен обладать достаточно высокой квалификацией. Опыт показывает, что такой необходимой квалификацией обладают лишь специалисты, проектирующие и создающие информационные системы, и сам термин "пользователь" с учетом современных тенденций здесь не совсем адекватен. Очевидно, ЕЯ-интерфейсы обладают большей гибкостью - один и тот же запрос обычно можно формулировать различными способами. Что немаловажно, ЕЯинтерфейсы, как правило, обладают системой понятий описанием предметной области, которая находится выше логического уровня хранения данных. Это позволяет абстрагироваться от деталей устройства той или иной базы данных, как на уровне структуры, так и на уровне содержимого. 
Средства графического построения запросов, которыми снабжаются многие "настольные" СУБД (например, MS Access, MS FoxPro), безусловно, обладают большим удобством - по крайней мере пользователь не должен держать в голове названия таблиц, полей и конструкции языка. Однако для работы с такими средствами необходим опыт и представление некоторых понятий, относящихся скорее к математике (например, термин связывания таблиц в реляционной алгебре), а не к предметной области, и иногда достаточно утомительные действия по заполнению форм. Так, в базе данных Microsoft Access для того, чтобы сформулировать выражение AVG(PERSONNEL.SALARY), эквивалентный ЕЯ-фразе "средняя зарплата", требуется около 15 нажатий мышью. Неподготовленный пользователь обычно пасует перед системами, требующими сложных действий. Как и в случае интерфейсов с формальным языком, пользователь должен представлять устройство базы данных. По сути, эти средства позволяют графически создавать формальные запросы, и не случайно они обычно позволяют редактировать пользователям полученный формальный запрос.

Интерфейсы, основанные на заполнении фрорм запросов, являются более дружественными, по сравнению с формальными языками. Сама метафора формы и ее заполнения подразумевает, что пользователь сразу видит набор критериев и параметров поиска, а иногда и список возможных значений полей формы, это сводит к минимуму ошибки при вводе запроса. От предыдущего метода построения пользовательских интерфейсов данный отличается тем, что как правило, все необходимые запросы уже написаны 
разработчиком интерфейса, и пользователь, чтобы получить ответ, должен просто вставить недостающие значения. Отличие заключается также в том, что задавая значения формы, пользователь обычно не выбирает, какие атрибуты данного класса объектов будут в результате, а сам список доступных классов (в реляционной базе - таблиц) ограничен множеством построенных форм. Так работают многие современные коммерческие приложения, работающие с базами данных пользователю информация в системе доступна в виде нескольких типовых "срезов" информационного пространства. К недостатку систем, основанных на таком подходе, как и в предыдущем, также следует отнести необходимость наличия у пользователя опыта работы с подобными системами, а также необходимость создания форм, что требует дополнительных усилий программиста для создания интерфейса.

Преимущества ЕЯ-интерфейсов достаточно очевидны:

- Минимальная предварительная подготовка пользователя. Естественный язык является наиболее привычным и удобным средством коммуникации, и именно в силу этого с ростом эффрективности ЕЯсистем, он, безусловно, будет вытеснять другие виды интерфейсов к СИД, традиционные в данный момент.

- Простота задания запросов на ЕЯ. Во многих случаях запрос на ЕЯ получается гораздо короче языка на фрормальном языке, поскольку ЕЯ-представление более емко, ведь в самой структуре языка содержится понятийная база, которую отражает структура источника данных. Зачастую сложность этой 
структуры отражается на сложности запроса на формальном языке.

- Большая скорость создания произвольного запроса (отсутствует стадия формального задания запроса). Как правило, пользователь сразу может сорормулировать корректное ЕЯ-представление запроса, поскольку такое представление является самым естественным для человека, тогда как построение запроса на формальном языке, даже с помощью вспомогательных средств, таит множество ошибок, зачастую исправить которые можно, только проанализировав результат запроса.

- Более высокий уровень модели предметной области. Традиционные интерфейсы обычно не обладают моделью предметной области как таковой, и в лучшем случае скрывают от пользователя искусственные средства и особенности структуры, присущие конкретному типу СИД (такие, как связи по идентификаторам между таблицами в реляционных базах данных или синтаксис XML).

Более подробно рассмотрим недостатки ЕЯ-интерфейса по сравнению с другими типами интерфейсов.

- Неоднозначность естественного языка приводит к множественности смыслов. Специфика естественного языка такова, что часто запрос может иметь несколько смыслов, о которых пользователь в момент задания запроса не предполагает. Формальные же языки лишены проблемы неоднозначности. Это свойство ЕЯ приводит к усложнению ЕЯ-интерфейсов и методов 
анализа, в противном случае ЕЯ-интерфейс получается слишком примитивным для реального использования.

- Недостаточная надежность анализаторов ЕЯзапросов может привести к неправильному пониманию. Современные ЕЯ-интерфейсы далеко не всегда позволяют диагностировать причины неудач понимания. Причины этих неудач могут быть как в лингвистической сорере, так и в концептуальной. Например, запрос к кадровой базе данных "Кто получает больше Иванова" может привести к непониманию, если ЕЯ-интерфейс не умеет распознавать вложенные запросы (а в данном случае надо сначала получить значение зарплаты Иванова, а затем сравнить с ней зарплату сотрудников). Это случай лингвистической проблемы. Второй пример "Как зовут жен сотрудников?" может привести к неудаче понимания, если ЕЯ-интерфейс не поймет, что имя супруга/супруги - это реальный атрибут сотрудника, но отсутствующий в данной базе данных. В данном случае налицо будет концептуальная проблема - ЕЯ-интерфейс должен уметь отличать реальную предметную область, которую имеет в виду пользователь, задавая ЕЯ-запрос, от той ее части или трансформации, которая представлена в данном источнике данных.

- Пользователь может иметь завышенные или заниженные ожидания от ЕЯ-интерфейса. Сравнительный анализ типов пользовательских 
интерфейсов (основанных на фрормах, с фрормальным языком запросов, графические) показывает, что в целях построения ЕЯ-интерфейсов превалирует желание максимально приблизить интерфейс к потребностям неподготовленного пользователя. Это несколько поднимает планку требований к дружественности и надежности ЕЯ-интерфейсов, поскольку пользователь, впервые столкнувшись с системой, понимающей естественный язык, слабо представляет, насколько интеллектуальна система. При этом ожидания к степени понимания ЕЯ может отличаться от реальных способностей системы в обе стороны - т.е. пользователь может спрашивать систему о том, чего она "не знает", а может "по привычке" использовать простейшие шаблонные фрормулировки запросов. В других же типах интерфейсов к СИД рамки того, что пользователь может делать с помощью интерфейса, видны, как правило, сразу.

Поскольку характеристики ЕЯ-интерфейсов и систем для их построения могут существенно различаться, то преимущества и недостатки ЕЯ-интерфейсов по сравнению с другими типами интерфейсов к СИД можно выделить довольно схематично, только на качественном уровне. Для сравнения подходов к построению ЕЯ-интерфейсов введем метрику показателей, характеризующих качество ЕЯ-интерфейсов к структурированным источникам данных. 


\subsection{2. Критерии качества ЕЯ-интерфейсов}

Для сравнительного анализа подходов к созданию ЕЯинтерфейсов рассмотрим такую качественную интегральную характеристику, как надежность. Под надежностью здесь понимается способность ЕЯ-интерфейса правильно понимать намерения пользователя по получению информации из источника, при условии, что пользователь корректно выразил потребности в виде ЕЯ-запроса. Надежность отражает правильность принципов, лежащих в методе ЕЯ-анализа, а также правильность (корректность) построения ЕЯ-интерфейса к конкретному СИД.

Любой ЕЯ-интерфейс имеет некоторое пространство правильно понимаемых запросов. Чем больше это пространство, тем большей полнотой обладает ЕЯ-интерфейс. Полнота - характеристика, тесно связанная с гибкостью интерфейса. Поскольку пространство ЕЯ-запросов весьма неоднородно, следует говорить о различных типах запросов, т.е. групп запросов, имеющих сходное строение. Гибкость показатель того, насколько разнообразные типы запросов может понимать ЕЯ-интерфейс. Речь в основном идет о так называемых "трудных" типах запросов, в числе которых вложенные, эллипсис, анафорические.

Другой важной характеристикой является дружественность интерфейса, которую можно определить как меру того, насколько ЕЯ-интерфейс удобен в работе, насколько корректно он может сообщать о проблемах понимания, может ли он помогать в переформулировке неберущихся запросов и т.д. 


\subsection{3. Критерии стоимости построения и сопровождения ЕЯ- интерфейса}

Вышеперечисленные характеристики входят в оценки качества ЕЯ-интерфейса. Важным критерием при сравнении ЕЯ-интерфейсов является также трудоемкость его создания, то есть необходимое количество усилий (времени), требуемых для его построения. Ранние ЕЯ-интерфейсы создавались для каждой базы данных отдельно, и, разумеется, их стоимость была очень большой. Все эти системы были экспериментальными. Усугубляло проблему также то, что до конца 70-х годов не было единого универсального формального языка запросов к базам данных. Ранние системы понимания ЕЯ-запросов к СУБД были непортируемыми на другие базы данных, и зачастую лингвистическое ядро не отделялось от предметно-ориентированных настроек.

Современные промышленные системы построения ЕЯинтерфейсов [8] обладают достаточно высокой степенью портируемости, что, безусловно, снижает стоимость построения ЕЯ-интерфейса. Лингвистическое ядро является универсальным элементом, словарь содержит универсальную лексику, используемую во многих ЕЯ-интерфейсах, модели предметной области могут содержать шаблоны, общие для нескольких предметных областей и т.д. Зачастую используется метафора "фрабрики и изделия", изделием выступает ЕЯинтерфейс, который собирается из готовых компонентов, которые настраиваются под конкретную базу данных.

Следует отметить, однако, что вопрос портирования на другие языки является открытым. Подавляющее большинство исследований проведено для английского языка, некоторые 
особенности которого изначально заложили в пути исследований мину замедленного действия - первоначально огромное количество усилий были потрачены на анализ синтаксиса. Сейчас можно сказать, что эти усилия не оправдали себя [41].

На трудоемкость создания ЕЯ-интерфейса влияет также необходимая квалификация настройщика ЕЯ-интерфейса. Для систем, требующих навыков лингвиста, трудоемкость построения ЕЯ-интерфейса больше, чем для систем, где для построения интерфейса требуется просто описать предметную область по некоторым предопределенным шаблонам и отобразить ее на схему базы данных, и дело здесь не только в стоимости труда лингвиста и инженера знаний или специалиста в области баз данных. Системы, требующие подстроек на уровне лингвистического ядра, являются более гибкими, поскольку позволяют разрешать проблемы понимания ЕЯзапросов написанием соответствующих "заплаток", однако работы по написанию таких "заплаток" являются настолько сложными, требуют такого уровня понимания принципов машинного анализа ЕЯ в целом, что настройка ЕЯ-интерфейса на уровне лингвистического процессора зачастую возможна только авторами системы построения ЕЯ-интерфейса. Впрочем, сложность подстройки ядра очень сильно зависит от принципов анализа, используемого при написании инструментария, открытости ядра и т.д. 


\subsection{4. Вопросы портируемости}

Коснемся теперь характеристики, присущей системам построения ЕЯ-интерфейсов - портируемость компонентов анализа. Существует несколько видов портируемости:

1. на другую предметную область,

2. на другой язык,

3. на другую СУБД,

4. на другие платформы и языки программирования.

Портируемость на другую предметную область (ПО). Обычно, если ЕЯ-интерфейс портируется на другую ПО, систему необходимо "научить" словам и концептам, используемым в новой предметной области. Также надо отобразить модель ПО (МПО) и модель БД (МБД). Портируемость на другую предметную область может проводиться различными специалистами, и механизмы портирования могут быть ориентированы на:

- программиста: в некоторых системах часть кода (обычно небольшая и четко определенная) должна быть переписана;

- инженера знаний: конфигурация системы без программирования, построением схем предметной области и/или введением и описанием новых концептов По;

- администратора СУБД: БД-центрическое описание предметной области, например, описание некоторых важных для ПО ЕЯИ характеристик для каждой таблицы и поля БД; 
- конечного пользователя: в предположении, что настройка ЕЯИ - постоянный процесс, ЕЯ снабжается средствами для настройки методом введения определений концептов на уровне ЕЯ и другими пригодными для конечного пользователя методами.

Портируемость на другой естественный язык. Подавляющее большинство ЕЯ-интерфейсов к БД были разработаны для английского языка. Переориентация ЕЯинтерфейса на другой язык является для большинства систем большой проблемой, вследствие активного использования законов языка на уровне морфологии, синтаксиса, существенно отличающихся от языка к языку. Иногда настройка на язык возможна переписыванием синтаксических и семантических правил, а также новым наполнением словаря. В описываемой работе переносимость на другой язык является достаточно высокой, что обусловлено использованием преимущественно семантической информации при анализе.

Портируемость на другую СУБД. Система является портируемой на другую СУБД, если она позволяет перенос ЕЯинтерфейса на другую СУБД. В случае, если ЕЯ-интерфейс генерирует запросы в распространенном языке (например, SQL), он может быть легко портирован на другую СУБД, если она поддерживает этот язык. Если язык запросов ЕЯинтерфейса не поддерживается новой СУБД, ЕЯ-интерфейс может быть портирован переписыванием компонента генерации формального языка, однако это справедливо только для систем, в архитектуру которых включен промежуточный уровень запроса. В противном случае для портирования необходимо существенно переписать ЕЯ-интерфейс. 
Портируемость на другую платорорму. Некоторые ЕЯинтерфейсы могли исполняться только на дорогих исследовательских машинах, используемых экзотические языки программирования (например, Lisp-машины), что делает их практически неприменимыми в реальных приложениях. Появление недорогих мощных компьютеров и повсеместная доступность языков, ориентированных на приложения искусственного интеллекта, как Lisp, Prolog, OCAML и Haskell, делают доступными ЕЯ-bynthatqcs, написанными на этих языках.

\subsection{5. Основные составные части ЕЯ-интерфейсов}

Кратко рассмотрим основные части ЕЯ-интерфейсов и их взаимосвязи. Прежде всего следует выделить из интерфейса анализатор ЕЯ как компонент, реализующий тот или иной метод анализа естественного языка, и от принципов построения которого зависит архитектура системы и основные характеристики интерфейсов на основе данного компонента.

Работа анализатора заключается в построении внутреннего представления входного ЕЯ-текста либо запроса, обычно в виде некоторой структуры, например, синтаксического дерева, семантической сети, фрреймовой структуры и т.д. Предшествующим этапом для процесса анализа является лексический анализ (пред-анализ), который преобразует входной текст как последовательность символов, в цепочку лексем, поступающей на вход анализатора.

Необходимым компонентом работы анализатора является словарь, который содержит слова и фрразы, обычно с привязкой к ним определенной информации, связанной с семантикой, 
морфологией и т.д., в зависимости от подхода анализа ЕЯ. Еще одним важным компонентом многих систем является модель предметной области, структура которой варьируется в очень больших пределах от системы к системе.

Для построения запроса на фрормальном языке источника данных используется модель источника данных, отражающая основную структуру СИД, ее части, существенные для данного ЕЯ-интерфейса.

Для перевода запроса из внутреннего представления системы в формальный язык источника данных предназначен процесс генерации фоормального запроса. Некоторые системы имеют также модуль синтеза ЕЯ, который может применяться для генерации естественно-языкового представления запроса, например, для верификации понимания запроса системой, а также для генерации уточняющих вопросов [8].

Модель предметной области в некоторых системах дополняется базой знаний со средствами вывода новых знаний.

\section{4. СОЗДАНИЕ И ВНЕДРЕНИЕ ТЕХНИЧЕСКИХ И ЭКОНОМИЧЕСКИХ ПРОЕКТОВ ПРИ ПОМОЩИ СОВРЕМЕННЫХ ИНТЕЛЛЕКТУАЛЬНЫХ СИСТЕМ}

\subsection{1. Принципы и методы создания интеллектуальных информационных систем}

Проектирование ИС - процесс создания и внедрения проектов комплексного решения экономических задач по новой технологии. Сюда включается: детальная разработка отдельных проектных решений, их анализ, апробация и внедрение.

Качественное проектирование и внедрение являются основной предпосылкой эфффективного фрункционирования 
системы при постоянном совершенствовании ее обеспечивающих и функциональных составляющих.

Цель всех этих работ состоит не только в компьютеризации информационных потоков, но и в совершенствовании самого управления и организации основной деятельности экономического объекта. Поэтому первый руководитель должен иметь представление об имеющихся на рынке технических и программных средствах, тенденциях в их развитии, основных принципах проектирования ИС. В каждом подразделении организации должен быть назначен сотрудник, ответственный за проектирование и внедрение ИС, который собирает нужную информацию, подбирает технику и программные средства, ведет обучение персонала, руководит внедрением и анализом функционирования информационных систем.

Современные предприятия относятся к классу больших динамических систем с характерной многопрофрильной деятельностью и большим числом кооперативных связей с партнерами. При этом возрастает динамичность бизнеспроцессов, связанных с изменяющимися потребностями и сильной конкуренцией. Управление бизнес-процессами предполагает рассмотрение всех материальных, фринансовых, трудовых и информационных потоков с системных позиций, т.е. во взаимодействии. Достижения в области ИС и ИТ дают возможность проведения инжиниринга и реинжиниринга бизнес-прочессов.

Реинжиниринг бизнес-процессов - это создание новых, более эфрфективных бизнес-процессов без учета предшествующего развития (все начинается заново, 
подвергается сомнению, проявляется творческое начало во всех действиях). Реинжиниринг выдвигает на первый план новые цели и методы, способствующие: глобализации бизнеса (работа с клиентом в режиме «24 ч. 365 дней» в любой точке мирового пространства); снижению затрат и численности персонала; ускоренному продвижению новых технологий; росту мобильности персонала и ориентации деятельности на будущие потребности клиентуры; росту качества продукции и услуг.

Технология реинжиниринга основана на том, что в процессе управления пользователь активно использует современные информационные технологии для обучения, стратегического и тактического планирования, анализа возможных путей перестройки и улучшения бизнес-процессов, управления изменениями, реализацию проектов и др.

Инжинирине бизнес-процессов включает в себя реинжиниринг бизнес-процессов, проводимый с определенной периодичностью, например, один раз в 5 лет, и последующее непрерывное улучшение.

Обратный инжиниринट предполагает исследование функционирующих на предприятии бизнес-процессов. Цель этапа заключается в проведении диагностики «узких мест» в организации существующих бизнес-процессов и формулировании направлений их реорганизации.

На этапе обратного инжиниринга постановка задач реорганизации бизнес-процессов (РБП) уточняется, сорормулированные на этапе идентификации бизнес-процессов в общем виде цели РБП могут быть скорректированы по 
результатам исследования существующей системы организации бизнес-процессов.

Для оценки эфффективности существующих бизнеспроцессов используются прежде всего методы и средства для выявления:

- наиболее трудоемких и затратных функций;

- функций, не вносящих вклад в образование прибыли;

- функций с низким коэффициентом использования ресурсов.

Массовое проектирование ИС базируется на использовании нормативно-правовой базы (федеральных законах, ГОСТах и пр.) и семи основополагающих принципах:

1. Принцип эфрфективности заключается в том, что выгоды от новой автоматизированной системы должны быть равными или больше расходов на нее.

2. Принцип контроля требует, чтобы информационная система обладала механизмами для защиты имущества фирмы, ее данные были бы достаточно надежны для принятия управленческих решений.

4. Принцип совместимости предполагает, что проект системы будет учитывать организационные и человеческие факторы предприятия. Иными словами, система должна учитывать организационную структуру предприятия, а также интересы, квалификацию и отношение людей, выполняющих различные функции.

4. Принцип гибкости требует от системы возможности расширения без проведения больших изменений. Например, в новую автоматизированную систему учета можно легко ввести 
новые счета в план счетов, если он изменился, новые хозяйственные операции и др.

5. Принципы системности позволяют исследовать объект как единое целое во взаимосвязи всех его элементов. На базе системного подхода применяется и метод моделирования, позволяющий моделировать изучаемые процессы вначале для анализа, а затем и синтеза создаваемых систем.

6. Принцип развития заключается в непрерывном обновлении функциональных и обеспечивающих составляющих системы.

7. Принцип стандартизации и унификации предполагает использование уже накопленного опыта в проектировании и внедрении ИС посредством программирования типовых элементов, что позволяет сократить затраты на создание ИС. Под унификацией понимается реализация при разработке программ принципа единообразия в методах, средствах, содержании и формах представления информации. Под стандартизацией понимается обязательное соблюдение при разработке проектных решений, утвержденных гос. стандартом образцов форм представления и описания элементов проекта ИC.

К известным методикам и стандартам, касающимся организации жизненного цикла ИС, можно отнести: методику Oracle CDM (Custom Development Method) по разработке прикладных ИС под заказ; международный стандарт ISO/IEC 12207 по организации жизненного цикла продуктов программного обеспечения; отечественный стандарт ГОСТ 34.003-90.

Методы проектирования ИС, т.е. способы создания ИС: 
- индивидуальный (оригинальный);

- типовое проектирование;

- автоматизированный проект (САПР).

1. Индивидуальное проектирование характеризуется тем, что все виды работ для различных объектов выполняются по индивидуальным проектам. В процессе индивидуального проектирования применяются свои оригинальные методики и средства проведения работ. Состав работ на всех этапах обследования, проектирования и внедрения создаются для конкретного объекта по мере необходимости. Для этого метода проектирования характерны высокая трудоемкость, большие сроки проектирования, плохая модернизируемость, слабое сопровождение.

2. Типовое проектирование - разбиение системы на множество составных компонентов и создание для каждого из них законченного проектного решения, которое при внедрении привязывается к конкретным условиям объекта. В зависимости от декомпозиции различают: 1) элементное проектирование, 2) подсистемное и 3) объектное.

При элементном методе проектирования, вся система разбивается на конечное множество элементов, каждый из которых является типовым. В качестве элементов могут выступать проектные решения по инфрормационному, техническому, программному видам обеспечения.

Подсистемный метод проектирования характеризуется более высокой степенью интеграции элементов ИС. Декомпозиция системы осуществляется на уровне функциональных подсистем, иногда комплекса задач, каждая 
из выделенных подсистем представляется в законченном виде ППП.

Объектное проектирование - декомпозиция ИС не производится. Типовой объект создается в целом для некоторого обобщенного объекта, определенной группы.

В последнее время все большее число организаций, предприятий, фирм предпочитает покупать готовые пакеты и технологии, а если необходимо, добавлять к ним свое программное обеспечение, так как разработка собственных ИС и ИТ связана с высокими затратами и риском.

Рассмотрим первый из путей, т.е. возможности использования типовых проектных решений (ТПР), включенных в пакеты прикладных программ (ППП). Наиболее эффективно информатизации поддаются следующие виды деятельности: бухгалтерский учет, включая управленческий и финансовый; справочное и информационное обслуживание экономической деятельности; организация труда руководителя; автоматизация документоо6орота; экономическая и финансовая деятельность, обучение.

Наибольшее число ППП создано для бухгалтерского учета: «1С: бухгалтерия», «Турбо-Бухгалтер», «ИнфоБухгалтер», «Парус», «ABACUS», «Бэмби+» и др.

Справочное и информационное обеспечение управленческой деятельности представлено следующими ППП: «ГАРАНТ» (налоги, бухучет, аудит, предпринимательство, банковское дело, валютное регулирование, таможенный контроль); «КОНСУЛЬТАНТ+» (налоги, бухучет, аудит, предпринимательство, банковское дело, валютное регулирование, таможенный контроль). 
Экономическая и фринансовая деятельность представлена следующими ППП: А) «Экономический анализ и прогноз деятельности фрирмы, организации» (фирма «ИНЕК»), реализующий фрункции: экономический анализ деятельности фрирмы, предприятия; составление бизнес-планов; техникоэкономическое обоснование возврата кредитов; анализ и отбор вариантов деятельности; прогноз баланса, потоков денежных средств и готовой продукции. Б) Многопользовательский сетевой комплекс полной автоматизации корпорации «Галактика» (АО «Новый атлант»), который включает такие важные аспекты управления, как планирование, оперативное управление, учет и контроль, анализ, а для принятия решений позволяет в рамках СППР обеспечивать решение задач бизнеспланирования с использованием ППП Project-Expert.

В основе типового проектирования лежит первоначальная классификация или типизация экономических объектов по их важнейшим параметрам. Затем создаются типовые схемы их решения, внедрение которых в дальнейшем на конкретном предприятии сводится к привязке их в условиях данного предприятия. Декомпозиция функциональных компонентов ИС является основой технологии типового проектирования. Типовое проектирование предполагает разбиение ИС на отдельные составляющие и создание для каждого из них законченного проектного решения, которое затем с некоторыми модификациями будет использоваться при проектировании ИС.

ТПР в области ИС представляет комплект технической документации, содержащей проектное решение по части объекта проектирования и предназначенные для многократного использования в процессе разработки, внедрения и 
функционирования ИС с целью уменьшения трудоёмкости и разработки, затрат на создание ИС.

4. Сущность технологии автоматизированного проектирования. В области автоматизации проектирования ИС в последние годы сформировалось новое направление CASE-технологии (Computer Aided System / Software Engineering). Это совокупность методов анализа, проектирования, разработки и сопровождения ИС с максимальной автоматизацией процессов разработки и функционирования систем. Организационно CASE-индустрия включает компании 3 типов:

- разработчиков средств анализа и проектирования;

- разработчиков специальных средств с ориентацией на узкие предметные области;

- обучающие, информирующие и консалтинговые фрирмы, оказывающие соответствующие услуги при использовании CASE-пакетов.

Компании, предоставляющие такие услуги, получили название системных интеграторов. Следует отметить, что этот термин имеет два понятия. Согласно первому, под термином «системный интегратор» понимаются как компании, специализирующиеся на сетевых и телекоммуникационных решениях (сетевые интеграторы), имеющие в свою очередь, сеть своих продавцов, так и компании - программные интеграторы. Существует и другая трактовка понятия «системный интегратор», которая закрепляет за компанией комплексное решение задач заказчика при проектировании ИС. При этом имеется в виду, что заказчик полностью доверяет детальную проработку и реализацию проекта системному 
интегратору, оставляя за собой лишь определение исходных данных и задач, которые должна решать реализуемая ИС.

Фирмы-интеграторы создают, как правило, дилерскую сеть представительств в ряде городов России и в странах СНГ. При этом компании осуществляют техническую и информационную поддержку своих дилеров, проводя совместные семинары и презентации, регулярно рассылая им информационнорекламные материалы о новых продуктах и перспективных технологиях, осуществляют совместное участие в крупных региональных проектах.

Другим вариантом организации системной интеграции является выполнение проектов от консалтинга до создания прикладной системы, т.е. заказчику сдается готовая к эксплуатации информационная система «под ключ» и допускается привлечение организаций и квалифицированных специалистов в качестве партнеров для реализации.

CASE-технологии проектирования ИС ориентируются на архитектуру готовых программных изделий. Это обусловлено необходимостью быстрее создавать и внедрять ИС при меньших затратах; обеспечить единый простой интерфейс; сократить усилия на обслуживание существующих приложений при их адаптации к постоянным изменениям в программнотехнической среде. CASE-технология включает вопросы определения требований к системе и создание проекта на глобальном уровне, так чтобы он наиболее полно отвечал требованиям с учетом заданных экономических и технологических ограничений. CASE-технология содержит средства поддержки всех основных этапах проектирования и внедрения ИС, при этом на этапе анализа целей создания 
системы обычно используется концепция диаграмм потоков данных. Причем особенно уделяется внимание связям между данными. В результате между входными и выходными данными устанавливаются парные связи. CASE-технология обеспечивает: последовательную декомпозицию сложной задачи на более простые компоненты; уменьшение времени и стоимости создания системы по сравнению с неавтоматизированными технологиями; контроль за взаимосвязями и полнотой представления отдельных компонент проекта; одновременное внесение нескольких изменений в проект.

Ядром системы является база данных проекта репозиторий (словарь данных). Он представляет собой специализированную базу данных, предназначенную для отображения состояния проектируемой ЭИС в каждый момент времени.

Репозиторий содержит информацию об объектах проектируемой ЭИС и взаимосвязях между ними, все подсистемы обмениваются данными с ним. В репозитории хранятся описания следующих объектов:

- проектировщиков и их прав доступа к различным компонентам системы;

- организационных структур;

- диаграмм и пр.

Преимущества CASE-технологии по сравнению с традиционной технологией оригинального проектирования сводятся к следующему: 
- улучшение качества разрабатываемого программного приложения за счет средств автоматического контроля и генерации;

- возможность повторного использования компонентов разработки;

- поддержание адаптивности и сопровождения ЭИС;

- снижение времени создания системы, что позволяет на ранних стадиях проектирования получить прототип будущей системы и оценить его;

- освобождение разработчиков от рутинной работы по документированию проекта, так как при этом используется встроенный документатор;

- возможность коллективной разработки ЭИС в режиме реального времени.

\subsection{2. Этапы создания информационных систем}

Выделяются несколько этапов создания ИС:

1. Предпроектная стадия:

1.1. Обследование объекта и обоснование необходимости создания ИС;

1.2. Формирование требований пользователя к ИС;

1.3. Офрормление отчета о выполненной работе и заявки на разработку ИС;

1.4. Разработка и утверждение технического задания ИС.

2. Проектная часть:

2.1. Разработка проектных решений по системе и ее частям;

2.2. Разработка документации на ИС; 
2.3. Разработка и оформление документации на поставку изделий для комплектования ИС;

2.4. Разработка рабочей документации на систему или ее части;

2.5. Разработка или адаптация программ.

3. Стадия внедрения:

3.1. Подготовка объекта автоматизации к вводу в действие;

3.2. Подготовка персонала, проводится обучение персонала;

3.3. Строительно-монтажные работы, в том случае, если строится специализированное здание;

3.4. Проведение предварительных испытаний;

3.5. Проведение опытной эксплуатации;

3.6. Проведение опытных испытаний;

3.7. Введение в промышленную эксплуатацию.

4. Анализ функционирования:

4.1. Гарантийное и послегарантийное обслуживание;

4.2. Внесение изменений в проектные решения.

Основными участниками процесса создания ИС являются предприятие-заказчик, для которого она создается и предприятие-разработчик, выполняющий работы по проектированию ИС. Юридические и организационные взаимоотношения конкретно заказчиков и разработчиков регулируются заключенными между ними договорами.

Заказчик обязан заключить договор на создание ИС, приобрести технические средства, подготовить задание на строительство или реконструкцию помещения, если необходимо, совместно с разработчиком выполнить работы 
предпроектной стадии, в необходимые сроки подготовить помещение, приобрести и установить технические средства, разработать и осуществить мероприятия по совершенствованию организации управления и производства. На стадии проектирования необходимо обеспечить обучение персонала, обеспечить запись необходимой информации на машинные носители и ее контроль, обеспечить уточнение исходных данных по составу и структуре информационной базы, завершить ее формирование, подготовить контрольные примеры, организовать поэтапную приемку рабочих программ с проверкой на контрольных примерах. При подготовке объекта к внедрению заказчик выполняет следующие работы: внедряет локальные и общегосударственные классификаторы, унифицированные формы документов, проводит в намеченные сроки мероприятия по подготовке объекта к внедрению ИС. При вводе системы в действие заказчик завершает ввод в эксплуатацию технических средств, завершает опытную эксплуатацию комплекса задач и принимает в промышленную эксплуатацию. Разрабатывает и согласовывает с разработчиком программу приема сдаточных испытаний и организуют работу приемочной комиссии по проведению испытаний системы.

Основная цель разработчика - создание ИС. На предпроектной стадии проводит обследование объекта, обрабатывает материалы обследования, определяет задачи, комплексы задач, подлежащие автоматизации, определяет экономическую эффрективность. На стадии ТП разрабатывает документацию, в соответствии с утвержденным Т3 осуществляет методическое руководство работами по 
созданию классификаторов, внедрению унифицированных систем документации, разрабатывает структуру информационной базы, принимает участие в обучении персонала заказчика. На стадии рабочей документации осуществляет разработку программного обеспечения, генерацию рабочих программ, участвует в разработке должностных инструкций управленческого персонала, технологических инструкций пользователя. При вводе системы в действие разработчик осуществляет методическое руководство, вносит корректировки в проекты, принимает участие в сдаче задач и комплексов задач в промышленную эксплуатацию и участвует в работе комиссии по приемке системы в промышленную эксплуатацию.

\subsection{3. Реинжиниринг бизнес-процессов с помощью системы ReThink}

С интегрированным подходом к поддержке реинжиниринга на основе интеллектуальных технологий можно ознакомиться на примере одного из перспективных инструментальных средств BPR - системы ReThink, разработанной фрирмой Gensym (США). В этой системе объединены возможности ключевых современных информационных технологий: графический объектно-ориентированный язык для описания моделей и проектов, средства анимации и имитационного моделирования реконструируемых процессов, методы искусственного интеллекта для полного и адекватного представления экспертных знаний о процессах. Bce это открыло доступ к непосредственному моделированию и реконструированию бизнес-процессов новой группе 
пользователей - менеджерам. Сочетание прозрачных средств интерактивной графики с возможностями моделирования процессов в реальном времени позволяет им самостоятельно, без помощи программистов, воплощать свои идеи в виде работающих моделей процессов.

Система ReThink построена на базе инструментального комплекса G2 и является проблемно-ориентированным приложением, позволяющим разработчикам использовать не только специализированные средства моделирования бизнеспроцессов, но и универсальные средства комплекса по созданию интеллектуальных объектно-ориентированных систем управления реального времени.

Фирма Gensym, основанная в 1986 году, специализируется на создании объектно-ориентированных интеллектуальных систем, функционирующих в реальном масштабе времени и использующих средства имитационного моделирования. Основной программный продукт фрирмы - инструментальный комплекс G2, представляющий собой универсальную среду разработки приложений, функционирующих в реальном масштабе времени. Комплекс G2 нашел применение практически во всех отраслях промышленности, а также в космических приложениях (NASA), телекоммуникациях, безопасности офисов и др. Разработчики, использующие комплекс G2, отмечают такие его достоинства, как существенное сокращение сроков создания приложений по сравнению со средствами традиционного программирования; удобные средства интерактивной графики и анимации, обеспечивающие прозрачность и наглядность моделей и приложений в целом; средства вывода решений, позволяющие 
параллельно обрабатывать тысячи параметров в реальном масштабе времени; архитектура" клиент-сервер"; разнообразие аппаратно-программных платформ.

Тесная связь фрирмы Gensym с техническими университетами обеспечивает быстрое внедрение новейших достижений в области информационных технологий в коммерческие программные продукты фрирмы. На базе комплекса G2 разработан ряд проблемно-ориентированных инструментальных средств для решения задач диагностики и мониторинга процессов, решения задач составления расписаний, решения задач пространственного планирования, обучения на основе методов нейронных сетей и ряд других.

Для представления моделей бизнес-процессов используются диаграммы, состоящие из блоков и соединений. Блоки представляют задачи в бизнес-процессах, а соединения потоки сущностей: документов, информации, а также предметов, фригурирующих в бизнесе, - например, запасных частей или упаковок с отпускаемой продукцией. В системе реализован ряд стандартных блоков, которые могут быть использованы в качестве сборочных элементов для построения работающих моделей практически любых процессов, например: источник заявок, принятие решения, обработка задания. Свойства и поведение блоков могут описываться как точными, так и случайными величинами. В случае необходимости разработчик переопределяет поведение блоков или задает новые их классы с помощью встроенных базовых средств.

Объектная ориентация системы ReThink позволяет создавать понятные и довольно наглядные модели бизнеспроцессов, что упрощает освоение и использование системы 
непрограммирующими пользователями. Объекты, построенные в результате моделирования бизнес-процессов, становятся естественной основой для проектирования информационных систем поддержки этих процессов. В этом смысле средства системы ReThink могут рассматриваться как развитие CASEсредств.

ReThink поддерживает анимацию потоков работ в ходе моделирования деятельности компании. Благодаря этому менеджер имеет возможность непосредственно наблюдать функционирование моделей, что повышает степень его доверия к результатам моделирования. Данная система обеспечивает создание иерархических моделей, позволяющих описывать процессы с различной степенью детализации. Это гарантирует простоту и естественность при создании сложных моделей больших компаний (рисунок 4.8).

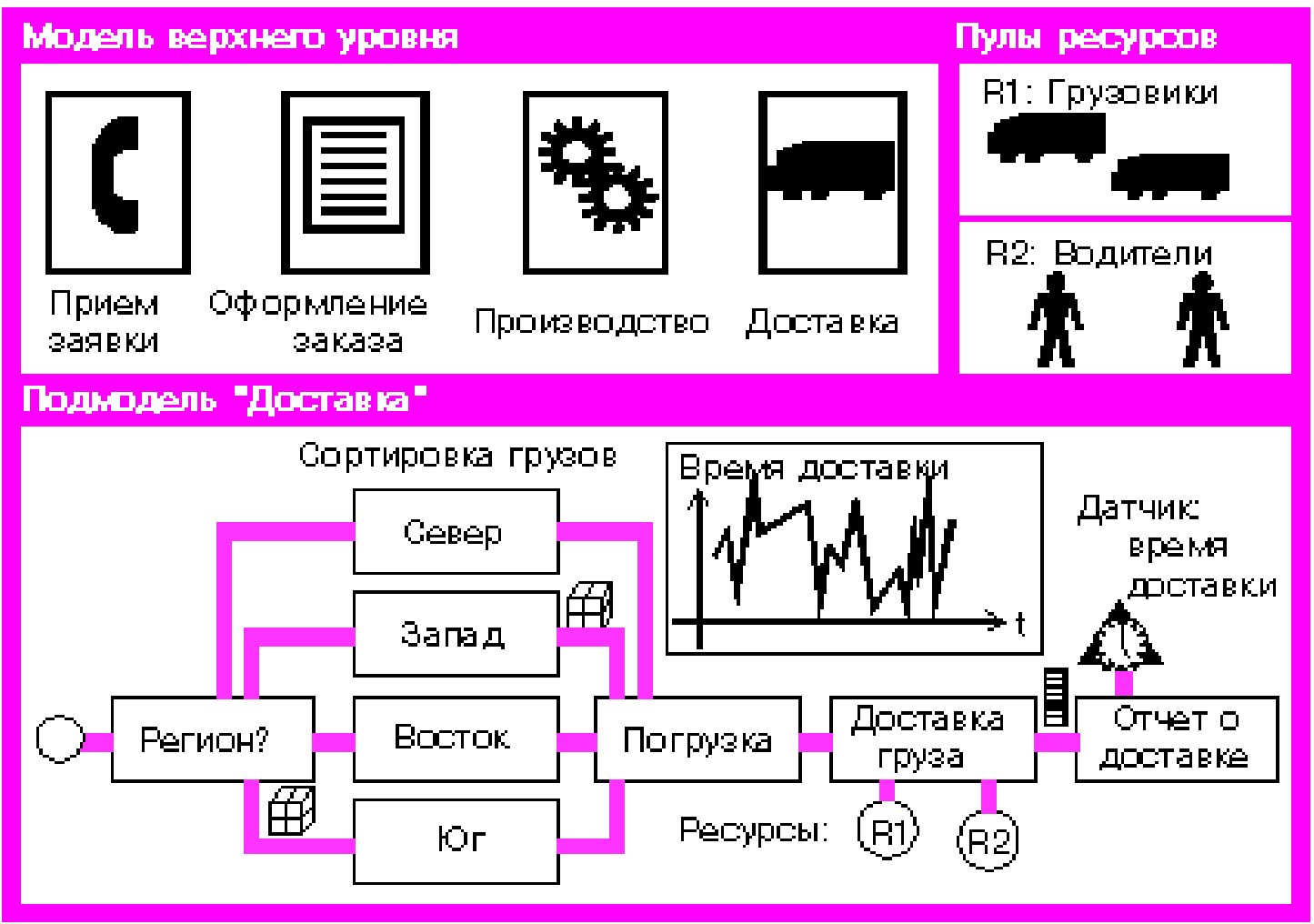

Рисунок 4.8 - Пример иерархической модели 
Все элементы моделей, включая ресурсы процессов, могут модифицироваться непосредственно во время исполнения, результаты изменений можно увидеть сразу же после их введения.

Система ReThink позволяет формировать стоимостные и временные характеристики различных проектов для их объективного сравнения, а также проверять гипотезы типа "что, если". Для анализа работы моделей предусмотрен целый набор инструментариев: блоки-датчики для сбора данных, блокиустановщики значений атрибутов сущностей, графики для наглядного отображения результатов моделирования, всевозможные просмотровые табло из стандартных средств комплекса G2. С помощью датчиков можно снимать такие показатели, как длительность цикла обработки сущности на том или ином этапе, стоимость обработки, а также другие свойства, определенные разработчиком модели. Для отсева шумов и выявления тенденций можно использовать специальные блокфильтры.

Для проверки гипотез "что, если" в системе реализован механизм сценариев. Сценарии позволяют исследовать зависимость поведения одной и той же модели от поведения внешнего мира, (например, частота поступления заявок, их сложность и т.д.), а также от каких-либо параметров этой модели (например, количества транспортных средств или численности служащих, занятых офрормлением заказов). Варьируемые параметры и измеряемые показатели выносятся на отдельное окно сценария, после чего в результате прогона модели автоматически формируется отчет. Кроме этого, система позволяет использовать сценарии для объективного 
сравнения альтернативных проектов: один и тот же сценарий, описывающий некоторое заранее заданное поведение внешнего мира, может применяться для прогона различных моделей. Результаты, вынесенные в отчет, являются основой для сопоставления и оценки этих моделей.

Основа данной системы - поддержка коллективной работы с приложениями на основе архитектуры "клиент-сервер" с помощью системы Telewindows комплекса G2. Telewindows обеспечивает множественный доступ к централизованному приложению на сервере с других рабочих станций или с ПК. Коллективная разработка и использование приложений имеет принципиальное значение при проведении глобального реинжиниринга крупной компании или их объединения в рамках отрасли.

Средства стандартных интерфейсов с внешними приложениями (GSI - G2 Standardlnterface) комплекса G2 позволяют использовать в моделях реальные данные. Это обеспечивает надежность при тестировании, а кроме того, превращает графические модели, создаваемые средствами системы ReThink, в идеальную основу для мониторинга бизнеспроцессов, управления инфрормационными потоками, непрерывного инкрементального реконструирования текущих процессов, а также поддержки принятия решений в оперативном управлении. Полученные приложения будут естественным образом стыковаться с технологическими приложениями диагностики и мониторинга производственных процессов, разработанными на базе комплекса G2.

C помощью интерфейсов GSI возможна стыковка системы ReThink с внешними приложениями. В частности, реализованы 
стандартные средства сопряжения с СУБД Oracle, Sybase, Rdb и Informix и с системами сбора данных в реальноммасштабе времени. Имеются средства сопряжения с Visual Basic. Как и инструментальный комплекс G2, система ReThink функционирует на Unix-рабочих станциях, системахOPEN VMS, а также на ПК в среде Windows.

При создании системы ReThink фрирма Gensym не ставила своей целью предложить какую-либо конкретную методологию реинжиниринга. Ее задача - создание удобного универсального средства для реализации различных методологий. Система адресована, в первую очередь, консалтинговым фрирмам и информационным подразделениям крупных компаний для воплощения их оригинальных идей в области реинжиниринга. Предоставлена возможность развития системы средствами инструментального комплекса G2 - вплоть до реализации новых нестандартных средств моделирования и анализа.

Сегодня ReThink используется в ряде компаний, среди которых патентное ведомство США и компания Xerox, осуществившая реинжиниринг отделения по закупке сопутствующих материалов с годовым оборотом в 3 млрд. долл. В компании Xerox при проведении реинжиниринга сначала использовался пакет ABC FlowCharter, а построенная модель работы отделения включала 17 процессов и 314 рабочих процедур. Анализ модели показал, что 70\% процедур оказались непроизводительными. Затем была разработана новая модель процессов закупки, включающая всего 42 рабочие процедуры. Столкнувшись с таким существенным сокращением Количества процедур, руководство компании поставило вопрос о работоспособности новой организации: не возникнут ли перед 
компанией серьезные непредвиденные проблемы после того, как она сделает основные капиталовложения в реконструкцию отделения? Чтобы обосновать предложенный проект, было решено использовать систему ReThink, с помощью которой предполагалось исследовать имитационную модель планируемой организации работы отделения. В результате несколько процессов пришлось снова перепроектировать, что привело к выигрышу в качестве проекта, а, следовательно, снизило риск неудачи при проведении реинжиниринга.

\subsection{4. Интеллектуальный анализ данных}

\section{Интеллектуальный анализ данных (ИАД) (Data Mining)} - это процесс поддержки принятия решений, основанный на поиске в данных скрытых закономерностей (шаблонов информации). При этом накопленные сведения автоматически обобщаются до информации, которая может быть охарактеризована как знания.

В общем случае процесс ИАД состоит из трёх стадий [19]:

1) выявление закономерностей (свободный поиск);

2) использование выявленных закономерностей для предсказания неизвестных значений (прогностическое моделирование);

3) анализ исключений, предназначенный для выявления и толкования аномалий в найденных закономерностях.

Иногда в явном виде выделяют промежуточную стадию проверки достоверности найденных закономерностей между их нахождением и использованием (стадия валидации).

Все методы ИАД подразделяются на две большие группы по принципу работы с исходными обучающими данными. 
В первом случае исходные данные могут храниться в явном детализированном виде и непосредственно использоваться для прогностического моделирования и/или анализа исключений; это так называемые методы рассуждений на основе анализа прецедентов. Главной проблемой этой группы методов является затрудненность их использования на больших объемах данных, хотя именно при анализе больших хранилищ данных методы ИАД приносят наибольшую пользу.

Во втором случае информация вначале извлекается из первичных данных и преобразуется в некоторые фрормальные конструкции (их вид зависит от конкретного метода). Согласно предыдущей классификации, этот этап выполняется на стадии свободного поиска, которая у методов первой группы в принципе отсутствует. Таким образом, для прогностического моделирования и анализа исключений используются результаты этой стадии, которые гораздо более компактны, чем сами массивы исходных данных. При этом полученные конструкции могут быть либо "прозрачными" (интерпретируемыми), либо "черными ящиками" (нетрактуемыми).

Оперативная аналитическая обработка u интеллектуальный анализ данных - две составные части процесса поддержки принятия решений. Но сегодня большинство систем OLAP заостряет внимание только на обеспечении доступа к многомерным данным, а большинство средств ИАД, работающих в сфере закономерностей, имеют дело с одномерными перспективами данных. Эти два вида анализа должны быть тесно объединены, то есть системы OLAP должны фокусироваться не только на доступе, но и на 
поиске закономерностей. Как заметил N. Raden, "многие компании создали прекрасные хранилища данных, идеально разложив по полочкам горы неиспользуемой информации, которая сама по себе не обеспечивает ни быстрой, ни достаточно грамотной реакции на рыночные события".

K. Parsaye вводит составной термин "OLAP Data Mining" (многомерный интеллектуальный анализ) для обозначения такого объединения (рисунок 4.9). J. Han предлагает еще более простое название - "OLAP Mining", и предлагает несколько вариантов интеграции двух технологий.

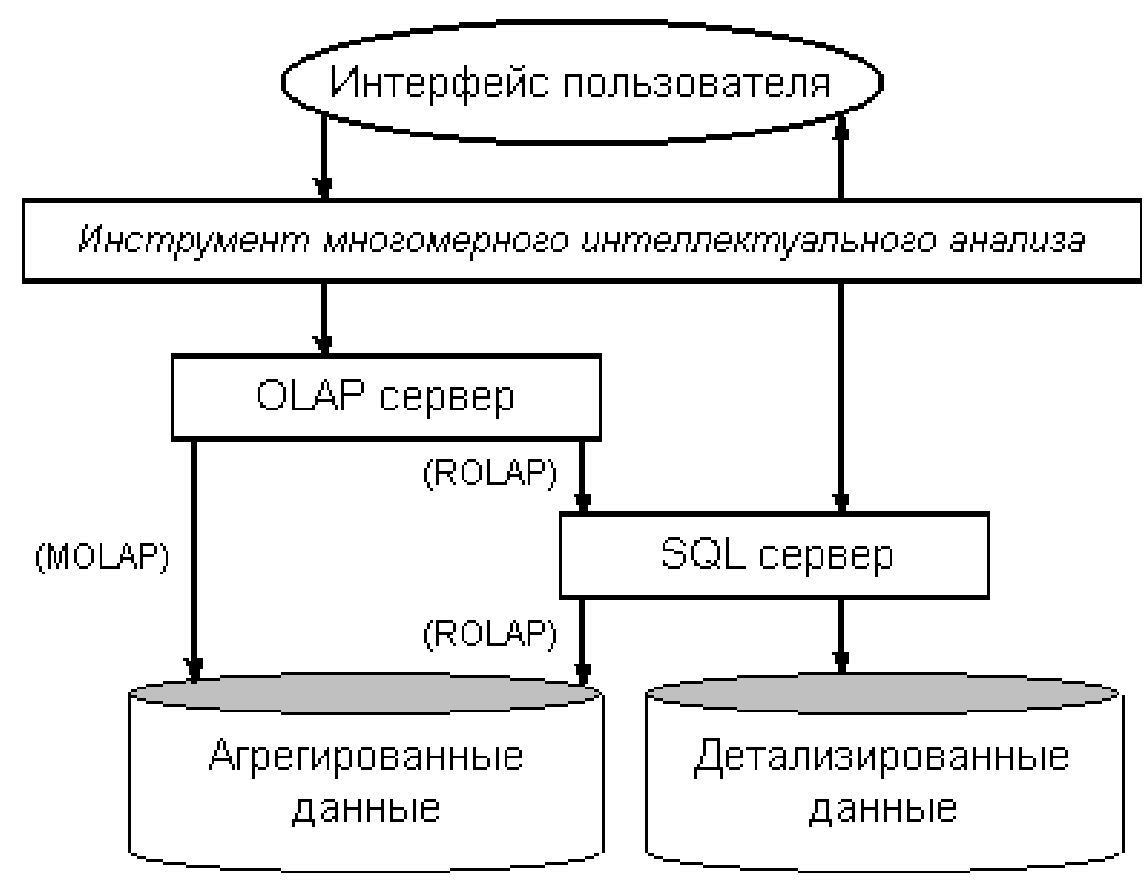

\section{Рисунок 4.9 - Архитектура системы многомерного интеллектуального анализа данных}

Целью управления решателями задач является перманентное приведение их свойств в соответствие с постоянно изменяющимися текущими требованиями, условиями 
эксплуатации, знаниями предметной области, а также возможными изменениями онтологии предметной области.

"Cubing while mining". Этот гибкий способ интеграции позволяет автоматически активизировать однотипные механизмы интеллектуальной обработки над результатом каждого шага многомерного анализа (перехода между уровнями обобщения, извлечения нового фрагмента гиперкуба и т. д.).

К сожалению, очень немногие производители предоставляют сегодня достаточно мощные средства интеллектуального анализа многомерных данных в рамках систем OLAP. Проблема также заключается в том, что некоторые методы ИАД (байесовские сети, метод к-ближайшего соседа) неприменимы для задач многомерного интеллектуального анализа, так как основаны на определении сходства детализированных примеров и не способны работать с агрегированными данными.

\section{4. РАБОТЫ С ОСНОВНЫМИ ОБЪЕКТАМИ, ПРОЦЕССАМИ И ЯВЛЕНИЯМИ, СВЯЗАННЫМИ С ИНТЕЛЛЕКТУАЛЬНЫМИ СИСТЕМАМИ И ИСПОЛЬЗОВАНИЕ МЕТОДОВ ИХ НАУЧНОГО ИССЛЕДОВАНИЯ}

В настоящее время научные исследования направлены на изучение и построение сложных, больших и слабо фрормализуемых технических, экологических, экономических, политических и социальных проблем, порождаемых процессом развития цивилизации. По мнению некоторых ученых, только использование всего потенциала знаний, накопленных человеком и создаваемых его интеллектом, позволяет успешно решать возникающие проблемы и находить пути адаптации 
человека к новым условиям его жизни при развитии цивилизации.

Интеллектуальные системы и носители интеллекта традиционно находили применение в различных системах управления, включая ручное и полуавтоматическое управление. C момента начала исследований по искусственному интеллекту понималось создание вычислительных систем, обладающих свойствами имитации творческих процессов, логических выводов, восприятие естественно-язычных запросов и команд, аккумуляции знаний в компьютере. В качестве начальных научных направлений исследований новой информационной технологии можно выделить работы по интеллектуальным информационно-поисковым системам, обеспечивающим в процессе диалога человека с компьютером пользователей непрограммистов с базами данных и знаний на профрессиональных языках пользователей близких к естественному языку.

\subsection{1. Структура систем интеллектуального управления}

Построение структуры системы интеллектуального управления связано в первую очередь с построением модели системы, в которой должны быть определены как традиционные элементы системы управления, так и модели обработки знаний, реализуемые интеллектуальной системой. В интеллектуальной системе управления новыми элементами по сравнению с традиционной системой управления являются все интеллектуальные преобразования или элементы управления знаниями, которые связаны с реализацией искусственного интеллекта, т.е. с использованием технологий экспертных 
систем, базы знаний, принятия решений, ассоциативной памяти, нечеткой логики, семиотических сетей, управления структурной динамикой и т.п.

Анализируя принятые структуры систем управления с решающими устройствами [22] можно и для обобщенной интеллектуальной системы использовать аналогичную структуру (рисунок 4.9), которая взаимодействует с внешней средой и в процессе ее получения от нее необходимой информации формирует цель действия $и$ анализирует воздействия на систему (физические и информационные).

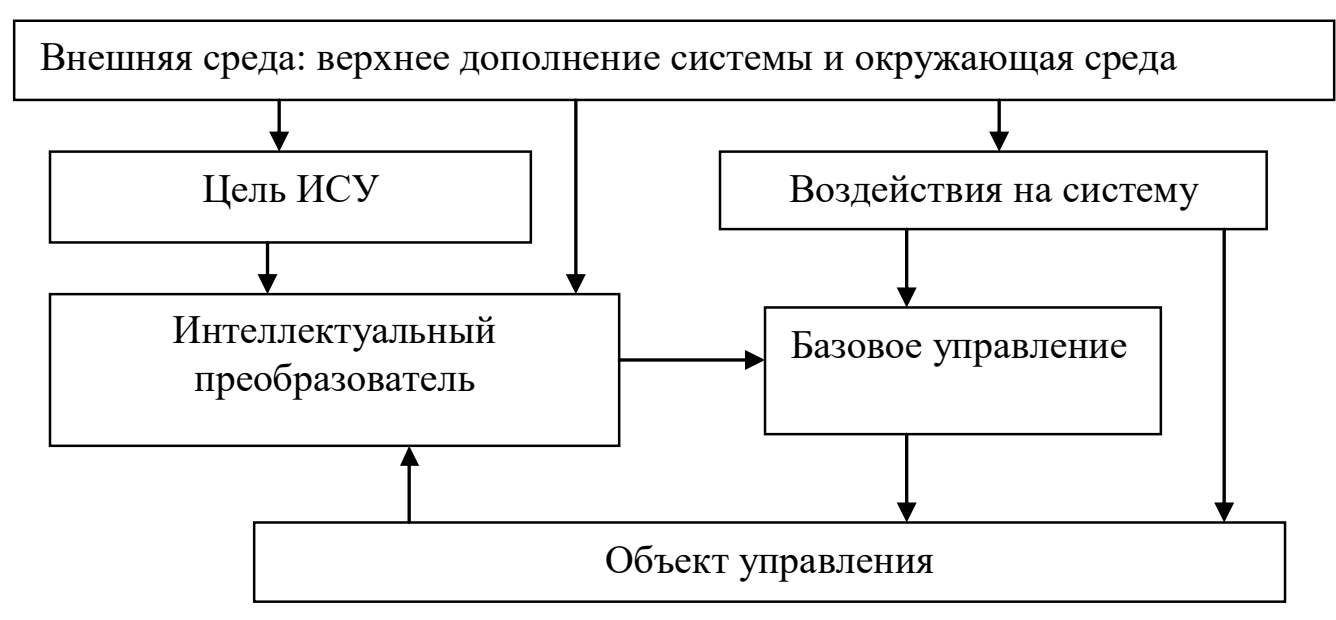

\section{Рисунок 4.9 - Обобщенная схема системы интеллектуального управления}

Определяющими элементами системы управления в этом случае являются: интеллектуальный преобразователь и базовая система управления.

Можно заметить, что использование интеллекта человека строиться на основе рассмотренной структуры, когда человек участвует в управлении в качестве интеллектуального преобразователя, согласованного с внешней средой через специализированные датчики и реализующий воздействие на 
систему управления через ручку управления или интерфейс взаимодействия с компьютером. В практике управления подвижными объектами такие системы получили специальное название. Системы управления подвижными объектами (в авиации, в космической технике, автомобиле и других транспортных средствах) получили название систем полуавтоматического управления, когда используется способность человека наблюдать и оценивать ситуации, возникающие при движении объектов, и формировать непрерывное управление ими. В системах ручного управления на человека - оператора возлагаются дополнительные функции по управлению движением подвижным объектом, связанные с тем фактом, что он осуществляет полностью функции базового управления и воздействует на органы управления. В ручных системах управления человек - оператор рассматривается как звено управления, фрормирующее закон и программу управления. В автоматизированных системах управления (автоматизированным управлении космическим кораблем, атомной электростанцией и других подобных системах управления) человек - оператор оказывает воздействие на базовую автоматическую систему через вычислительные системы, что адекватно может быть описано предлагаемой структурой.

В случае использования в системе управления искусственного интеллекта в качестве интеллектуального преобразователя реализуются [18]:

- экспертные системы $[11,15]$;

- ситуационное управление [12,15]; 
- управление структурной динамикой сложных технологических [3] и другие интеллектуальные системы и их элементы.

Интересным примером использования интеллектуального преобразователя в системе управления является использование динамической экспертной системы.

Математическая модель интеллектуальной системы управления состоит из трех частей:

- интеллектуального преобразователя (экспертной системы, включающей базы данных и знаний);

- объекта управления;

- управляющее устройства системы (вычислительных и преобразующих и исполнительных устройств).

Интеллектуальный преобразователь представляет из себя логико-преобразующее устройство, которое преобразовывает информацию о внешней среде и объекте управления трансформирует в сигналы $\mathbf{Y}$, в сигналы воздействия на управляющие устройства системы [18]. Математическая модель интеллектуального преобразователя оператором вида

$$
\mathbf{Y}=\mathbf{F}(\mathbf{x}, \mathbf{u}, \mathbf{w}, \mathbf{p}, \mathbf{z}) \text {, }
$$

где: $\mathbf{F ( . ) ~ - ~ н е к о т о р ы и ̆ ~ о п е р а т о р ~ и н т е л л е к т у а л ь н о г о ~}$ преобразования, характеризующий структуру или работу интеллектуального преобразователя,

x - вектор состояния системы управления,

u - вектор управления,

w - вектор воздействий внешней среды,

p- вектор сигналов цели,

z- вектор параметров объекта. 
Объект управления в достаточно общем случае описывается уравнениями вида:

$x=f(x, u, w, z, t), y=C(x), x\left(t_{0}\right)=x_{0}, t \geq t_{0}$,

где:

$\mathrm{f}($.$) - вектор - функция, описывающая объект управления,$

C(.) - заданная фрункция выходных сигналов,

$\mathrm{t}$ - координата времени,

у- вектор выхода или измерений.

Управляющее устройства системы (вычислительных и преобразующих и исполнительных устройств) формируют управляющие воздействия на объект управления $\mathbf{u}$ из множества его возможных значений в соответствие с решаемой задачей для достижения сформированной интеллектуальным преобразователем цели.

Для формирования воздействий на систему управления объектом в интеллектуальном преобразователе используется блок принятия решения, который может быть рассмотрен как самостоятельный элемент. Блок принятия решений формируется на основе теории принятия решений [25 ... 27].

\subsection{2. Модели принятия решения в условиях конфликта}

Основные этапы процесса принятия решения согласно теории принятия решения декомпозируются на следующие этапы [27]:

- определение цели решения возникшей проблемы;

- выбор наиболее предпочтительного варианта действий, ведущего к достижению цели;

- реализация решения (выбранного варианта действия). 
Определение цели решения возникшей проблемы реализуется в блоке интеллектуального преобразователя, получающего и обрабатывающего информацию о внешней среде с системы датчиков. В условиях конфликта цель может зависеть от имеющихся ресурсов и фракторов, которые образуют проблемную ситуацию, т.е. ситуацию принятия решения в условиях конфрликта. Способ действия для управления объектом в процессе принятия решения называют стратегиями, а результат, к которому может привести выбранная стратегия, называют исходом. Условия конфликта порождают фракторы, воздействующие на стратегию и соответственно на управление, реализуемое интеллектуальной системой. С точки зрения наличия информации об условиях конфрликта фракторы разделяются на две группы:

- определенные (фиксированные) фракторы, значения которых известны;

- неопределенные факторы, о которых априорно не известно, какое значение они примут.

В зависимости от происхождения неопределенные фракторы делятся на случайные и неопределенные нестохастического характера, состоящие из природных и стратегических. Математическая модель принятия решений формируется с учетом всех фракторов и имеющейся о них информации. Упрощенная модель принятия решения в этом случае может быть описана следующей системой

$$
D_{0}=\langle Y, G, U, L, J, \Omega>,
$$

где:

Y - множество исходов (результатов); 
G - модель предпочтений исходов (принимаемых решений);

$\boldsymbol{U}$ - множество стратегий принятия решений,

$\boldsymbol{L}$ - множество возможных значений неопределенных фракторов;

J - фрункция, определяющая взаимосвязь неопределенного фактора и исход, получаемый в результате принятого решения;

$\boldsymbol{\Omega}$ - вся остальная инфрормация о принимаемом решении в формализованном виде (сведения о конфликте, предпочтения других лиц, участвующих в конфликте и др.).

Удобство использования модели (4.3) в условиях конфрликта определяется тем положением, что она позволяет просто и наглядно связать значения неопределенных фракторов и стратегий с управлением, реализуемым интеллектуальной системой. Множества $\boldsymbol{Y}, \boldsymbol{G}, \boldsymbol{U}, \boldsymbol{L}$ и фрункция $\boldsymbol{J}$ фрормально задают компоненты принимаемого решения и определяют связь с системой управления через понятия критерия и показателей эфффективности системы. В теории управления наиболее часто отношения предпочтения описываются с помощью специальных функций: показателей качества и критериев. Под показателем W качества или эффективности системы управления понимается мера степени соответствия реального результата управления $\boldsymbol{Y}$ требуемому $\boldsymbol{Y}^{\mathrm{mp}}$ для достижения цели и получения оценок или измерений интенсивности исходов. Под критерием $\boldsymbol{K}$ понимается правило, позволяющее сопоставлять принимаемые решения и стратегии с точки зрения выбранных показателей оценок исходов. Критерии вводятся на основе определенной концепции рационального поведения интеллектуальной системы [25]: пригодности, оптимизации и адаптивности. 
Более общей моделью принятия решения в условиях конфликта по сравнению с (4.3) является модель динамической системы интеллектуального управления на основе моделей теории игр $[28,29]$ и современного аппарата функционального анализа [30].

Теория игр как раздел математики в настоящее время стал теорией математических моделей [29]. При этом под конфрликтом понимается явление, которое связано с ответом на вопросы:

Кто и как в этом явлении участвует?

Каковы возможные исходы конфликта?

Кто в этих конфликтах заинтересован?

В чем состоит заинтересованность участников конфрликта? Для описания конфликта вводится понятия:

- коалиций действия $\mathbf{R}_{\mathbf{g}}$, объединяющее множество игроков (участников конфрликта) по их действиям;

- коалиций интересов $\mathbf{R}_{\mathbf{д}}$ объединяющих игроков по интересам;

- стратегий, характеризующих решения коалиций К (действий $\mathbf{R}_{\mathbf{g}}$ и коалиций интересов $\mathbf{R}_{\text {й }}$ которые в зависимости от типа игры могут иметь одних и тех же игроков или образовываться из разных игроков);

- отношений предпочтения $\mathbf{G}$, как абстрактного бинарного отношения на множестве всех стратегий (нередко отношения предпочтения задаются функцией выигрыша $\mathbf{W}_{\mathbf{K}}$ и тогда коалиция $\mathrm{K}$, если она предпочитает ситуацию $\mathbf{x}$ ситуации $\mathbf{y}$, то обозначают через отношение предпочтение в виде $\mathbf{x} \mathbf{G}_{\mathbf{K}} \mathbf{y}$ или при 
использовании функции выигрыша, если $\mathbf{W}_{\mathbf{K}}(\mathbf{x}) \mathbf{W}_{\mathbf{K}}(\mathbf{y})$, то в виде $\left.\mathbf{x} \mathbf{W}_{\mathbf{K}} \mathbf{y}\right)$.

Тогда фрормальное описание конфликта состоит в задании системы

$\Gamma=<\mathbf{R}_{\mathrm{A}}, \mathbf{S}_{\mathrm{R}}, \mathbf{S}, \mathbf{R}_{\mathbf{U}}, \mathbf{G}_{\mathrm{R}}>$,

где: $\mathbf{S}_{\mathbf{R д}}$ множество стратегий коалиции действия;

$\mathbf{G}_{\mathrm{R}}-$ множество отношений коалиции интересов.

В работе [30], как и в ряде других исследованиях по общей системной теории управления, предложено рассматривать динамические системы управления состоящие из объекта управления, характеризуемого некоторым множеством состояний, и регулятора, под которым понимается математическая модель, состоящую из элемента, обеспечивающего оценку состояния объекта, и элемента, формирующего управление.

Для описания динамической системы используется математическая модель совокупности элементов, удовлетворяющих следующим основным аксиомам:

А. Заданы множества моментов времени Т, множество состояний системы $X$. Множество значений входных воздействий $U$, непустое множество их допустимых значений

$\Omega=\{\omega: T \rightarrow U\}$,

множество значений выходных величин Ү и множество их допустимых значений

$\mathrm{Y}=\{\gamma: \mathrm{T} \times \mathrm{X} \rightarrow \mathrm{Y}\}$. 
В. Множество $\mathrm{T}$ есть некоторое упорядоченное подмножество множества вещественных чисел (направление времени).

С. Существует переходная фрункция

$\Phi=\{\varphi: T \times T \times X \times \Omega \rightarrow X\}$,

где состояния системы $x(t)=\varphi\left[t, t_{0}, x\left(t_{0}\right), \omega\right] \in X$.

D. Задано входное отображение

$\mathrm{Y}=\{\gamma: \mathrm{T} \times \mathrm{X} \rightarrow \mathrm{Y}\}$.

(4.8)

Приведенная модель в наиболее общем виде динамического объекта или системы изображена на рисунке 4.10.

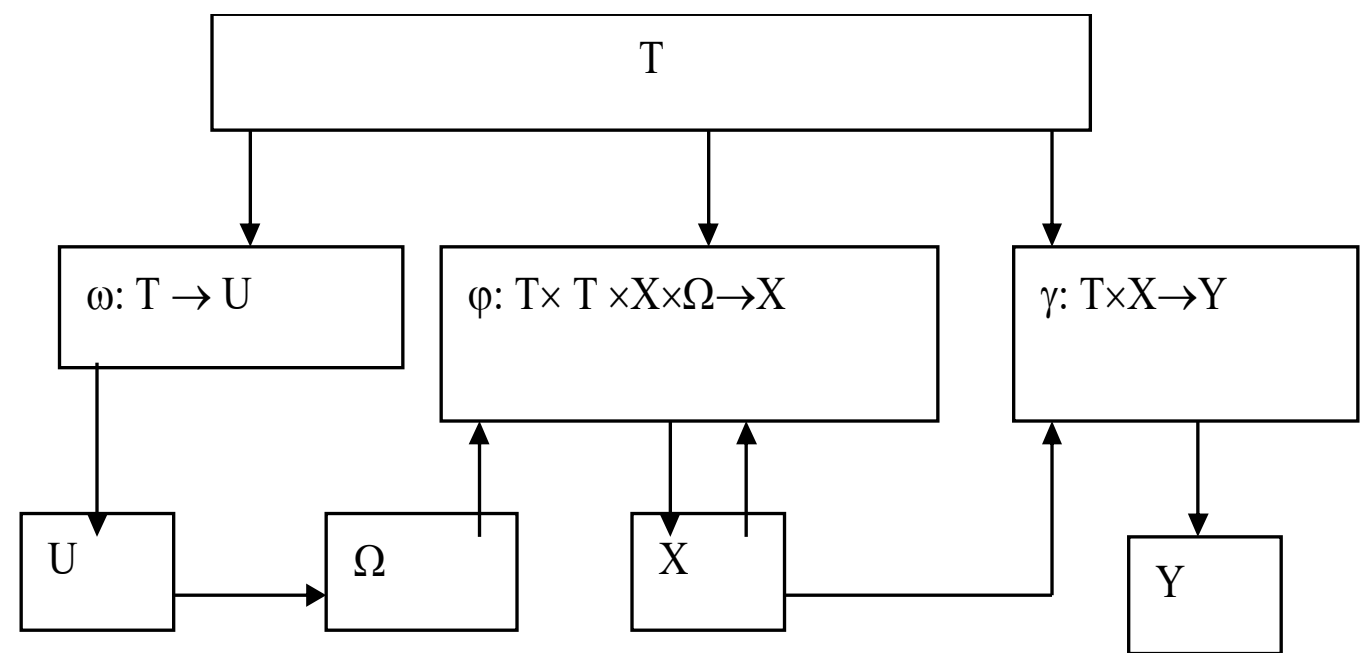

\section{Рисунок 4.10 - Множественная схема динамической системы}

Для описания динамической системы используются дополнительные термины. Так, состояние системы х в момент времени $\mathbf{t}$, или пара элементов множества $\mathbf{T} \times \mathbf{X}$ называется событием (или фразой) динамической системы. Множество Т×X 
называется пространством событий, или фразовым пространством. В том случае, когда множество выходных воздействий используется для управления, то оно называется управлением. Управление переводит систему из одного состояние в некоторое другое. При этом система находится в движении, описывая в пространстве состояния траекторию. В рассмотренной формализации динамическая система рассматривается как объект управления.

Для реализации систему управления в классической теории систем выделяют объект управления и регулятор управления, состоящий в простейшем случае из элемента оценки состояния системы и элемента, фрормирующего закон управления. Так как объект управления нами уже рассмотрен как динамическая система, то введем понятия закона управления и оценки состояния системы.

Законом управления принято называть отображение

$\mathrm{k}: \mathrm{T} \times \mathrm{X} \rightarrow \mathrm{U}$,

где величины $\mathbf{u}(\mathbf{t})=\mathbf{k}[\mathbf{t} ; \mathbf{x}(\mathbf{t})]$ управления, принадлежащие множеству $U$.

Для реализации управления необходимо знание переменных состояния системы $\mathbf{x}(\mathbf{t})$, что требует операции определения обратного отображения

$\gamma^{-1}: Y \rightarrow X$

и тогда координаты системы определяются из условия $\mathbf{x}(\mathbf{t})=\gamma^{-1}[\mathbf{y}(\mathbf{t})]$. 
Кроме того, для оценки состояния системы необходимо оценивать точность определения $\mathrm{x}(\mathrm{t})$, т.е. получать оценку состояния $\mathbf{x}_{\mathbf{0}}(\mathbf{t})$.

Структурно - логическая схема системы управления, состоящая из объекта управления и регулятора, показана на рисунке 4.11.

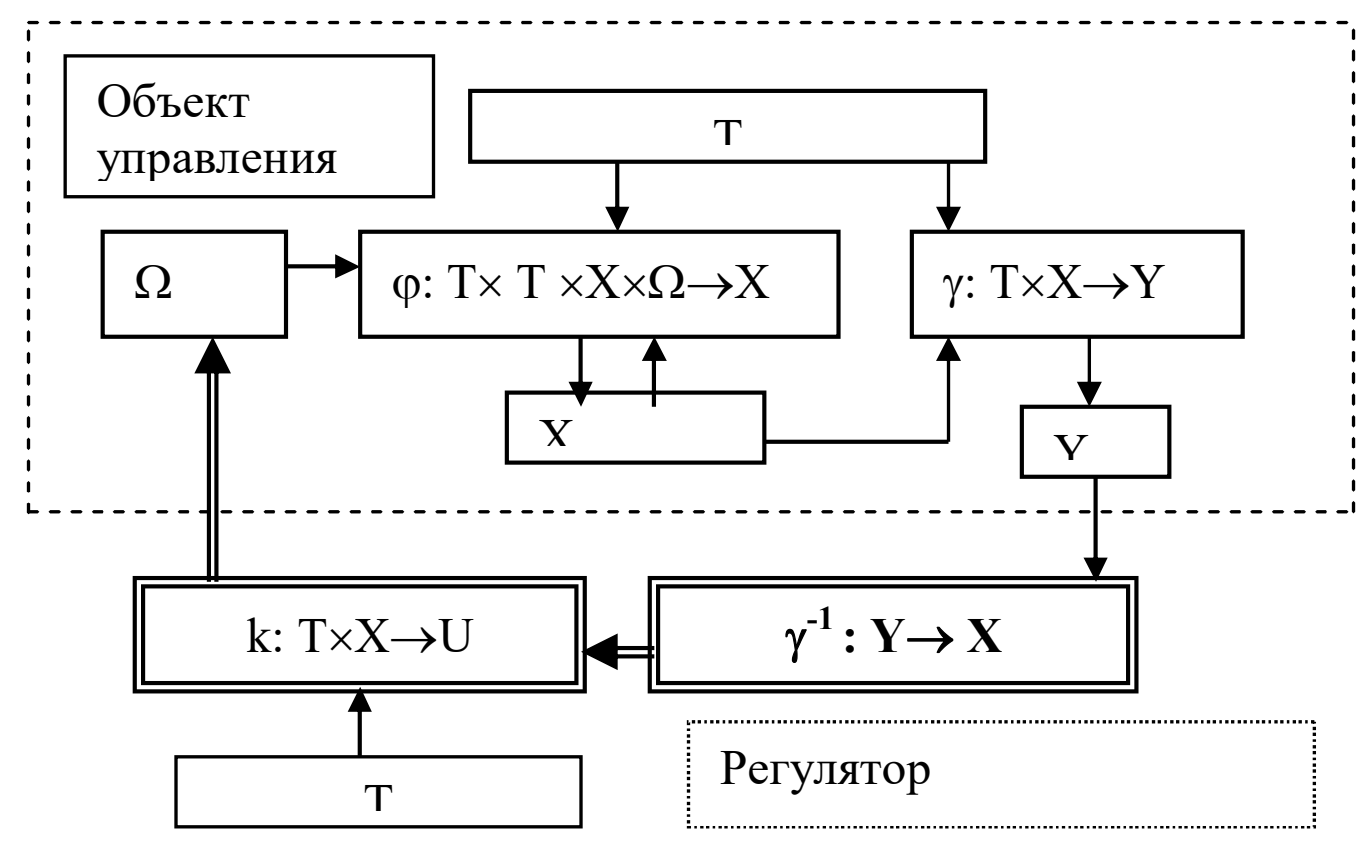

\section{Рисунок 4.11 - Структурно-логическая схема блока основного управления системы}

Для учета фракторов воздействия внешней среды и конфрликта необходимо провести учет воздействий этих объектов. При этом фракторы внешней среды и условий конфликта необходимо рассматривать и описывать с позиций динамической системы.

При принятии решения в системе интеллектуального управления возникает необходимость объединения интеллектуального преобразователя, включающего блок принятия решения, и динамическую систему управления. 


\subsection{4. Определение оптимальной интеллектуальной системы принятия решения и управления в условиях конфликта}

Понятие оптимальности получило широкое распространение в теории управления и теории принятия решений. Под оптимальной системой автоматического управления понимают «наилучшую» систему, которую выбирают из множества систем по принятому показателю качества системы или эфффективности ее функционирования. При этом система является оптимальной, если она обеспечивает экстремум принятого показателя. В зависимости от конкретного вида показателя понятие оптимальности связывается с критерием, т.е. с минимумом или максимумом показателя. Если, например, в качестве показателя используется средняя квадратическая ошибка системы, то оптимальной системой считают ту, которая реализует критерий - минимумом средней квадратической ошибки. Если же в качестве показателя используется вероятность невыхода ошибки системы из заданных допусков, то оптимальной считают ту систему, которая реализует критерий - максимум невыхода ошибки системы из заданных допусков.

Принятие решений в условиях определенности (фриксированности) фракторов и в случае, когда неопределенность является случайной и о факторе имеется полная априорная информация, то оптимальность решения определяется аналогично тому, как это делается в системах автоматического управления.

В условиях стратегической (поведенческой) неопределенности, которая появляется в условиях конфрликта, 
понятие оптимальности принимаемого решения значительно труднее поддается фрормализации. Теория математических моделей принятия оптимальных решений составляет значительную часть науки, которая получила название исследования операций [1]. Особое место в исследовании операций занимает раздел, занимающейся теорией математических моделей принятия оптимальных решений в условиях конфликта, который получил название теории игр [29]. Теории игр, как теория математических моделей базируется на использовании формальных, знаковых моделей для описания конфликта, а также использует фрормальные средства их анализа. В теории игр успешно были реализованы определения понятия конфрликта и принятия решения. В тоже время понятие оптимальности удалось в настоящее время реализовать только для части игр. Поэтому при анализе систем принятия решений и управления мы ограничимся рассмотрением только тех конфликтов, которые описываются моделями бескоалиционных (множества коалиций действия и интересов совпадают, определены фрункции выигрыша) и антагонистических (число игроков равно двум, а значения их функций выигрыша в любой ситуации равны и противоположны по знаку) игр. Для бескоалиционных и антагонистических игр условия оптимальности основываются на понятии равновесия.

Вопрос об оптимальности управления и принятия решений в интеллектуальных системах усложняется и тем фрактом, что для реализации системы используются экспертные знания, которые не всегда удается реализовать. Эта трудность преодолевается за счет допущения, что в системе реализуется интеллектуальный датчик, который однозначно определяет 
инфрормацию о действиях другой стороны за счет фризических измерений действия противоположных игроков, воздействующих на систему управления и принятия решения в условиях конфликта. Фактически в интеллектуальной системе реализуется рациональное управление и принятие решения. Достоверность и степень приближения к точному оптимальному управлению и принятию решения определяется той инфрормацией, которую получает, отрабатывает и выдает интеллектуальная система, или интеллектуальный датчик. При этом в результате ошибок интеллектуального датчика, связанных с использованием экспертных знаний, появляются риски, связанные с ошибочным формированием цели принятия решения и управления, определением показателей и критериев оценки эфрфективности работы системы, выбором лучшей системы. Для уменьшения рисков в интеллектуальной системе используются методы обучения и самообучения, которые в настоящее время начинают разрабатываться в интеллектуальных системах и которые всегда присутствовали в биологическом интеллекте [17 ... 21].

Решение задач синтеза систем оптимального управления и принятия решения в условиях конфрликта традиционно связаны с математическими методами отыскания экстремумов функций и функционалов, нахождения равновесных состояний, что позволяет решать задачи синтеза систем управления и принятия решений в практически важных случаях.

Рассмотрение структуры систем интеллектуального принятия решения и управления в условиях конфрликта (рисунок 4.12) показывает, что система состоит из трех основных 
элементов (подсистем), каждый из которых имеет свои модели и специфические методы исследования:

- интеллектуальная подсистема;

- подсистема принятия решения;

- подсистема управления объектом и объект управления.

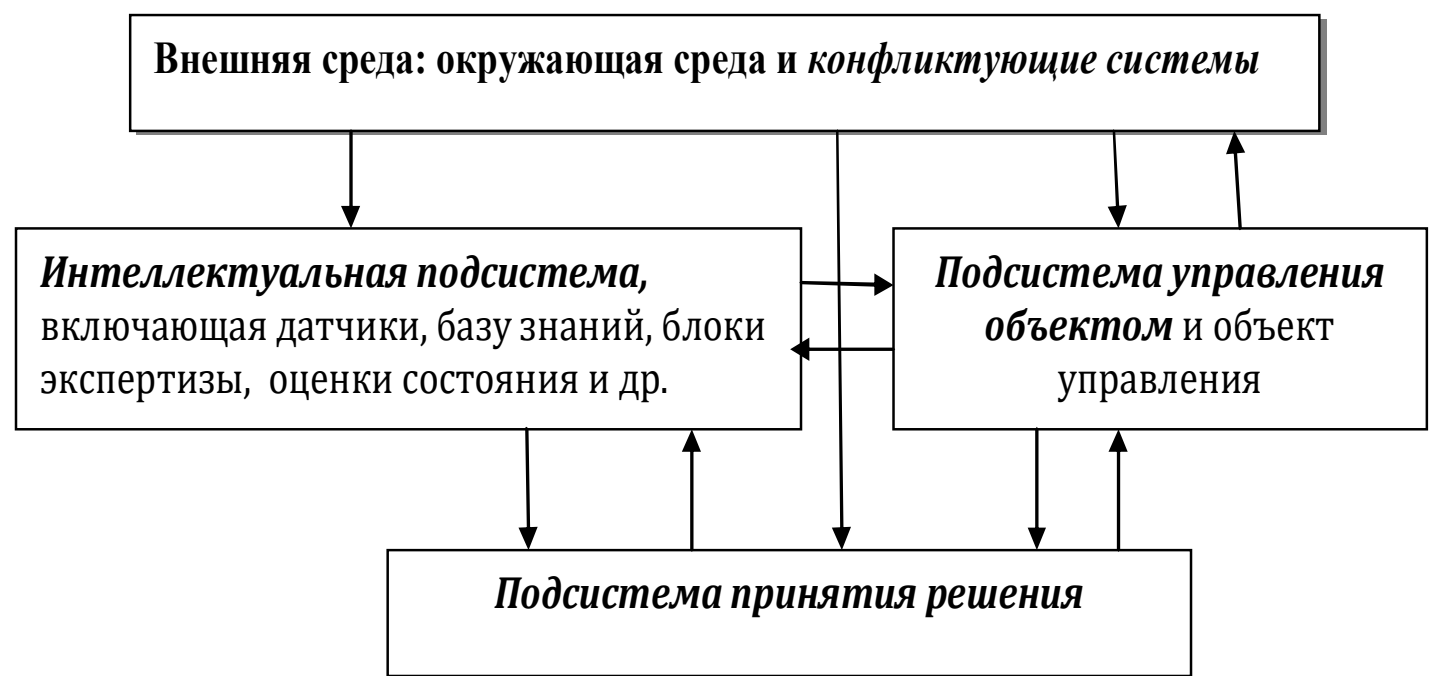

\section{Рисунок 4.12 - Структура интеллектуальной системы}

принятия решения и управления в условиях конфликта, порождаемого конфликтующими системами

Не смотря на свою сложность и методологические особенности элементов интеллектуальных систем принятия решения и управления в условиях конфликта при определении оптимальной системы, удается выделить следующие основные задачи:

- построение модели условий конфликтного взаимодействия оптимизируемой системы с другими системами, изучение и описание информации о воздействиях на систему; 
- формирование интеллектуальной подсистемы, включающей датчики, базу знаний, блоки экспертизы, оценки состояния, фоормирования целей, выбор показателей и критериев оптимизации системы и других элементов интеллектуальной деятельности;

- принятие решений, обеспечивающих оптимальное противодействие одной или нескольким конфрликтующим системам;

- определение и математическое описание классов допустимых систем управления объектом управления;

- отыскание экстремума критерия или точек равновесия в игровых задачах, а также соответствующих им характеристик.

Формирование модели условий конфликтного взаимодействия оптимизируемой системы с другими системами основывается в простейшем случае с позиции теории игр как конфликт двух игроков (A, В). При этом конфликт рассматривается как операция, В которой игроки имеют различные цели и реализуют свою деятельность и выбирают свои стратегии в соответствии со своими целями (рисунок 4.13) $[1,24 \ldots 26]$.

Исследование операции проводится всегда с точки зрения одного игрока, а в рассматриваемом случае это проводится с позиции интеллектуальной системы принятия решения и управления (для определенности примем, что в конфликте это игрок $\mathbf{A})$. 


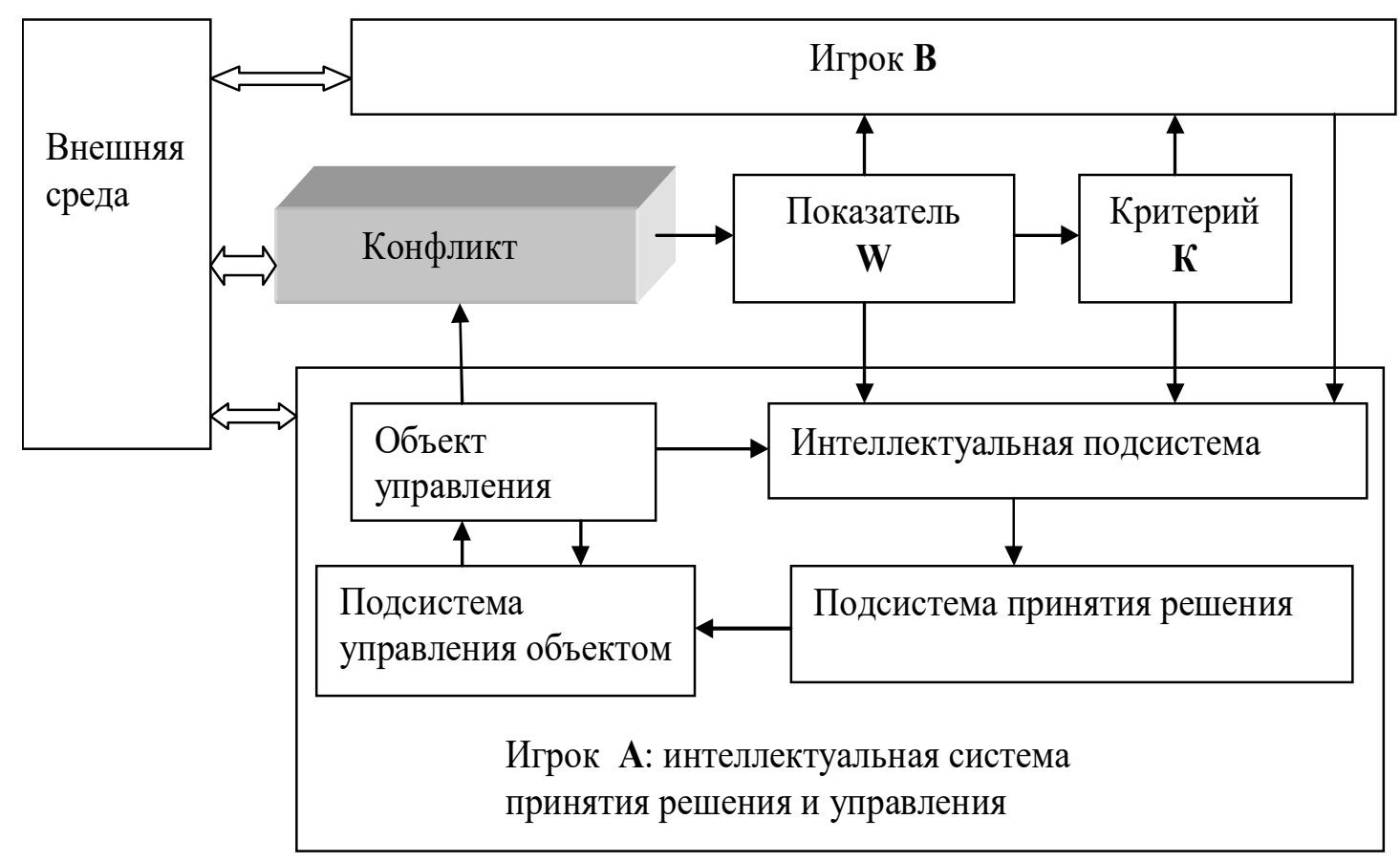

\section{Рисунок 4.13 - Общая схема конфликта как операции двух систем с разными целями}

Будем считать, что эфрфект достижения цели определяется векторными показателем $\mathbf{W}=\left(\mathbf{W}_{\mathbf{A}}, \mathbf{W}_{\mathbf{B}}\right)$ и критерием $\mathbf{K}=\left(\mathbf{K}_{\mathrm{A}}, \mathbf{K}_{\mathrm{B}}\right)$, связанные с целями поведения сторон. При этом в зависимости от наличия датчиков получения информации о целях действия игроков предполагается, что идентификация целей позволяет интеллектуальной системе определять критерии и показатели, используемые игроками для идентификации показателей и критериев игроков.

Вопросы формирование интеллектуальной подсистемы, включающей датчики, базу знаний, блоки экспертизы, оценки состояния, формирования целей, выбор показателей и критериев оптимизации системы и других элементов интеллектуальной деятельности были рассмотрены в первом 
разделе лекции, когда анализировались интеллектуальные системы и их элементы.

Принятие решений, обеспечивающих оптимальное противодействие одной или нескольким конфликтующим системам конфликтующим системам, основывается в условиях конфликта на использовании моделей, методов и алгоритмов принятия оптимальных решений В теории игр. В рассматриваемом нами случае мы ограничиваемся матричными антагонистическими (игры двух лиц с нулевой суммой), которые имеют развитый инструментарий решения прикладных задач

Определение и математическое описание классов допустимых систем управления объектом управления основывается на теории систем управления [1, 31]. В основе рассматриваемой задачи оптимизации системы управления объектом используется подход, основанный на использовании корреляционной теории статистической оптимизации систем, разработанной профрессором Н.И. Андреевым [22, 32]. В его работах разработаны методы исследования сложных линейных и нелинейных динамических систем, подверженных случайным воздействиям. При постановке задач определения оптимальных динамических систем по статистическим критериям (по минимуму средней квадратической ошибки системы, максимуму вероятности невыхода ошибки системы из заданных допусков и др.) им разработана методология учета ограничений типа неравенств, накладываемые на фрунции управления и вектора. Большое внимание им уделено исследованию динамических систем с заданной структурой, так как для прикладных задач эти системы играют, с одной стороны, важную роль, а, с другой стороны, приводят к значительному усложнению 
математических задач оптимизации этого класса систем. В его работах исследовано ряд новых задач, относящихся к оценке параметров системы, фрильтру Калмана, синтезу нелинейных динамических систем, построению адаптивных систем оценивания и управления, развитию методов принятия статистических решений, определению оптимальных систем управления с решающими устройствами.

Проиллюстрируем проведенный анализ постановки задачи определения оптимальной интеллектуальной системы принятия решения и управления в условиях конфликта на простом примере, в иной постановке задачи оптимизации.

Пример. Рассмотрим задачу определения интеллектуальной системы принятия решения и управления, на вход которой поступает сигнал, представляющего сумму полезного сигнала $\mathrm{G}(\mathrm{t})$ и помехи Z(t). При этом будем предполагать, что слежение за полезным сигналом осуществляет интеллектуальная система управления (игрок $\mathbf{A}$ ), a помеху фрормирует противоположная сторона (игрок В), которая выбирает характеристики такими, чтобы ошибки следящей системы были большими. В результате возникает конфликт, который часто рассматривается в теории игр. Для наглядности и простоты изложения будем полагать, что каждая из сторон имеет две стратегии управления и по этой причине можно ограничить решение задачи на основе матричной и биматричной игр.

Пусть помеха представляет собой нормально

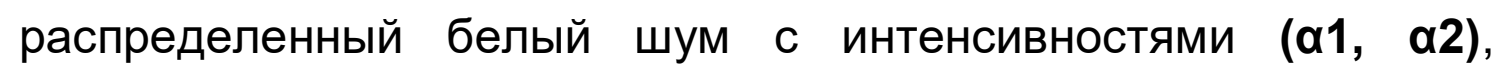
выбором величины которых управляет игрок А. Полезный сигнал $\mathbf{G}=\mathbf{G}_{0}$ числовая случайная величина, принимающая 
значения $\boldsymbol{\beta}_{0}$ и $-\boldsymbol{\beta}_{0}$ с вероятностью 0,5 , величина которых формируется игроком А и может принимать значения $\left(\boldsymbol{\beta}_{01}, \boldsymbol{\beta}_{02}\right)$.

Желаемая выходная величина фрормируемой системы слежения - полезный сигнал. Система выбирается на классе стационарных систем, время регулирования которых не превосходит время $\mathbf{T}$.

В качестве показателя качества системы принимается суммарная ошибка системы ошибка системы $\mathbf{D}_{\Sigma}$, которая определяется биноминального распределения полезного сигнала $\mathbf{D}_{1}$ и случайным характером помехи $\mathbf{D}_{2}$. Запишем ошибки системы в следующем виде:

$$
\begin{aligned}
& T T \\
& D_{1}=\iint \delta\left(T_{1}-T_{2}\right) \omega\left(T_{1}\right) \omega\left(T_{2}\right) d T_{1} d T_{2} \text {, } \\
& 00
\end{aligned}
$$

где: $\delta\left(\mathbf{T}_{1}-\mathbf{T}_{2}\right)$ - дельта-фрункция, принимающая нулевое значение, если $\left(\mathbf{T}_{\mathbf{1}}-\mathbf{T}_{\mathbf{2}}\right) \neq \mathbf{0}$, и равна $\infty$, если $\left(\mathbf{T}_{\mathbf{1}}-\mathbf{T}_{\mathbf{2}}\right)=\mathbf{0}$;

$\boldsymbol{\omega}\left(\mathbf{T}_{1}\right)$ - весовая функция при переменной $\mathbf{T}_{1}$;

$\boldsymbol{\omega}\left(\mathbf{T}_{2}\right)$ - весовая функция при переменной $\mathbf{T}_{2}$;

$$
D_{2}=\left(\beta_{0}\right)^{2}\left\{\int \omega(T) d T_{1}-1\right\}^{2}
$$$$
0
$$$$
D_{\Sigma}=D_{1}+D_{2} \text {. }
$$

Базовая подсистема управления будет описываться весовой функцией, параметры которой зависят от решения игровой задачи и выбора подсистемой интеллектуального управления цели системы и соответствующих показателей и критериев оптимизации.

Тогда для иллюстрационного примем Т =1 и выражение для весовой функции можно записать в виде

$$
\omega_{\mathrm{IJ}}(\tau)=\beta_{0 \mathrm{~J}}^{2}\left(\alpha_{\mathrm{i}}+\beta_{0 \mathrm{~J}}^{2}\right)^{-1},
$$


где управление реализуется в виде весовых функций в зависимости от стратегий игроков (В - максимизирует дисперсию ошибки, а А -минимизирует ошибку слежения).

В этом случае дисперсии для принятой весовой функции записываются в следующем виде, учитывающем стратегии игроков

$$
\begin{aligned}
& D_{1}{ }^{\mathrm{IJ}}=\alpha_{\mathrm{i}}\left(\alpha_{\mathrm{i}} \beta^{-2}{ }_{0 \mathrm{~J}}+1\right)^{-2}, \\
& D_{2}^{\mathrm{IJ}}=\alpha_{\mathrm{i}}^{2} \beta^{2}{ }_{0 \mathrm{~J}}\left(\alpha_{\mathrm{i}}+\beta^{2}{ }_{0 \mathrm{~J}}\right)^{-2} .
\end{aligned}
$$

Интеллектуальная подсистема В, наблюдая с помощью своих информационных и физических датчиков за игроком $\mathbf{A}$, определяет его действия и формирует свою стратегию движения в каждой конкретной ситуации. Возникает задача ситуационного управления движением, когда решения и управления должны осуществляться в соответствие с той ситуацией, которая складывается в текущий момент конфоликта.

Одной из сложных задач в этом случае является задача определения типа антагонизма между игроками и определения целей действия систем, выяснения их интересов. В практике конфрликтных ситуаций о действиях другой стороны или игрока, как правило, используется информация, получаемая через информационные сообщения, телекоммуникационные сети и путем сбора различными способами конфиденциальной информации. При реализации интеллектуальной экспертной системы используются эксперты и их оценки, но и возможен аналитический подход к решению идентифрикации намерений и цели противоположной стороны на основе анализа конфликта. Если реализуется интеллектуальная подсистема на основе ситуационного управления, то возможна декомпозиция общей задачи на две части, когда интеллектуальная подсистема 
идентифицирует конкретную ситуацию, а управление в конкретной ситуации формируется на основе решения игровых задач для определения неопределенных стратегий, или неопределенных параметров противодействующей стороны. Вместе с тем интеллектуальная подсистема должна определять тип модели игры в конфликте. Возникает вопрос, как это может реализовать интеллектуальная подсистема.

Покажем возможность оценки действий противника на основе обработки информации по решению задачи с помощью теории игр. Для этого проанализируем результаты принятия решения при реализации матричной антагонистической игры. Вначале рассмотрим влияние конфликта на управление на примере единичной ситуации, когда время управления $\mathbf{T}$ фиксировано и единственное, а затем рассмотрим условную модель ситуационного управления на основе сценария, в котором достижение цели обеспечивается несколькими ситуациями управлениями в разные моменты времени $\mathrm{T}_{\mathrm{v}}$.

Примем, что игроки могут реализовать по две стратегии, т.е. конфрликт описывается матрицей размерности $2 \times 2$, где $\left(\boldsymbol{\beta}^{2}{ }_{01}\right.$ $\left.=1, \beta_{02}^{2}=2\right)$ значение стратегий игрока В и $\left(\alpha_{1}=1, \alpha_{2}=2\right)$ значение стратегий игрока А. В этом случае при принятых исходных данных матрицы выигрышей можно записать в следующем виде:

при анализе системы по дисперсии $\mathbf{D}_{\mathbf{2}}$

\begin{tabular}{|c|c|c|c|c|}
\hline Стратегии B \A & $\beta_{01}^{2}=1$ & $\beta_{02}^{2}=2$ & Min по j & Max $\min =$ \\
\hline$\alpha_{1}=1$ & 0,5 & 0,667 & 0,5 & 0,5 \\
\hline$\alpha_{2}=2$ & 0,333 & 0,4 & 0,4 & \\
\hline Max по i & 0,5 & 0,667 & & \\
\hline Min $\max =$ & \multicolumn{4}{|l|}{0,5} \\
\hline
\end{tabular}


при анализе системы по дисперсии $\mathbf{D}_{1}$

\begin{tabular}{|l|c|c|c|c|}
\hline $\begin{array}{l}\text { Стратегии В I } \\
\text { A }\end{array}$ & $\begin{array}{c}\boldsymbol{\beta}^{2}{ }_{\mathbf{0 1}}= \\
\mathbf{1}\end{array}$ & ${\boldsymbol{\boldsymbol { \beta } ^ { 2 }}}^{2} \mathbf{2} \mathbf{2}$ & Min по j & $\begin{array}{c}\text { Max min } \\
\mathbf{=}\end{array}$ \\
\hline $\boldsymbol{\alpha}_{\mathbf{1}}=\mathbf{1}$ & 0,25 & 0,011 & 0,011 & \\
\hline $\boldsymbol{\alpha}_{\mathbf{2}}=\mathbf{2}$ & 0,011 & 0,08 & 0,08 & $\mathbf{0 , 0 8}$ \\
\hline Max по i & 0,011 & 0,08 & & \\
\hline Min $\boldsymbol{m a x}=$ & $\mathbf{0 , 0 8}$ \\
\hline
\end{tabular}

при анализе системы по дисперсии $\mathbf{D}_{\Sigma}$

\begin{tabular}{|c|c|c|c|c|}
\hline $\begin{array}{l}\text { Стратегии В I } \\
\text { A }\end{array}$ & $\begin{array}{c}\beta^{2}{ }_{01}= \\
1\end{array}$ & $\beta^{2}{ }_{02}=2$ & Min по j & $\begin{array}{c}\text { Max min } \\
=\end{array}$ \\
\hline & 0,75 & 0,678 & 0,678 & \\
\hline$\alpha_{2}=2$ & 0,344 & 0,48 & 0,48 & 0,48 \\
\hline Max по i & 0,75 & 0,48 & & \\
\hline $\operatorname{Min} \max =$ & 0,48 & & & \\
\hline
\end{tabular}

Все три антагонистические игры имеют седловые точки $\max \min \mathrm{D}_{\mu}{ }^{\mathrm{ij}}=\min \max \mathrm{D}_{\mu}, \mu=(1,2,3), \mathrm{i}=\mathrm{J}=(1,2)$

\section{$\boldsymbol{i} \boldsymbol{j} \boldsymbol{j} \mathbf{i}$}

В чистых стратегиях, но цены игр у них разные. Интересным результатом анализа дисперсий ошибок анализируемой системы является то, что гарантированная суммарная ошибка системы (равна 0,48) меньше гарантированной ошибки, получаемой только при учете нормальной составляющей ошибки (равной 0,5). Понятно, что полученное уменьшение дисперсии суммарной ошибки в результате отказа от стратегии $\boldsymbol{\alpha}_{1}$, которая ведет к увеличению дисперсии нормальной составляющей ошибки. Это также связано с тем, что дисперсии ошибок от изменения сигнала помехи существенно меньше при $\boldsymbol{\alpha}_{2}$ влияют на дисперсию $\mathbf{D}_{1}$. 
По этой причине, если игрок А будет выбирать свою стратегию из условия увеличения дисперсии помехи, то он может быть наказан игроком $\mathrm{B}$, который в этом случае может реализовать свою стратегию $\boldsymbol{\beta}^{2}{ }_{01}=1$ (провести адаптивное управление) благодаря этого получить дополнительный выигрыш, который будет равен 0,344, т.е. меньше гарантированного выигрыша на 0,135 (уменьшает дисперсию на 28.5\%). Таким образом интеллектуальная подсистема на основе получения оценок интенсивности шума сожжет определить, какой стратегии придерживается игрок А при противодействии игроку В. Логика рассуждений интеллектуальной подсистемы может быть продолжена в том направлении, если игрок В откажется от использования гарантированных оценок, а будет применять критерии: минимаксного сожаления Сэвиджа, пессимизмаоптимизма Гурвица, «недостаточного основания» Бернулли [25, 27].

Рассмотрим теперь случай, когда для достижения цели управления необходимо выполнения нескольких операций по слежению, согласно определенному сценарию (рисунок 4.14), в котором последовательно реализуются три ситуации со временем управления $\mathrm{T}_{1}=1, \mathrm{~T}_{2}=2, \mathrm{~T}_{3}=3$ а также показано начало работы системы и достижение цели в случае успешного выполнения все планируемых операций.

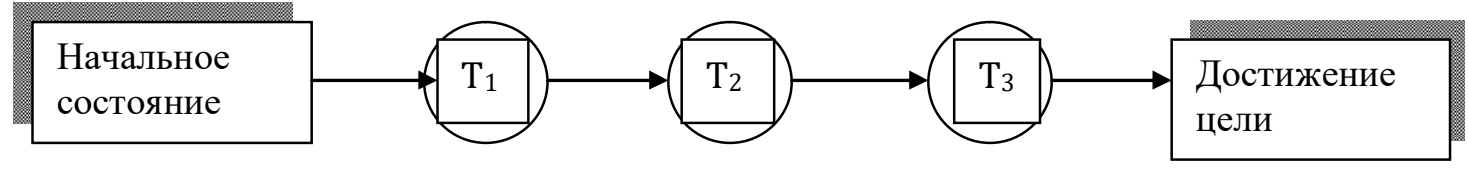

Рисунок 4.14 - Сценарий на основе сетевой модели, вершины которой соответствуют фактам, а дуги связям 
В качестве критерия эфффективности достижения цели примем условие получения оптимальных оценок в каждой ситуации, как это было сделано в первой ситуации при $\mathrm{T}_{1}$.

Для произвольного $\mathrm{T}_{v}$ дисперсии и определяемые весовые функции будут равны

$$
\begin{aligned}
& D_{1} \mathrm{IJ}=T_{v} \alpha_{i}\left(\alpha_{i} \beta^{-2}{ }_{0 J}+T_{v}\right)^{-2}, \\
& D_{2}^{I J}=\alpha_{i}^{2} \beta_{0 J}^{2}\left(\alpha_{i}+T_{v} \beta_{0 J}^{2}\right)^{-2}, \\
& \omega_{\mathrm{IJ}}(\tau)=\beta_{0 J}^{2}\left(\alpha_{i}+T_{v} \beta_{0 J}^{2}\right)^{-1}, \\
& \text { где } \mathbf{v}=(1,2,3), \mathbf{i}=(1,2), J=(1,2), \text { если использовать }
\end{aligned}
$$
данные, принятые в начальных расчетах дисперсий и весовой функции при T1.

Одним из интересных предложений по развитию интеллектуальной подсистемы для оценки степени антагонизма между игроками и соответственно между интеллектуальными системами в условиях конфрликта стало использование теории биматричных игр.

\section{ВИДЕОРОЛИКИ ПО ГЛАВЕ}

\begin{tabular}{l} 
Интеллектуальная система управления \\
транспортными потоками \\
http://www.youtube.com/watch?v=aJEt5UDS5U \\
\hline $\begin{array}{l}\text { Интеллектуальная система «Умный дом» } \\
\text { http://www.youtube.com/watch?v=GfdoLiul82w }\end{array}$
\end{tabular}




\begin{tabular}{l} 
Интеллектуальная система системы \\
кормления животных \\
http://www.youtube.com/watch?v=WbKIEHKPpW0 \\
\hline $\begin{array}{l}\text { Cравнениe Google Search и Siri } \\
\text { http://habrahabr.ru/post/146962/ }\end{array}$
\end{tabular}

\section{КОНТРОЛЬНЫЕ ВОПРОСЫ}

1. Перечислите основные направления развития диалоговых интерфейсов интеллектуальных систем.

2. Приведите примеры применения систем распознавания голоса.

3. Приведите примеры интеллектуальных систем с билогической обратной связью

3. Приведите примеры интеллектуальных систем виртуальной реальности.

4. Интеллектуальный анализ данных.

5. Перечислите основные направления эволюционного моделирования.

6. Объясните принцип работы генетического алгоритма.

7. Основные этапы технологии генетического программирования. 


\section{5. ИНТЕЛЛЕКТУАЛЬНЫЕ СИСТЕМЫ В ОТРАСЛЯХ ТРАНСПОРТНО-ДОРОЖНОГО КОМПЛЕКСА}

\section{1. ИНТЕЛЛЕКТУАЛЬНЫЕ СИСТЕМЫ АКТИВНОЙ ПОМОЩИ ВОДИТЕЛЮ}

Рассмотрим современные интеллектуальные системы активной помощи водителю (Advanced Driver Assistance System (ADAS)), применяемые на легковых автомобилях на примере моделей легковых автомобилей марки Мерседес-Бенц, как одного из мировых лидеров в области инноваций в автомобильной электронике.

Развивая свои достижения в области обеспечения безопасности водителя и пассажиров, специалисты компании Мерседес-Бенц сконцентрировались на предотвращении дорожно-транспортных происшествий (ДТП) и уменьшении степени их тяжести. Главную роль в этом сыграют новые интеллектуальные системы помощи водителю, представленные на новых моделях автомобилей.

Синергия современных технологий активной безопасности позволяет назвать новые модели Мерседес-Бенц действительно «разумными»: автомобиль «видит», анализирует и действует самостоятельно. Мерседес-Бенц представляет уникальный симбиоз сложных электронных систем безопасности, наделяя свои машины интеллектом и дополнительными «органами чувств».

Основанием для разработки новых интеллектуальных систем помощи водителю стал анализ реальных ДТП. Аналогичным подходом руководствовались инженеры компании Мерседес-Бенц и при разработке ставших уже привычными 
систем ABS, ESP, Brake Assist и PRE-SAFE. Были проанализированы причины ДТП, в том числе с тяжелыми последствиями, такие как несоблюдение дистанции между транспортными средствами, нарушение скорости, сонливость водителя, движение в темное время суток, непроизвольный съезд автомобиля с полосы движения.

В результате, помимо радарных датчиков, стали применяться также и видеокамеры. Камеры дальнего радиуса действия контролируют области вокруг автомобиля и способны распознавать опасные ситуации. Так, например, новая интеллектуальная система на основании данных видеокамер помогает водителю удерживать автомобиль на полосе движения, распознает знаки ограничения скорости и управляет светом фар в зависимости от дорожной обстановки, значительно улучшая обзор дороги в темное время суток.

\subsection{1. Адаптивное управление головным светом}

Adaptive Highbeam Assist (Адаптивное управление головным светом) распознает движущиеся попутные и встречные автомобили с включенным светом фар и в реальном времени непрерывно управляет приборами освещения, обеспечивая максимальную дальность и, в то же время, не допуская ослепления других водителей (рисунок 5.1). 


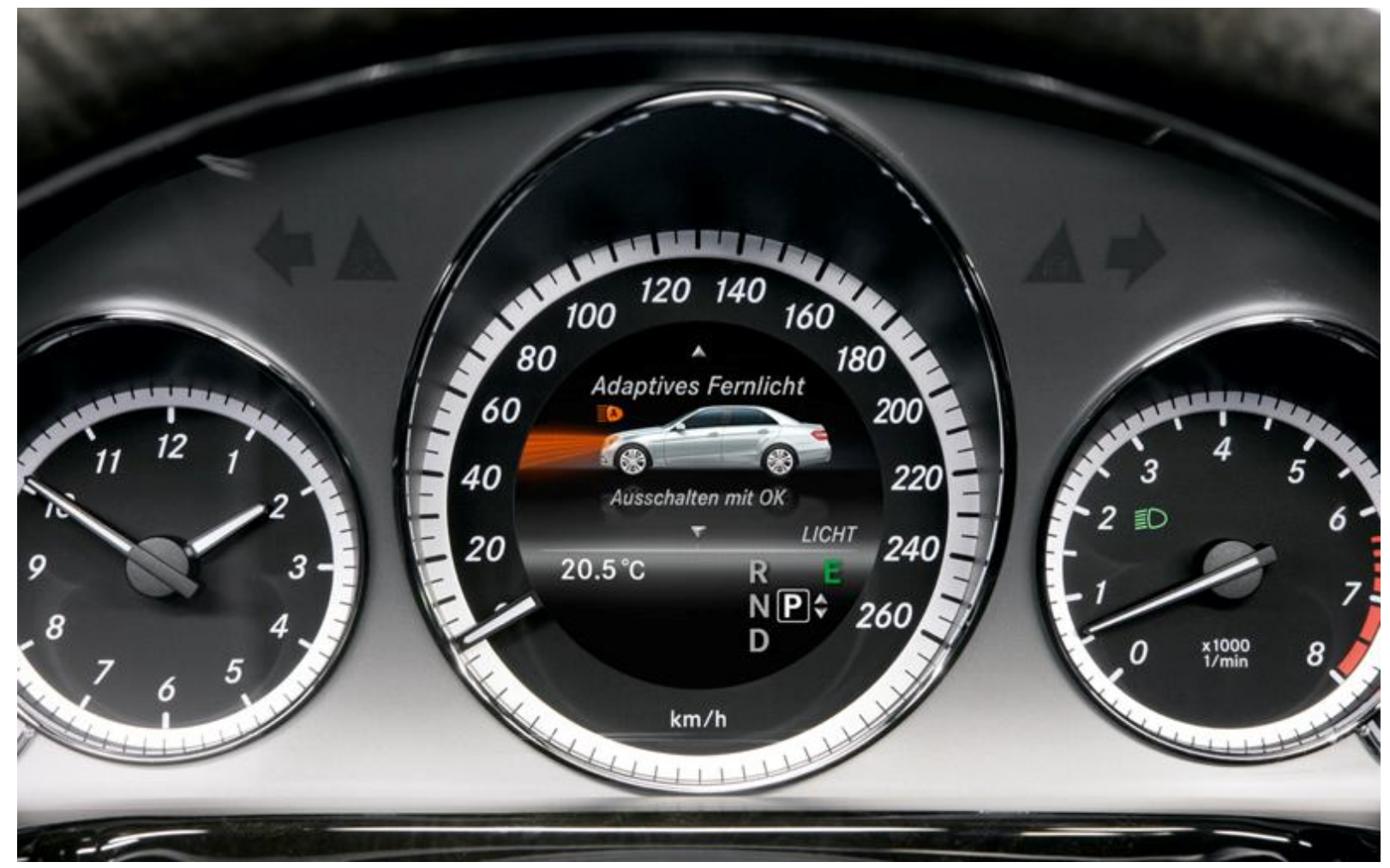

Рисунок 5.1. - Адаптивное управление головным светом

Таким образом, дальность освещения в режиме ближнего света может увеличиваться со стандартных 65 метров до 300 метров. Если дорога впереди свободна, система самостоятельно переключается на дальний свет. Принцип работы мерседесовской системы коренным образом отличается от систем, уже представленных на рынке, в которых просто происходит автоматическое переключение между ближним и дальним светом.

Результаты проведенных тестов свидетельствуют, что водители, которые используют Adaptive Highbeam Assist, являются более безопасными участниками дорожного движения при движении в темноте, так как они замечают пешеходов, велосипедистов и препятствия на 150 метров раньше, чем водители, движущиеся с обычным ближним светом. Более того, использование этой системы снижает утомляемость водителя, 
так как пропадает необходимость постоянно переключать режимы света вручную. Таким образом, водитель может лучше сконцентрироваться непосредственно на управлении автомобилем. Достаточно активировать систему Adaptive Highbeam Assist один раз, и дорога всегда будет освещена на максимально возможное расстояние.

Основным элементом системы является видеокамера, установленная на лобовом стекле изнутри салона, которая посылает данные в процессор каждые 40 миллисекунд. Это позволяет непрерывно управлять приводами биксеноновых ламп.

\subsection{2. Система ночного видения}

Инженеры Мерседес-Бенц разработали также систему Night View Assist (система ночного видения) (рисунок 5.2), работающую в инфракрасном спектре. Система контролирует дорогу впереди автомобиля на максимально возможное расстояние.

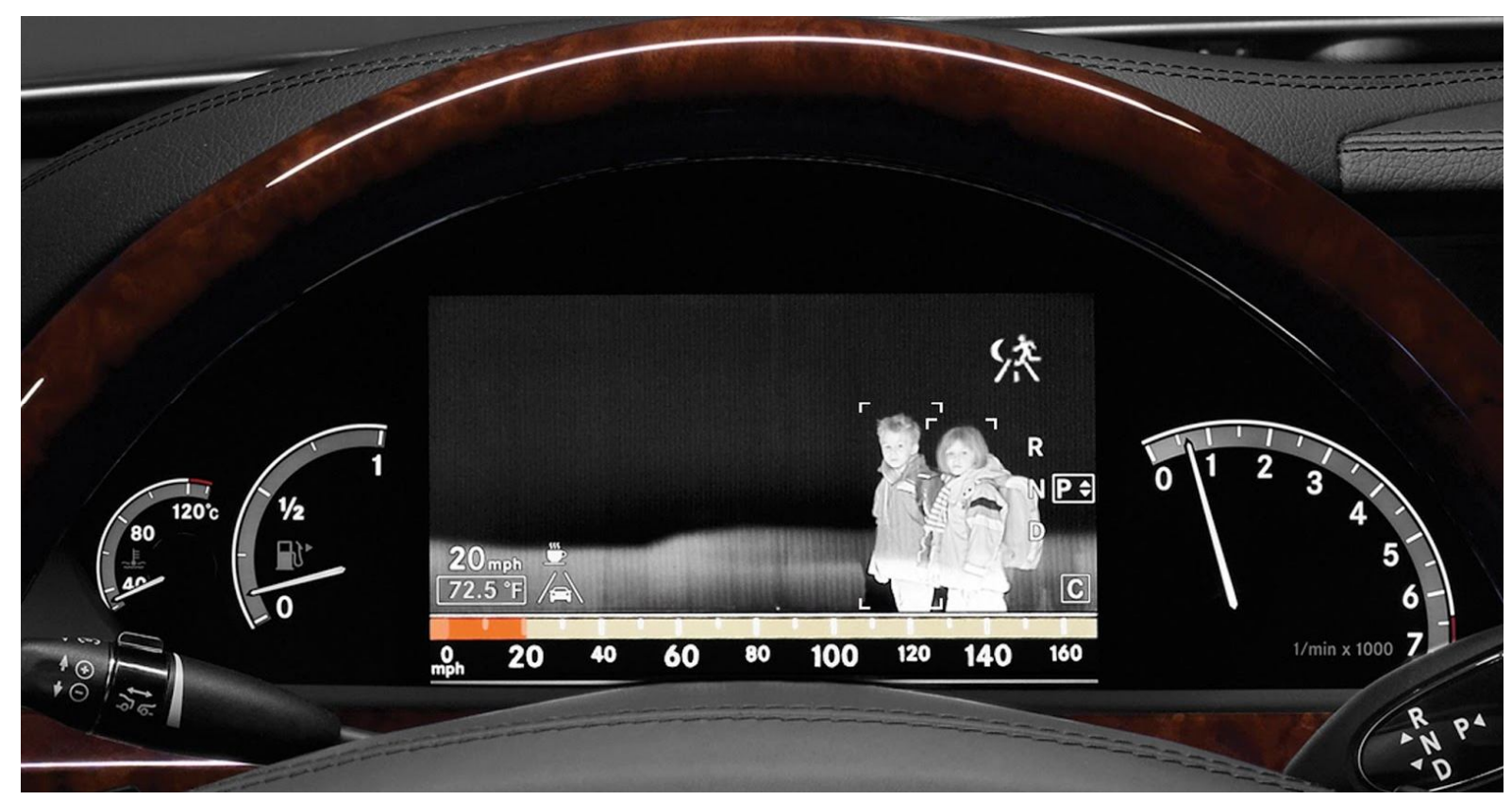




\section{Рисунок 5.2. Система ночного видения}

Во втором поколении этой системы реализована функция распознавания пешеходов: как только система «видит» пешехода впереди машины, эта информация тут же отражается на дисплее.

\subsection{3. Система мониторинга положения автомобиля}

Еще одной новинкой от Мерседес станет интеллектуальная система предотвращения ДТП, вызванных непроизвольным съездом автомобиля с выбранной полосы движения. Более трети смертей на дорогах Германии приходится на ДТП такого типа. Именно поэтому инженеры Мерседес-Бенц разработали превентивную систему мониторинга положения автомобиля Active Lane Keeping Assist (рисунок 5.3).

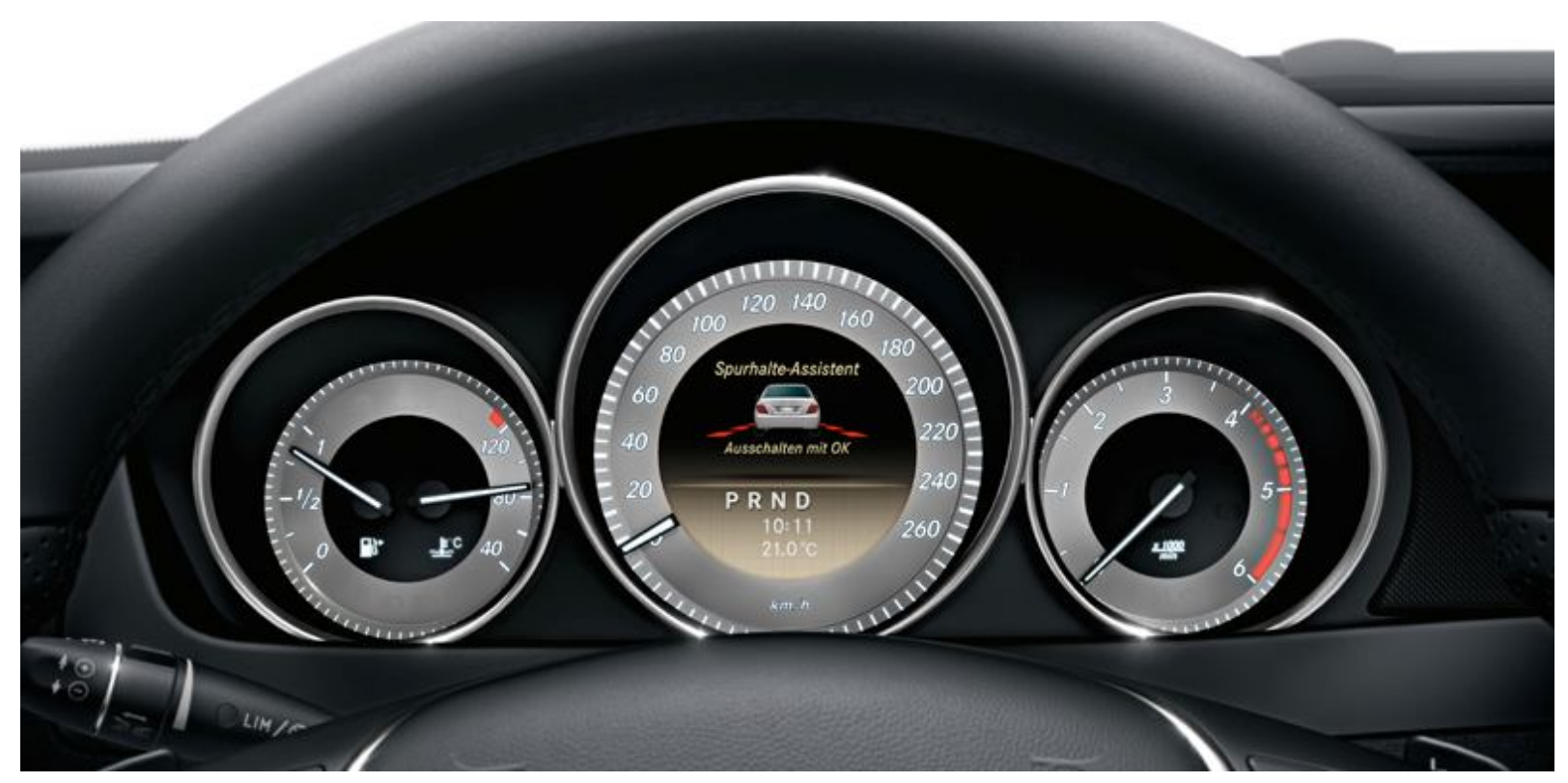

Рисунок 5.3. Система мониторинга положения автомобиля

Видеокамера непрерывно фриксирует положение автомобиля в рамках выбранной водителем полосы движения, 
а также анализирует действия самого водителя. Система способна распознать ситуацию, когда автомобиль непроизвольно уклоняется с выбранной полосы и возникает риск ДТП. В этом случае система заблаговременно оповещает об этом водителя с помощью вибрации рулевого колеса, заставляя его скорректировать траекторию движения.

В отличие от представленных на рынке систем, данная система также оценивает действия водителя, что позволяет с большой точностью определить заведомую непреднамеренность маневра. Система не сработает, если водитель ускоряется перед обгоном или при выезде на автомагистраль, пользуется тормозом или рулит для входа в поворот. Если система определит непреднамеренный сход с полосы движения, то активируется электропривод в рулевом колесе, который заставляет его вибрировать. Время оповещения разнится в зависимости от ширины дороги и от типа дорожной разметки. Если автомобиль пересекает сплошную полосу разметки, система сработает раньше, чем при пересечении прерывистой.

\subsection{4. Система распознавания дорожных знаков}

Еще одна новая интеллектуальная система напоминает водителю о действующем на данном участке дороги ограничении скорости. Камера, расположенная на лобовом стекле, распознает знаки ограничения скорости во время движения автомобиля и затем отображает максимально допустимую скорость на дисплее спидометра. Водитель всегда оповещен о максимально допустимой скорости и может 
скорректировать её. Дисплей выключается, когда скорость автомобиля снижается до допустимой.

Благодаря большим успехам, достигнутым в области обработки изображений, система Speed Limit Assist (рисунок 5.4) способна работать в реальном времени, анализируя графрическую информацию за десятые доли секунды.

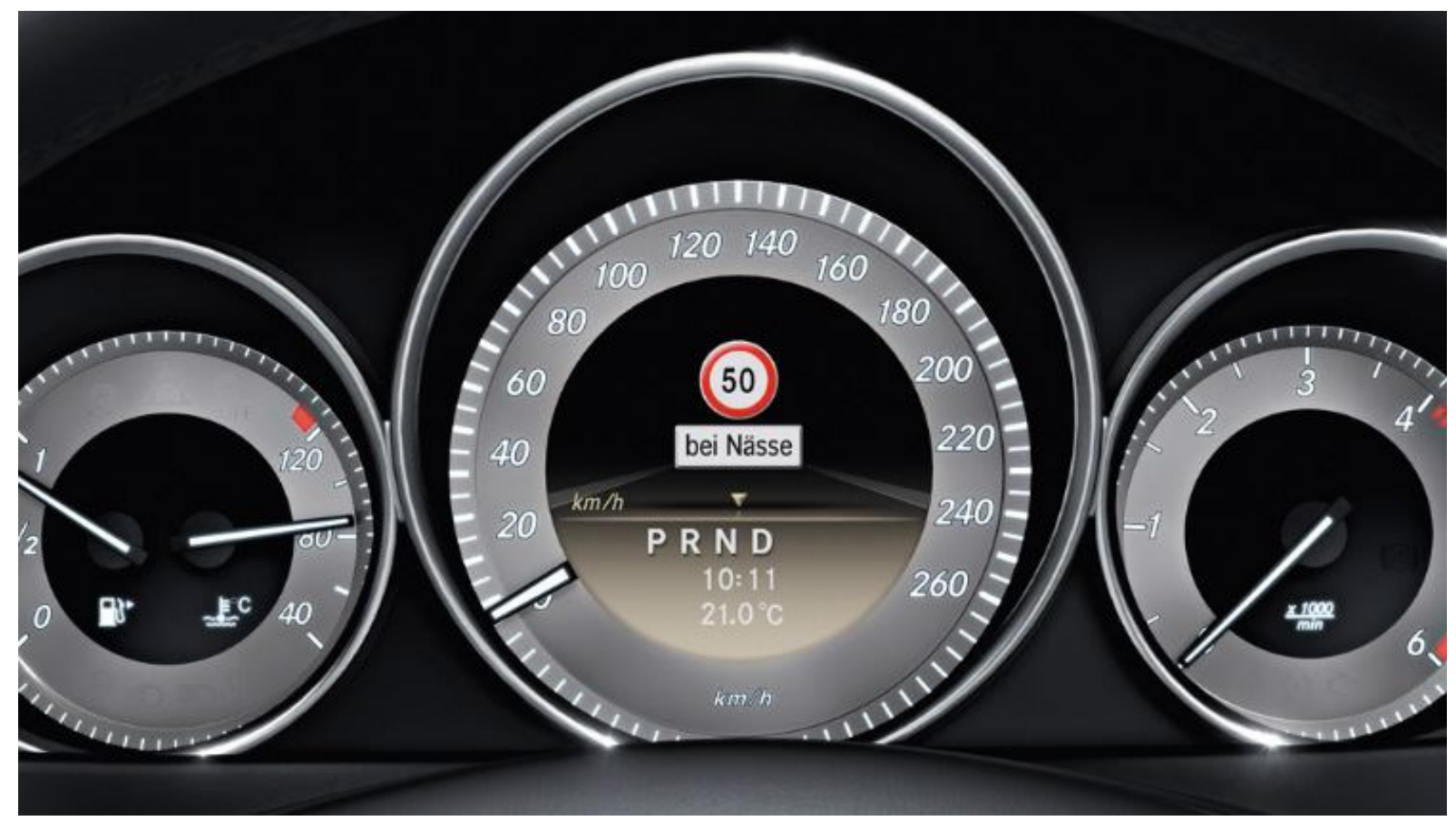

\section{Рисунок 5.4 - Система распознавания дорожных знаков}

Таким образом, при движении автомобиля у водителя всегда есть информация о действующих ограничениях скорости. Система одинаково эффективно распознает знаки как сбоку дороги, так и находящиеся на перетяжках над дорогой.

Более того, Speed Limit Assist анализирует данные из загруженной В навигационную систему цифровой карты, проверяя достоверность информации, полученной от камеры. Например, если навигационная система определяет, что автомобиль въехал в населенный пункт, то данные о последнем 
ограничении скорости, полученные от камеры, стираются с дисплея.

\subsection{5. Система контроля степени усталости водителя}

Благодаря новой технологии в будущих моделях Мерседес-Бенц автомобиль сможет контролировать степень усталости водителя. Цель системы - заблаговременно определить сонливость водителя и не допустить его засыпания за рулем. Согласно данным исследований, примерно четверть серьезных ДТП происходит из-за засыпания водителя.

Система Attention Assist (рисунок 5.5) снабжена высокочувствительными датчиками, которые контролируют поведение водителя, текущую дорожную обстановка, а также еще более 70 прочих параметров.

Благодаря этим данным, система в состоянии определить, когда концентрация внимания водителя начинает снижаться. Непрерывность анализа данных системы очень важна, чтобы определить переходное состояние между бодрствованием и сном и предупредить об этом водителя на ранней стадии. Помимо скорости движения, бокового и продольного ускорения автомобиля, система также анализирует, как водитель использует поворотники и педали, а также его реакцию на внешние воздействия, такие как боковой ветер и неровности на дороге. 


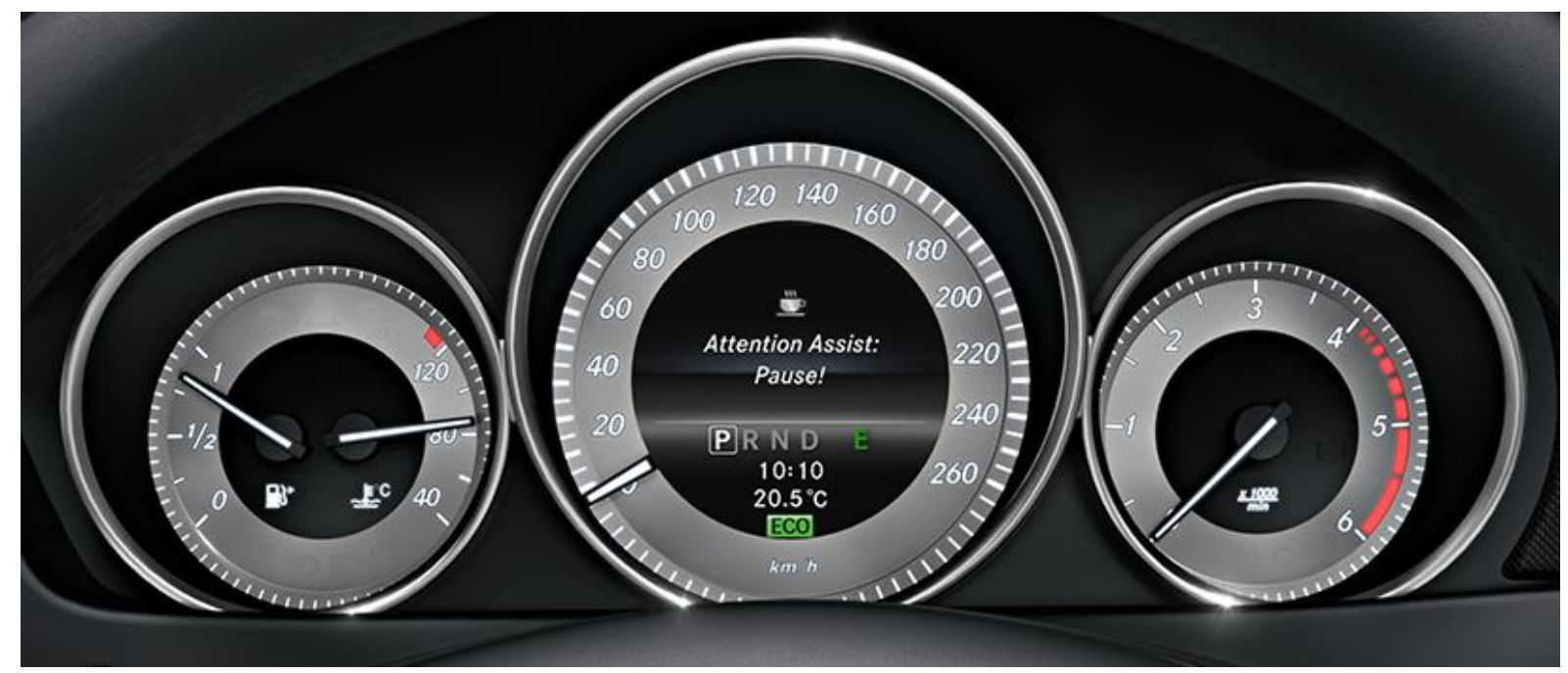

Рисунок 5.5 - Система контроля степени усталости водителя

С точки зрения анализа состояния водителя, очень полезным является оценка особенностей его руления. Полевые испытания, проводимые инженерами Мерседес-Бенц в течение последних нескольких лет и в которых приняли участие на данный момент более 550 водителей, доказывают, что сонные водители корректируют небольшие уводы автомобиля с курса неоправданно быстрыми и резкими движениями руля. Это регистрируется высокочувствительным датчиком углового положения рулевого колеса. Если Attention Assist определяет типичные проявления сонливости водителя по этим и другим параметрам, то немедленно включается звуковой сигнал, а на дисплее появляется мигающая надпись «ATTENTION ASSIST. Break!».

\subsection{6. Система натяжения ремней безопасности перед неизбежным столкновением}

Еще одной системой, входящей в стандартное оснащение этих моделей, станет PRE-SAFE® - система преднатяжения 
ремней безопасности водителя и пассажиров. Система анализирует данные датчиков и на основании полученной информации определяет ситуацию, которая может привести к ДТП. При этом мгновенно осуществляется комплекс превентивных мер, позволяющих ремням безопасности и подушкам безопасности сработать максимально эффективно в случае столкновения.

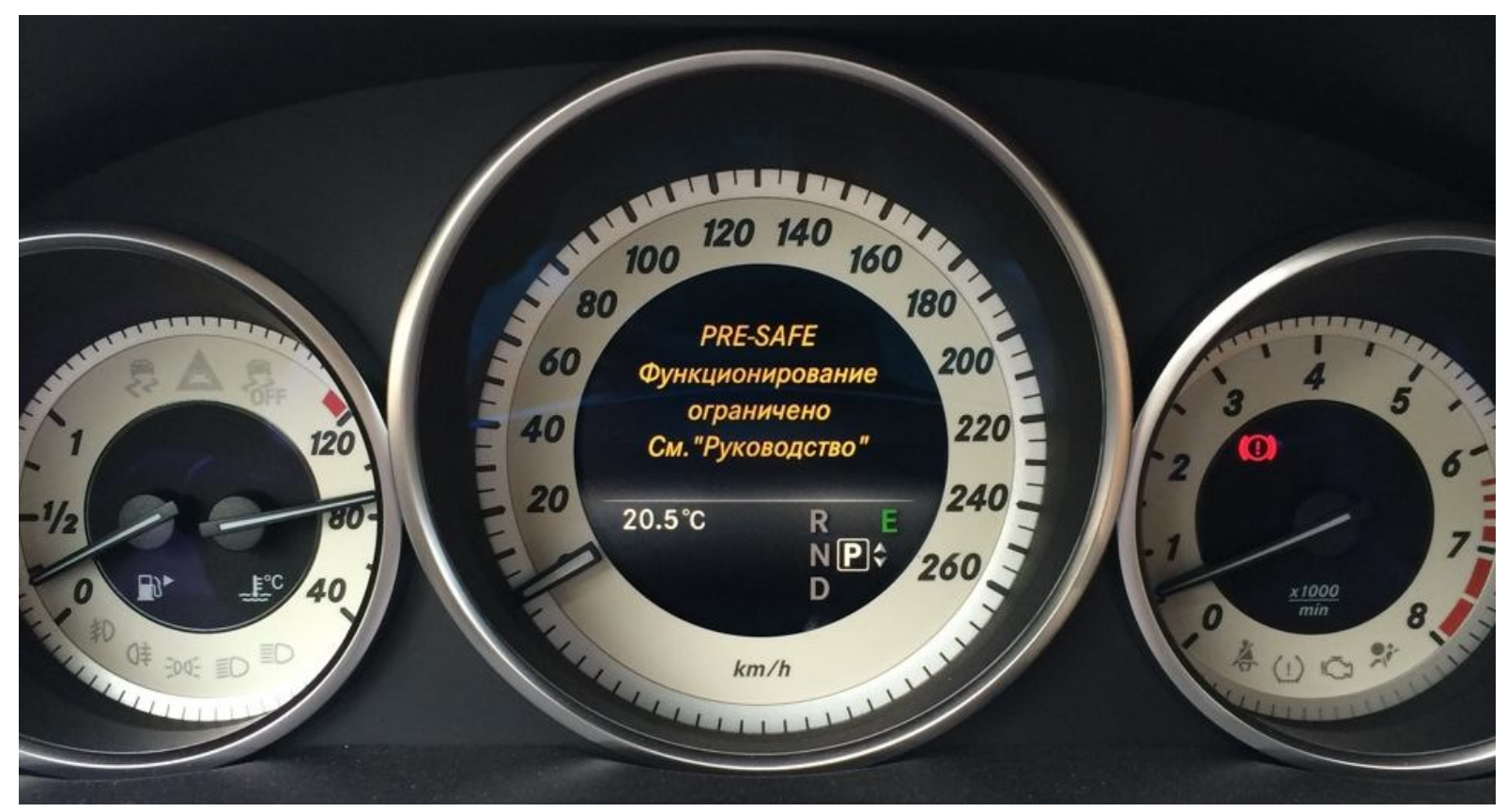

Рисунок 5.6 - Система натяжения ремней безопасности

Таким образом, PRE-SAFE® является связующим звеном между системами активной и пассивной безопасности, она взаимодействует с системами Brake Assist и Electronic Stability Program (ESP®), датчики которых способны распознать потенциально опасную ситуацию при движении автомобиля и передать эту информацию в распоряжение блока управления за тысячные доли секунды.

Еще одной новинкой является использование радара ближнего радиуса действия: получаемая информация при 
необходимости будет приводить к срабатыванию натяжителей ремней в самый последний момент перед неизбежным столкновением, что значительно снизит нагрузку на водителя и переднего пассажира в момент удара.

\subsection{7. Система радарных датчиков среднего и дальнего радиуса действия для предотвращения столкновений}

\section{DISTRONIC PLUS $и$ Brake Assist PLUS -}

интеллектуальные системы безопасности, разработанные инженерами Мерседес-Бенц с применением современных технологий на основе радарных датчиков, - доказали свою эфффективность в деле предотвращения столкновений (рисунок $5.7)$.

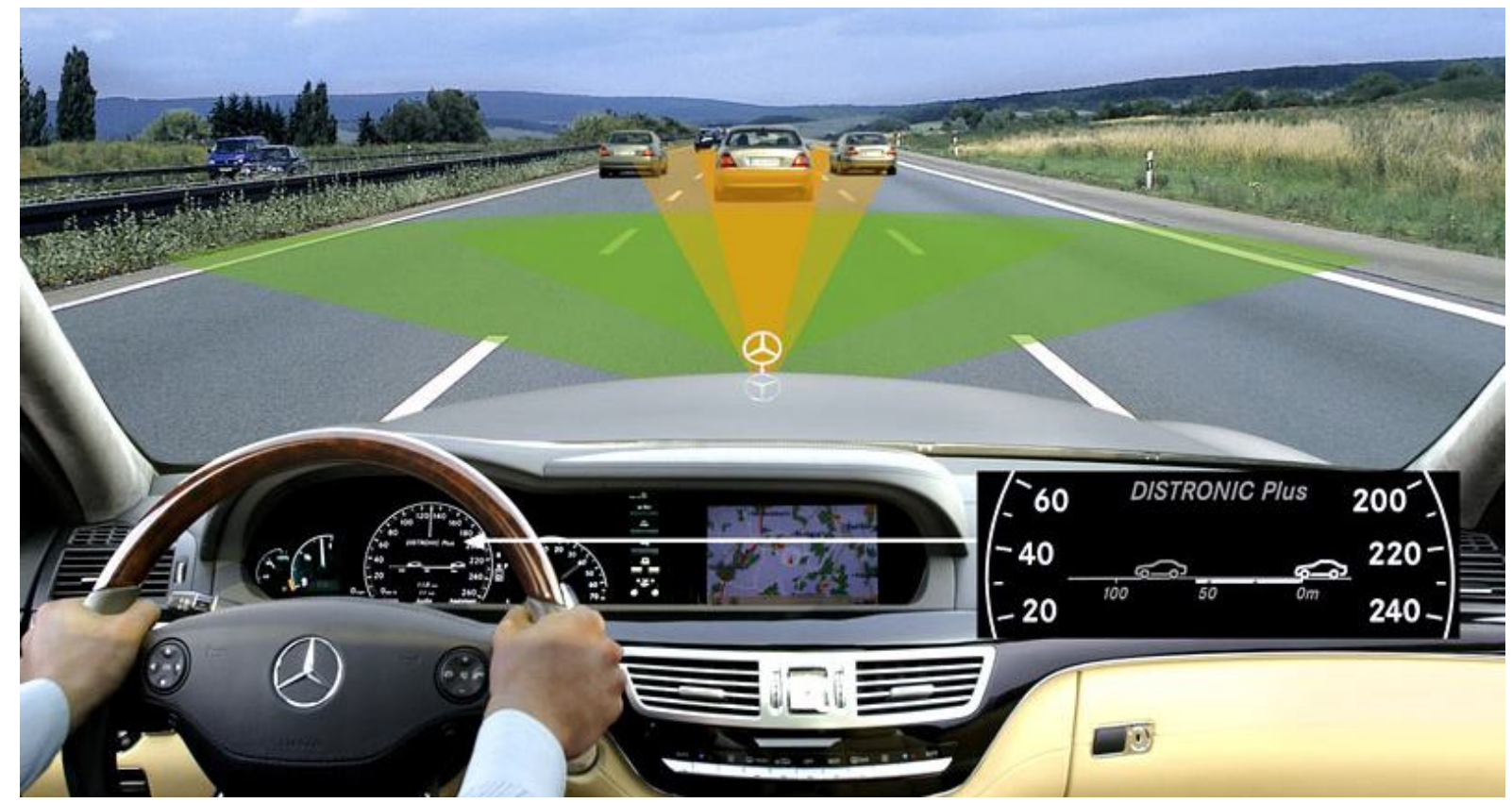

Рисунок 5.7 - Система радарных датчиков среднего и дальнего радиуса действия для предотвращения

\section{столкновений}

Анализ реальных ДТП, имевших место в Германии, показывает, что использование данной технологии в среднем 
может предотвратить до $20 \%$ столкновений с движущейся впереди машиной. При движении по автомагистрали, частоту возникновения такого типа ДТП можно уменьшить на $36 \%$.

Радарная система дальнего радиуса действия действует на расстоянии до 200 м. Помимо этого, датчик может действовать и на средней дистанции, что позволяет контролировать область до 60 м перед автомобилем, с углом охвата 60 градусов. Это позволяет более точно оценивать дорожную обстановку впереди автомобиля и лучше отслеживать движущиеся объекты, к примеру, неожиданное изменение курса впереди идущего транспортного средства. Также используются два широкоугольных радарных датчика ближнего радиуса действия с углом охвата 80 градусов в ширину при дальности действия до 30 метров.

Используемая на новых моделях радарная система способна не только оповестить водителей о неизбежном столкновении с впереди идущим автомобилем, но и помочь осуществить экстренное торможение.

Радары взаимодействуют с системой Brake Assist PLUS, которая автоматически рассчитывает тормозное усилие, необходимое для предотвращения столкновения. Данная интеллектуальная система, активирующаяся при нажатии водителем педали тормоза, обеспечивает необходимое и достаточное замедление или, при необходимости, экстренное торможение, в зависимости от скорости движения и расстояния до впереди идущей машины.

Если водитель не реагирует на предупреждающие сигналы системы Brake Assist PLUS, то автоматически задействуется система PRE-SAFE $®$ Brake, которая начинает 
самостоятельно тормозить автомобиль, задействуя 40\% от максимального тормозного потенциала примерно за 1,6 секунд до расчетного момента столкновения.

Если водитель продолжает бездействовать и при автоматическом частичном срабатывании тормозной системы, то PRE-SAFE® Brake активирует на 100\% весь тормозной потенциал автомобиля примерно за 0,6 секунд до столкновения. Подобные действия позволяют значительно снизить степень тяжести столкновения. Данная система действует как «электронная» зона деформации, обеспечивая больший уровень безопасности водителю и пассажирам автомобиля.

\section{2. ИНТЕЛЛЕКТУАЛЬНАЯ СИСТЕМА УПРАВЛЕНИЯ НАЗЕМНЫМ ГОРОДСКИМ ПАССАЖИРСКИМ ТРАНСПОРТОМ}

\subsection{1. Общие сведения об интеллектуальной транспортной системе}

Интеллектуальная транспортная система (ИТС, англ. Intelligent transportation system) - это интеллектуальная система, использующая инновационные разработки в моделировании транспортных систем и регулировании транспортных потоков, предоставляющая конечным потребителям большую информативность и безопасность, а также качественно повышающая уровень взаимодействия участников движения по сравнению с обычными транспортными системами.

Несмотря на то, что фрактически ИТС может включать все виды транспорта, европейское определение ИТС согласно директиве 2010/40/EU of 7 July 2010 трактует ИТС как систему, в 
которой применяются информационные и коммуникационные технологии в сфрере автотранспорта (включая инфраструктуру, транспортные средства, участников системы, а также дорожнотранспортное регулирование), и имеющую наряду с этим возможность взаимодействия с другими видами транспорта.

Интерес к ИТС появился с приходом проблем дорожных заторов как результат объединения современных технологий моделирования, управления в реальном времени, а также коммуникационных технологий. Дорожные заторы появляются по всему миру как результат увеличивающейся автомобилизации, урбанизации, а также как роста населения, так и увеличивающейся плотности заселения территории. Дорожные заторы уменьшают эффрективность дорожнотранспортной инфраструктуры, увеличивая таким образом время пути, расход топлива и уровень загрязнения окружающей среды.

ИТС различаются по применяемым технологиям: от простых систем автомобильной навигации, регулирования светофоров, систем регулирования грузоперевозок, различных систем оповестительных знаков (включая информационные табло), систем распознавания автомобильных номеров и систем регистрации скорости транспортных средств, до систем видеонаблюдения, а также до систем, интегрирующих информационные потоки и потоки обратной связи из большого количества различных источников, например из систем управления парковками (Parking guidance and information (PGI) systems), метеослужб, систем разведения мостов и прочих. Более того, в ИТС могут применяться технологии 
предсказывания на основе моделирования и накопленной ранее информации.

В ИТС могут использоваться различные виды беспроводной связи.

Например, может использоваться радиосвязь на большие (ДМВ) и короткие (УКВ) расстояния.

На небольших расстояниях может использоваться беспроводная связь по стандартам IEEE 802.11 (Wi-Fi), особенно стандарт IEEE 802.11p (WAVE). Также, например, в США используется стандарт DSRC, продвигаемый американской общественной организацией интеллектуального транспорта и департаментом транспорта США.

Также могут использоваться технологии WiMAX, GSM, 3G или 4G.

Современные разработки в технологиях встраиваемых систем позволяют использовать операционные системы реального времени, а также более высокоуровневые приложения, дающие возможность применять разработки в области искусственного интеллекта. Рост мощностей процессоров, используемых во встраиваемых системах, а также повышение их совместимости с процессорами в персональных компьютерах, ведёт к расширению возможностей повторного использования кода и переносу более интеллектуальных сервисов с уровня ПК в уровень встраиваемой системы.

\subsection{2. Концепция интеллектуальной транспортной системы}

В целях решения проблемы перегруженности городских автомагистралей, повышения эффеективности управления дорожным движением Правительство Москвы своим 
постановлением от 11.01.2011 №1-ПП утвердило Концепцию интеллектуальной транспортной системы (рисунок 5.8).

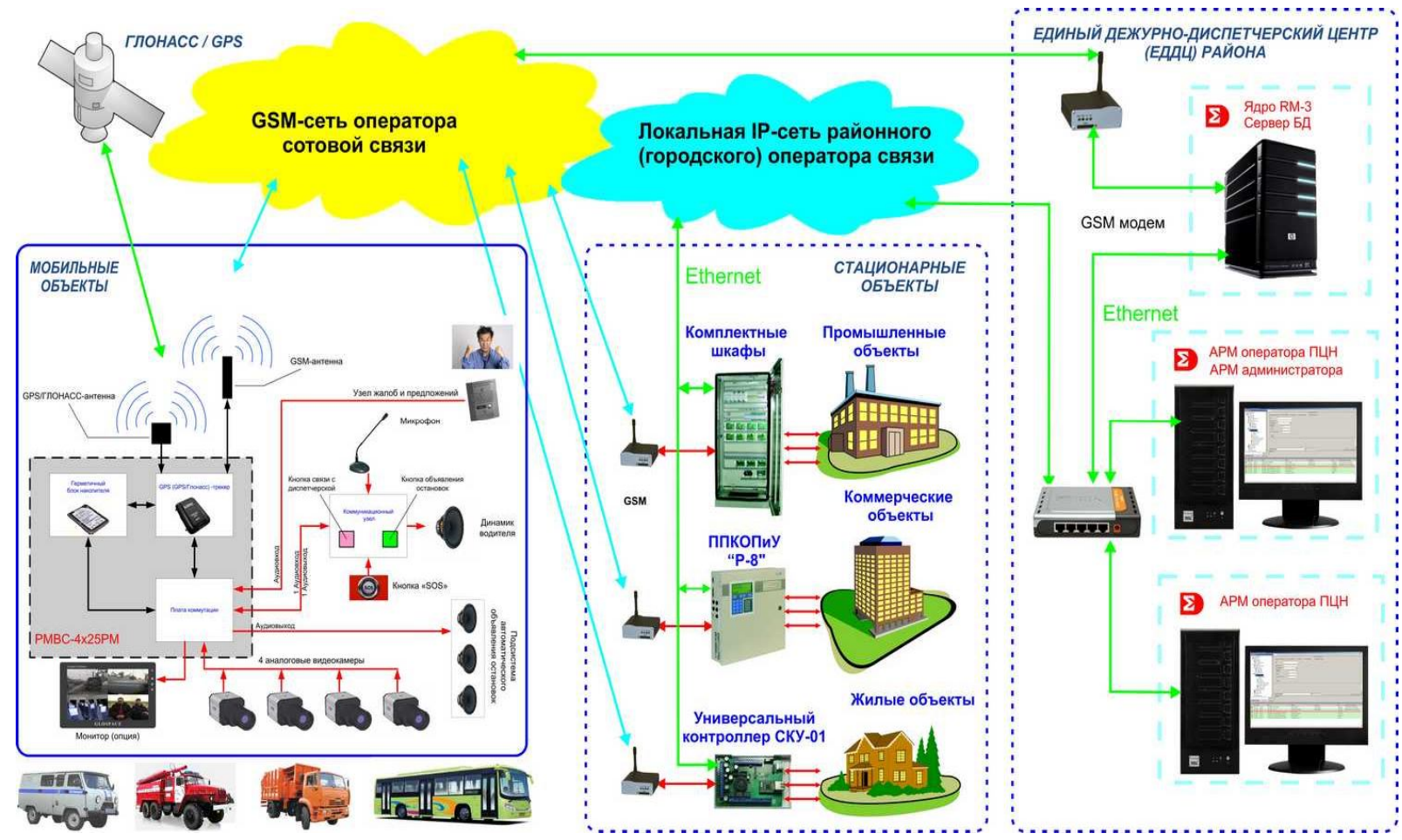

\section{Рисунок 5.8 - Обобщенная структура интеллектуальной}

\section{транспортной системы города}

Для решения существующих транспортных проблем и улучшения условий движения транспорта необходимо иметь достоверную информацию о складывающейся дорожнотранспортной ситуации, а также соответствующие организационные и технические возможности, позволяющие на нее воздействовать. В целях эффрективного управления перевозками на наземном городском пассажирском транспорте и координации деятельности оперативных специальных и иных городских служб необходимо создание единой навигационноинфрормационной системы. Для оптимальной реализации положений Концепции необходимо создать единую интеллектуальную систему, чтобы она могла осуществлять: 
- сбор сведений о параметрах транспортных потоков;

- функцию автоматического выявления инцидентов;

- фриксацию нарушений правил дорожного движения;

- сбор сведений о наличии парковочных мест;

- контроль за движением общественного (пассажирского) и специального транспорта, а также автотранспорта служб городского хозяйства;

- передачу информации на абонентские (пользовательские) мобильные электронные устройства;

- функционирование геоинформационного ресурса.

Конструктивное решение, которое может комплексно выполнить поставленные задачи, на рынке уже существует. Это российская разработка, пока не имеющая аналогов в мире.

Система видеонаблюдения и диспетчеризации для государственного и муниципального автотранспорта является новейшей совместной разработкой НПФ «СИГМА-ИС» и НИИ космического приборостроения. Данная система сможет обеспечить высокий уровень безопасности на российском транспорте, включая возможность быстрого реагирования на тревожные события. Основным элементом системы является видеорегистратор со встроенной функцией определения координат по сигналам со спутников ГЛОНACC/GPS, который занял 1-е место в конкурсе инновационных продуктов на главном российском форуме по безопасности MIPS-2011. Помимо этого, система соответствует всем мировым требованиям для аналогичных подсистем и была представлена на международной конференции The IEEE International 
Symposium on Broadband Multimedia Systems and Broadcasting B Германии.

Главной целью создания системы является обеспечение максимальной степени безопасности всех участников транспортного движения, создание условий для непрерывного и безопасного движения транспортных потоков. Система обеспечит оперативное обнаружение любой нештатной и чрезвычайной ситуации, а также быстро передаст информацию на центр мониторинга (видеоизображение, видеокадры, сигналы от кнопки SOS, охранных и технологических датчиков).

Система может осуществлять:

- обработку видео- и аудиоданных;

- запись полученных данных;

- получение координаты местонахождения транспортного средства во время движения в режиме онлайн со спутников ГЛОНACC/GPS;

- дуплексную связь по GSM-каналу между водителем транспортного средства и диспетчерским пультом;

- подключение внешних источников видео- и аудиосигналов;

- отображение видео со всех подключенных камер одновременно в режиме квадратора;

- использование интеллектуальных видеодетекторов.

Функции новой системы дают следующие возможности:

- контроль за местоположением, маршрутом, скоростью, расходом топлива и другими параметрами транспортного средства; 
- собирать и выдавать актуальную информацию о качестве дорожного покрытия, плотности движения, наличии пробок;

- воспроизведение видео в режиме реального времени на внешний монитор;

- сопоставление видеозаписи маршрута координатам на карте;

- распознавать и сообщать об оставленных вещах, кражах, вандализме, заснувшем водителе, нарушителях порядка, количестве пассажиров;

- дистанционное управление системами транспортного средства (тормозная система, бортовая электрическая сеть, двигатель и др.);

- создать базу данных изображений отдельных участков: сложные дорожные развязки с возможностью наложения навигационных знаков на фотоизображение, изображения достопримечательностей для помощи автотуристам и др.

Контроль состояния объектов осуществляется путем обмена информацией между объектовыми устройствами, устанавливаемыми на стационарных и подвижных охраняемых, и центром мониторинга, оборудованным автоматизированными рабочими местами дежурного (оператора).

\subsection{3. Интеллектуальная система мониторинга улично- дорожной сети}

Основная проблема городской транспортной системы несоответствие пропускной способности улично-дорожной сети 
реальному спросу на транспортные услуги. Все города мира решают проблему достижения транспортного баланса между спросом на движение и реальной пропускной способностью улично-дорожной сети сочетанием мер по совершенствованию дорожной сети и управления движением с мерами по созданию приоритета движению общественного транспорта над личным. Москва быть исключением из этого правила не может.

Для решения существующих транспортных проблем и улучшения условий дорожного движения в соответствии с постановлением Правительства Москвы проводятся работы по созданию Интеллектуальной транспортной системы города: вводятся платные парковки и ограничения на въезд в определенные зоны города, фрормируются полосы для приоритетного движения общественного транспорта, оптимизируются алгоритмы управления светофорной сигнализацией, вводятся средства автоматической фриксации нарушения Правил дорожного движения, ведется мониторинг условий движения в реальном масштабе времени, развиваются функции информирования участников движения о дорожных условиях, о графиках движения общественного транспорта, о наличии свободных мест на парковках и т.д.

Система мониторинга улично-дорожной сети предназначена для эффективного управления транспортными потоками, увеличения пропускной способности уличнодорожной сети, предотвращения автомобильных заторов, уменьшения задержек в движении транспорта, повышения безопасности дорожного движения, информирования участников движения о складывающейся дорожно-транспортной ситуации и вариантах оптимального маршрута движения, 
обеспечения бесперебойного движения наземного городского пассажирского транспорта.

Состав система мониторинга улично-дорожной сети:

- система мониторинга параметров транспортных потоков;

- система инфрормирования участников дорожного движения;

- система управления техническими средствами регулирования и организации дорожного движения;

- система телеобзора; система управления парковочным пространством;

- система фротовидеофиксации нарушений Правил дорожного движения;

- система навигационно-информационного обеспечения на основе ГЛОНАСС.

В настоящее время ведутся работы по обустройству улично-дорожной сети городов и подвижного состава наземного городского пассажирского транспорта техническими средствами ИТС, созданию управляющего аппаратно-программного комплекса, центров управления движением и центра обработки данных системы фотовидеофиксации (рисунок 5.9). 


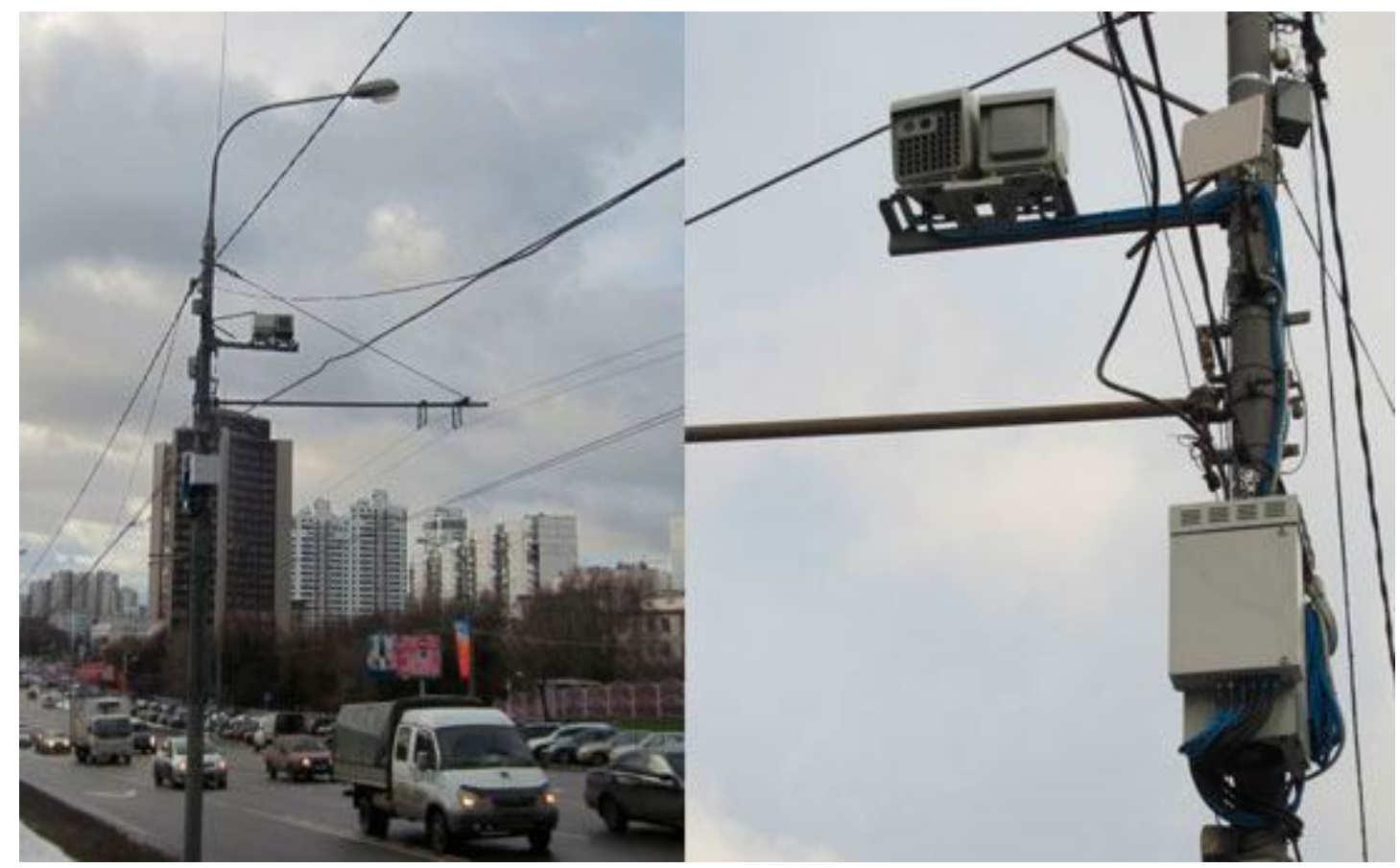

Рисунок 5.9 - Система фотовидефиксации

Уже сегодня имеется возможность получения и анализа данных о параметрах транспортных потоков, в адаптивный режим управления введено значительное количество светофрорных объекта (перекрестков), осуществляется диспетчерское управление и контроль движения части подвижного состава ГУП «МОСГОРТРАНС». Реализуется функция автоматизированного информирования участников дорожного движения о складывающейся ситуации. Функционирует Центр автоматизированной фриксации административных правонарушений в области дорожного движения УГИБДД ГУ МВД России по г. Москве (ЦАФАП ОДД).

В настоящее время создан Ситуационный центр (рисунок 5.10) - самый современный в Европе. 


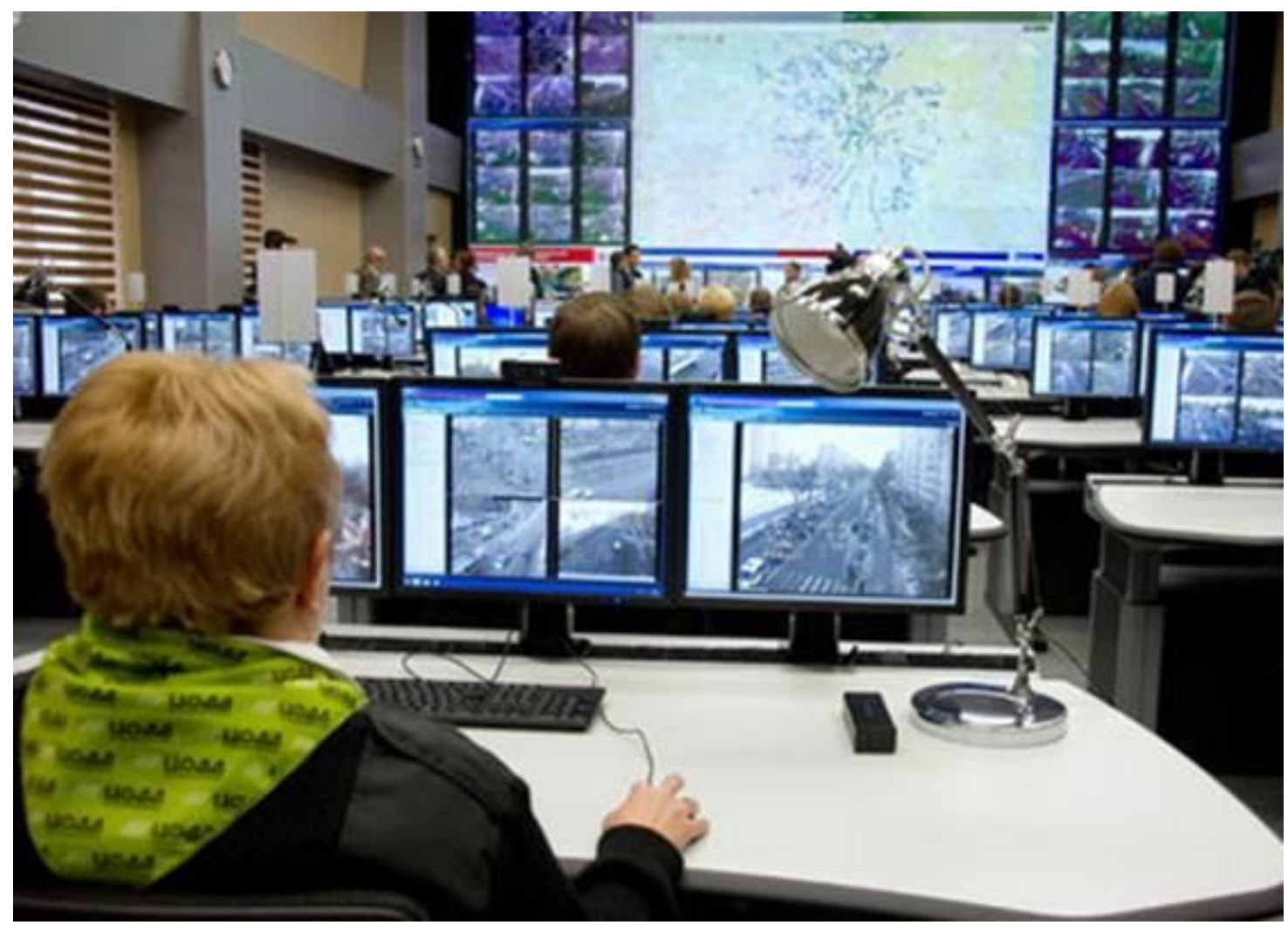

Рисунок 5.10 - Ситуационный центр

Значительное количество единиц подвижного состава наземного городского пассажирского транспорта оснащены терминалами ГЛОНАСС.

В городе установлены электронные табло (рисунок 5.11) отображения инфрормации, комплексы фротовидеофиксации нарушений Правил дорожного движения, контролируется парковочные места. 


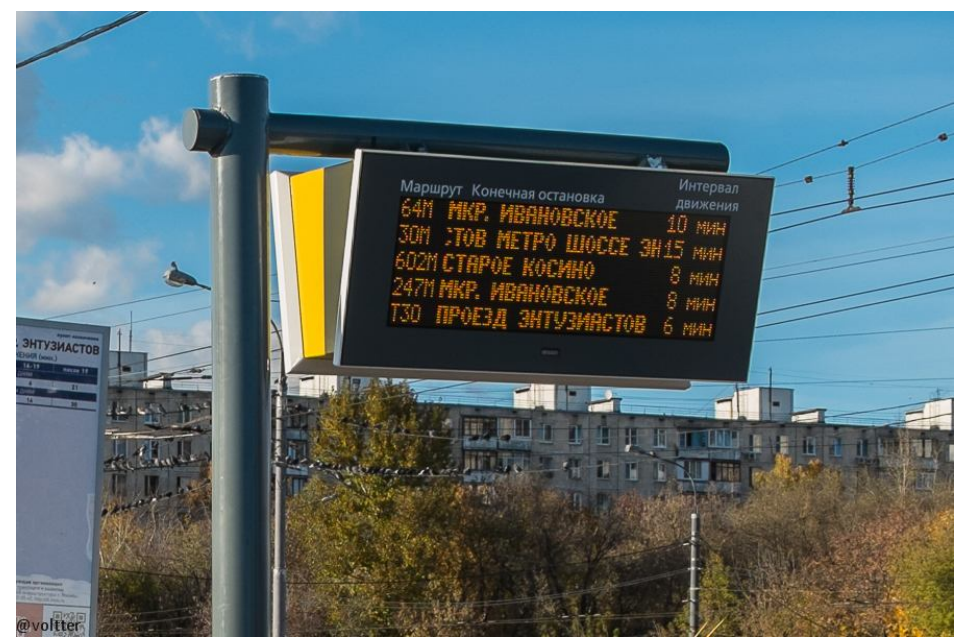

\section{Рисунок 5.11 - Электронное табло}

Управление в транспортном комплексе одного из крупнейших мегаполисов мира (г. Москва) - сложный и многофункциональный процесс. Создание ИТС в этих условиях - это непрерывное наращивание фрункциональных возможностей и расширение зоны действия.

В состав ИТС включены транспортные средства, перевозящие специальные, опасные, крупногабаритные и тяжеловесные грузы, транспортные средства территориального центра медицины катастроф, скорой и неотложной медицинской помощи, транспортные средства организаций жилищнокоммунального хозяйства, включая снегоуборочные машины, мусоровозы и др.

Важнейшим направлением функционального развития ИТС остается информирование участников дорожного движения. Самый интеллектуальный элемент интеллектуальной транспортной системы - это человек. От того, насколько человек будет осознанно участвовать в дорожном движении, насколько уважительно будет относиться к 
другим участника зависит обстановка на дороге: и в плане безопасности, и в плане времени поездки, и в плане экологии.

А ИТС должна и будет создавать условия для разумного выбора вариантов действий и принятия решений в пути. Несомненно, будет расширяться применение Интернет и ГЛОНАСС технологий с тем, чтобы водители могли выбирать альтернативные маршруты движения.

Необходимо доводить до водителей информацию о наличии свободных мест на парковках. Опыт многих городов мира говорит о полезности информации о погодных условиях, о загрязнении воздуха, об изменениях в организации движения.

В более широком плане водителя надо начинать информировать до того, как выйдет из дома - с тем, чтобы он имел возможность выбрать общественный транспорт в качестве альтернативы автомобильной поездке.

Только на этой основе в рамках функционирования интеллектуальной транспортной системы могут и будут решаться задачи обеспечения транспортного баланса между реальной пропускной способностью улично-дорожной сети и спросом на дорожное движение.

\subsection{4. Интеллектуальные системы повышения качества обслуживания пассажиров наземного городского пассажирского транспорта}

Интеллектуальные

информационные

системы

«Безопасный автобус» и «Умная остановка» являются элементами ИТС города, повышающими качество обслуживания пассажиров наземного общественного транспорта за счет предоставления им актуальной информации, обеспечения комфорта и безопасности. 


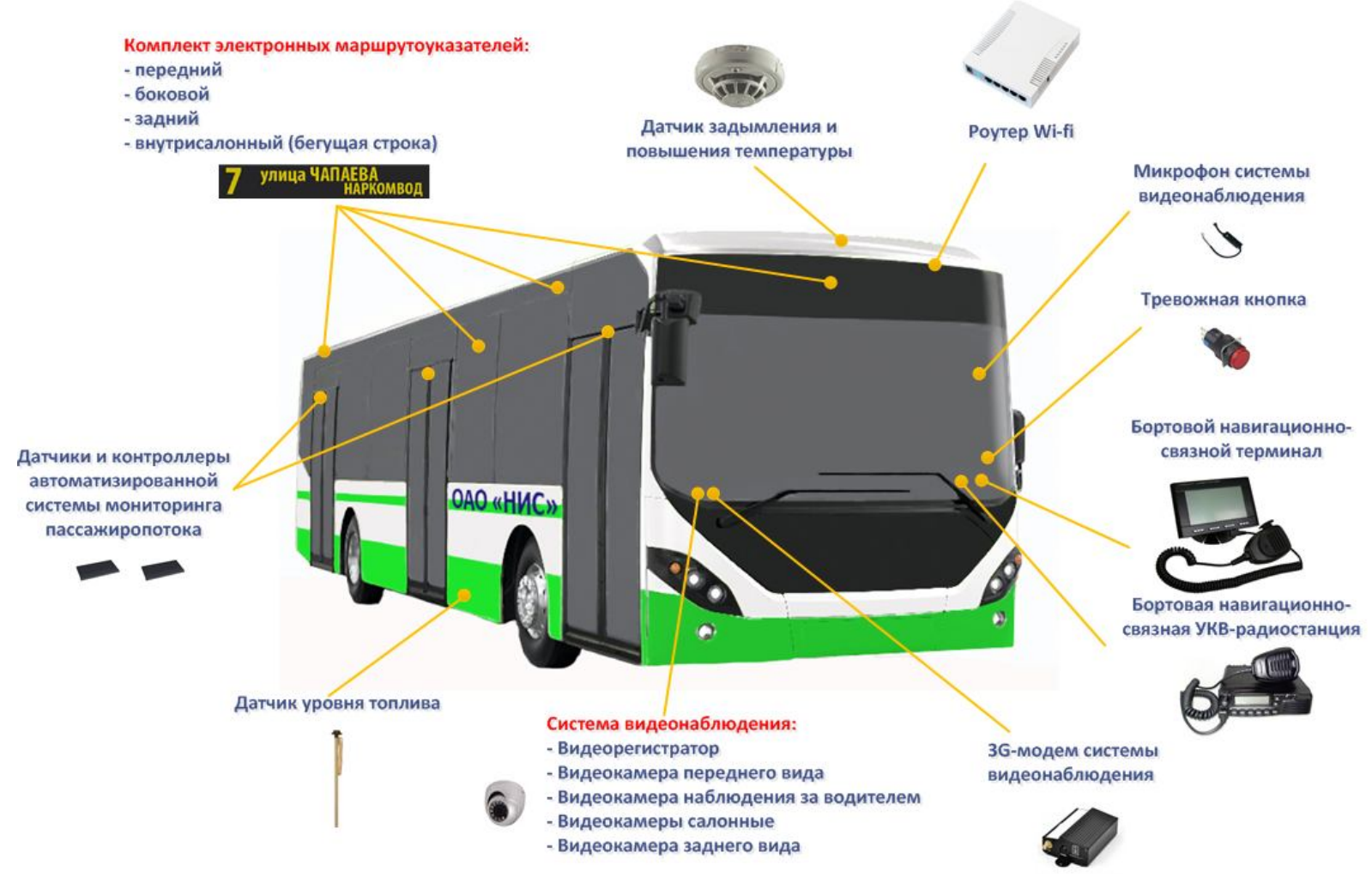

Рисунок 5.12 - «Безопасный автобус»

«Безопасный автобус» обеспечивает:

- видеонаблюдение в салоне транспортного средства;

- видеорегистрацию событий в салоне, кабине автобуса, а также дорожной обстановки;

- аудиорегистрацию переговоров водителя с помощью особо чувствительного скрытно установленного микрофона;

- вызов водителем диспетчера или служб экстренного реагирования с использованием скрытой кнопки подачи сигнала тревоги («тревожная кнопка»);

- мониторинг состояния среды в салоне (задымленность, температура воздуха);

- мониторинг пассажиропотоков с помощью бесконтактных датчиков, установленных над 
входными дверями автобуса, для подсчета вошедших и вышедших пассажиров;

- информирование пассажиров о номере маршрута, начальной и конечной остановке, направлении движения автобуса;

- информирование пассажиров о следующем остановочном пункте в режиме бегущей строки.

«Умная остановка» обеспечивает:

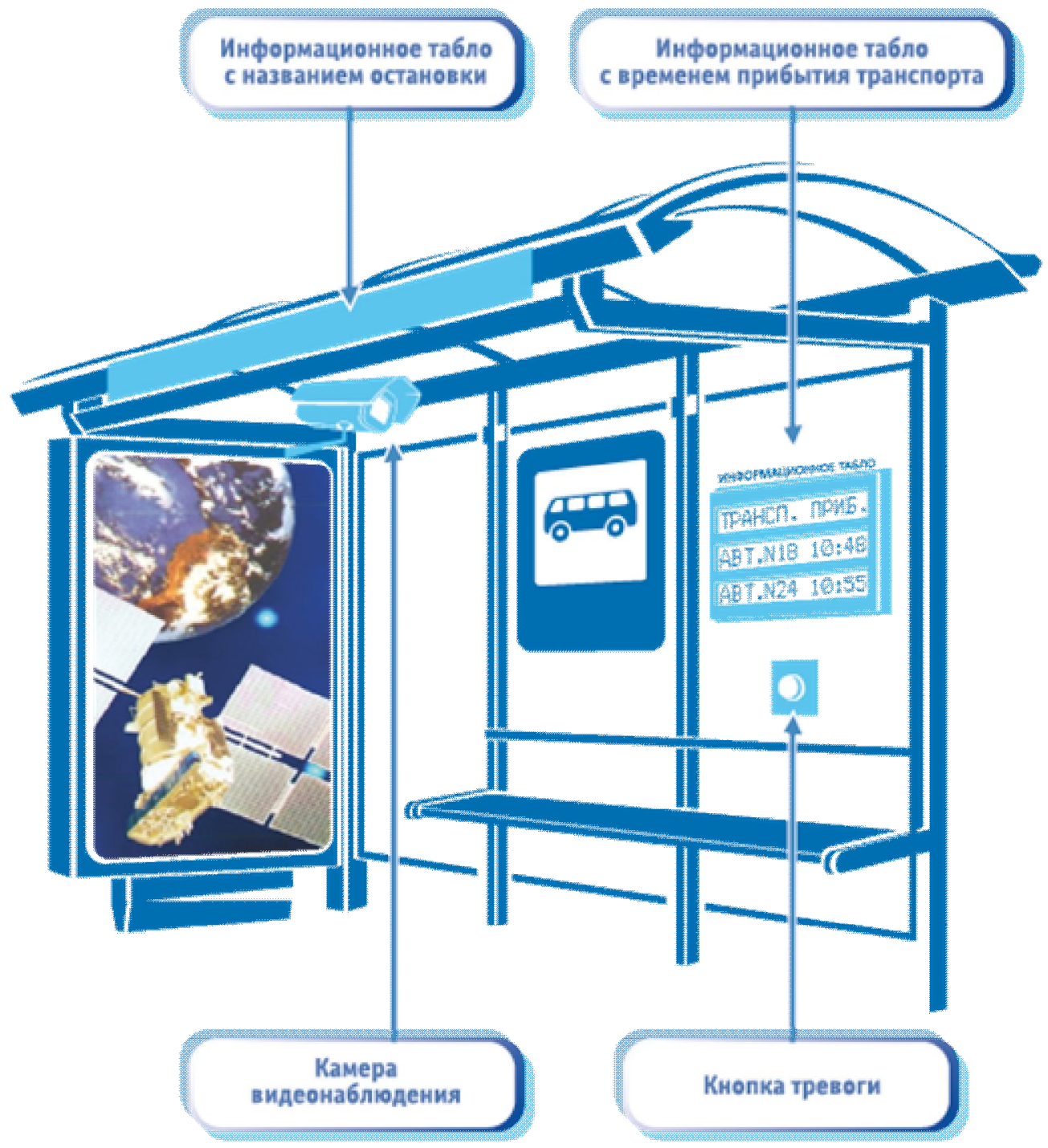

Рисунок 5.13 - «Умная остановка» 
- информирование пассажиров о времени прибытия автобусов/троллейбусов/трамваев на остановку в режиме реального времени;

- информирование пассажиров о номерах маршрутов и видах общественного транспорта, курсирующего на данной линии;

- инфрормирование пассажиров об изменениях в расписаниях и маршрутах движения общественного транспорта, изменениях тарифов на оплату проезда, возникновении внештатных ситуаций и т.п.;

- безопасность пассажиров за счет видеонаблюдения и возможности вызова диспетчера ситуационного центра и служб экстренного реагирования с помощью тревожной кнопки.

\section{3. ТРАНСПОРТНЫЕ СРЕДСТВА С ВЫСОКОЙ СТЕПЕНЬЮ АВТОМАТИЗАЦИИ}

В настоящее время происходит активное развитее и внедрение систем для создания высокоавтоматизированного транспорта, а также разрабатываются полностью беспилотные автомобили, осуществляющие движение без постоянного присутствия оператора на месте водителя. Внедрением автоматизированных транспортных средств занимаются крупнейшие организации различных стран, для описания транспортных средств, имеющих функции автоматизации, применяется ряд терминов, при этом ни один из них не является общепризнанным и нормативно закрепленным на международном уровне:

- Автономный автомобиль; 
- Высокоавтоматизированное транспортное средство;

- Беспилотный автомобиль;

- Роботизированный автомобиль;

- Беспилотное транспортное средство;

- И др.

Высокоавтоматизированное транспортное средство транспортное средство, выпущенное в обращение на территории Евразийского экономического союза, допущенное к участию в дорожном движении на территории Российской Федерации, в конструкцию которого внесены изменения, связанные с его оснащением автоматизированной системой вождения, и не подлежащее отчуждению в период проведения эксперимента.

Рассмотрим шесть уровней автоматизации вождения от «нет автоматизации» до полной автоматизации. Эти уровни являются описательными, а не нормативными и техническими или юридическими. Они подразумевают определенный порядок выхода на рынок.

Элементы указывают скорее минимум возможностей системы для каждого уровня. Конкретное транспортное средство может иметь несколько фрункций автоматизации, позволяющих работать на разных уровнях в зависимости от задействованных функций.

Система относится к системе помощи водителю, комбинации систем помощи водителю или автоматизированной системе вождения. Исключены системы предупреждения и мгновенного вмешательства, которые не автоматизируют какую-либо часть задачи динамического вождения на 
постоянной основе и, следовательно, не изменяют роль водителя в выполнении задачи динамического вождения.

\section{Уровень 0 - отсутствие автоматизации}

Структура SAE начинается с уровня 0: отсутствие автоматизации. Водитель-человек отвечает за $100 \%$ того, что SAE называет «задачей динамического вождения», что означает работу по фрактическому вождению автомобиля на постоянной основе.

Важно отметить следующий момент: существует множество современных автомобилей с функциями помощи водителю, которые по-прежнему соответствуют уровню 0.

Например, антиблокировочная система тормозов не считается автоматизацией, потому что человеку все равно приходится нажимать на педаль тормоза. Даже системы, которые автоматизируют сиюминутную задачу, такие как автоматические системы экстренного торможения, установленные на некоторых новых автомобилях, не считаются автоматизацией, потому что они не автоматизируют «динамическую задачу вождения» на постоянной основе.

Уровень 1 - Driver Assistance - Некоторая помощь для человека-водителя

Уровень 1 - самый низкий уровень автоматизации. Автомобиль имеет единый аспект автоматизации, который помогает водителю c ADAS. Примеры этого включают управление рулем, скоростью или управление торможением, но не более одного из них.

Помимо базовых моделей начального уровня, большинство автомобилей последних лет оснащено системой 
круиз-контроля. Принцип работы данной системы прост: водитель разгоняется до желаемой скорости, активирует режим круиз-контроля, и затем система будет удерживать автомобиль на этой скорости даже вверх и вниз по склонам уже после того, как водитель убирает ногу с педали акселератора.

Это не считается «автоматизацией» в рамках SAE, потому что динамическая часть задачи вождения не автоматизирована: человек все еще должен быть готов нажать на педаль тормоза (и деактивировать систему).

В последние годы автопроизводители начали предлагать более совершенные системы круиз-контроля, так называемый адаптивный круиз-контроль. Адаптивные системы круизконтроля умнее: они используют радар, чтобы держать ваш автомобиль на безопасном расстоянии от автомобиля впереди. Если автомобиль впереди замедляется, система автоматически замедляет автомобиль, чтобы сохранить безопасную дистанцию.

Благодаря адаптивному круиз-контролю одна часть задачи динамического вождения - управление ускорением и торможением - автоматизирована. Конечно, автоматизация происходит при определенных обстоятельствах, а именно когда водитель активирует систему во время движения по шоссе. Но этого достаточно, чтобы поднять адаптивную систему круизконтроля на уровень 1.

Уровень 2 - Partial Automation - частичная автоматизация

Автомобиль может одновременно контролировать ускорение и торможение, но человек должен следить за ситуацией и быть готовым принять управление. Примеры 
уровня 2 включают в себя помощь транспортным средствам в полосе движения и функции самостоятельной парковки с более чем одним аспектом ADAS.

Уровень 2 иногда может показаться самостоятельным вождением, HO это

не так. Супер круиз в автомобилях марки "Tesla" и автопилот в автомобилях "General Motors", которые могут разгоняться,

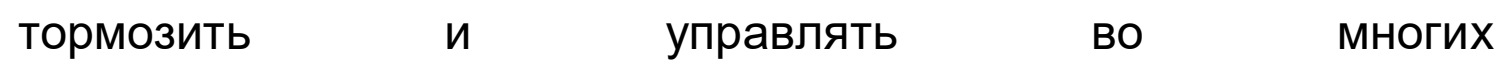
(но не во всех) обстоятельствах, безусловно, могут напоминать о «самостоятельном вождении». Но есть причина, по которой "General Motors" и "Tesla" очень осторожны, чтобы не описывать их как полностью самодвижущиеся системы в их нынешних формах: в обоих случаях водитель должен быть бдительным

и готовым снова взять на себя задачу вождения в самые кратчайшие сроки.

Это критическое различие. Если в короткие сроки требуется человек-водитель, то систему не следует называть «самостоятельным вождением». Вместо используется такое определение, как усовершенствованная система помощи водителю (ADAS).

Текущая версия автопилота "Tesla" предупреждает водителей не снимать

руки

с рулевого колеса во время использования системы. Более того, в системе предусмотрены датчики, позволяющие определить, находятся ли руки водителя на руле.

Если руки водителя не находятся на руле, система выдает визуальное напоминание через 30 секунд, а затем звуковое 
предупреждение через 45 секунд. Через минуту без вмешательства водителя система автопилота отключается и не может быть включена до тех пор, пока автомобиль не будет перезапущен.

Практика показывает, что такую систему легко обмануть водители могут просто подтолкнуть руль, когда загорятся огни, чтобы сбросить цикл предупреждения.

Решение "General Motors" позволяет управлять автомобилем без помощи рук. Вместо того, чтобы обнаруживать движения рулевого колеса, он использует камеру для отслеживания положения головы водителя. Если система обнаруживает, что взгляд водителя не на дороге, она начинает серию подсказок, чтобы попытаться вернуть внимание водителя на дороге.

Как и предупреждения “Tesla”, Супер Круиз предлагает переход

от мигающего огня на ободе рулевого колеса к звуковому сигналу и вибрации сиденья, к голосовой команде - и в этот момент система Супер Круиз отключается. Ho "General Motors" идет дальше, чем "Tesla": если водитель все еще не берет на себя управление, система будет постепенно приводить автомобиль к полной остановке, активировать сигнализаторы об опасности и вызывать помощь (используя систему "General Motors OnStar").

"General Motors" также встроил множество дополнительных мер безопасности в Супер Круиз, чтобы убедиться, что он используется только в тех обстоятельствах, когда это безопасно. Например, если транспортное средство не находится на шоссе, дорожные разметки нечетко видны или 
система считает, что водитель не полностью внимателен, то режим автоматизации даже не включится.

Можно сказать, что система уровня 2 - это усовершенствованная система помощи водителю, которая позволяет управлять автомобилем без помощи рук при благоприятных для её использования обстоятельствах.

Уровень 3 - Conditional Automation - условная автоматизация

SAE определяет уровень 3 как «условную автоматизацию». Транспортные средства уровня 3, способные обнаруживать окружающую среду вокруг них, содержат систему, которая классифицируется как автоматизированная система вождения, а не ручная система. С помощью этой более продвинутой технологии транспортные средства уровня 3 могут самостоятельно принимать обоснованные решения, такие как обгон транспортных средств, следующих с меньшей скоростью. Однако, в отличие от автономных транспортных средств с более высоким рейтингом, человеку необходимо взять управление на себя, когда машина не может выполнить поставленную задачу или система выходит из строя. Разница между уровнем 2 и уровнем 3 зависит от ответа на вопрос: «насколько бдительным должен быть человек на сиденье водителя транспортного средства?»

С системой уровня 2 водитель должен быть очень внимательным, готовым сразу же приступить к выполнению задачи вождения, если система столкнется с чем-то, с чем она не может справиться. На уровне 3 ожидается, что система сможет справиться с управлением, пока 
оно находится в пределах «рабочей области проектирования», что означает, что роль человека должна быть «запасной».

\section{Уровень 4 - High Automation - высокая автоматизация}

Основное различие между уровнем 3 и уровнем автоматизации 4 заключается в том, что автомобили уровня 4 могут вмешиваться, если что-то идет не так или происходит сбой системы. В этом смысле эти автомобили оставлены полностью

на своих собственных устройствах без какого-либо вмешательства человека

в подавляющем большинстве ситуаций, хотя возможность ручной отмены

остается

в трудных обстоятельствах.

Система уровня 4 является истинным самостоятельным вождением, пока она работает в своих пределах. Неважно, отвлечен ли человек, сидящий на сиденье водителя, спит или даже не присутствует - система уровня 4 безопасно доставит транспортное средство к месту назначения, если оно работает в установленных пределах.

Уровень 5 - Full Automation - полная автоматизация

Точно так же транспортные средства уровня 5 не требуют человеческого внимания. Ключевым отличием является гораздо более отзывчивое и утонченное обслуживание, сравнимое с адаптивным и ситуативным ручным управлением человеком. Например, автомобили уровня 5 могут обеспечить вождение по бездорожью и другим ландшафтам, что, как правило, недоступно транспортным средствам уровня 4. Другими словами, автомобили уровня 5 имеют гораздо более совершенную систему обнаружения окружающей среды. Это 
единственный класс автоматизированных транспортных средств, который не имеет типичных элементов управления вождением.

Собственно, главной отправной точкой любой системы автопилота является самоопределение транспортного средства в пространстве. То есть автомобиль должен «понимать», где он находится, и главное - что вокруг него происходит, чтобы оперативно реагировать на возникновение тех или иных препятствий.

Для этого в современной машине установлен целый комплекс различных радаров, из-за количества которых некоторые модели представляют собой, по сути, локационные станции (рисунок 5.14).

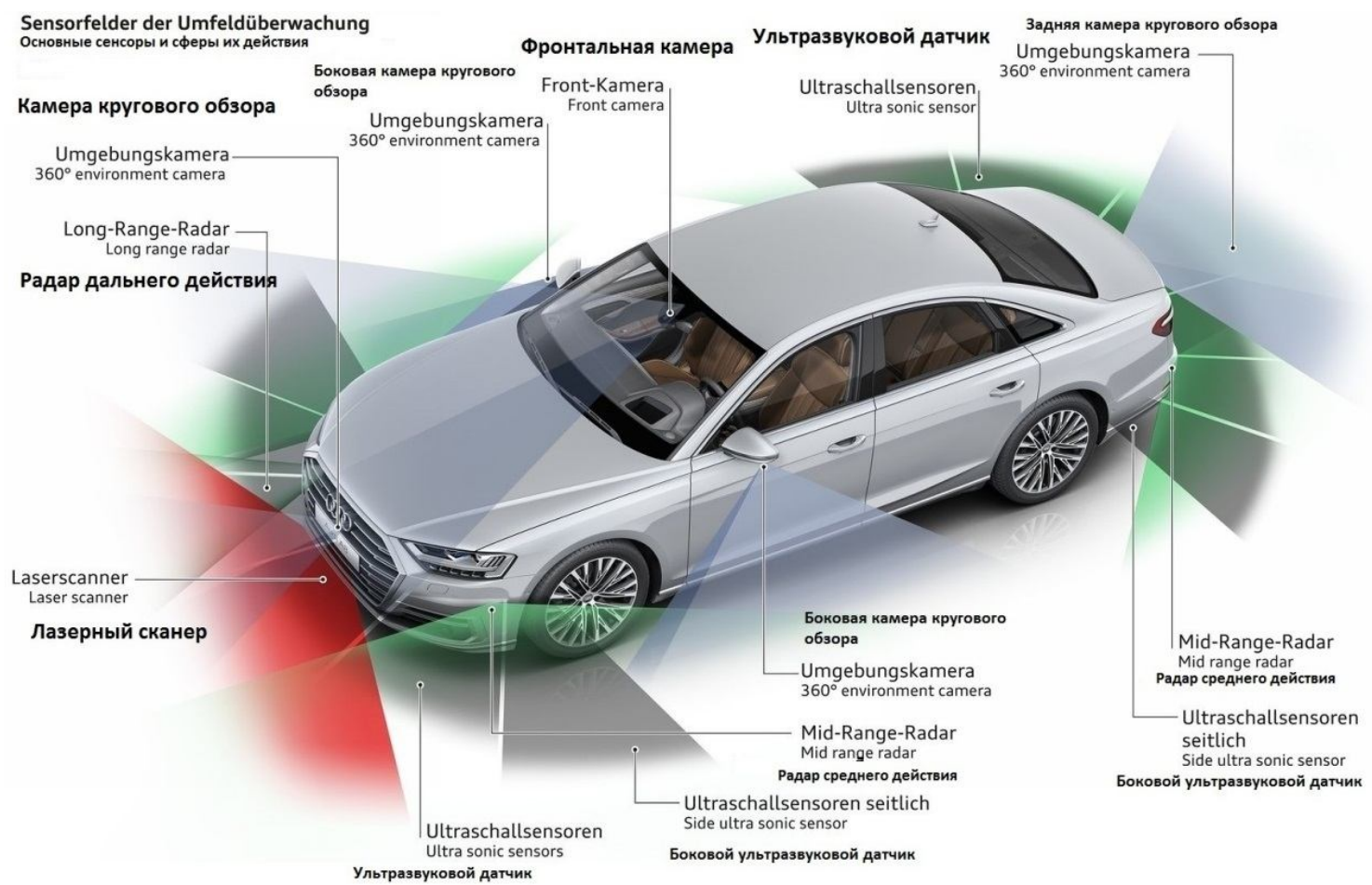

Рисунок 5.14 - Система автопилота «Eyes Off» 
Например, одним из главных радаров на автомобиле Audi А8, определяющим обстановку впереди автомобиля, и является Система автопилота «Eyes Off».

Система автопилота «Eyes Off» на Audi A8 позволяет водителю отпустить педали и руль в процессе движения. Правда есть пока и ряд ограничений. В частности автопилот работает на скоростях до 60 км/ч и только на двухполосной дороге с разделительным ограждением. Также, автомобиль может самостоятельно осуществлять парковку в гараж.

Лазерный радар или лидар (от англ. LIDAR - Laser Imaging Detection and Ranging) работает, в общем-то, по традиционной схеме (рисунок 5.15).

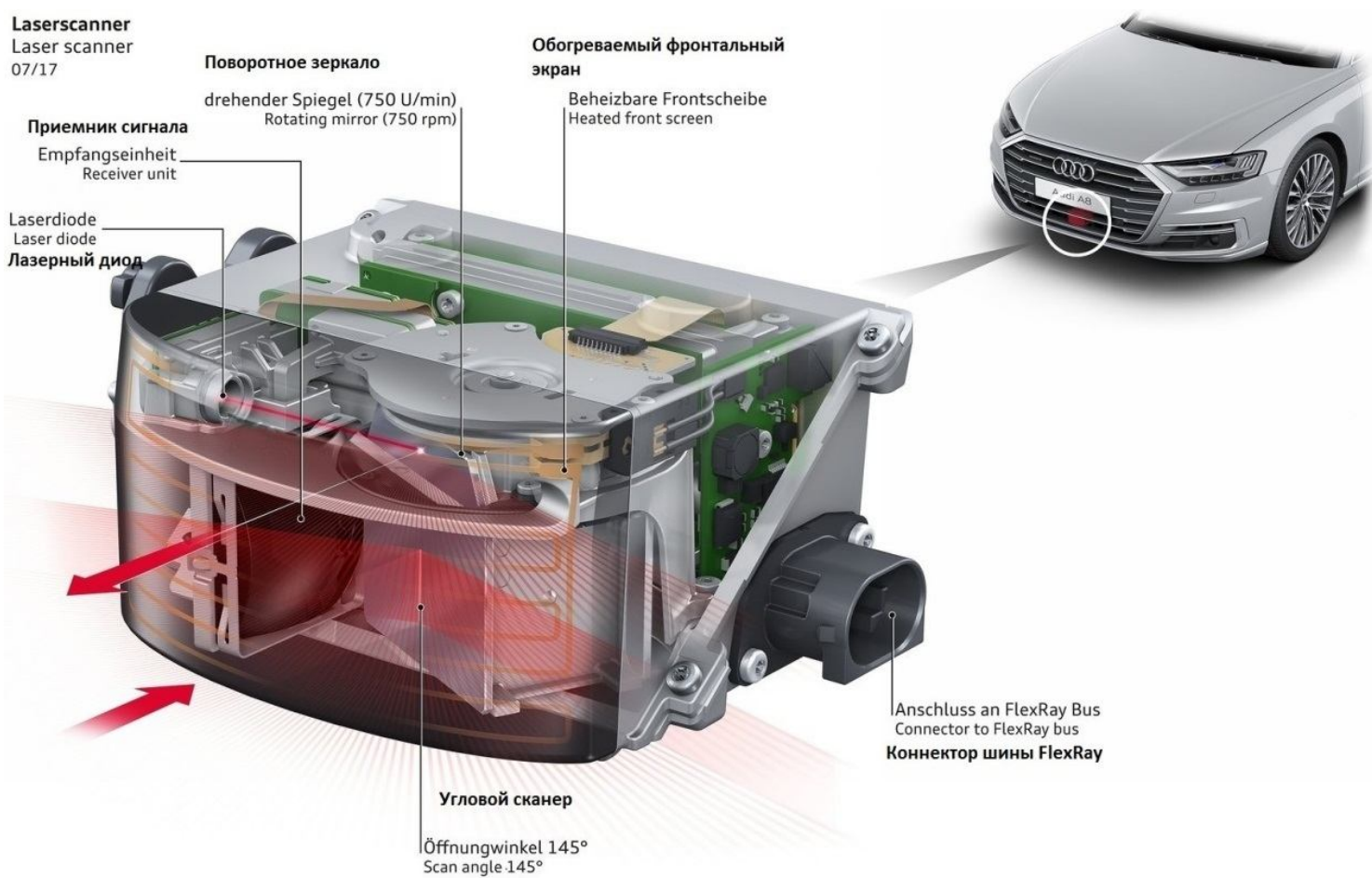

Рисунок 5.15 - Лидар в системе автопилота «Eyes Off»

Внутри устройства имеется излучатель и приемник: когда испускаемый световой луч достигает объекта, он отражается и попадает в приёмник, создавая электрический сигнал. 
Расстояние между излучателем и препятствием определяется временем возвращения сигнала.

Прогресс заключается в скорости и сверхвысокой точности лидара, который помогает автомобилю определять обстановку впереди себя в режиме реального времени.

Лидар включает в себя четыре лазерных диода и проецирует их луч на треугольную призму с двумя отражающими поверхностями. Непрерывно вращаясь, зеркала сканируют угол 145 градусов 25 раз в секунду и направляют отражённые лучи в оптический приёмник.

Вращение зеркал «отслеживает» датчик угла поворота NTN-SNR, который состоит из магнитного кольца с двумя дорожками, установленного на двигателе ротора зеркал, а также неподвижного сенсора, измеряющего угловое положение ротора.

NTN-SNR разработал высокоточный сенсор с более, чем 5000 импульсов за оборот и точностью измерения до десятой доли градуса. Благодаря второй магнитной дорожке, контрольный импульс определяет абсолютное угловое положение зеркала и подтверждает его на каждом обороте. Такая высокая точность была обязательным требованием к магнитному сенсору, который по цене и прочности выигрывает по сравнению с оптическим сенсором.

Система формирует 3D-изображение окружающей обстановки автомобиля с точностью до нескольких сантиметров. Измерения, полученные при каждом сканировании местности, сравниваются между собой, позволяя определять и относительную скорость объектов. 


\section{4. ИНТЕЛЛЕКТУАЛЬНАЯ СИСТЕМА УПРАВЛЕНИЯ СТРОИТЕЛЬСТВОМ ОБЪЕКТОВ ТРАНСПОРТНО- ДОРОЖНОГО КОМПЛЕКСА}

Современные технологии и материалы ускоряют строительство автомагистралей, улучшают их качество.

\section{Интеллектуальная транспортная инфраструктура}

Самоуправляемые автомобили, появление которых на дорогах общего пользования, по многим прогнозам, не за горами, потребуют преображения всей улично-дорожной инфраструктуры. Она должна будет иметь связь в режиме real time для обмена инфрормацией с цифровыми, телеметрическими, геопозиционными устройствами автомобилей.

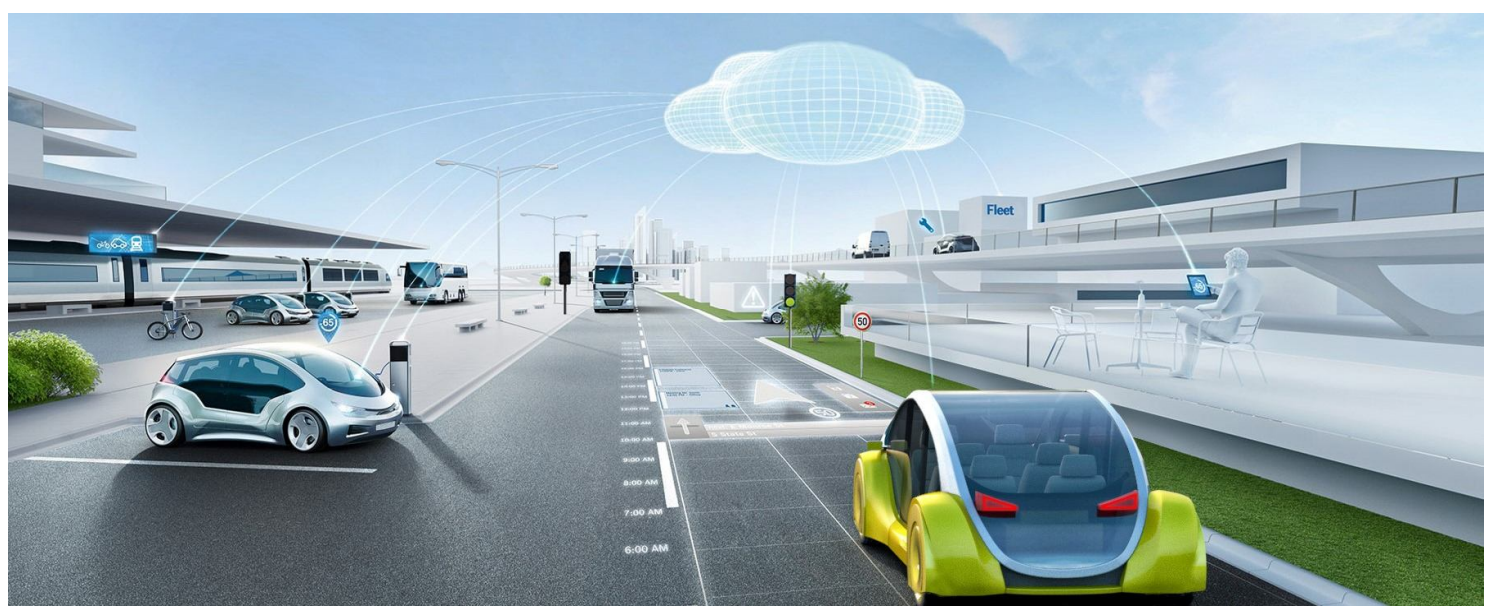

Рисунок 5.16 - Интеллектуальная транспортная инфрраструктура

Дороги будут оборудованы камерами и устройствами «компьютерного зрения», всевозможными датчиками, передающими информацию о ситуации на трассе и около нее водителю (в перспективе - роботу), пассажирам, а также формирующими базу Big Data. Внедрение подобных технологий позволит существенно повысить безопасность дорожного 
движения и сократить аварийность, откроет колоссальные возможности для анализа транспортных потоков.

Автодороги и транспортные средства постепенно превращаются в интегрированную интеллектуальную систему. В настоящее время активно внедряются интеллектуальные системы управления трафиком в зонах крупных городских агломераций, что в столице уже оказало положительное влияние на загрузку улично-дорожной сети. При этом внедрение интеллектуальных систем на автодорогах, запуск беспилотного движения в нашей стране будет зависеть не только и не столько от скорости развития технологий, сколько от формирования соответствующей нормативно-правовой базы.

Информационное моделирование и цифровой двойник

Технологии BIM (Building Information Modeling) дают возможность проектировщикам создать понятную модель будущей дороги со всеми необходимыми характеристиками на всем ее протяжении, включая сложные развязки, эстакады, мосты и тоннели.

В автоматическом режиме происходит сопряжение всей информации о потенциальных нагрузках, трафике, пиковых временных периодах, климате, учитываются внешние фракторы, связанные с расположенными вдоль трассы объектами. Скорость, с которой эта технология позволяет анализировать данные, на несколько порядков превосходит старые методы. BIM позволяет в 3D-фрормате заранее увидеть все элементы дорожно-транспортного сооружения, анализировать его эксплуатационные параметры и варьировать себестоимость проекта. 


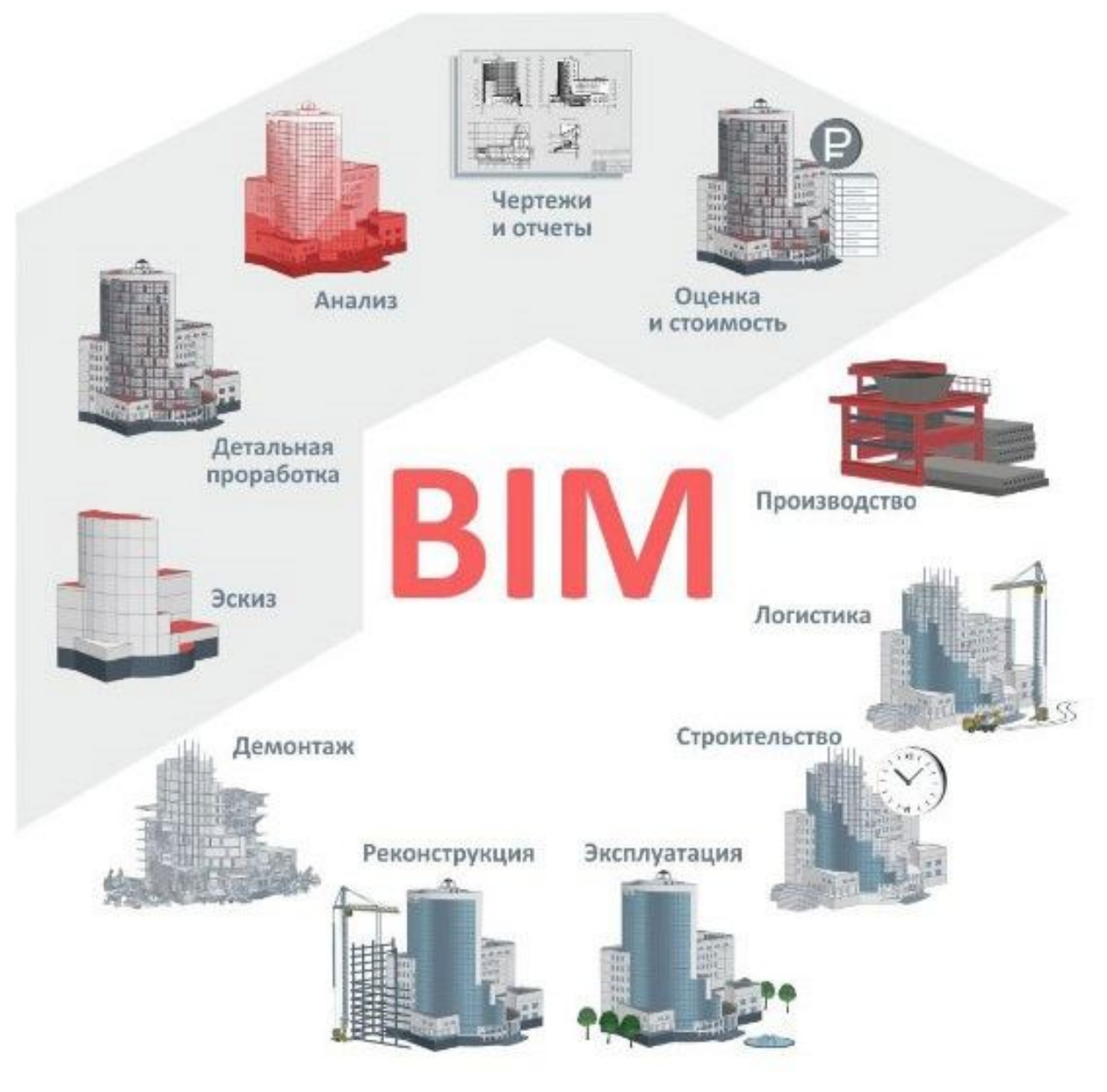

\section{Рисунок 5.17 - Экосистема технологии ВIM}

Цифровизация городов просто невозможна без сближения технологий ГИС и ВІМ: беспилотный транспорт будет использовать дорожную инфраструктуру, которая проектируется сейчас. Для того чтобы все это стало реальностью, компании продолжат инвестировать в области, где пересекаются возможности информационного моделирования и геопространственного анализа.

Один из наиболее известных примеров транспортных объектов, построенных в мире с помощью ВІМ-технологий, проект второго автодорожного моста Сутун через реку Янцзы в Китае общей длиной 57 км (2007). Элементы имитационного 
моделирования также применялись при строительстве моста через Керченский пролив.

\section{Интеллектуальная дорожно-строительная техника}

Дорожная одежда - это сложная и многослойная структура из грунта земляного полотна, нескольких слоев щебня, песка и их смеси, асфральтобетона и пр. Задачей систем управления техникой является формирование поверхностей каждого слоя. Для работы таких систем требуется использование 3Dцифровых моделей «комплексных коридоров» автодорог, то есть поверхностей структурных слоев, для каждого из которых нужен определенный вид техники на каждом этапе выполнения работ.

Сейчас производство «умной» дорожной техники внедряется на отечественных машиностроительных предприятиях. Производители дорожно-строительной техники оснащает свои машины интеллектуальной системой нивелирования, позволяющей обеспечить точное позиционирование ковша экскаватора или отвала бульдозера. В скором времени планируется создание нового бульдозера с полноценной бортовой информационно-управляющей системой, которая будет обеспечивать контроль функционирования всех агрегатов, позволит полностью автоматизировать управление машиной и еe рабочим оборудованием, в том числе в дистанционном режиме.

Применение «умных» машин позволяет повысить уровень производительности, исключить человеческий фрактор и обеспечить безопасность оператора техники, который может дистанционно управлять несколькими машинами одновременно. 
Компания Volvo Construction Equipment, специализирующая на разработке строительной техники, протестировала беспилотники и электрокары на территории карьера Викан-Кросс вблизи Гетеборга. Целью 10-недельных испытаний было снижение выбросов вредных веществ на 95\%, а общих издержек на $25 \%$.

Исследовательский проект, получивший название Electric Site, подразумевает максимальную автоматизацию рабочих процессов - от добычи и первичного дробления породы до ее перевозки. Для этого Volvo и еe основной клиент строительная группа Skanska будут использовать прототипы автономных самосвалов, управляемый по кабелю гибридный экскаватор и дизель-электрический погрузчик.

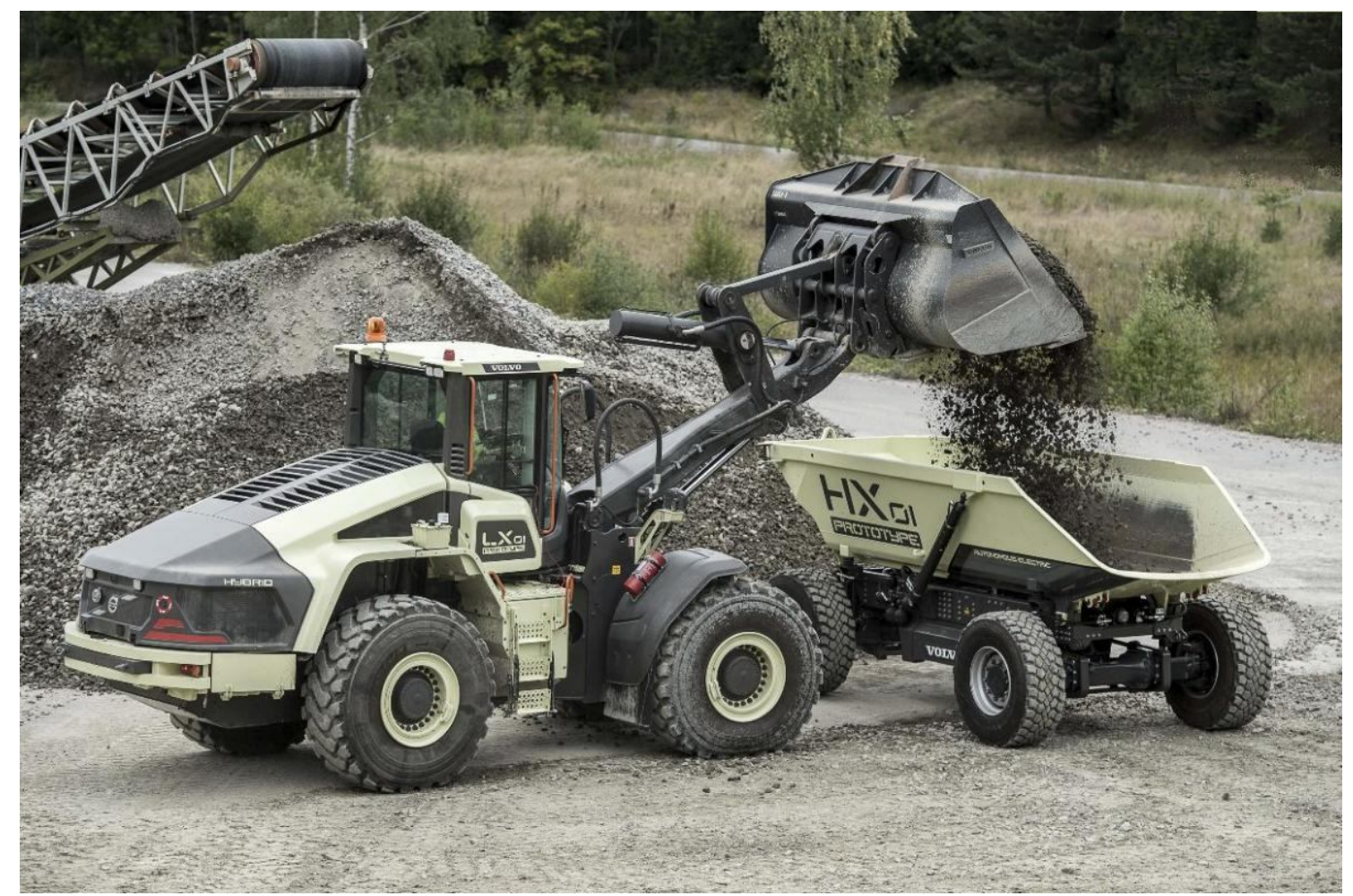

Рисунок 5.18 - Погрузчик Volvo LX1 работает в паре C беспилотным самосвалом Volvo HX2 
Вместо трех тяжелых самосвалов, на карьере будут работать восемь компактных беспилотников HX2, оснащенных электромоторами, батареей и силовой электроникой, разработанной Volvo Group. Машины также оборудованы системой искусственного зрения, которая может различать препятствия на дороге и людей.

Помимо самосвалов, на производственной площадке будут использовать 70-тонный экскаватор EX1, укомплектованный дизель-электрической силовой установкой. Он управляется так же как обычный, однако подключен по кабелю к основной энергосистеме карьера.

Погрузчик LX1 на 98 процентов состоит из новых деталей и на 50 процентов эффрективнее машины с традиционным ДВС.

Volvo Trucks также представила два электрических грузовика: 16-тонный FL Electric и FE Electric массой 27 тонн. Их предполагается использовать для перевозки отходов и тяжелых грузов.

\section{Ремонт дорог дронами}

В Британии учёные разрабатывают новый революционный процесс ремонта автомобильных дорог, который будет происходить с дронами и 3D-принтерами. Машина постоянно патрулирует улицу в поисках ямы. При обнаружении она отправляет сигнал в центр управления, а затем отправляется совершать ремонт.

Такая концепция является частью более глобального университетского плана «саморемонтирующихся городов». В нём указывается, как роботехника может заменить человека на тяжёлых ремонтных работах. 
Планируется, что дрон ночью будет анализировать состояние дорожного покрытия в поисках трещин и небольших выбоин, а затем отправлять координаты трещин на второй дрон. Этот беспилотник должен прибыть на отмеченное место с грузом асфральта нужной формы, который будет печататься на 3D-принтере, чтобы отремонтировать дорогу. Как заверяют авторы проекта, некоторые исправления занимают менее минуты.

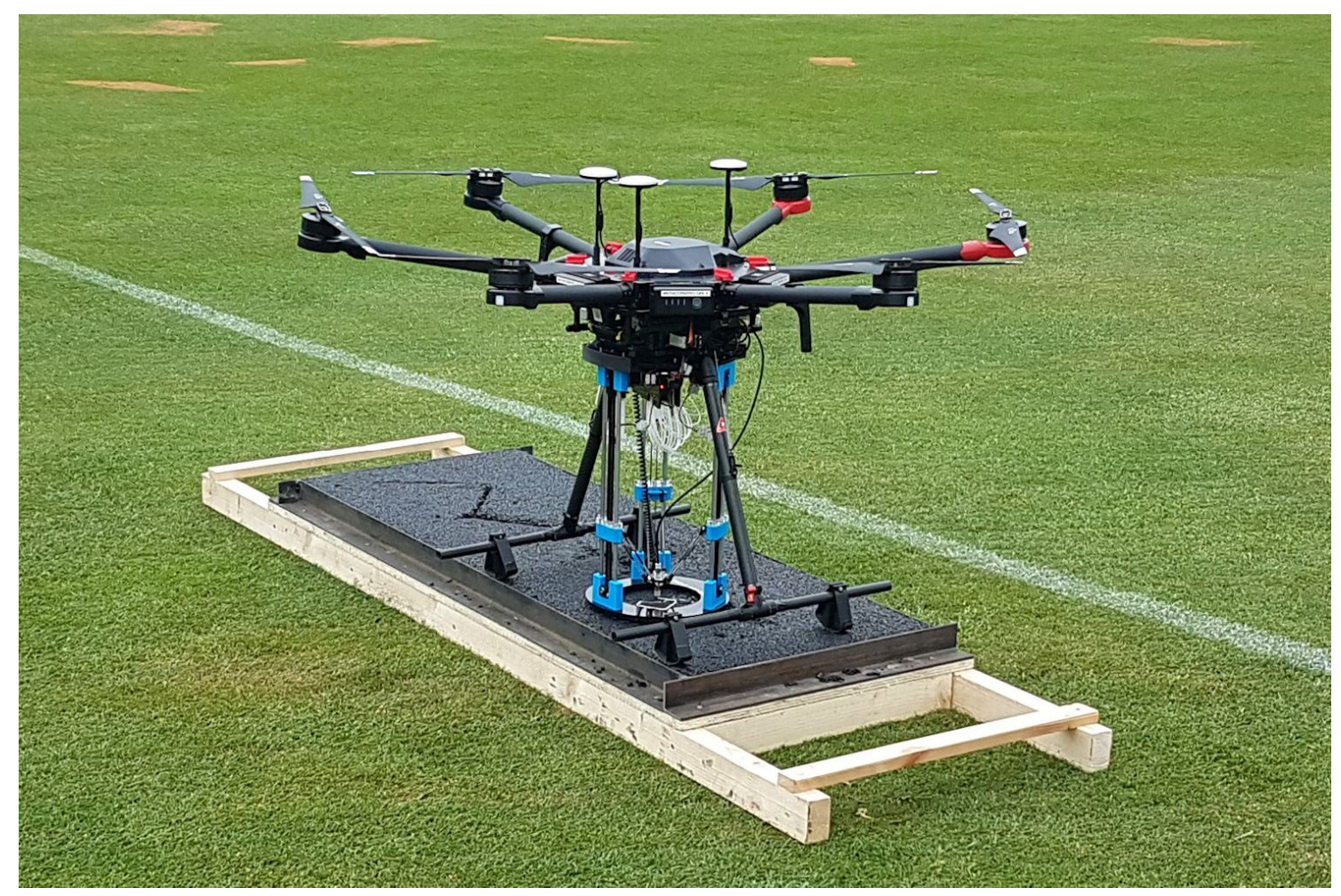

Рисунок 5.19 - Дорожный беспилотный летательный аппарат

Ключевым моментом для дорожных беспилотников является то, что они будут отправлены на ремонт трещин на дорогу раньше, чем эти трещины станут выбоинами. Еще одним преимуществом будет очистка дорог от ремонтного оборудования, которое обычно создает заторы. 
Однако пока еще остается неизвестным, как беспилотные летательные аппараты будут печатать асфальт нужной формы на 3D-принтере, а также то, как большой дрон сможет перевозит грузы.

Как сообщается, когда проект начался, многие представляли себя решение, В котором скоординированный фрлот дронов объединялся для перевозки тяжелых конструкций.

\section{ВИДЕОРОЛИКИ ПО ГЛАВЕ}

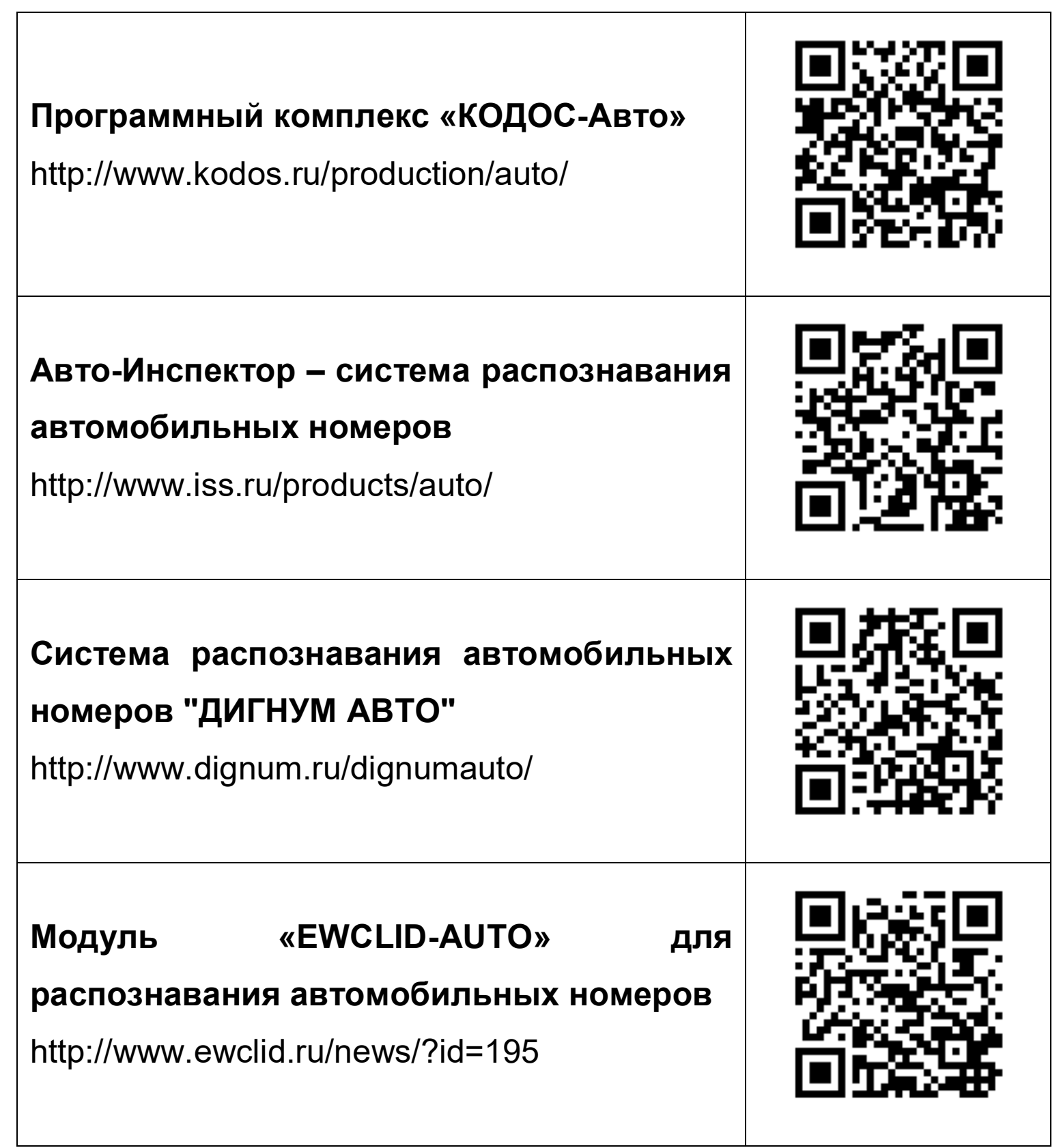




\section{КОНТРОЛЬНЫЕ ВОПРОСЫ}

1. Охарактеризуйте основные направления исследований, проводимых в области развития интеллектуальных систем в отраслях транпортно-дорожного комплекса.

2. Приведите известные вам примеры интеллектуальных систем в отраслях транпортно-дорожного комплекса.

3. Назовите основные функции, присущие интеллектуальным транспортным системам.

4. Перечислите известные Вам системы активной помощи водителю при управлении транспортным средством.

5. Перечислите устройства, необходимые для движения автомобиля в режиме автопилота. 


\section{СПИСОК ИСПОЛЬЗОВАННЫХ ИСТОЧНИКОВ}

1. Суркова Н.Е. Методы проектирования инфрормационных систем / Н.Е. Суркова, А.В. Остроух - М.: PocHOУ, 2004. 144 c. - ISBN 5-89789-021-8.

2. Остроух А.В. Основы построения систем искусственного интеллекта для промышленных и строительных предприятий: монография / А.В. Остроух. - М.: ООО «Техполиграфцентр», 2008. - 280 с. - ISBN 978-5-94385033-2.

3. Остроух А.В. Автоматизация транспортировки продукции / A.В. Остроух, Н.Г. Куфтинова - Saarbrucken, Germany: LAP LAMBERT Academic Publishing, 2011. - 146 p. - ISBN 9783-8454-1089-0.

4. Остроух A.B. Рефракторинг баз данных. Автоматизация технологических процессов рефакторинга баз данных промышленных предприятий / А.В. Остроух, Д.А. Пшеничный, О.Б. Рогова. - Saarbrucken, Germany: LAP LAMBERT Academic Publishing, 2013. - 133 p. - ISBN 9783-659-38753-1.

5. Остроух А.В. Автоматизация управления производством. Повышение эфффективности автоматизированных аналитических систем предприятий автомобильной промышленности / А.В. Остроух, Э.А. Чернов, Д.Т. Нгуен. Saarbrucken, Germany: LAP LAMBERT Academic Publishing, 2013. - 285 p. - ISBN 978-3-659-34762-7.

6. Остроух А.В. Системы планирования перевозок. Программно-технологические решения по разработке 
системы планирования заданий для заказных пассажирских перевозок / А.В. Остроух, А.Б. Львова, А.Р. Исмаилов. - Saarbrucken, Germany: LAP LAMBERT Academic Publishing, 2013. - 121 p. - ISBN 978-3-65943619-2.

7. Остроух А.В. Интеллектуальные системы в науке и производстве / А.В. Остроух, А.Б. Николаев. - Saarbrucken, Germany: Palmarium Academic Publishing, 2012. - 312 p. ISBN 978-3-659-98006-0.

8. Остроух А.В. Мультимедиа-технологии / А.В. Остроух, А.М. Васьковский, А.Б. Николаев. - Saarbrucken, Germany: Palmarium Academic Publishing, 2012. - 228 p. - ISBN 9783-659-98030-5.

9. Остроух А.В. Ввод и обработка цифровой информации: учебник для нач. проф. образования / А.В. Остроух. - М.: Издательский центр «Академия», 2012. - 288 с. - ISBN 978-5-7695-9457-1.

10. Остроух А.В. Оперативный контроль транспортноэкспедиционной деятельности. Процессный подход к агрегированию системы показателей деятельности транспортно-экспедиционного предприятия / А.В. Остроух, A.М. Ивахненко, Н.А. Крупенский. - Saarbrucken, Germany: Palmarium Academic Publishing, 2013. - 221 p. - ISBN 9783-659-98329-0.

11. Исмоилов М.И. Подготовка и переподготовка персонала предприятий промышленного и транспортного комплексов с применением мобильных технологий: монография / М.И. Исмоилов, А.Б. Николаев, А.В. Остроух. - Saint-Louis, MO, 
USA: Publishing House Science and Innovation Center, 2013. - 166 c. - ISBN 978-0-615-67111-6.

12. Николаев А.Б. Информационные технологии в менеджменте и транспортной логистике: учебное пособие / A.Б. Николаев, А.В. Остроух. - Saint-Louis, MO, USA: Publishing House Science and Innovation Center, 2013. - 254 c. - ISBN 978-0-615-67110-9.

13. Остроух А.В. Системы искусственного интеллекта В промышленности, робототехнике и транспортном комплексе: монография / А.В. Остроух - Красноярск: Научно-инновационный центр, 2013. - 326 с. - ISBN 978-5906314-10-9.

14. Остроух А.В. Основы информационных технологий: учебник для сред. профр. образования / А.В. Остроух. - М.: Издательский центр «Академия», 2014. - 208 с. - ISBN 978-5-4468-0588-4.

15. Суркова Н.Е. Методология структурного проектирования информационных систем: монография / Н.Е. Суркова, А.В. Остроух. - Красноярск: Научно-инновационный центр, 2014. - 190 c. - ISBN 978-5-906314-16-1.

16. Покровский А.К. Системный анализ и компьютерные технологии при управлении транспортным обслуживанием предприятий: монография / А.К. Покровский, А.В. Остроух, А.М. Ивахненко. - М.: Известия, 2014. - 261 с. - ISBN 9785-94280-314-7.

17. Демидов Д.Г. Программные и аппаратные средства систем мультимедиа. Часть 1. Аппаратные средства: учебное пособие / Д.Г. Демидов, А.М. Васьковский, А.Б. Николаев, 
А.В. Остроух, П.И. Лукащук, В.А. Виноградов. - М.: МГУП имени Ивана Федорова, 2014. - 78 с.

18. Демидов Д.Г. Программные и аппаратные средства систем мультимедиа. Часть 2. Программные средства: учебное пособие / Д.Г. Демидов, А.М. Васьковский, А.Б. Николаев, А.В. Остроух, П.И. Лукащук, В.А. Виноградов. - М.: МГУП имени Ивана Федорова, 2014. - 70 с.

19. Остроух А.В. Проектирование системы распределенных баз данных / A.B. Остроух, А.В. Помазанов. - Saarbrucken, Germany: Palmarium Academic Publishing, 2015. - 117 p. ISBN 978-3-659-60041-8.

20. Остроух А.В. Автоматизация управления автотранспортными предприятиями. Новый подход на основе интеллектуальных мультиагентных систем / А.В. Остроух, А.В. Воробьева, Н.Е. Суркова. - Saarbrucken, Germany: LAP LAMBERT Academic Publishing, 2015. - 117 p. - ISBN 978-3-659-47576-4.

21. Суркова Н.Е. Профрессиональные инфрормационные системы и базы данных: методические указания к лабораторным работам / Н.Е. Суркова, А.В. Остроух, Т.И. Еремина. - Красноярск: Научно-инновационный центр, 2015. - 49 c. - ISBN 978-5-906314-23-9. DOI: 10.12731/asu.madi.ru/PISDB.2015.49.

22. Остроух А.В. Об одном походе к построению автоматизированной навигационной системы мониторинга и диспетчерского контроля и учета работы транспорта нестедобывающих предприятий / А.В. Остроух, Д.Б. Ефименко, В.Н. Жучков // Инженер-нефтяник. - 2011. №2. - C. 43-47. 
23. Остроух А.В. Разработка информационно-аналитической системы мониторинга технологических процессов предприятия автомобильной промышленности / А.В. Остроух, Ю. Тянь // В мире научных открытий. Красноярск: «Научно-инновационный центр», 2013. - № 8.2 (44). - C. 191-205.

24. Остроух А.В. Интеграция компонентов системы мониторинга / А.В. Остроух, Юань Тянь // Молодой ученый. - 2013. - №10. - C. 182-185.

25. Остроух А.В. Исследование начального периода моделирования на точность среднеинтегральной оценки имитационных моделей / А.В. Остроух, А.А. Солнцев, Н.В. Солдатов, К.А. Новицкий, П.С. Якунин // Вестник МАДИ. 2010. - Вып. 2(21). - С. 61-65.

26. Остроух А.В. Математическая модель связей в системе диагностики электрооборудования автомобилей / А.В. Остроух, А.А. Солнцев, О.Ф. Калухов, Г.Г. Ягудаев // Вестник МАДИ. - 2010. - Вып. 2(21). - С. 66-70.

27. Антонов П.Д. User Is A Great Obstacle For Security Systems / П.Д. Антонов, А.В. Остроух // Молодой ученый. - 2011. №4. T.3. - C. 62-63.

28. Краснянский М.Н., Карпушкин С.В., Обухов А.Д., Молоткова Н.В., Галыгина И.В., Остроух А.В. Структура системы электронного документооборота для управления научно-образовательной деятельностью высшего учебного заведения // Промышленные АСУ и контроллеры. - 2014. - №8. - C. 23-31.

29. M.N. Krasnyanskiy, A.V. Ostroukh, S.V. Karpushkin, A.D. Obukhov. Information Technology for the Development of 
Automated Control System for University Projects // Математические методы в технике и технологиях - ММТT27: сб. трудов XXVII Междунар. науч. конф.: в 12 т. Т.4. Секции 10, 11 / под общ. ред. А.А. Большакова. - Тамбов: Тамбовск. гос. техн. ун-т, 2014. - С. 42-45. - ISBN 978-57433-2386-9.

30. Краснянский М.Н., Остроух А.В., Карпушкин С.В., Обухов А.Д. Разработка комплексной системы управления научно - инновационной деятельностью: взаимодействие базы данных изделий и архива документации // Приборы и системы. Управление, контроль, диагностика. - 2014. №12. - C. 19-23.

31. Сальный А.Г., Остроух А.В. Исследование производительности фрайловых систем ядра Linux // Автоматизация и управление в технических системах. 2014. - №4 (12). - C. 158-167. DOI: 10.12731/2306-15612014-4-16.

32. Обухов П.А., Николаев А.Б., Остроух А.В. Исследование эффрективности работы сетевых серверов в среде имитационного моделирования AnyLogic // Международный журнал экспериментального образования. - 2015. - № 3-3. - С. 338-342.

33. Пастухов Д.А., Юрчик П.Ф., Остроух А.В. Сравнительный анализ гипервизоров // Международный журнал экспериментального образования. - 2015. - № 3-3. - С. 346-350.

34. Сальный А.Г., Остроух А.В. Исследование эффрективности структур хранения данных ядра Linux // Международный 
журнал экспериментального образования. - 2015. - № 3 C. $366-367$.

35. Чувиков Д.А., Феоктистов В.П., Остроух А.В. Исследование 3D фрорматов хранения данных в интеллектуальных системах виртуальной реальности // Международный журнал экспериментального образования. - 2015. - № 3-3. - C. 416-420.

36. Терентьев Д.И., Николаев А.Б., Остроух А.В. Исследование дисковых массивов RAID по параметрам надежности и быстродействия // Международный журнал экспериментального образования. - 2015. - № 3-3. - С. 423-427.

37. Круглов А.М. Актуализация сведений о данных информационной системы средствами активного словарясправочника данных / А.М. Круглов, А.В. Будихин, Д.А. Буров, А.В. Остроух // Научный вестник МГТУ ГА. Серия Аэромеханика и прочность. - 2007. - №119 (9). - С. 166171.

38. Николаев А.В. Принципы организации динамических интерфейсов доступа к данным с использованием словарей-справочников данных / А.В. Николаев, А.В. Будихин, Д.А. Буров, А.В. Остроух // Научный вестник МГТУ ГА. Серия Аэромеханика и прочность. - 2007. №119 (9). - C. 172-178.

39. Остроух А.В., Баринов А.П., Николаев А.В., Будихин С.А. Использование словаря-справочника данных для реализации пользовательских средств обработки информации // Приборы и системы. Управление, контроль, диагностика. - 2008. - №3. - С. 13-17. 
40. Пшеничный Д.А. Анализ параметров и сравнение СУБД для реализации информационного обеспечения промышленного предприятия / Д.А. Пшеничный, А.В. Будихин, А.В. Остроух // Промышленные АСУ и контроллеры. - 2010. - №12. - С. 7-11.

41. Помазанов А.В. Методика оптимизации баз данных / А.В. Помазанов, А.И. Белоусова, А.О. Васильева, А.В. Остроух // В мире научных открытий. Серия «Проблемы науки и образования». - 2012. - №12. - С.49-54.

42. Ostroukh A.V., Krasnyanskiy M.N., Karpushkin S.V., Obukhov A.D. Development of Automated Control System for University Research Projects // Middle East Journal of Scientific Research. 2014. Vol. 20 (12). pp. 1780-1784. DOI: 10.5829/idosi.mejsr.2014.20.12.21091.

43. Ostroukh A., Pomazanov A. Realtime Development and Testing of Distributed Data Processing System for Industrial Company // Middle East Journal of Scientific Research. 2014. Vol. 20 (12). pp. 2184-2193. DOI: 10.5829/idosi.mejsr.2014.20.12.21106.

44. Ostroukh A.V., Belousova A.I., Pavlov D.A., Yurchik P.F. Problems of organization and search the knowledge base in the CRM-systems // IOSR Journal of Engineering (IOSRJEN). 2014. Vol. 04. Issue 02. V3. pp. 18-23. DOI: 10.9790/302104231823. ANED: 0.4/3021-04231823.

45. Krasnyanskiy M.N., Karpushkin S.V., Obukhov A.D., Ostroukh A.V. Automated control system for university research projects // International Journal of Advanced Studies (iJAS). 2014. Vol. 4, Issue 1, pp. 22-26. DOI: 10.12731/2227-930X-2014-1-4. 
46. Mikhail Nikolaevich Krasnyanskiy, Andrey Vladimirovich Ostroukh, Sergey Viktorovich Karpushkin, Artyom Dmitrievich Obukhov, Nataliya Vyacheslavovna Molotkova and Irnina Vladimirovna Galygina. Electronic Document Management Systems Structure for University Research and Education // Journal of Engineering and Applied Sciences. 2014. Vol 9. Issue 5. pp. 182-189. DOI: 10.3923/jeasci.2014.182.189.

47. Помазанов А.В., Остроух А.В. Создание и тестирование распределённой системы работы с удалёнными узлами // Автоматизация и современные технологии. - 2014. - №7. - C. 17-23.

48. Помазанов А.В., Остроух А.В. Новый подход к разработке прототипа распределенной системы баз данных промышленного предприятия // Промышленные АСУ и контроллеры. - 2014. - №9. - С. 11-20.

49. Суркова Н.Е., Остроух А.В. Методика обучения технологии баз данных для студентов непрофильных направлений подготовки В технических ВУЗах // ИНЖЕНЕРНАЯ ПЕДАГОГИКА. - М: МАДИ, 2015. - ВЫП. 17. Т.3. - С. 146156.

50. Суркова Н.Е., Остроух А.В., Еремина Т.И. ЭЛЕКТРОННОЕ УЧЕБНОЕ ИЗДАНИЕ «ПРОФЕССИОНАЛЬНЫЕ ИНФОРМАЦИОННЫЕ СИСТЕМЫ И БАЗЫ ДАННЫХ: МЕТОДИЧЕСКИЕ УКАЗАНИЯ $К$ ЛАБОРАТОРНЫМ РАБОТАМ» // Хроники объединенного фонда электронных ресурсов Наука и образование. 2015. № 3 (70). С. 10.

51. Krasnyanskiy M.N., Karpushkin S.V., Obukhov A.D., Ostroukh A.V. Model of Documents Management for Academic and Research Universities on Basis Set Theory/l American- 
Eurasian Journal of Agricultural \& Environmental Sciences. 2015. Vol. 15. No. 5. pp. 824-831, DOI: 10.5829/idosi.aejaes.2015.15.5.12639.

52. Краснянский М.Н., Карпушкин С.В., Обухов А.Д., Остроух А.В. Математическая модель электронного документооборота на основе теории множеств // Промышленные АСУ и контроллеры. - 2015. - №5. - С. 5258.

53. Краснянский М.Н., Обухов А.Д., Карпушкин С.В., Остроух А.В. Разработка информационной системы электронного документооборота управления фрундаментальных и прикладных исследований // Вестник Тамбовского государственного технического университета. 2015. Т. 21. № 2. C. $216-230$.

54. Ostroukh A.V., Mezencev K.N., Krasnyanskiy M.N., Punam J., Surkova N.E. SIMULATED OPERATION OF THE COMPUTER NETWORK // SGEM2015 Conference Proceedings, ISBN 978-619-7105-34-6 / ISSN 1314-2704, June 18-24, 2015, Book2 Vol. 1, 299-306 pp. DOI: 10.5593/SGEM2015/B21/S7.037.

55. Ostroukh A.V., Krasnyanskiy M.N., Obukhov A.D., Karpov S.V., Dedov D.L. DEVELOPMENT OF AUTOMATED INFORMATION SYSTEMS FOR MONITORING OF INTELLECTUAL ACTIVITY RESULTS // SGEM2015 Conference Proceedings, ISBN 978-619-7105-34-6 / ISSN 1314-2704, June 18-24, 2015, Book2 Vol. 1, 101-108 pp. DOI: 10.5593/SGEM2015/B21/S7.014.

56. Баринов К.А. Опыт разработки и использования ролевых игр для подготовки и переподготовки специалистов 
предприятий промышленности и транспортного комплекса / К.А. Баринов, Д.А. Буров, А.В. Бугаев, А.В. Остроух // Научный вестник МГТУ ГА. - 2009. - №141. - С. 189-197.

57. Николаев А.Б., Остроух А.В., Краснянский М.Н. Разработка информационно-образовательной системы для повышения квалификации персонала предприятий химической промышленности и транспортного комплекса // ЭЛЕКТРОННОЕ ОБУЧЕНИЕ И ДИСТАНЦИОННЫЕ ОБРАЗОВАТЕЛЬНЫЕ ТЕХНОЛОГИИ. - 2013. - № 1; URL: eodot.esrae.ru/1-10 (дата обращения: 11.12.2013).

58. Лукащук П.И. Адаптивная методика прогнозирования пассажиропотоков В АСУ пассажирского автотранспортного предприятия / П.И. Лукащук, С. Бенгедаш, А.Г. Николаев, А.В. Остроух // Приборы и системы. Управление, контроль, диагностика. - 2006. №11. - C. 7-11.

59. Кузнецов И.А. Особенности реализации автоматизированной информационно-аналитической системы центра планирования перевозок строительных грузов / И.А. Кузнецов, А.В. Остроух // Вестник МАДИ(ГТУ). - М.: МАДИ (ГТУ), 2008. - Вып. 1(12). - С. 92-96.

60. Куфтинова Н.Г. Процессно-ориентированный подход к автоматизации планирования n управления транспортировкой продукции предприятий промышленности / Н.Г. Куфттинова, А.В. Остроух // Вестник МАДИ - 2010. - Вып. 4(23). - С. 62-66.

61. Остроух А.В., Кусттинова Н.Г. Имитационное моделирование управления транспортными потоками в 
мегаполисе // Автотранспортное предприятие. - 2010. №12. - C. 41-42.

62. Остроух А.В., Алтунина А.В. Система автоматизации и контроля за продажами и производством автомобилей // Автотранспортное предприятие. - 2011. - №3. - С. 41-43.

63. Польгун М.Б. Анализ моделей оперативного диспетчерского управления городским пассажирским транспортом / М.Б. Польгун, А.В. Воробьева, А.В. Остроух // Молодой ученый. - 2011. - №4. Т.3. - С. 9-13.

64. Ефименко Д.Б. Автоматизированная навигационная система диспетчерского контроля и учета работы транспорта нефтедобывающих предприятий / А.И. Губанов, Д.Б. Ефименко, А.Б. Николаев, А.В. Остроух // Молодой ученый. - 2011. - №4. Т.3. - С. 18-21.

65. Соломатин А.В. Об одном подходе к решению задачи регулирования дорожного движения: автоматизация системы управления светофорами / А.В. Остроух, А.В. Соломатин, О.О. Варламов // Автотранспортное предприятие. - 2011. - №6. - С. 43-45.

66. Ефименко Д.Б., Остроух А.В., Филатов С.А. Развитие навигационной системы диспетчерского управления грузовым транспортом (на примере нефтедобывающих предприятий) // Автотранспортное предприятие. - 2011. №11. - С. 32-34.

67. Ефименко Д.Б. Концепция автоматизированной навигационной системы диспетчерского контроля и учета работы транспорта нефтедобывающих и нестеперерабатывающих предприятий / Д.Б. Ефименко, А.В. Остроух, А.Б. Николаев, А.И. Губанов // 
Автоматизация, телемеханизация и связь в нефтяной промышленности. - 2011. - №11. - С.12-14.

68. Остроух А.В. Научный подход к разработке автоматизированной навигационной системы диспетчерского контроля и учета работы транспорта нефтедобывающих и нефтеперерабатывающих предприятий / А.В. Остроух, А.Б. Николаев, Д.Б. Ефименко, С.В. Жанказиев // Автоматизированные системы управления и приборы автоматики. - Харьков: ХНУРЭ, 2011. - Вып. 157. - С. 48-58.

69. Ostroukh A.V., Kuftinova N.G. Automation of Planning and Management of the Transportation of Production for Food Processing Industry Enterprises // Automatic Control and Computer Sciences. 2012. Vol. 46. No. 1. pp. 41-48. DOI: 10.3103/S0146411612010063.

70. Остроух А.В. Автоматизация планирования и управления транспортировкой продукции предприятий пищевой промышленности / А.В. Остроух, Н.Г. Куфтинова // Автоматика и вычислительная техника. - Рига: ИЭ и ВТ Латвийского университета, 2012. - №1. - С.57-67.

71. Остроух А.В. Розробка автоматизованої навігаційної системи диспетчерського контролю та обліку роботи транспорту нафтовидобувних підприємств / А.В. Остроух, А.Б. Николаев, Д.Б. Ефименко, С.В. Жанказиев // Нафтова і газова промисловість. - Киев: Укргазпром, 2012. - № 3. C. 48-52.

72. Данчук К.А. Автоматизированные информационные системы на автотранспортном предприятии / К.А. Данчук, 

А.Б. Львова, С.А. Порфирьева, А.В. Остроух, П.С. Якунин // В мире научных открытий. - 2012. - №2.6 (27). - С. 34-38.

73. Ефименко Д.Б. Использование программного обеспечения радионавигационных диспетчерских систем для транспортного обслуживания специальных объектов нефтедобывающих компаний / Д.Б. Ефименко, А.В. Остроух, А.Б. Николаев, А.Р. Исмаилов // Автотранспортное предприятие. - 2012. - №2. - С. 42-44.

74. Волков Н.Н. Автоматизация процессов начальной установки бинокулярных астровизиров в бортовых автономных инфрормационно-вычислительных системах ориентации и навигации / А.В. Остроух, Н.Н. Волков, Е.А. Прохорова // Авиакосмическое приборостроение. - 2012. №10. - C. 8-15.

75. Куфттинова Н.Г. Разработка информационно-логической модели транспортной сети мегаполиса / Н.Г. Куфтинова, А.В. Остроух // Бюллетень транспортной информации. 2013. - №1 (211). - C. 23-26.

76. Польгун М.Б. Автоматизация процессов диспетчерского управления городским пассажирским транспортом / М.Б. Польгун, А.В. Остроух, А.Б. Николаев, Д.Б. Ефименко // Промышленные АСУ и контроллеры. - 2013. - №5. - С. 1016.

77. Исмаилов А.Р. Разработка архитектуры подсистемы планирования организации заказных перевозок клиентских групп при проведении XXII зимних Олимпийских Игр / А.В. Остроух, А.Р. Исмаилов, А.Б. Львова // Бюллетень транспортной информации. - 2013. - №12 (222). - С. 3-10. 
78. Исмаилов

A.P.

Автоматизированная

система

планирования заданий для заказных перевозок пассажиров при проведении Олимпийских Игр / A.P. Исмаилов, А.В. Остроух, А.Б. Львова, А.Б. Николаев, П.Ю. Збавитель // Транспорт Российской Федерации. - 2013. №6 (49). - С. 46-51.

79. Исмаилов А.Р. Программно-технологические решения по разработке подсистем планирования заданий для заказных перевозок пассажиров при проведении Олимпийских Игр / А.Р. Исмаилов, А.Б. Львова, А.В. Остроух // Приборы и системы. Управление, контроль, диагностика. - 2013. - №11. - С. 74-85.

80. Ismailov A., Lvova A., Nikolaev A., Ostroukh A. Organization and Management of Transport Provided for the Guests and Participants of the Olympic Games // Middle East Journal of Scientific Research. 2013. Vol. 17 (8). pp. 1098-1104. DOI: 10.5829/idosi.mejsr.2013.17.08.12300.

81. Башмаков И.А., Остроух А.В. Процессная модель технологии транспортировки бетонных смесей автомобильным транспортом // Автоматизация и управление в технических системах. - 2013. - № 4.1. - С. 75-81. DOI: 10.12731/2306-1561-2013-4-14.

82. Джха П., Остроух А.В. Автоматизированная система управления складом железобетонных изделий // Автоматизация и управление в технических системах. 2013. - № 4.1. - C. 51-56. DOI: 10.12731/2306-1561-2013-49.

83. Остроух А.В., Синха Б.Р. Исследование информационных систем управления взаимоотношениями с поставщиками // 
Автоматизация и управление в технических системах. 2013. - № 4.1. - C. 56-62. DOI: 10.12731/2306-1561-2013-410.

84. Башмаков И.А., Польгун М.Б., Джха П., Остроух А.В. Обзор технологий транспортировки бетонных смесей автомобильным транспортом // Автоматизация и управление в технических системах. - 2013. - № 4.2. - С. 178-189. DOI: 10.12731/2306-1561-2013-4-38.

85. Башмаков И.А., Польгун М.Б., Остроух А.В. Оптимизация параметров процессов автотранспортного обслуживания потребителей бетонных смесей // Автоматизация и управление в технических системах. - 2013. - № 4.2. - С. 189-198. DOI: 10.12731/2306-1561-2013-4-39.

86. Башмаков И.А., Остроух А.В. Минимизация производственных рисков при автотранспортном обслуживании потребителей бетонных смесей // Автоматизация и управление в технических системах. 2013. - № 4.2. - C. 83-90. DOI: 10.12731/2306-1561-2013-440.

87. Ostroukh A.V., Polgun M.B. Automation of processes supervisory control urban passenger transport // International Journal of Advanced Studies (iJAS). 2013. Vol. 3. No 3. pp. 39. DOI: 10.12731/2227-930X-2013-3-1.

88. Ostroukh A.V., Polgun M.B. New approaches to development of automated supervisory systems of industrial enterprises transport // International Journal of Advanced Studies (iJAS). 2013. Vol. 3. No 4. pp. 3-9. DOI: 10.12731/2227-930X-2013-41. 
89. Остроух А.В., Исмаилов А.Р., Львова А.Б. Проектирование программно-технологических решений подсистемы планирования заданий для заказных перевозок пассажиров при проведении XXII Зимних Олимпийских Игр // Автоматизация и управление в технических системах. 2014. - № 1.1 (8). - C. 98-111. DOI: 10.12731/2306-15612014-1-11.

90. Остроух А.В. Применение графов дорожной сети в автоматизированной системе управления транспортировкой дорожно-строительных материалов / А.В. Остроух, М.Б. Польгун, В.В. Тихоцкий // Приборы и системы. Управление, контроль, диагностика. - 2014. №1. - C. 12-17.

91. Ostroukh A.V., Bashmakov I.A., Surkova N.E. Process Model of the Technology of Concrete Mixtures Transportation by Road // World Applied Sciences Journal (WASJ). 2014. Vol. 31, No 4 . pp. 500-507. DOI: 10.5829/idosi.wasj.2014.31.04.333.

92. Остроух А.В., Исмаилов А.Р., Львова А.Б. Разработка логической модели данных подсистемы планирования заказных перевозок при проведении XXII Зимних Олимпийских Игр // Автоматизация и управление в технических системах. - 2014. - № 1.2 (9). - С. 111-122. DOI: 10.12731/2306-1561-2014-1-25.

93. Krupensky N.A., Ivakhnenko A.M., Ostroukh A.V. Processoriented aggregation scorecards operational control forwarding activities // Автоматизация и управление в технических системах. - 2014. - № 1.2 (9). - C. 123-142. DOI: 10.12731/2306-1561-2014-1-26. 
94. Ostroukh A.V., Bashmakov I.A., Polgun M.B. ProcessFunctional Model of Transportation Mix Concrete // Journal of Transportation Technologies (JTT). 2014. Vol. 4, Issue 2, pp.157-163. DOI: 10.4236/jtts.2014.42016.

95. Башмаков И.А., Остроух А.В. Процессная модель технологии транспортировки бетонных смесей автомобильным транспортом // Промышленные АСУ и контроллеры. - 2014. - №3. - C. 10-18.

96. Andrey Ostroukh, Andrey Ivakhnenko, Nikita Krupensky. Development of Process-Oriented System For Operational Control of Freight Forwarding Activity // Journal of Applied Sciences (JAS). 2014. Vol. 14. No 20. pp. 2601-2607. DOI: 10.3923/jas.2014.2601.2607.

97. Andrey Ostroukh, Andrey Ismailov, Anna Lvova, Andrey Nikolaev. Architecture of Automated Navigation System of Passenger Transportation at Winter Olympic Games // Trends in Applied Sciences Research (TASR). 2014. Vol. 9. No 8. 425-437. DOI: 10.3923/tasr.2014.425.437.

98. Куфтинова Н.Г., Остроух А.В. Разработка автоматизированной системы обследования пассажиропотоков // Автоматизация и управление в технических системах. - 2014. - № 3 (11). - C. 23-33. DOI: 10.12731/2306-1561-2014-3-3.

99. Ostroukh A.V., Elhadi H. COMPARATIVE STUDY OF ROUTING PROTOCOLS IN VEHICULAR AD-HOC NETWORKS (VANETS) // International Journal of Advanced Studies (iJAS). 2014. Vol. 4. No 2. pp. 9-14. DOI: 10.12731/2227-930X-2014-2-2. 
100. Kuftinova N.Ya.G.E., Ostroukh A.V. Development of an automated system of survey passenger traffics // International Journal of Advanced Studies (iJAS). 2014. Vol. 4. No 4. pp. 39. DOI: 10.12731/2227-930X-2014-4-2.

101. Kuftinova N.G., Ostroukh A.V., Vorobieva A.V. Automated Control System For Survey Passenger Traffics // International Journal of Applied Engineering Research. 2015. Vol. 10. No 7. pp. 16419-16427.

102. Гусеница Д.О., Юрчик П.Ф., Остроух А.В. Применение облачного хранения данных В автоматизированной системе диспетчерского управления транспортом // Промышленные АСУ и контроллеры. - 2015. - №5. - С. 5966.

103. Gusenitsa D.O., Yurchik P.F., Ostroukh A.V. Cloud Computing Application on Transport Dispatching Informational Support Systems // International Journal of Advanced Studies (iJAS). 2015. Vol. 5. No 1. pp. 22-27. DOI: 10.12731/2227-930X2015-1-6.

104. Ostroukh A.V., Surkova N.E., Polgun M.B., Vorobieva A.V. AUTOMATED SUPERVISORY CONTROL SYSTEM OF URBAN PASSENGER TRANSPORT // ARPN Journal of Engineering and Applied Sciences. 2015. Vol. 10. No 10. pp. 4334-4340.

105. Остроух А.В., Суркова Н.Е., Воробьева А.В., Салих Х.С. Математическая модель системы дистанционной диагностики неисправностей автомобилей // В мире научных открытий. - 2015. - №6. - C. 63-70. DOI: 10.12731/WSD-2015-6-6. 
106. Васюгова С.А. Исследование перспектив и проблем интеграции человека с компьютером: искусственный интеллект, робототехника, технологическая сингулярность и виртуальная реальность / С.А. Васюгова, А.В. Остроух, М.Н. Краснянский, А. Самаратунга // Перспективы науки. Тамбов: «ТМБПринт», 2011. - № 4(19). - С. 109-112.

107. Белоусова А.И. Подход к формированию многоуровневой модели мультиагентной системы с использованием миваров / А.И. Белоусова, О.О. Варламов, М.Н. Краснянский, А.В. Остроух // Перспективы науки. - Тамбов: «ТМБПринТ», 2011. - № 5(20). - С. 57-61.

108. Варламов О.О. Анализ возможностей миварного подхода для систем искусственного интеллекта и современной робототехники / О.О. Варламов, А.В. Остроух, М.Н. Краснянский, Т.Л. Давыдова // Вестник ТГТУ. - 2011. T.17. - № 3. - C.687-694.

109. Ostroukh A., Nikonov V., Ivanova I., Morozova T., Strakhov V. Distributed System of Real Time Head Gesture Recognition in Development of Contactless Interfaces // Middle East Journal of Scientific Research. 2014. Vol. 20 (12). pp. 2177-2183. DOI: 10.5829/idosi.mejsr.2014.20.12.21105.

110. Ostroukh A., Nikonov V., Ivanova I., Morozova T., Sumkin K., Akimov D. Development of Contactless Integrated Interface of Complex Production Lines // Journal of Artificial Intelligence (JAI). 2014. Vol. 7, No 1. pp. 1-12. DOI: 10.3923/jai.2014.1.12.

111. Morozova T., Sumkin K., Akimov D., Ostroukh A. Contactless integrated interface of production lines // International Journal of Advanced Studies (iJAS). 2014. Vol. 4, Issue 1, pp. 32-38. DOI: 10.12731/2227-930X-2014-1-6. 
112. Омар М., Омар Ф., Исмоилов М.И., Остроух А.В. Применение систем распознавания образов в различных предметных областях // Автоматизация и управление в технических системах. - 2014. - №4 (12). - C. 32-47. DOI: 10.12731/2306-1561-2014-4-4.

113. Омар М., Омар Ф., Исмоилов М.И., Остроух А.В. Анализ современного состояния развития интеллектуальных роботов // Автоматизация и управление в технических системах. - 2014. - №4 (12). - C. 48-54. DOI: 10.12731/2306-1561-2014-4-5.

114. Ле К.Х., Суркова Н.Е., Остроух А.В. Генетические алгоритмы в задачах рациональной организации информационно-вычислительных процессов сетей // Автоматизация и управление в технических системах. 2014. - №4 (12). - C. 82-99. DOI: 10.12731/2306-1561-20144-9.

115. Valeriy Ivchenko, Petr Krug, Tatiana Morozova, Andrey Ostroukh, Sergey Pavelyev. The Remotely Reconfigurable Intelligence of the Space-Based Mobile Robot // Journal of Engineering and Applied Sciences. 2014. Vol. 9. Issue 10. pp. 389-395. DOI: 10.3923/jeasci.2014.389.395.

116. Ostroukh A.V., Gusenitsa D.O., Golubkova V.B., Yurchik P.F. Integration of PDM and ERP systems within a unified information space of an enterprise // IOSR Journal of Computer Engineering (IOSR-JCE). 2014. Vol. 16. Issue 02. V6. pp. 31-33. DOI: 10.9790/0661-16263133. ANED: 11.0661/iosr-jce-E016263133.

117. Akimov D.A., Ignatov A.S., Ostroukh A.V., Pavelyev S.A., Tsunikova T.G. Modeling of Temporal Stability to Critical 
States for Predicting Operational Safety of Turbogenerators // International Journal of Signal System Control and Engineering Application. 2018. Vol. 11. No. 1. pp. 13-19. DOI: 10.3923/ijssceapp.2018.13.19

118. Ostroukh A.V., Kolbasin A.M., Moroz D.G., Vorobiev A.I., Gavriluk M.V., Akhterov A.V. Remote Monitoring Cement Silo Stock Data // Research Journal of Applied Sciences. 2018. Vol. 13. No 2. pp. 146-149. DOI: 10.3923/rjasci.2018.146.149.

119. Ostroukh A., Surkova N., Varlamov O., Chernenky V., Baldin A. Automated process control system of mobile crushing and screening plant // Journal of Applied Engineering Science. 2018. Vol. 16. No. 3. pp 343-348. DOI: 10.5937/jaes16-15586.

120. Остроух А.В., Воробьева А.В., Колбасин А.М. Цифровая система удаленной диагностики автомобильного транспорта // Промышленные АСУ и контроллеры. - 2018. - № 11. - C. 3-10.

121. Arbuzov V., Ivchenko V., Matiukhina E., Pavelyev S., Ostroukh A. APPLICATION OF NEURAL NETWORK TECHNOLOGIES FOR DIAGNOSTICS OF THE TECHNICAL STATE OF POWER PLANT TURBO GENERATORS BASED ON SPECTROGRAMS OF THE VIBRATION MEASUREMENTS // ARPN Journal of Engineering and Applied Sciences. 2018. Vol. 13. No 7. pp. 2549-2555.

122. Остроух А.В., Листов Н.О. Система инфрормационной поддержки адаптивного машинного обучения искусственных нейронных сетей с обратной связью // Промышленные АСУ и контроллеры. - 2018. - № 12. - С. 13-22. 
123. Остроух А.В., Колбасин А.М. Концепция цифрового бетонного завода башенного типа // Промышленные АСУ и контроллеры. - 2020. - № 4. - С. 39-50.

124. Остроух, А.В. Системы искусственного интеллекта [Электронный ресурс] : монография / А.В. Остроух, Н.Е. Суркова. - Электрон. дан. - Санкт-Петербург : Лань, 2019. - 228 с. - Режим доступа: https://e.lanbook.com/book/113401. - Загл. с экрана.

125. Остроух, А.В. Интеллектуальные информационные системы и технологии [Электронный ресурс] : монографрия / А.В. Остроух, А.Б. Николаев. - Электрон. дан. - СанктПетербург : Лань, 2019. - 308 с. - Режим доступа: https://e.lanbook.com/book/115518. - Загл. с экрана.

126. Pronin C., Ostroukh A., Pronin B., Vasiliev, Y., Kotliarskiy, E. Development of a quantum algorithm based on quantum parallelism for finding the shortest path in a graph // ARPN Journal of Engineering and Applied Sciences. 2019. Vol. 14. No 4. pp. 848-851.

127. Ostroukh A., Vakhrushev O., Maikov K., Kolbasin A. Combined identification method by reconstruction and analysis of face 3D structure // ARPN Journal of Engineering and Applied Sciences. 2019. Vol. 14. No 7. pp. 1385-1388.

128. Ostroukh A., Vasiliev, Y., Kotliarskiy, E., Sarychev, I. Connected Quarry Machines Digital Systems // ARPN Journal of Engineering and Applied Sciences. 2019. Vol. 14. No 1. pp. 135-140. 


\title{
Андрей Владимирович Остроух
}

\section{ИНТЕЛЛЕКТУАЛЬНЫЕ СИСТЕМЫ}

\author{
Монография \\ Компьютерный набор и верста: Максимов Я.А. \\ Корректор: Доценко Д.В.
}

Дата выхода в свет: 31.03.2020.

http://nkras.ru/arhiv/2020/ostroukh2.pdf

По вопросам приобретения и издания литературы обращаться по адресу:

Издательство «Научно-инновационный центр»

ул. 9 Мая, 5/192, г. Красноярск, 660127 Россия

тел. +7 (923) 358-10-20

Электронная почта: monography@nkras.ru

Дополнительная информация на сайте: www.nkras.ru 


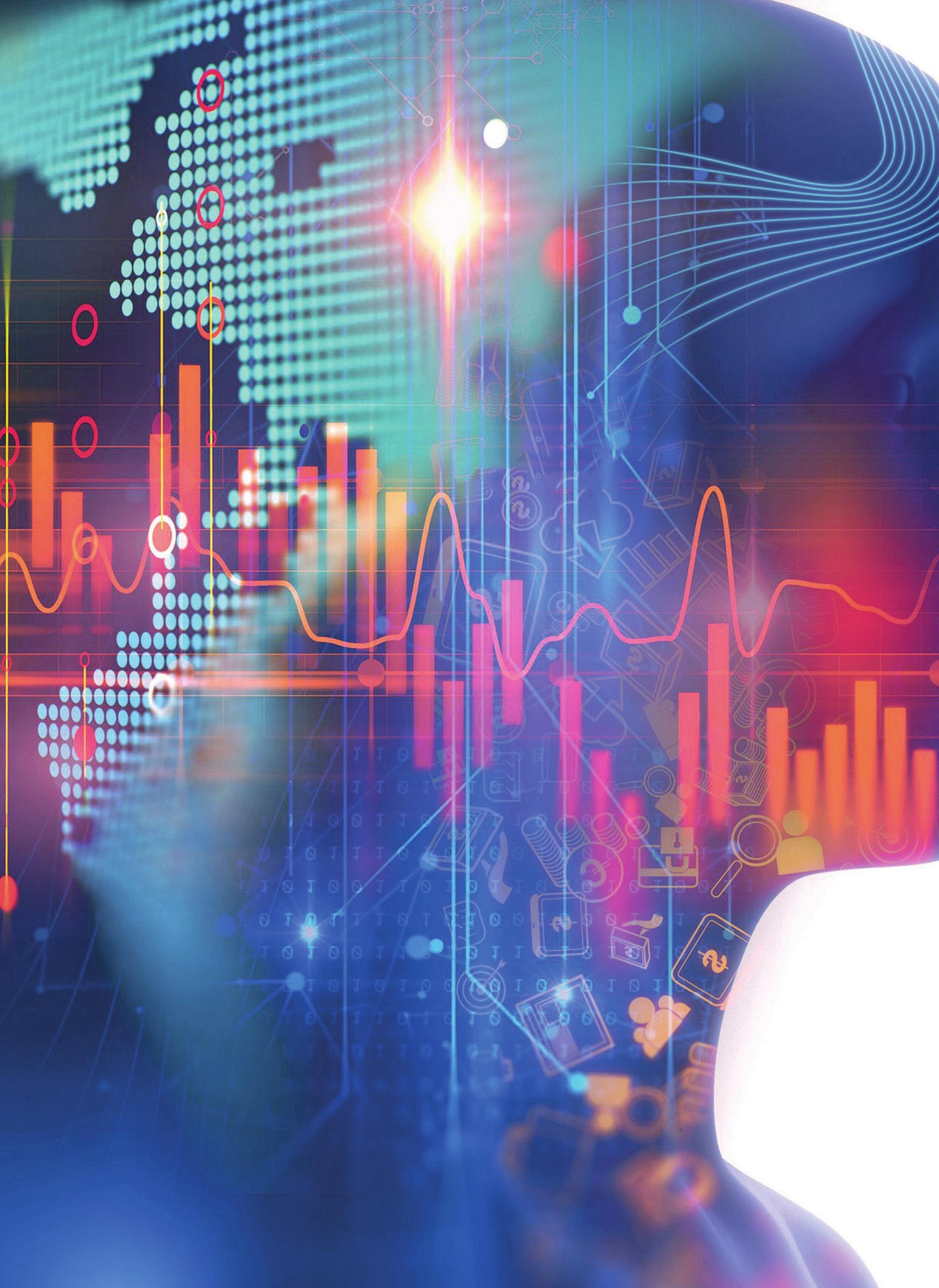

